\title{
II. Das Mordkomplott
}

\section{Rathenau in der öffentlichen Meinung}

Wie Matthias Erzberger und Philipp Scheidemann repräsentierte auch Walther Rathenau die aus Kriegsniederlage und Revolution geborene politische Nachkriegsordnung Deutschlands. Doch darüber hinaus verband den jüdischen Großbürger und Homme de lettres wenig mit dem katholischen Berufspolitiker und dem sozialdemokratischen Arbeiterführer-bis er wie sie Opfer eines politischen Anschlags werden sollte. Der 1867 in Berlin als Sohn des Fabrikbesitzers und späteren AEG-Gründers Emil Rathenau geborene Walther hatte nach einem mit der Promotion abgeschlossenen Studium der Philosophic, Physik und Chemie eine einjährige freiwillige Militärdienstzeit bei den Berliner Gardekürassieren absolviert und anschließend nach weiterer universitärer Vorbereitung die Leitung der von der AEG neugegründeten Elektrochemischen Werke Bitterfeld übernommen. 1899 wechselte er ins AEGDirektorium, wo ihm die Verantwortung über die Abteilung für Zentralstationen übertragen wurde, und trat 1902 in den Vorstand der Berliner Handels-Gescllschaft ein, der Hausbank der AEG. Rathenau setzte seine glänzende Karriere bald fort, wurde 1904 Mitglied und 1912 sogar Vorsitzender im Aufsichtsrat der AEG. Nach dem Tode seines Vaters 1915 gelang es ihm zwar nicht, zum Generaldirektor berufen zu werden, wohl aber konnte er seine Stellung als „Präsident“ der AEG festigen und scinen wirtschaftlichen Einfluß durch die Wahrnehmung ciner Vielzahl von Aufsichtsratsmandaten im In- und Ausland noch ausdehnen.

Nicht weniger als durch seine wirtschaftliche Tätigkeit sollte das öffentliche Bild Rathenaus durch sein Hervortreten als Schriftsteller geprägt werden. In Maximilian Hardens Zukunft, die 1897 seinen Erstlings-Aufsatz „Höre, Israel!“ abgedruckt hatte, fand der zunächst unter Pseudonym schreibende Essayist eine Plattform für eine ganze Reihe von Aufsätzen, die dann 1902 und 1908 gesammelt unter eigenem Namen als „Impressionen“ und „Reflexionen“ erschienen. 1912 eröffnete Rathenau mit dem Werk „Zur Kritik der Zeit" eine Reihe größerer Abhandlungen, in denen er, wie dann in "Zur Mechanik des Geistes“ (1913) und „Von kommenden Dingen“ (1917), aus der sozialphilosophischen Deutung der Krise seiner Zeit heraus Vorschläge zu ihrer Bewältigung unterbreitete. Folgerichtig ergänzte Rathenau fortan diese Gesamtschau durch eine Flut kleinerer, auch tagespolitisch bestimmter Schriften, mit denen er in aller Munde war und zu einem der meistgelesenen nicht-belletristischen Autoren des deutschsprachigen Raums aufstieg.

Die politische Karriere hingegen, dic seinen überdauernden Rang erst eigentlich begründet hat, nahm in Rathenaus Leben nur einen verhältnismäßig geringen Raum ein und war überdies mehr von Enttäuschungen als von wirklichen Erfolgen gekennzeichnet. Nachdem 1907 ein erster Versuch, als Protégé des damaligen Reichskanzlers Bülow in der Politik Fuß zu fassen, mißlungen und eine ins Auge gefaßte nationalliberale Reichstagskandidatur 1911 gescheitert war, gewannen Rathenaus Fähigkeiten und Kenntnisse erst mit Beginn des Ersten Weltkrieges die Aufmerksamkeit staatlicher Stellen: Seine Warnung vor einer drohenden Rohstoffknappheit der deutschen Kriegsindustrie führte zur schleunigen Errichtung eines Kriegsrohstoffamtes, das Rathenau bis 1915 selbst leitete. Ebenso diskret wie in dieser der Öffentlichkeit erst im weiteren Verlauf des Krieges bekanntgewordenen Tätigkeit wirkte er auch in den nächsten Jahren. Mit eincr Denkschrift, die auf den Wert Rußlands als künftiges Absatzgebiet der deutschen Wirtschaft hinwies, erregte Rathenau die Aufmerksamkeit 
Ludendorffs, zu dessen gelegentlichem Berater er nach dem August 1916 avancierte, ehe seine vergebliche Warnung vor der Ausweitung des U-Boot-Krieges die Beziehungen zu dem Heerführer abkühlen ließ. In der Revolution spiclte Rathenau keine Rolle. Seine Stunde schlug erst, nachdem die Republik, durch die im Kapp-Lüttwitz-Putsch gipfelnden gegenrevolutionären Bestrebungen weiter in die Defensive gedrängt, ihre Kräfte zu sammeln gezwungen war. Im April 1920 wurde er in die Zweite Sozialisierungskommission berufen und vertrat - gegen Stinnes - auf der Konferenz von Spa zur Regelung der Reparationsfragen im Juli des Jahres eine Linie des Ausgleichs mit den Alliierten, die später als „Erfüllungspolitik" bezeichnet werden sollte. Ein knappes Jahr später hatte Rathenau als Wiederaufbauminister Gelegenheit, diese Politik in größerem Stil zu erproben, als die Regierung Wirth unter dem Druck der Alliierten die ungeheuere Kriegsentschädigungssumme von 123 Milliarden Goldmark zu akzeptieren gezwungen war.

Aus seiner Position als Präsident der AEG und aus allen Aufsichtsratsämtern ausgeschieden, bemühte sich Rathenau als Minister, die deutschen Reparationsleistungen ihres politischen Charakters zu entkleiden und als Hebel zur Wiederbelebung der Wirtschaft zu nutzen. Im Oktober 1921 schloß er mit seinem französischen Kollegen Loucheur das aus mehreren Einzelverträgen bestehende Wiesbadener Abkommen, das einen Teil der jährlichen Geldschuld an Frankreich in Sachlieferungen umwandeltc. Nach dem durch die Völkerbundsentscheidung über die Teilung Oberschlesiens veranlaßten Rücktritt des ersten Kabinetts Wirth war Rathenau vorerst an der weiteren Verfolgung seiner politischen Ziele gehindert. Doch der abermals mit den Regierungsgeschäften betraute Wirth setzte im Januar 1922 Rathenaus Ernennung zum Außenminister durch, um sich für die kommende Konferenz mit den Alliierten in Genua der Unterstützung des international angesehenen Wirtschaftsfachmannes zu versichern. In der Tat machte Rathenau auf dieser Konferenz durch die Unterzeichnung des Ausgleichsvertrages von Rapallo mit Sowjetrußland Geschichte. Im Glauben, Deutschland drohe durch die französische Geheimdiplomatie gänzliche außenpolitische Isolierung, und durch seine Berater gedrängt, unterschrieb Rathenau ein Abkommen, durch das Deutschland als erstes westliches Land diplomatische Beziehungen zu Rußland aufnahm und gleichzeitig den gegenseitigen Verzicht auf Entschädigungsansprüche vereinbarte. Der Vertrag war eine Sensation, mit dem Rathenau die Grundlage seiner eigenen, auf Verständigung und Ausgleich mit den Alliierten zielende Politik in Frage stellte, aber gleichzeitig auch einen ersten Schritt zur Wiedererlangung außenpolitischer Handlungsfreiheit machte. Fünf Wochen später wurde der Minister ermordet.

Nichts an diesem Lebensweg schien den $\mathrm{Haß}$ plausibel zu machen, mit dem Rathenau um so stärker überzogen wurde, je mehr er in das Rampenlicht der Öffentlichkeit trat. Niemand begriff diese leidenschaftliche Ablehnung weniger als Rathenau selbst, der noch wenige Monate vor seiner Ermordung den pazifistischen Journalisten und Parteifreund Hellmut von Gerlach fragte: „Sagen Sie, warum hassen mich diese Menschen eigentlich so furchtbar?" Die Antwort, die Gerlach ihm gab ${ }^{1}$, traf zumindest in einem Punkt den Kern: Rathenau war Jude und teilte das Schicksal der jüdischen Deutschen insgesamt, die nach einer Jahrzehnte währenden Phase politischer und sozialer Emanzipation zunehmend auf wiederaufflammende Gegnerschaft stießen, eine Gegnerschaft, die sich nicht mehr wie einst vorwiegend religiös, sondern rassisch legitimierte. Rathenau mußte früh erfahren, daß seine jüdische Herkunft ihm selbst die Beförderung zum Reserveoffizier verschloß. Er reagierte auf diese Ausgrenzung mit einem psychischen Mechanismus der Verinnerlichung erfahrener Ablehnung, die

1 Sie lautete: „Ausschließlich, weil Sie Jude sind und mit Erfolg für Deutschland Außenpolitik treiben. Sie sind die lebendige Widerlegung der antisemitischen Theorie von der Schädlichkeit des Judentums für Deutschland." Zit. nach Schulin, Rathenau. Hauptwerke und Gespräche, S. 854. 
bis zum Selbsthaß reichte und ihn zu Handlungen führte, die für seine Stellung in der Öffentlichkeit von erheblicher Bedeutung sein sollten. Weniger zählt hierzu sein 1894/95 der jüdischen Gemeinde Charlottenburg angezeigter (aber nie rechtsgültig vollzogener) „Austritt aus dem Judenthume“; ein höchst irritierendes Zeugnis quälenden Selbsthasses bildete jedoch der pseudonym in der Zukunft abgedruckte Aufsatz „Höre, Israel!“, mit dem der Dreißigjährige 1897 sein literarisches Debüt gab. Gerichtet vor allem gegen die Protzerei jüdischer Neureicher einerseits, die Ghettokultur der besonders aus dem galizischen Raum nach Preußen strömenden sogenannten Ostjuden andererseits, entwarf Rathenau in diesem Artikel das Bild eines fremden Organismus im Leibe des deutschen Volkes und offenbarte Anschauungen, die Theodor Lessing zu Recht als „jüdischen Antisemitismus“ qualifiziert hat ${ }^{2}$. In späteren Jahren mildertc Rathenau diese schroffe Absage an die eigene jüdische Identität; der 1911 entstandene Aufsatz „Staat und Judentum“ nimmt die 1897 angeschnittene "Judenfrage" wieder auf, sucht die Lösung aber nicht mehr in der Selbstpreisgabe, sondern in einer auf Vollendung der Emanzipation gerichteten Judenpolitik als Voraussetzung „zum herzlichen Verständnis" von christlich-deutscher und jüdischer Seite. Weiterhin aber verwarf Rathenau den Übertritt zum Christentum aus Gründen der sozialen Anerkennung, weil „ein ideeller Schritt seine Reinheit verlieren muß, wenn er zu materiellen Vorteilen führt"3. Konsequent lehnte Rathenau es bis an sein Lebensende ab, sich taufen zu lassen, obwohl er zur jüdischen Religion nur mehr das lockere Verhältnis eines "abgeklärten Deismus“ unterhielt ${ }^{4}$. Von der Auffassung eines Mannes, der weder zum Christentum konvertieren noch als Jude eingeordnet werden wollte, sondern seine Religion als Privatsache behandelte, ließ sich Rathenau nicht mehr abbringen. Noch im Personalbogen des Außenministers verweigerte er eine Antwort auf die Frage nach der Konfession mit dem handschriftlichen Eintrag: „Diese Frage entspricht nicht der Verfassung. “5

Doch nicht nur jüdische Herkunft und soziale Stellung beeinflußten Rathenaus öffentliches Ansehen, sondern ebensosehr seine widerspruchsvolle Persönlichkeit. Schwerlich wird es gelingen, in der jüngeren deutschen Geschichte eine zweite Figur von solchem äußeren Einfluß und gleichzeitig solcher inneren Zerrissenheit zu finden. Die Zeitgenossen sahen jenseits aller politischen Positionen in Rathenaus Rätsellıaftigkeit das eigentliche Grundmuster seiner Persönlichkeit und tauften ihn spöttisch „das paradoxeste aller paradoxen Lebewesen des alten Deutschlands" 6 . Schon im Sträuben des Sohnes, seinem Vater beruflich nachzufolgen, zeigte sich Rathenaus innere Unentschiedenheit, wie er rückblickend in einem Lebenslauf unter dem Stichwort „Berufswahl“ bestätigte: „Schwanken zwischen Malerei, Literatur und Naturwissenschaft. Entscheidung für Physik, Mathematik und Chemie als

2 Selbsthaß, S. 30.

3 Rathenau, Staat und Judentum, S. 189.

4 Ebenda, S. 185.

5 PA/AA, Presseabteilung, Deutschland 9, Akten Reichsminister Dr. Rathenau, Bd. 1.

6 Die Republik vom 19.12.1918. Ähnlich dachte auch der Rathenau durchaus freundschaftlich zugetane Stefan Zweig: „Bei Rathenau spürte ich immer, daß er mit all seiner unermeßlichen Klugheit keinen Boden unter den Füßen hatte. Seine ganze Existenz war ein einziger Konflikt immer neuer Widersprüche. Er hatte alle denkbare Macht geerbt von seinem Vater und wollte doch nicht sein Erbe sein, er war Kaufmann und wollte sich als Künstler fühlen, er besaß Millionen und spielte mit sozialistischen Ideen, er empfand sich als Jude und kokettierte mit Christus. Er dachte international und vergötterte das Preußentum, er träumte von einer Volksdemokratie und war jedesmal hochgeehrt, vom Kaiser Wilhelm empfangen und befragt zu werden." Zweig, Welt von gestern, S. $204 \mathrm{f}$. 
Grundlagen neuzeitlicher Technik und Wissenschaft. " 7 Noch als Zweiunddreißigjähriger, der bereits über langjährige Erfahrungen beim Aufbau der elektrochemischen Industrie verfügte, spielte Rathenau mit dem Gedanken, seiner Stellung als Industrieller und Geschäftsmann den Rücken zu kehren: „1899, nach siebenjährigem Aufenthalt in der kleinen Fabrikstadt Bitterfeld, fingen die Unternehmungen an zu prosperieren. Ich beschloß, mich von der Industrie zurückzuziehen, um literarisch zu arbeiten. ${ }^{8}$ Rathenau hat die ihm selbst bewußte Gegensätzlichkeit seines Wesens immer wieder thematisiert, gelegentlich offen wie in einer Rede zu seinem 50. Geburtstag", häufiger aber verschlüsselt wie in der Scheidung zwischen "Zweck" und „Seele" 10 oder in der an Heines Gegenüberstellung von Hellenen und Nazarenern angelehnten Teilung der Welt in Mut-bzw. Zweck- und Furchtmenschen, die er 1904 in einem „Von Schwachheit, Furcht und Zweck“ betitelten Aufsatz entwickelte. Es mag mit derselben Doppelnatur zusammenhängen, daß Rathenau weder in seinen Gedanken noch in seinen Handlungen fest einzuordnen war ${ }^{11}$ und nie eine stabile Anhängerschaft hinter sich wußte. Am irritierendsten aber wirkte der Gegensatz zwischen Leben und Lehre dieses Mannes, der wider den Reichtum stritt, aber selbst in ihm lebte, den der von Abermillionen Deutscher im nationalen Taumel gefeierte Kriegsausbruch zu Tränen der Verzweiflung rührte und der dennoch kurz darauf in einer Denkschrift die Bombardierung Londons durch Zeppeline und die Deportation Zehntausender belgischer Arbeiter empfahl.

Dennoch stellt es cine Vereinfachung dar, die Beziehung Walther Rathenaus zur Öffentlichkeit als eine unweigerlich in die Katastrophe mündende Talfahrt zu beschreiben, die den Mordanschlag vom 24. Juni 1922 als Folge einer kontinuierlichen Verschlechterung seiner öffentlichen Reputation zu fassen sucht ${ }^{12}$. Ganz im Gegenteil war am Ende des dritten Kriegsjahres Rathenaus Ansehen infolge seiner allmählich bekanntgewordenen Leistung bei der Kriegsrohstoffbewirtschaftung so gestiegen, daß seine Verdienste als Gegengewicht gegen antisemitische Vorurteile gewertet werden konnten ${ }^{13}$. Bis weit in konservative Kreise hinein wurde Rathenau zeitweilig - wenngleich oft widerwillig - als Retter des Vaterlands und Hindenburg ebenbürtiger Inspirator eines wirtschaftlichen Generalstabes gerühmt ${ }^{14}$. Die sich abzeichnende Kriegsniederlage und die wiederaufflammende Judenfeindschaft sorgten allerdings dafür, daß das publizistische Bild Rathenaus schnell diese hellen Farben verlor. Auch wenn es weiterhin nicht an Stimmen fehlte, die Rathenaus Wirken fast überschwenglich feierten ${ }^{15}$, tendierten die Reaktionen auf Rathenaus Schriften in der Kriegszeit und besonders auf die im Januar 1918 erschienene „neue Wirtschaft" zu immer entschiede-

7 PA/AA, Presseabteilung, Deutschland 9, Akten Reichsminister Dr. Rathenau, Bd. 1; vgl. Kessler, Rathenau, S. 33.

${ }^{8}$ Zit. nach Simon, Leben, S. 8.

9 "Von meiner Jugend her ist es mir ein Erbteil gewesen - ein Erbteil, das ich schwer verstanden habe und noch heute schwer verstehe -, daß ich in dem, was die Natur mir gab, mich in der Doppelheit fühle." Vier Tischreden, S. 21.

${ }^{10}$ Rathenau, Mechanik des Geistes, S. 35 f.

${ }^{11}$ Vgl. das Urteil Carl Fürstenbergs: „Die Vielseitigkeit dieses Mannes hat ihm in dem Spezialistenland Deutschland vielleicht am meisten geschadet. Die Industriellen sahen in ihm zunächst nur den halben Schriftsteller, die Schriftsteller den halben Industrie- und Bankdirektor." Fürstenberg, Lebensgeschichte, S. 380.

12 Vgl. Kessler, Rathenau, S. $129 \mathrm{ff}$.

${ }^{13}$ Anonymus, Judenstatistik; vgl. Williamson, Rathenau, S. 254.

${ }^{14}$ B.Z. am Mittwoch vom 13. 12. 1916; Deutsche Tageszeitung vom 23. 12. 1916; vgl. Wilde, Walther Rathenau, S. 91.

${ }^{15}$ Vgl. z.B. Thimme, Publizist, S. 565 ff. 
nerer Ablehnung ${ }^{16}$. Das „System Rathenau“, so behauptete Leopold von Wiese, bedeute nichts anderes als eine Verlängerung der Kriegswirtschaft ${ }^{17}$. Der Widerspruch gegen Rathenaus Ideen und Person wurde um so schärfer, je konservativer er angesiedelt war ${ }^{18}$. Vollends gehässig reagierten völkische Antisemiten wie Theodor Fritsch ${ }^{19}$ oder Walther Lambach, der durch die „neuc Wirtschaft“ Landstriche veröden und Städte aussterben sah, da der Polyp Berlin alle Kräfte zu dem einen von Rathenau vorbedachten Zweck an sich ziehe: „Er will die ,neue Wirtschaft', weil er weiß, daß in ihr ihm die Wirtschaftsdiktatur zufallen wird.“ Lambachs Schlußfolgerung wies der völkischen Agitation den weiteren Weg: „So wird Rathenau zum Verführer und Verderber auf allen Gebieten. “20

Rathenau selbst isolierte sich in den lctzten Kriegswochen weiter mit einem am 7. Oktober 1918 in der Vossischen Zeitung publizierten Aufruf „Ein dunkler Tag“, dessen Grundgedanke einer levée en masse ${ }^{21}$ zur Verbesserung der Friedensbedingungen zuvor bereits im Reichskabinett diskutiert worden war. Das Echo auf diesen Vorstoß war verhecrend und wurde dadurch nicht gemildert, daß Rathenau seine Initiative vermutlich nur taktisch gemeint hatte. Nicht einmal Ludendorff mochte mitgehen; im Reichskabinett fand nach Auffassung Scheidemanns Rathenaus Idee „auch nicht die geringste Gegenliebe “22 oder wurde, so Schiffer, mit einem Lächeln quittiert ${ }^{23}$. Ablehnend verhielt sich auch die Mehrheit der Reichstagsabgeordneten, nur auf der Rechten fand Rathenau diesmal Zustimmung. In der publizistischen Reaktion zeigte sich nahezu dasselbe Bild. Sein Appell hatte Rathenau „zu den am erbittertsten befchdeten Männern“ gesellt $t^{24}$ und ihn als Kriegsverlängerer stigmatisiert, dessen Sorge für die Kriegsrohstoffversorgung nun im nachhinein in weit ungünstigerem Licht erschien. Besonders auf seiten der Linken war die Verurteilung vollständig, und sie sollte später dazu führen, daß Rathenau nach der Revolution weder in die Sozialisierungskommission noch in die Delegation für die Pariser Friedenskonferenz aufgenommen wurde. Alfons Goldschmidt verwahrte sich in der Weltbühne dagegen, „daß aus einer Grunewald-Villa heraus einem Volk, das fünfzig Monate lang diese ungeheuern Opfer gebracht hat, mit künstlich hären gemachter Stimme die billige Mahnung zugeschleudert wird, zum Schutze der Kriegsgewinnler immer weiter sein Blut zu vergießen“25.

Der Umsturz der politischen Verhältnisse in Deutschland schwemmte schließlich auch den Rest an Respekt davon, der dem AEG-Präsidenten in den letzten Monaten der Kaiserzeit noch verblicben war. Während der Revolution wurde Rathenau von den einen mit Ernst von Borsig unter die opportunistischen „Affen der Revolution“ gerechnet, die ihre reaktionären Absichten nun eilfertig unter demokratischen Mäntelchen zu verbergen trachteten ${ }^{26}$, von den anderen als der Schuldige identifiziert, der den Krieg "geistig vorbereitet" habe ${ }^{27}$. Deutlicher

${ }^{16}$ Vgl. Giraud, L' image, S. $90 \mathrm{ff}$.

${ }^{17}$ Wiese, Wirtschaft, S. $68 \mathrm{ff}$.

${ }^{18}$ Die Deutsche Zeitung vom 8. 2. 1918 sprach gar von einem Deutschland durch Rathenau drohenden staatlichen Arbeitszuchthaus (Grundlegende Änderungen unseres Wirtschaftslebens in Sicht).

${ }^{19}$ Roderich-Stoltheim [Theodor Fritsch], Anti-Rathenau.

${ }^{20}$ Lambach, Diktator Rathenau, S. 52 und 62.

${ }^{21}$ Den Begriff selbst vermied Rathenau allerdings in seinem Aufruf.

${ }^{22}$ Scheidemann, Zusammenbruch, S. 187.

${ }^{23}$ Vgl. Schiffer, Liberalismus, S. 69. Schiffers Sicht wird allerdings von Hecker bestritten (Rathenau, S. 437).

${ }^{24}$ Ebenda, S. 465.

${ }^{25}$ Goldschmidt, Retter, S. 374.

26 Olf, Reaktion, S. 499.

${ }^{27}$ Bergisch-Märkische Zeitung vom 23. 2. 1919; vgl. Hecker, Rathenau, S. 465. 
als durch den spontanen Heiterkeitsausbruch in der Nationalversammlung über den aus dem Ausland kommenden Vorschlag, Walther Rathenau zum Präsidenten zu wählen, konnte die Unpopularität des von allen Seiten Abgelehnten allenfalls noch durch die grobschlächtige Weise dokumentiert werden, in der der sozialdemokratische Wirtschaftsminister Wissell RathenausZukunftsentwürfe als Versuch hinstellte, die deutsche Wirtschaft „gewissermaßen zu einer großen AEG“ zu machen ${ }^{28}$. Ein „Apologie“ betitelter und 1919 veröffentlichter Abriß, in dem Rathenau sich ausführlich gegen die umlaufenden Vorwürfe zur Wehr zu setzen versuchte, blieb wirkungslos: Die Weltbübne beispielsweise empfahl ihren Lesern, diese und Rathenaus sonstigen Abhandlungen am besten zu ignorieren ${ }^{29}$.

Bereits im März 1919 war Rathenaus Abrechnung mit Wilhelm II. erschienen ${ }^{30}$ und hatte zu dem in der Weimarer Publizistik seltenen Fall geführt, daß - wenn auch aus unterschiedlichsten Motiven - die Ablehnung von links und rechts einmütig war. An der diesmal von Kurt Tucholsky stammenden Kritik in der Weltbühne mochte weniger die Stoßrichtung überraschen als die Heftigkeit, mit der der Angriff auf Rathenau vorgetragen wurde: Der Rezensent ließ durchblicken, daß dieses Werk eines immer „geölten Diktaphons“, das sich zu allem und jedem äußere, die Lektüre nur verdiene, um den byzantinischen Opportunismus seines Verfassers zu beleuchten, und verbat sich seine politische Einmischung: „Neue Anschauungen müssen von neuen Männern vorgetragen werden. "31 Aber auch die deutschnationale Deutsche Tageszeitung, die Rathenau im Februar 1919 noch ganz zustimmend zitiert hatte, machte im April ihre Leser in ironischen Wendungen mit dem „neuen Schreibwerk“ bekannt und klassifizierte "die vorschnellen, eigenartigen Äußerungen des Herrn Rathenau" kurz als "treulos und gemein" 32 . Mit fast denselben Argumenten griff Die Tat den Kritiker der kaiserlichen Schwächen an und fragte ihn, warum er sein vernichtendes Urteil denn erst nun, nach dem Sturz des Monarchen, mitteile: „Aber ist das jetzt nicht ein billiges Pasquill und hätte zu Lebzeiten des Kaisertums eine befreiende Kampfschrift sein könnon?“ $\mathrm{Daß}$ hier ein Großbürger, der dem Kaiser nahestand, dessen Liebe zum Großbürgertum als tragischen Zug beurteilte, fand Die Tat nur mehr abstoßend: „Uns graust, fast widert es. “33

Nie zuvor und nie mehr später wurde Rathenau von links und rechts gleichermaßen so negativ beurteilt. Denn wenn die Feindseligkeit in nationalistischen Kreisen auch noch erheblich zunahm, so kam das angesichts der fortschreitenden Polarisierung der jungen Republik einer allmählichen Aufwertung Rathenaus im liberalen und sozialdemokratischen Spektrum gleich. Dies zeigte sich bereits gegen Ende 1919, als Ludendorff vor dem Untersuchungsausschuß des Reichstages eine von Rathenau in „Der Kaiser" mitgeteilte Prophezeiung nutzte, um seine Version der ihn entlastenden Dolchstoßlegende kundzutun. Rathenau hatte folgende Wendung gebraucht: „Nie wird der Augenblick kommen, wo der Kaiser, als Sieger der Welt, mit seinen Paladinen auf weißen Rossen durchs Brandenburger Tor zieht. An diesem Tage hätte die Weltgeschichte ihren Sinn verloren. Nein! Nicht einer der Großen, die in diesen Krieg zichen, wird diesen Krieg überdauern. "34 Ludendorff verkürzte in seiner Aussage dieses Zitat geschickt so, daß es als Legitimation seiner Entlastungsbehauptung herhalten konnte, nach der der Krieg nicht an der Front, sondern in der Heimat verloren worden sei: „Ich muß einen Ausspruch Walther Rathenaus wiedergeben, in dem er etwa sagt,

28 Kessler, Rathenau, S. 275

${ }^{29}$ Die Weltbühne vom 9. 10. 1919, S. 459.

30 Rathenau, Kaiser.

31 Tucholsky, Schnellmaler, 29. 5. 1919, S. 619.

32 O. F., Walther Rathenau, 14. 4. 1919; vgl. O. F., Suche Brot in der Fremde, 2. 2. 1919.

33 Oestreich, Kaiser-Epilog, S. 395.

34 Rathenau, Kaiser, S. 305. 
an dem Tage, wo der Kaiser als Sieger mit seinen Paladinen auf weißen Rossen durch das Brandenburger Tor einziehen würde, hätte die Weltgeschichte ihren Sinn verloren. Es waren also Strömungen im Volke vorhanden, die nicht die Ansicht der Obersten Heeresleitung vertraten, daß wir auf den Sieg kämpfen müßten, und diesen Strömungen mußten wir Rechnung tragen. " ${ }^{35}$ In einer Zeit, in der gerade in den von Deklassierung besonders bedrohten bürgerlichen Schichten der Bedarf an personalisierbaren Erklärungsmustern immer weiter stieg, traf Ludendorffs Denunziation auf offene Ohren. Gegen die flagrante Umkehrung der Tatsache, daß angesichts der drohenden Kapitulation gerade er die lévee en masse gefordert und Ludendorff sie abgelehnt hatte, mochte Rathenau sich publizistisch und brieflich nach Kräften wehren, es nützte nichts. Das Verlangen nach mit griffigen Formeln belegbaren Schuldzuweisungen, wie sie Rathenau durch seinen Hang zu bildlichen Aphorismen unfreiwillig selbst lieferte, immunisierte sich gegen Richtigstellung und historische Wahrheit. In keiner Schmähschrift sollte fortan die von Ludendorff geprägte Version des „Kaiser-Zitates“ fehlen, und in der völkischen Agitation amalgamierte sie sich mit der verfälschenden Aufnahme einer Formulierung Rathenaus von 1909 über die „Dreihundert Männer, [...] die [die] wirtschaftlichen Geschicke des Kontinents [leiten] ${ }^{“ 36}$ zum scheinbaren Nachweis der „überstaatlichen Mächte“, dic Deutschland in den Ruin gestürzt hätten. Die von dieser Verteufelung ausgehende Bedrohung war groß; Harry Graf Kessler hielt Rathenau hinfort für einen Gezeichneten ${ }^{37}$.

Immerhin setzte mit dem politischen Aufstieg Rathenaus, der 1920 zunächst zu seiner Berufung in die Zweite Sozialisierungskommission und in den Reichwirtschaftsrat führte, ein allmählicher Meinungsumschwung wenigstens in der liberalen Publizistik ein. Die Umstände der Bestellung warfen allerdings ein bezeichnendes Licht auf die Widerstände, die der Name Rathenaus auch unter Republikanern im Juni 1920 noch auslöste. Die Reichsregierung hatte nach der Darstellung der Vossischen Zeitung sich das geradezu als „lex Rathenau“ apostrophierte Vorschlagsrecht für zwölf Mitglicder des Reichswirtschaftsrates vor allem mit dem Hinweis vorbehalten, „daß man auf die Entsendung von Männern, wie Rathenau, durch die wirtschaftlichen Korporationen kaum rechnen könne ${ }^{\text {" } 38}$. Überraschend strich aber der sozialdemokratische Wirtschaftsminister Schmidt den Namen Rathenaus wenige Tage vor der entscheidenden Kabinettsitzung wieder von der Liste; Rathenaus Berufung erfolgte nun erst, nachdem ein anderes Ratsmitglied zurückgetreten war und die Vossische Zeitung sich massiv für den AEG-Präsidenten eingesetzt hatte. Die noch uneinheitliche Neubewertung Rathenaus in der liberalen und linksliberalen Publizistik verdeutlicht eine ebenfalls im Juni 1920 in der Weltbübne erschienene Betrachtung zu Rathenau in der Reihe „Industriekapitäne". Der Artikel schob die politische Rolle Rathenaus ganz zur Seite, um statt dessen den Widerspruch zwischen dem Propagandisten und dem Privatmann, zwischen dem AEGPräsidenten und dem Wirtschaftstheoretiker zu beleuchten. Der Kritiker fand an dem „maßlos überschätzte[n] Sohn eines schon maßlos überschätzten Vaters“ buchstäblich keinen lobenswerten Zug. Für ihn war er als AEG-Präsident fehl am Platz, als Geschäftsführer der Berliner Handels-Gesellschaft ohne Leistungen, als Organisator der Kriegsrohstoff-

35 Zit. nach Kessler, Rathenau, S. 287.

36 Rathenau, Unser Nachwuchs; vgl. auch ders., Was wird werden?, S. 5; Hecker, Rathenau, S. 475 f.

37 Vgl. Kessler, Rathenau, S. 288; vgl. Kallner, der den Rufmord Ludendorffs als „Ruf nach dem Mord an Rathenau“ interpretiert (Herzl und Rathenau, S. 388), und Hecker, der mit Fürstenberg (Erinnerung, S. 386) Ludendorff als einen der moralisch Hauptschuldigen am Mord an Rathenau sieht (Rathenau, S. 476).

38 Bernhard, Fall Rathenau. 
versorgung Ausbeuter fremder und überdies naheliegender Empfehlungen, die dazu den

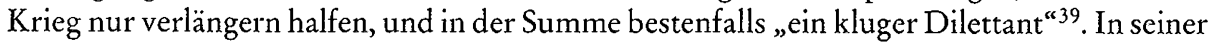
Schärfe war dieser Verriß für die republikfreundliche Publizistik nicht mehr repräsentativ, aber Rathenaus Aktivitäten in der ersten Hälfte des Jahres 1920 wurden auch von anderen liberalen und linksstehenden Blättern, wenn überhaupt, dann kühl besprochen, gleichviel, ob auf wirtschaftspolitischem Gebiet ${ }^{40}$ oder im Feuilleton.

In der nationalistischen Presse hingegen war von Urteilsunsicherheit nichts mehr zu spüren. Die Berufung in den Reichswirtschaftsrat war für die Deutsche Tageszeitung Anlaß, Rathenau zum Landesverderber zu stempeln ${ }^{41}$. Der Artikel, der Rathenaus Äußerungen in bezug auf das Kohleabkommen von Spa als Ermunterung der Alliierten zur Verschärfung ihrer Maßnahmen bis hin zu Ruhrgebietsbesetzungen wertete, verband diesen vermeintlichen Landesverrat mit dem Diktum über die „Dreihundert Männer“, um Rathenau implizit als Vertreter internationaler Kräfte zur Unterdrückung Deutschlands anprangern zu können. Auch der Hinweis auf den Aufsatz „Höre, Israel!“ fehlte nicht, um so anzudeuten, was expressis verbis zu sagen der Autor Ernst Graf Reventlow sich noch scheute: daß es die jüdische Internationale sei, der Rathenau sich zum Schaden Deutschlands verpflichtet fühle.

Das Jahr 1921 sah eine weitere Polarisierung des öffentlichen Urteils über Rathenau, der mit der Übernahme seines ersten Ministeramtes und der Konzeption der „Erfüllungspolitik“ immer stärker zum Repräsentanten der "Weimar-Deutschen“ und zum Feindbild der „Potsdam-Deutschen“" wurde ${ }^{42}$. Während Frankfurter Zeitung und Berliner Tageblatt die Ernennung Rathenaus zum Wiederaufbauminister zustimmend kommentierten ${ }^{43}$ und die Vossische Zeitung sich fast demonstrativ um publizistische Schützenhilfe für ihn bemühte ${ }^{44}$, reagierten Sprecher der Wirtschaft und besonders der Mittelstandsvereinigungen mit argwöhnischer Besorgnis ${ }^{45}$. Vollends die Rechtspresse machte gegen die mit Rathenau identifizierte „Erfüllungspolitik“ vom ersten Tag an Front. So bekundete die Neue Preußische Zeitung Anfang Juni 1921 ihr Unverständnis darüber, daß Rathenau das alliierte „Ultimatum für erfüllbar erklärt, was bisher unseres Wissens noch kein deutscher Minister getan hat", und fürchtete, daß er „ein Opfer seiner Stimmung und Lust an Einfällen geworden sei“46. Zwei Tage später nutzte das Blatt die Regierungserklärung des neuen Rcichskanzlers Wirth zu einer Generalabrechnung und rückte die Haltung Rathenaus gegenüber dem Londoner Ultimatum in den Kontext einer Regierung, die „die deutsche Knechtschaft auf Generationen hinaus" besiegelt habe, wcil die hinter ihr stehenden Parteien im Weltkrieg den Vernichtungswillen der Feinde gestärkt und Deutschland wehrlos gemacht hätten. Die letzte Erklärung sah der Kommentator „in der persönlichen Zusammensetzung des Kabinetts Wirth und seinem starken jüdischen Einschlag “47. Mit diesem antisemitischen Erklärungsmuster, das die Neue Preußische Zeitung kurz darauf mit einer eingehenden Behandlung des Aufsatzes „Höre,

${ }^{39}$ Ganz, Industriekapitäne, S. 718 ff.

40 Vgl. etwa Pinner, Schwerindustrie.

41 Reventlow, Wirtschaftsrat.

42 Diese anschauliche Terminologie verwendet Brecht, Rathenau und das deutsche Volk, S. 7.

${ }^{43}$ Frankfurter Zeitung und Berliner Tageblatt vom 31. 5. 1921. Mit freundlicher Erwartung begrüßte auch S. Großmann im Tage-Buch den neuen Wiederaufbauminister (Rathenau, S. 708 ff.).

${ }^{44} \mathrm{Vgl}$. Vossische Zeitung vom 27., 29. und bes. 30. 5. 1921.

${ }^{45} \mathrm{Vgl}$. Reichert, Zwangswirtschaft, S. 1030 ff. Schärfer noch artikulierte der Hansabund seine Gegnerschaft; Frankfurter Zeitung, Zweites Morgenblatt, vom 31. 5. 1921.

46 Neue Preußische Zeitung - Kreuzzeitung vom 3. 5. 1921. Das im Zitat erwähnte Londoner Ultimatum der Alliierten vom 5. 5. 1921 betraf die Anerkennung der deutschen Reparationsschuld.

47 Westarp, Politik der Woche. 
Israel!" unterfütterte ${ }^{48}$, war das Stereotyp des jüdischen Reichsfeindes geboren, der Deutschland an den Abgrund gedrängt habe.

Die Völkischen sprachen bereits offen aus, was die deutschnationale Agitation nur zwischen den Zeilen anzudeuten wagte, und überschwemmten das Land mit Flugblättern und Klebezetteln, in denen mit der Ernennung Rathenaus und anderer Juden zu Reichsministern die Herrschaft des ,internationalen Judentums“ über das deutsche Volk für angebrochen erklärt wurde. Die von Rathenau entworfene Erfüllungspolitik veranlaßte auch den Deutschvölkischen Alfred Roth, der den neuen Aufbauminister schon bei seiner Ernennung als „Fremdling aus Judaan“ und „Gerichtsvollzieher der Entente“ geschmäht hatte ${ }^{49}$, seine Agitation noch zu steigern. Unter Berufung auf Rathenaus Feststellung, es gebe keine absolute Unerfüllbarkeit, denn cs handle sich lediglich darum, wic weit man cin Volk in Not geraten lassen wolle, schrieb Roth: „Das also ist Rathenaus Meinung. Danach hat er in Wiesbaden gehandelt; Frankreich und das Weltjudentum sind mit ihm zufrieden. Die deutsche Not ist weiter auf dem Marsche. Der Strick ist gedreht, an dem wir Deutschen durch den Judaismus immer tiefer hineingeführt werden. Dank Rathenau. " ${ }^{50}$ Nur wenig nuancierter klagte die Deutsche Tageszeitung im Juli 1921 Rathenau als „Hans Dampf in allen Gassen “51 an, der das deutsche Volk verhöhne und das Geschäft der Alliierten besorge.

Mit dem Ausscheiden Rathenaus aus der Regierungspolitik nach der Demissionierung des ersten Kabinetts Wirth ließen die Angriffe auf Rathenau von rechts vorerst nach. Zwar wertete die Neue Preußische Zeitung wie andere rechtsstehende Blätter seinen aus Fraktionsdisziplin erzwungenen Verzicht auf Rückkehr in das Ministeramt als eitle Selbstgefälligkeit, die sich in der Hoffnung wiege, bald doch als unentbehrlich zurückgerufen zu werden ${ }^{52}$. Gemessen an dem leidenschaftlichen $\mathrm{Haß}$, der Rathenau im Jahr darauf entgegenschlagen sollte, war das wenig und entsprach dem geringen Interesse, mit dem er 1921 von linksliberaler und sozialdemokratischer Seite bedacht worden war ${ }^{53}$. Einen Vorgeschmack auf die bei seiner Rückkehr in ein Ministeramt bevorstchenden Auseinandersetzungen lieferte allerdings Der Tag, der eine „angebliche Äußerung Rathenaus“ auf der Titelseite abdruckte: „Ich vertrete nicht, wie Herr Stinnes, Deutschland, sondern ich vertrete den internationalen Finanzgeist! "Zwar zweifelte das Blatt immerhin an der Zuverlässigkeit dieser Meldung, gab aber Rathenau, der als Vertrauensmann Wirths in London einen Zahlungsaufschub für die fälligen Reparationsleistungen erwirken sollte, dessenungeachtet den Rat mit, „sich etwas mehr vom deutschen als vom internationalen Finanzgeist leiten" zu lassen ${ }^{54}$.

Die weitere Polarisierung der öffentlichen Meinung setzte sich erst 1922 nach Rathenaus Amtsantritt als Reichsaußenminister, aber dann in einem solchen Maß fort, daß nun eine Stellungnahme zu Rathenau einem Urteil über die Republik gleichkam. Am deutlichsten ist dieser Wandel an der Weltbübne abzulesen, die Rathenau bis zu seiner Ermordung nun gleich sieben Artikel widmete, deren erster noch deutliche Vorbehalte gegenüber dem frischgebakkenen Minister crkennen ließ ${ }^{55}$. Nur wenige Wochen später aber eröffnete Felix Pinner eine Reihe „Wirtschafts-Führer“ mit einem Porträt Rathenaus, das zu der zwei Jahre älteren Serie

${ }^{48} \mathrm{H}$. W., Rathenaus Stellung zur Judenfrage.

49 Roth, Gerichtsvollzieheramt der Entente, 23. 6. 1921, zit. nach ders., Rathenau, S. 9 und 11.

50 Roth, Der Strick ist gedreht, 13. 10.1921, zit. nach: Ebenda, S. 13.

51 W. S., Hans Dampf in allen Gassen.

52 Neue Preußische Zeitung - Kreuzzeitung vom 28. 10. 1921.

53 So befaßte sich dic Weltbühne 1921 anders als in den Jahren zuvor nicht ein einziges Mal mit Rathenau.

${ }^{54}$ Der Tag vom 30. 12. 1921.

55 Tyrus, Brief an Herrn Rathenau, S. 131. 
„Industriekapitäne“ von Hans Ganz in derselben Zeitschrift in einem Kontrast stand, der größer kaum gedacht werden konnte. Pinner feierte ungeachtet einiger weiterbestehender Reserven Rathenau nahezu panegyrisch, nannte den einstigen Dilettanten nun „genialen Organisator“ und die ehedem an ihm bemängelte Widersprüchlichkeit und opportunistische Gelenkigkeit „dialektische Wesensart“"56.

Zustimmend wurden Rathenaus neuerliche Ernennung und seine politische Linie 1922 auch von der liberalen Tagespresse begleitet, wenngleich die graduellen Unterschiede beachtlich blieben. Einzig die Vossische Zeitung stand fast bedingungslos hinter dem Inaugurator der Erfüllungspolitik, während im Berliner Tageblatt und in der Frankfurter Zeitung bei allem Wohlwollen kritische Töne unüberhörbar waren ${ }^{57}$. Im ganzen reklamierte die republikanische Presse Rathenau trotz mancher Skepsis gegenüber seinen staatsmännischen Fähigkeiten als Repräsentanten des demokratischen, auf Ausgleich mit den Siegermächten bedachten Deutschland, während sich in konservativen Kreisen die Abneigung gegen Rathenau immer stärker an die jüdische Herkunft heftete, die den Minister zur Erfüllungspolitik und zum Verrat an den deutschen Interessen gebracht hätte. Weniger gilt dies für der DVP nahestehende Blätter wie die Kölnische Zeitung, die zwar „keinen Anlaß [sah], dem neuen Minister des Auswärtigen irgendwelche Vorschußlorbeeren zu geben " 58 , aber ihre distanzierte Darstellung seiner Politik von allen persönlichen Angriffen freihielt. Diese fanden sich in der deutschnationalen Publizistik anläßlich der Bestellung des neucn Außenministers um so zahlreicher. Die Neue Preußische Zeitung schrieb Rathenaus Triumph seiner geschickt agierenden Selbstgefälligkeit $\mathrm{zu}^{59}$, und für die Deutsche Zeitung „bedeutet seine offene Teilnahme an den Geschäften den Beginn einer unumschränkten Herrschaft der Kreise, die wir für die Todfeinde bewußten und aufrechten Deutschtums ansehen müssen" 60 . Mit dieser Ansicht war der Antisemitismus wie vorher in der völkischen, so nun auch in der deutschnationalen Presse zum entscheidenden Urteilskriterium geworden. Seine Anwendbarkeit war auf den Nachweis negativer Persönlichkeitsmerkmale nicht mehr angewiesen, sondern erlaubte im Gegenteil, die Effizienz im Handeln Rathenaus gleichzeitig zu bewundern und dennoch, oder gerade deshalb, als Verrat an der deutschen Sache aufzufassen ${ }^{61}$.

Gegen die schrankenlose Hetze der Rechtsradikalen hob sich selbst dieser Antisemitismus als noch vergleichsweise gesittet ab. Für den Völkischen Beobachter, der Rathenau nachsagte, sich selbst nominiert zu haben ${ }^{62}$, war der neue Außenminister der Feind Deutschlands schlechthin, der seine Befehle von den „Weisen von Zion“ empfing. Folgerichtig kommentierte das Blatt die Berufung mit der sinistren Drohung, daß schon mehr als einer in die Grube gefallen sei, die er anderen gegraben habe ${ }^{63}$. Rathenau als Außenminister mobilisierte nationalistische Parteien und Verbände in kaum gekanntem Maße. In München verabschiedeten gleich mehr als zehn rechtsgerichtete Organisationen eine "Entschließung“ gegen die Ernennung Rathenaus, weil „sie ihn nach seiner bisherigen unverantwortlichen Tätigkeit für ungeeignet erachten, die Angelegenheiten des deutschen Volkes nach außen zu vertreten “; sie forderten, „daß auf der Conferenz von Genua [...] das deutsche Volk nicht von Repräsentan-

\footnotetext{
${ }^{56}$ Faßland [= Felix Pinner], Wirtschafts-Führer, S. 185 ff.

57 Giraud, L' image, S. 230 ff.

${ }^{58}$ Kölnische Zeitung vom 1. 2. 1922.

59 Neue Preußische Zeitung - Kreuzzeitung vom 1. 2. 1922.

${ }^{60}$ Deutsche Zeitung vom 1. 2. 1922.

61 Vgl. z. B. ebenda vom 25. 2. 1922.

62 Rosenberg, ,Neuc Zeitung gegen ,Neue Zcitung‘.

${ }^{63}$ Völkischer Bcobachter vom 11. und 8. 2. 1922.
} 
ten des internationalen Finanzgeistes, sondern von deutschen Männern vertreten werde" 64 . Haß prägte 1922 auch die aus einer ganz anderen politischen Richtung vorgetragene Auslassungen Maximilian Hardens. Die Zukunft hatte ihren früheren Autor 1921 fast gänzlich ignoriert, aber mit dessen Berufung zum Außenminister begann Harden, die Enttäuschung des ins Abseits geratenen Mentors in ätzende Kritik am einstigen Protegé umzusetzen. Rathenau galt ihm jetzt als ein für das politische Amt gänzlich ungeeigneter, dafür eitler Streber, der zu allem Unglück das von Harden als „Rathenauwirth" titulierte Kabinett beherrsche ${ }^{65}$. Die journalistische Verbreitung dieses Rathenau-Bildes, dem allerdings, anders als den Verdammungsurteilen der Rechten, jeder antisemitische Beigeschmack fehlte, war freilich gering; die Zahl der Zukunft-Abonnenten lag um diese Zeit schon unter $400^{66}$.

Das Echo auf die Konferenz von Genua jedoch war geeignet, die überkommenen politischen Gegensätze in der Beurteilung des Außenministers zu relativieren. So mehrte der Vertrag von Rapallo die Skepsis der Weltbühne gegenüber Rathenau erheblich ${ }^{67}$, während das USPD-Blatt Die Freibeit den überraschenden Ausgleich mit Sowjetrußland trotz der bedenklichen innenpolitischen Zustimmung von rechts billigte ${ }^{68}$. Der Vorwärts hingegen hielt den Rapallo-Vertrag für gefährlich, weil er dic Rückkehr Frankreichs zur Sanktionspolitik fördern könnte ${ }^{69}$. Auch in der konservativen Publizistik fügte sich die Bewertung des Vertrages nicht in den für Rathenaus politische Bemühungen gemeinhin bereitstehenden Urteilsrahmen. So war trotz mancher Vorbehalte für die Nene Preußische Zeitung das deutsch-russische Übereinkommen „immerhin ein Versuch Deutschlands, selbständig Politik zu treiben "70. Günstige Aufnahme fand der Vertrag auch in der Deutschen Allgemeinen Zeitung ${ }^{71}$, die doch Rathenaus Politik bisher im Einklang mit dem Standpunkt der DVP strikt abgelehnt hatte; das Blatt rettete sich über das Dilemma, indem es Rathenaus Anwesenheit in Genua praktisch ignorierte ${ }^{72}$.

Die antisemitische Presse hingegen ließ auch nicht die geringste Differenzierung ihres Rathenau-Bildes zu; der Völkische Beobachter schrieb Rathenau in gewohnter Manier eine Drahtzieherrolle in Genua zu und betrachtcte das dcutsch-russische Abkommen als Teil einer „jüdischen Verschwörung zur Verschacherung des deutschen Volkes" ${ }^{\text {73 }}$. Hilflos wirkten hiergegen die Bemühungen etwa der C.V.-Zeitung, als Stimme der jüdischen Deutschen Rathenau vor judenfeindlichen Angriffen in Schutz zu nehmen ${ }^{74}$, zumal wenigstens unter Zionisten die Auffassung nicht eben selten anzutreffen war, Rathenau hätte angesichts der objektiv bestehenden Judenfrage und des in Deutschland verbreiteten Antisemitismus sein

${ }^{64}$ Unter anderem unterzeichneten der Alldeutsche Verband, der Hochschulring deutscher Art, der Nationalverband deutscher Offiziere, die Thulc-Gesellschaft, der Verband nationalgesinnter Soldaten, die Bayerische Mittelpartei, der Bayerische Ordnungsblock, der Bund Oberland und der Deutschvölkische Schutz- und Trutzbund. Das Auswärtige Amt wurde im Februar 1922 mit einer ganzen Reihe weiterer Protestresolutionen gegen die Ernennung Rathenaus überzogen. BA, R43 I/ 903; PA/AA, Büro Reichsminister, Persönliche Angelegenheiten des Ministers, Bd. 7.

${ }^{65}$ Vgl. insbesondere Hardens Artikel „Rausch aus Hurenwein“, „Lüge in Schneeweiß“ und „Sexagesima“.

66 Weller, Harden und die "Zukunft", S. 86.

${ }^{67}$ Vgl. Morus, Katastrophenpolitik, S. 428, und ders., Ergebnis von Genua, S. 536.

${ }^{68}$ Die Freiheit vom 18. und 29. 4. 1922.

${ }^{69}$ Vorwärts vom 18. 4. 1922.

${ }^{70}$ Neue Preußische Zeitung - Kreuzzeitung vom 18. 4. 1922.

${ }^{71}$ Deutsche Allgemeine Zeitung vom 18. und 23. 4. 1922.

72 Vgl. hierzu Giraud, L' image, S. 190.

${ }^{73}$ Völkischer Beobachter vom 22. 4. und 20. 5. 1922.

${ }^{74}$ Vgl. C.V.-Zeitung vom 11. 5. und 15. 6. 1922. 
Amt niemals annehmen dürfen ${ }^{75}$. Tatsächlich war es wohl weniger die von Rathenau verantwortete Politik, die die völkische Agitation gegen Rathenau seit dem Februar 1922 auf eine neue Stufe führte, als die bloße Tatsache, daß ein Jude an die Spitze des Außenministeriums getreten und damit verantwortlich für die außenpolitische Bewältigung der Kriegsfolgen geworden war. Wenige Wochen nach der Ernennung erschien in der deutschvölkischen Mitteldeutschen Presse ein „Offener Brief an Herrn Dr. Walter Rathenau“, der wie in einem Hohlspiegel alle Stereotypien bündelte, aus denen sich das Rathenau-Bild der Völkischen seit Kriegsende zusammensetzte: Rathenau sei zum Außenminister nicht von der Mehrheit des deutschen Volkes, sondern von den "Logen der international-jüdischen Freimaurerbünde“ berufen worden, an deren Spitze die von ihm selbst erwähnten „Dreihundert Männer“ stünden. Daß er cine Gefahr für das deutsche Volk darstelle, zeige seine-mit der Prophezeiung über das Schicksal Wilhelms II. eingestandene - Arbeit gegen einen deutschen Sieg im Weltkrieg. Schließlich sei Rathenau verantwortlich für die Kriegsgesellschaften, mit deren Hilfe das deutsche Volk von jüdischem Kapital ausgeplündert worden sei. Deutlich wurde hinter diesen Anwürfen das Bemühen erkennbar, ein umfassendes Erklärungsmodell für die unverarbeitete Kriegsniederlage mit all ihren sozialen und wirtschaftlichen Folgen zu finden und eine klare Schuldzuweisung anzubieten: „Zu einer Zeit, wo mein Vaterland aus tausend Wunden blutend aufs Schwerste darniederliegt, so daß an seinem Aufkommen gezweifelt wird, sind Sie Minister des Äußeren geworden. "76 Weit vor der Konferenz von Genua meinte der Verfasser schon die Gefahr einer von Rathenau vermittelten Übereinkunft zwischen Rußland und Deutschland erkennen zu können: „Denn in Rußland ruht die öffentliche Macht in jüdischen Händen. Und Deutschland soll ebenfalls jüdischer Herrschaft unterworfen werden. "77 Der Abschluß des Rapallo-Vertrages mußte den Lesern dieser Presse als letzte Bestätigung ihrer Befürchtungen erscheinen.

Die Vermutung liegt nahe, daß in solchen Vorstellungswelten auch der Gedanke reifte, den vermeintlichen Verderber durch ein Attentat zu beseitigen. Tatsächlich verdichteten sich in den Monaten vor dem Mord die publizistischen Anzeichen einer immer weiteren Radikalisierung der Feindschaft gegen Rathenau. Am 9. März 1922 machte der Central-Verein den Außenminister auf eine Nummer des als Amtsblatt der bayerischen Regierung ausgewiesenen Nabburger Volksboten vom 11. Februar aufmerksam, in der unter der Artikelüberschrift „Nur die allerdümmsten Kälber wählen ihre Metzger selber" Rathenau mit rohesten antisemitischen Anwürfen konfrontiert wurde ${ }^{78}$. Am 13. März sah sich das Auswärtige Amt gezwungen, in einer an alle größeren Berliner Tageszeitungen gerichteten Presseerklärung zu dementieren, daß Rathenau geäußert habe, „aus ihm spreche der Geist des internationalen Kapitals“. Am 20. Mai 1922 titelte die Scblesische Zeitung: „Rathenau kauft die staatlichen Industriewerke Österreichs. "79 Aus völkischen Blättern waren dem Außenminister obendrein kaum verhüllte Morddrohungen entgegengeschleudert worden. Die Hetzschrift Alfred Roths über „Rathenau. Der Kandidat des Auslandes“ schloß mit der Bemerkung: „Wir harren der ,kommenden Dinge', erklären aber mit aller Deutlichkeit, daß in Deutschland für

${ }^{75}$ Blumenfeld, Judenfrage, S. 142 ff.; Schulin, Integrationsversuch, S. $36 \mathrm{ff}$.

${ }^{76}$ Hottenrott, Offener Brief.

77 Ebenda. Ebenso sah auch A. Roth in einem Artikel vom 13. 2. 1922 bereits „Deutschlands Bolschewisierung" hereinbrechen, in: Ders., Rathenau, S. $30 \mathrm{ff}$.

${ }^{78}$ PA/AA, Deutschland 9, Akten Reichsminister Dr. Rathenau, Bd. 1, Der CV an Walther Rathenau, 9. 3. 1922.

${ }^{79}$ Ebenda. 
einen Trotzky-Rathenau keine Statt ist. Wir sind zum Äußersten entschlossen und bereit. " 80 Unversöhnliche Gegnerschaft kennzeichnete nach der Konferenz von Genua auch die parlamentarische Auseinandersetzung um die Politik des Außenministers. Am 23. Juni 1922 holte Rathenaus wirtschaftspolitischer Gegenspieler, der Deutschnationale Karl Helfferich, im Reichstag zu einem Rundumschlag gegen die „Leidenswege der Politik der Erfüllung aus“: Diese habe „die furchtbare Entwertung des deutschen Geldes gebracht, hat unseren Mittelstand zermalmt, hat zahllose Familien in Not und Elend gebracht, hat zahllose Menschen in Verzweiflung und Selbstmord getrieben, sie hat große wertvolle Teile unseres nationalen Produktiv-Kapitals dem Ausland ausgeliefert, sie hat unsere wirtschaftliche und soziale Ordnung in ihren Grundfesten erschüttert". Die vom Deutschen Reich übernommenen Verpflichtungen, behauptete Helfferich in seiner von tumultuarischen Reaktionen unterbrochenen Rede, seien ein "Verbrechen“, eine Regierung, die dies verantworte, gehöre vor den Staatsgerichtshof ${ }^{81}$.

In der linksstehenden Publizistik wurden diese Drohungen ernst genommen. Zwei Tage vor dem tödlichen Anschlag ließ Kurt Tucholsky in einer „Was wäre, wenn ...?“ überschriebenen Vision einen Minister Opfer des Umsturzes von rechts werden ${ }^{82}$.

\section{Warnungen vor einem Anschlag}

Die fortgesetzte publizistische Stigmatisierung im nationalistischen Lager hatte dazu geführt, daß bald nach Antritt seines ersten Ministeramtes eine Flut von brieflichen Schmähungen und Morddrohungen über Rathenau hereinbrach ${ }^{1}$. Der Minister wußte, daß sein Leben bedroht war. Schon als er der Witwe Erzbergers kondolierte, verband er dies mit dem Hinweis, er werde das nächste Opfer sein², und Federn-Kohlhaas zufolge soll er sich gescheut haben, seiner Mutter die Ernennung zum Außenminister mitzuteilen, um sie nicht zu beunruhigen ${ }^{3}$. Der Hamburger Bankier Max Warburg erinnerte sich, von Rathenau vier Wochen vor dessen Ermordung gehört zu haben: "Sie glauben gar nicht, wie viele Drohbriefe ich bekomme."4 Schon ein Jahr zuvor hatte er einem britischen Offizier gegenüber bekannt, daß er sich in Gefahr wähne: „In einigen Teilen meines Landes marschieren Kompanien von Männern im Rhythmus der Worte: ,Schlagt tot den Walther Rathenau/ die gottverdammte Judensau! " "5 Vollends nach seiner Ernennung zum Außenminister schien er mit seinem Leben nahezu abgeschlossen zu haben, wie aus den fatalistisch wirkenden Bemerkungen hervorgeht, die er

80 Roth, Deutschlands Bolschewisierung, 13. 2. 1922, in: Dcrs., Rathenau, S. 32. Weitere Beispiele trug die C.V.-Zeitung vom 12.6. 1922 zusammen.

81 Neue Preußische Zeitung - Kreuzzeitung vom 24. 6. 1922, Morgen-Ausgabe.

82 Tucholsky, Was wäre, wenn ...?, S. $615 \mathrm{ff}$.

1 Eine Liste von Drohbriefen bei Loewenberg, Murder and Mystification, S. 4, Anm. 10.

2 Mitteilung Gabriele Erzbergers an den Verfasser, 9. 4. 1989. Dieselbe Äußerung überlieferte Max Scheler: „Oft äußerte er, daß er Erzbergers Schicksal teilen werde. “ Norlind, Gespräche und Briefe, S. 123; vgl. d'Abernon, Zeitenwende, Bd. 1, S. 341.

${ }^{3}$ Vgl. Federn-Kohlhaas, Rathenau, S. 233; Norlind, ebenda, S. 103.

4 Warburg, Aufzeichnungen, S. 107; vgl. Warburgs fast gleichlautende Äußerungen gegenüber der Münchener Post vom 29. 6. 1922.

${ }^{5}$ Roddie, Peace Patrol, zit. nach der Übs., in: Schulin, Rathenau. Hauptwerke und Gespräche, S. 841; vgl. Spiero, Schicksal und Anteil, S. 300. 
unterschiedlichsten Menschen seiner Umgebung gegenüber machte; ${ }^{6}$ Politikerkollegen wie Eugen Schiffer bewunderten seinen Mut, sehenden Auges einen ungeschützten Weg zu gehen, der in den Untergang führen könne?

Die Behörden nahmen die Bedrohung allerdings ernster. Rathenau war schon nach dem Antritt seines ersten Ministeramtes veranlaßt worden, zu seinem Schutz einen Revolver bei sich zu tragen ${ }^{8}$. Später wurde er zusätzlich von der Politischen Abteilung des Berliner Polizeipräsidiums "auf die Notwendigkeit hingewiesen, sich einen besonderen polizeilichen Schutz gefallen lassen zu müssen"9. Tatsächlich erhielt der Außenminister eine ständige Begleitung von zwei Zivilpolizisten, die er aber als eine solche Einschränkung seines persönlichen Freiraums empfand, daß er sich ihrer so häufig als möglich zu entledigen trachtete ${ }^{10}$; Wirth erinnerte sich später, daß Rathenau sich polizeilichen Schutz ausdrücklich verbeten hatte ${ }^{11}$. Da Rathenau auf seiner verhängnisvollen letzten Fahrt am 24. Juni 1922 tatsächlich ohne polizeiliche Begleitung war, liegt der Schluß nahe, daß die vom Polizeipräsidium angeordneten Sicherungsmaßnahmen aufgrund der ablehnenden Haltung Rathenaus eingestellt worden waren. Diese Vermutung trifft aber die Wahrheit nur zum Teil. Zwar räumte der Leiter der Berliner Politischen Polizei nach dem Tode des Ministers ein, daß Rathenau sich gegen den ihm angebotenen Schutz gesträubt habe. „Trotzdem waren seit vielen Wochen zwei besonders tüchtige Kriminalbeamte mit der Beschützung des Ministers beauftragt worden, einer von ihnen begleitete den Minister fast ständig auf seinen Fahrten, obwohl Dr. Rathenau dies immer wieder ablehnte [...]. Gerade an dem Mordtage fuhr der Minister unglückseligerweise ohne Begleitung. " 12

Schon diese allgemeinen Hinweise auf die Lebensgefahr, in der Rathenau zumindest seit der Übernahme des Außenministeriums schwebte, fordern die Frage heraus, ob seine Ermordung nicht durch einfache Vorsichtsmaßnahmen wie etwa das Benützen eines ge-

${ }^{6}$ Auf Roddies Bitte, sich vorzusehen, antwortete Rathenau: „Was sein wird, wird sein. Ich habe cine Aufgabe zu erfüllen - vielleicht nicht zu vollenden. Wenn meine Stunde geschlagen hat - und nicht früher - werde ich genommen werden." (Roddie, ebenda, S. 853) Im gleichen Sinne schrieb Rathenau an Lore Karrenbrock: „Sie sollen sich um meine Erhaltung keine Sorge machen. Wenn ein unvergeudetes Leben enden soll, so geschieht es nicht aus Willkür, sondern weil es seinen Abschluß gefunden hat." Zit. nach Federn-Kohlhaas, Rathenau, S. 248; vgl. auch Haber, Leben mit Fritz Haber, S. 66; Schwaner, Rathenau; Lemmer, Manches war doch anders, S. 96.

7 GStA, Rep. 92, NL Eugen Schiffer, Heft 1, S. 25; vgl. Loewenberg, Murder und Mystification, S. 9.

${ }^{8}$ Eine „kleine automatische Pistole“, die Rathenau offenbar bereits im Herbst 1921 ständig mit sich gcführt hatte (Roddie, Peace Patrol, zit. nach Schulin, Rathenau. Hauptwerke und Gespräche, S. 841), erwähnt auch Kessler: „Als ich, kurz nach seiner Ernennung zum Außenminister, zum erstenmal mit dem üblichen ,Guten Tag, wie geht's?' sein Arbeitszimmer in der Wilhelmstraße betrat, griff er rückwärts in die Hosentasche, zog einen Browing heraus und antwortete: ,So geht's!' Es sei so weit, daß er nur noch mit diesem kleinen Instrument ausgehen könne." Kessler, Rathenau, S. 353.

${ }^{9}$ Lemmer, Manches war doch anders, S. 96.

10 Vgl. Schulin, Rathenau. Hauptwerke und Gespräche, S. 852 f.; Pfeiffer-Belli, Kessler. Tagebücher, S. 616 f.; Kerr, Erinnerungen, S. 9. Mindestens einmal meldete Rathenau allerdings fremde Eindringlinge in seinem Haus - die sich als harmlos herausstellten - auch der Polizei; vgl. Loewenberg, Murder und Mystification, S. 8.

${ }^{11}$ Wirth an Kessler, 5. 7. 1928, in: Wirth, Rathenau vor seinem Tode, S. 1307; vgl. H. Fürstenberg, Erinnerung, S. 413, und die von Kessler überlieferten Erinnerungen Lili Deutschs, in: Pfeiffer-Bclli, Kessler, S. 555.

12 Interview mit Weiß, in: Bcrliner Tageblatt vom 19. 7. 1922. Wie Loewenberg nachweist, war auch Rathenaus Wohnumfeld Gegenstand ständiger Kontrolle und wurde von Polizeistreifen observiert; Murder and Mystification, S. 8. 
schlossenen Kraftwagens hätte verhindert werden können. Vollends angesichts der im Laufe des Jahres 1922 den Behörden bekanntgewordenen konkreten Attentatswarnungen wird der Eindruck unabweisbar, daß - hauptsächlich wegen Rathenaus eigenem Unwillen - bei weitem nicht das Mögliche getan wurde, um den Politiker zu schützen. Denn die sich über Monate erstreckende Vorbereitung des Attentates hatte durchaus Spuren hinterlassen, die dem Minister wie der Polizeibehörde zur Kenntnis gebracht, aber nicht weiter verfolgt worden waren. $\mathrm{Zu}$ vernachlässigen ist hier der von den Tätern selbst reklamierte Anspruch, ihr Opfer gewarnt zu haben. Daß beispielsweise der Kopf der Verschwörer in Berlin, Erwin Kern, am Vorabend des 24. Juni 1922 bei Rathenau zu Hause angerufen hätte, um ihm seine Ermordung anzukündigen ${ }^{13}$, darf getrost als billige Erfindung angesehen werden, mit der ein Tatkomplice die Unvereinbarkeit von Offiziersehre und Meuchelmord zu vertuschen hoffte.

Eine ernstzunehmende Warnung aber erreichte Rathenau über Hellmut von Gerlach, der erfahren hatte, daß der Heidelberger Privatdozent Arnold Ruge den Außenminister erschießen wolle ${ }^{14}$. Gerlach setzte Rathenau in Kenntnis, doch der zeigte sich gar nicht überrascht, weil er - so Gerlach - über Wirth bereits erfahren haben wolltc, daß sein Leben durch einen Mann bedroht werde, der zum Mord an ihm ausgewählt worden sei. Falsch war zwar die Vcrmutung, daß beide Warnungen sich auf ein und denselben Attentatsplan bezogen, nicht aber Gerlachs Nachricht. Der völkische Fanatiker Ruge aber, der seine radikalantisemitischen Auffassungen so nachdrücklich propagierte, daß ihm als cinzigem Hochschullehrer auf seiten der Rechten die Venia legendi aus politischen Gründen entzogen worden war ${ }^{15}$, hatte tatsächlich einen entsprechenden Plan gefaßt. Trotz eines gegen ihn bestehenden Haftbefehls hatte er sich Ende Februar 1922 nach Berlin begeben, seine Absichten aber so wenig zu verbergen gewußt, daß der Reichskommissar für Überwachung der öffentlichen Ordnung am 27. Februar auf die von Ruge ausgehende Gefahr hinweisen konnte: „In seiner Begleitung sollen sich einige Elemente befinden, die zur Ausführung eines Attentats auf den Herren Rcichsaußenminister Dr. Rathenau bereit sein sollen. " ${ }^{16}$ Umgehend wurden die Pförtner im Außenministerium und in Rathenaus Villa benachrichtigt und mit Ruges Foto versehen, um dessen Vordringen zu Rathenau zu verhindern ${ }^{17}$. Dennoch gelang es Ruge wenige Wochen später, in der Verklcidung eines Hausierers, der einen japanischen Leuchter verkaufen wolle, Zutritt zu Rathenaus Haus zu erlangen. Sein dilettantischer Plan scheiterte jedoch schon daran, daß Rathenau gar nicht daheim war; die Frau seines Dieners drängte den vorgeblichen Händler resolut aus dem Haus und bedeutete ihm, „daß er sich in solchen Angelegenheiten schriftlich an Herrn Dr. wenden solle" 18 .

Auch das schließlich ausgeführte Attentat war nicht so lautlos vorbereitet worden, wie seine Initiatoren gehofft haben mochten. Rathenau hatte, wie Franz Blei später erzählte, einige Monate vor seinem Tod davon gesprochen, daß die USPD ihn vor einem bevorstehen-

${ }^{13}$ Die Vorspicgelung stammt von Techow, dem Fahrer des Mordwagens: „Kern ging ans Telephon und ließ sich mit der Villa Rathenau verbinden; denn er könne Rathenau nicht so ahnungslos abschießen, er solle wissen, was ihm bevorstehe und sich schützen, wenn er wolle. "E. W. Techow, „Gemeiner Mörder?!“, S. 27.

${ }^{14}$ Gerlach war von einem Informanten benachrichtigt worden: „Ich komme zu Ihnen, weil Sie mit Rathenau befreundet sind. Eben ist Dr. Ruge aus Breslau hier eingetroffen. Gestern waren wir mit ihm in kleinem Kreise zusammen. Er hat die feste Absicht, Rathenau zu crschießen. Die Waffe dafür hat er bei sich." Gerlach, Von rechts nach links, S. 259.

15 Material über Ruges politische Tätigkeit enthält cine Akte des RKO: BA/P, 15.07-658.

16 Ebenda, Der RKO an den Preußischen Staatskommissar, 27. 2. 1922.

17 PA/AA, Pcrsönliches Büro des Ministers, R 27 931, Der RKO an Obcrstleutnant Simon, 28. 2. 1922.

18 Ebenda, Der RKO an Oberstleutnant Simon, 22. 3. 1922. 
den Attentatsplan gewarnt und ihm zwei ihrer Leute als ständige Schutzbegleitung angeboten habe ${ }^{19}$. Auch der Leiter des Darmstädter Centralvereins deutscher Staatsbürger jüdischen Glaubens hatte von rechtsradikalen Aktivitäten im Frankfurter und Münchener Raum erfahren, die auf ein Mordkomplott gegen den Außenminister schließen ließen, und den Vorsitzenden des Centralvereins in Berlin noch wenige Tage vor dem Anschlag gebeten, Rathenau streng vertraulich zu unterrichten ${ }^{20}$. Ob dies geschehen ist, läßt sich nicht feststellen. Jedenfalls war die Information nicht aus der Luft gegriffen, denn sie ging auf die Aussagen zurück, die der Spitzel Theodor Brüdigam am 12. Juni in Kassel gemacht hatte. Denselben Kenntnisstand besaß zu diesem Zeitpunkt auch die Berliner Politische Polizei, die auf ausdrücklichen Wunsch Scheidemanns einen Kriminalkommissar zur Vernehmung Brüdigams nach Kassel entsandt hatte. Doch da der Kasseler Oberstaatsanwalt Noetzel mit dem energischen Hinweis reagiert hatte, „daß die Verantwortung für die sachgemäße Leitung des Ermittlungsverfahrens auf mir allein ruhe “21, waren den Berliner Ermittlern die Hände gebunden, als er am 19. Juni nach dem Untertauchen Brüdigams die schon beantragten Haftbefehle gegen Heinz, Karl Tillessen und Plaas zurückzog. Damit war gleichzeitig den selbständigen Nachforschungen des CV in Hessen der Boden entzogen, von dem Brüdigam ein kleines Honorar empfangen hatte, „damit er zunächst noch weiter scheinbar im Dienste der Radikalen der O.C. bleibt“22. Der nach seiner Vernehmung mit Wissen Noetzels nach Frankfurt zurückgekehrte Brüdigam wurde am 14. Juni vorsorglich unter polizeiliche Überwachung gestellt. Stunden vorher aber war er zu einer erneuten Besprechung mit Karl Tillessen, Heinz und Plaas zusammengetroffen, von der weder die Frankfurter Polizei noch Noetzel etwas ahnten. Was er bei dieser Gelegenheit hörte, hätte die zuständigen Behörden in Alarm versetzen müssen - wenn Brüdigams neuerliche Vernehmung am 16. Juni 1922 nicht von dem zuständigen Amtsrichter in Frankfurt abgebrochen worden und der Zeuge anschließend verschwunden wäre. So erfuhr nur der CV von Brüdigam, was der Bruder des Erzbergermörders dem Spitzel gegenüber offenbart hatte: „Für sich sähe er keinen anderen Ausweg mehr, als ,eine Kugel Rathenau durch den Kopf und eine zweite Kugel sich selbst durchs Herz zu schießen'."23

Ein weiterer Hinweis auf ein geplantes Verbrechen an Rathenau stammte aus einer ganz anderen Quelle und wurde von Kessler in seiner Rathenau-Biographie veröffentlicht. Hiernach kam Ende Mai 1922 ein katholischer Priester zu Wirth „und eröffnete ihm zitternd unter Bruch des Beichtgeheimnisses: ein Mann habe ihm im Beichtstuhl gestanden, daß er ausgelost sei, um Rathenau zu ermorden “24. Es handelte sich um dieselbe Warnung, auf die Rathenau im Februar 1922 zu sprechen gekommen war, nachdem Gerlach ihn auf den Attentatsplan Ruges aufmerksam gemacht hatte. Daß der Priester, wie Gerlach angab, aus „Süddeutschland" kam, wurde allerdings von Wirth nicht bestätigt und war offenbar eine Zutat Gerlachs. Auch Kesslers Schilderung war nicht ganz zuverlässig und veranlaßte Wirth zu einer brieflichen Richtigstellung, die er kurz darauf zusammen mit Kesslers Antwort in einem Zeitschriftenartikel veröffentlichte. Der frühere Reichskanzler bestritt keineswegs die War-

19 Vgl. Blei, Männer und Masken, S. 268.

${ }^{20}$ ASD, NL Severing, Mappe 89, Der CV, Landesverband Hessen-Nassau und Hessen, an Dr. Holländer, 15. 6. 1922.

${ }^{21}$ SAM, 567-1-2647, Bericht Oberstaatsanwalt Dr. Noetzel an den RMJ, 22. 6. 1922 (Hervorhebung in Orig.).

${ }^{22}$ ASD, NL Severing, Mappe 89, Der CV, Landesverband Hessen-Nassau und Hessen, an Dr. Holländer, 15.6. 1922.

${ }^{23}$ Ebenda.

${ }^{24}$ Kessler, Rathenau (Neuausg.), S. 315. Diese in der ersten Auflage seiner Rathenau-Biographie enthaltene Angabe hatte Kessler in der zweiten Auflage weggelassen; vgl. ebenda, S. 356, Anm. 1. 
nung selbst, nahm aber Anstoß an Kesslers Behauptung, der fragliche Priester habe „unter Bruch des Beichtgeheimnisses" gehandelt, womit eine unter Katholiken höchst sensible Frage berührt war ${ }^{25}$. Wirth war sich sicher, daß der Priester im Rahmen seiner Amtsbefugnis gehandelt habc; woher dieser sein Wissen hatte, wußte allerdings auch er nicht ${ }^{26}$.

Der Politiker bemühte sich, den Priester von dem Verdacht zu reinigen, gegen ein fundamentales kirchliches Verbot verstoßen zu haben, und verzichtete wahrscheinlich schon deshalb auf die Wiedergabe von Details ${ }^{27}$. Es kann aber als sicher angenommen werden, daß angesichts der Vielzahl von Drohungen, die Rathenau erreichten, der Priester seine Warnung konkreter gefaßt haben mußte, um die von Wirth beobachtete Reaktion hervorzurufen: „Meine Mitteilung machte auf Minister Rathenau einen tiefen Eindruck. Bleich und regungslos stand er wohl zwei Minuten vor mir. " ${ }^{28} \mathrm{Daß}$ Wirth nicht übertrieben hatte, bestätigte Kesslers Quelle Lili Deutsch, die sich an cine Unterhaltung mit Rathenau über diesen Vorfall erinnerte: „Bald nachdem er Außenminister geworden war, habe er ihr gesagt, Wirth sei zähneschlotternd zu ihm gekommen und habe ihm erzählt: ein katholischer Priester sei zu ihm gekommen und habe ihm gesagt, er müsse ihm nach schweren Gewissenskämpfen unter Verletzung des Beichtgeheimnisses mittcilen, ihm habe eins seiner Beichtkinder gebeichtet, der nächste, der drankomme, werde Rathenau sein; er werde nächstens ermordet. "29 Wenn diese Angaben zutrafen, mußte es sich um einen potentiellen Mörder oder Mittäter handeln, der von einer ihm vorgesetzten Instanz zur Ausführung seines Verbrechens bestimmt worden war; denn nur ein ernster Konflikt zwischen Befehl und Gewissen konnte seine unentschlossene Verhaltensweise verständlich machen. Gegen die Vermutung, daß sich die Warnung des katholischen Pfarrers auf die Vorbereitungen eben des Anschlages bezogen, der dann im Juni 1922 wirklich ausgeführt wurde, spricht nur die Datierung bei Gerlach auf den Februar 1922. Diese Angabe entbehrt allerdings insofern der inneren Wahrscheinlichkeit, als Gerlach in demselben Gespräch Rathenaus erfolgreiche Außenpolitik als Grund seiner Verhaßtheit in antisemitischen Kreisen anführt. Im Februar aber hatte die Außenpolitik des eben erst ernannten Außenministers Rathenau noch keine nennenswerten Ergebnisse gezeitigt; einen Sinn gibt diese Motivbestimmung im Grunde erst für die Zeit nach der Konferenz von Genua, also ab Mai 1922. Wirth selbst überlieferte in seiner Richtigstellung keine Zeitangabe, während Kessler mit Ende Mai 1922 ein Datum nannte, an dem die Vorbereitungen zur Ermordung Rathenaus tatsächlich bereits eingesetzt hatten.

Rathenau jedenfalls muß sich der Gefahr bewußt gewesen sein, in der er spätestens seit sciner Rückkehr aus Genua schwebtc. Daß er sic tatenlos hinnahm, im Grunde ignorierte, spricht für seine Furchtlosigkeit, hat aber seinen Mördern ihr Vorhaben ebenso erleichtert wie das unentschlossene Handeln der hessischen Ermittlungsbehörden in den letzten Tagen vor dem Anschlag.

${ }_{25}$ Vgl. Wirth, Walther Rathenau vor seinem Tode, S. 1305 ff. Kessler, dessen Darstellung eine kontroverse Diskussion in der katholischen Presse ausgelöst hatte (vgl. Märkische Volkszeitung vom 18.7., 26. 8. und 11. 9. 1928; Germania vom 28. 7. 1928; Deutsch-Evangelische Korrespondenz vom 22. 8. 1928), druckte Wirths Brief in der zweiten Auflage seiner Biographie ab (vgl. Kessler, Rathenau, S. 355 f.).

26 Wirth, ebenda, S. $1306 \mathrm{f}$.

27 Das Aufsehen, das Wirths Mitteilung über sechs Jahre nach Rathenaus Tod auch in der nicht konfessionell gebundenen Presse noch crregte, war dennoch beträchtlich. So titelte der Mittag (Düsseldorf) am 11. 7. 1928 auf der ersten Seite: „Neue Enthüllung über den Rathenau-Mord. Einer der Verschworenen enthüllte den Mordplan im Beichtstuhl. Der Priester warnte Reichskanzler Wirth./ Rathenaus Schicksal“; vgl. Deutsche Allgemeine Zeitung vom 13.7. 1928.

${ }^{28}$ Wirth, Walther Rathenau vor scinem Tode, S. 1307.

${ }^{29}$ Pfeiffer-Belli, Kessler. Tagebücher, S. 555. 


\section{Das Attentat auf Walther Rathenau am 24. Juni 1922}

Als Rathenau am 24. Juni 1922, einem Sonnabend, sein Haus in der Koenigsallee 65 kurz nach halb elf Uhr verließ, wurde er bereits dringend im Auswärtigen Amt erwartet, um dort einer Prüfung von Konsularanwärtern beizuwohnen ${ }^{1}$. Am Abend zuvor hatte er bei einem vom amerikanischen Botschafter Alanson Houghton gegebenen Essen den deutschen Standpunkt in der Reparationsfrage erläutert ${ }^{2}$. Zu der Besprechung war auf Wunsch Rathenaus auch der Industrielle Hugo Stinnes hinzugebeten worden, der den Außenminister trotz seiner konträren wirtschaftspolitischen Grundhaltung nach Kräften in der Auffassung unterstützte, daß die von der Regierung betriebene Inflationspolitik in Deutschland nicht nur die Reparationslast erleichtere, sondern gegenwärtig auch das einzige Mittel sei, um Absatz und Vollbeschäftigung zu sichern. Sowohl Stinnes wie Rathenau zeigten sich außerdem davon überzeugt, daß die deutschen Zahlungen an die Entente in Kürze eingestellt werden müßten und eine endgültige Lösung des Reparationsproblems in den nächsten Monaten bevorstehe ${ }^{3}$. Dieser Schulterschluß mit einem Exponenten im Kampf gegen die Erfüllungspolitik ließ einen grundsätzlichen Kurswechsel in der von Rathenau verkörperten Ausgleichspolitik gegenüber den Alliierten denkbar werden. Aus diesem Grunde hatte Rathenau Stinnes nach dem Essen noch in dessen Hotel begleitet und die Unterredung bis weit in die Nacht fortgesctzt ${ }^{4}$. Die pessimistische Einstellung gegenüber den Grundlagen seiner bisherigen Außenpolitik beherrschte Rathenau offenbar auch am nächsten Morgen noch. Nachdem er sein Haus bereits verlassen hatte, um in seinen seit zwanzig Minuten wartenden Wagen zu steigen ${ }^{5}$, kehrte er noch einmal um und notierte an seinem Schreibtisch als Überschrift auf einem Blatt Papier „Gesamtrahmen d. Pol." und darunter „Unerfüllbar" ${ }^{\text {"6 }}$. Dann erst, um 10 Uhr $45^{7}$, stieg er in den Fond seines von einem AEG-Fahrer gesteuerten dunkelgrauen NAG-Kabrioletts mit roten Rädern, dessen Verdeck trotz des regnerischen Wetters zurückgeklappt war ${ }^{8}$.

Um 10 Uhr 50 sah ein an der Koenigsallee postierter Schutzpolizist „das Auto des Herrn Minister Rathenau in Richtung Halensee an mir vorüberfahren. [...] Gleich darauf [...] folgte dem ersteren ein zweiter Wagen. [...] Insassen waren 1 Chauffeur und im Fond 2 Personen. Alle drei trugen eine Fliegerkappe ohne jeglichen Augenschutz. "9 Zur selben Zeit beobachtete wenige hundert Meter stadteinwärts der Bauarbeiter Walter Krischbin, der auf einer Baustelle an der Ecke Erdener Straße beschäftigt war ${ }^{10}$, daß sich vom Grunewald her zwei

1 Berliner Lokalanzeiger vom 24. 6. 1922, Abend-Ausgabe; vgl. Ahrens, Erinnerungen, S. 3.

${ }^{2} \mathrm{Vgl}$. Houghtons Bericht bei d'Abernon, Zeitenwende, Bd. 2, S. $66 \mathrm{ff}$.

${ }^{3}$ Hugo Stinnes, Aktennotiz, 4. 7. 1922, zit. nach Klass, Stinnes, S. 286 und S. 288; vgl. Feldman, Staatsmann, S. $84 \mathrm{ff}$.

${ }^{4}$ Die Zeitangaben über das Ende der nächtlichen Unterredung differieren: Klass gibt „um Mitternacht“ an (Klass, ebenda, S. 282) und Stinnes selbst „nach 1 Uhr“ (ebenda, S. 291), während Feldman Houghton folgt (Staatsmann, S. 96), der wiederum von Stinnes gehört haben wollte, daß Rathenau sich erst gegen vier Uhr morgens von ihm verabschiedet habe (d'Abernon, Zeitenwende, Bd. 2, S. 67).

5 SAM, 567-1-2599, Aussage Josef Prozeller, 26. 6. 1922.

6 Rathenau, Politische Briefe, S. 343.

7 SAM, 567-1-2590, Bericht Polizeiamt Wilmersdorf, 24. 6. 1922.

${ }^{8}$ Frankfurter Zeitung vom 25. 6. 1922, Erstes Morgenblatt.

9 SAM, 567-1-2590, Bericht Polizeiwachtmeister Apelt, 24. 6. 1922.

10 Vossische Zeitung vom 24. 6. 1922, 1. Abendausgabe. Es handelte sich um einen Neubau auf dem Grundstück Koenigsallee 21a (Bezirksamt Wilmersdorf von Berlin, Abt. Bauwesen, Vermessungsamt, Gebäudebuch Nr. 496). 
Autos näherten: „In dem vorderen, langsamer fahrenden Wagen, der etwa die Mitte der Straße hielt, saß auf dem linken Rücksitz ein Herr, man konnte ihn genau erkennen, da der Wagen ganz offen, auch ohne Sommerverdeck war. In dem hinteren, ebenfalls ganz offenen Wagen, einem großen sechssitzigen, dunkelfeldgrau gestrichenen starkmotorigen Tourenwagen saßen zwei Herren in langen nagelneuen Ledermänteln mit ebensolchen Lederkappen, die nur eben noch das Gesichtsoval freiließen." 11 Krischbins Schilderung für die Vossische Zeitung hat sich in der Literatur durchgesetzt ${ }^{12}$, obwohl sie vom tatsächlichen Tathergang erheblich abweicht und auch mit seiner Aussage vor dem Untersuchungsrichter nicht übercinstimmt ${ }^{13}$. Genauer beobachtete ein Postschaffner, der sich gerade an der Kurve befand, an der die Erdener Straße zusammen mit der Wallotstraße in die Koenigsallee mündet: „Der Wagen des Ministers fuhr scharf rechts, und da es kurz vor der Kurve war, langsam. In demselben Moment sah ich einen zweiten Kraftwagen in einem schnelleren Tempo hinter dem Wagen des Minister ankommen und sah mich unwillkürlich um, um zu sehen, ob dieser Wagen den Kraftwagen des Ministers überholen wollte." Von der Baustelle an der Koenigsallee aus sah cin anderer Bauarbeiter „zwei offene Autos mit einem Abstand von ca. 100 Meter herannahen. [...] Als der erste Wagen etwa noch $200 \mathrm{Mtr}$. von mir entfernt war, bemerkte ich, wie der hintere Wagen denselben zu überholen versuchte. In meiner Höhe fuhren beide Wagen Seite an Seite 3/4 Meter auseinander. [...] Der in der Fahrtrichtung links sitzende Mann beugte sich plötzlich nach vorn und erhob sich von seinem Sitz. Dann drehte er sich halbrechts seitwärts, und nun hörte ich plötzlich 8-10 Schüsse fallen. Ich bemerkte, daß sie aus einer Maschinenpistole abgegeben wurden, die der Mann noch in seiner linken Hand hielt. Nach diesem Vorgang war ein Bremsen beider Wagen zu sehen. Gleichzeitig bückte sich der rechtssitzende Mann in den Wagen hinein und erhob sich dann wieder, drehte sich rechts seitwärts und warf etwas in das Auto hinein. " ${ }^{14}$ Worum es sich handelte, erkannte Krischbin: „Als der cine Mann mit dem Schießen fertig war, stand der andere auf, zog ab - es war eine Eierhandgranate - und warf sie in den anderen Wagen, neben dem er dicht herfuhr. Vorher war der Herr schon auf seinem Sitz zurückgesunken, ganz zusammengesunken und lag auf der Scite." 15

Der zigarrerauchend im Fond sitzende Außenminister war von dem Anschlag offenbar völlig überrascht worden; auch sein Chauffeur Josef Prozeller hatte von einer Verfolgung nichts bemerkt und selbst bei dem Knall der auf Rathenau abgefeucrten Schüsse zuerst angenommen, ein Reifen seines Wagens sei geplatzt: „Ich hielt mich vorschriftsmäßig auf der rechten Seite der Straße. Plötzlich hörte ich hinter mir mehrere Schüsse, ich drehte mich um, sah den Minister zusammensinken, wobei er mich groß ansah, bemerkte im selben Augenblick einen links vorbeifahrenden Wagen [...] und hörte im selben Moment eine Detonation. Inzwischen war mein Wagen vollends zum Stehen gekommen, weil ich auf die Schüsse hin die Bremse scharf angezogen hatte. [...] Inzwischen war eine Frau herüber gekommen [...] und

11 Ebenda vom 25. 6. 1922.

12 Sein Bericht wurde mit jeweils leichten Abweichungen erst von Kessler(Rathenau, S. 365 ff.), dann von Salomon (Die Geächteten, S. 362 ff.) und seither von vielen anderen Autoren übernommen.

${ }^{13}$ SAM, 567-1-2590, Aussage Krischbin, 25. 6. 1922. Insbesondere seine falsche Behauptung, daß die Attentäter das Auto ihres Opfers rechts überholt hätten, die der besser informierte Kessler mit dem zum Gruncwald hin gerichteten Beobachtungsstandort Krischbins hatte erklären wollen (Rathenau, Neuausg., S. 324), diente später zu cbenso farbigen wie unrichtigen Schilderungen des Tathergangs (vgl. Haffner, Schüsse von rechts, S. 56 f.). Eine authentische Rekonstruktion des Überholvorgangs gibt die im Rathenaumord-Prozeß verwendete Tatortskizze wieder; SAM, 567-1-2590.

14 Aussage Pradelt und Aussage Schneider, 25. 6. 1922, in: Ebenda.

15 Vossische Zeitung vom 25. 6. 1922. 
stieg mit in den Wagen, indem sie den Minister stützte. "16 Die Frau war eine Krankenschwester, die in Erwartung der Straßenbahn auf einer Bank an der Ecke Erdener Straße gesessen und dem Vorgang in dem Glauben zugesehen hatte, „daß die Schüsse in den gegenüberliegenden Garten abgefeuert waren. [...] Dies spielte sich alles in ganz kurzer Zeit ab, und unmittelbar nach Abgabe der Schüsse schlug der überholende Wagen ein rasendes Tempo an und lenkte in die Wallotstraße, wo er aus meinen Augen entschwand. Inzwischen hatte ich den anderen Wagen bemerkt, der noch ein Endchen weiter gefahren war, bevor er endgültig zum Stehen kam, und zwar erfolgte das Stehenbleiben dieses Wagens gleichzeitig mit einem großen Knall und der Entwicklung einer großen Rauchwolke. Infolge des Knalles fuhr ich erschreckt zusammen, sprang hoch und sah in dem stehengebliebenen Auto den Insassen sich schräg nach der Seite hinüberlehnen und nahm an, daß er durch die Explosion verletzt sei. Ich eilte herüber, um ihm als Schwester Hilfe zu leisten. Als ich näher kam, sah ich, daß der Herr stark blutete am Gesicht und auch an den unteren Gliedmaßen und in dem Auto eine große Blutlache stand. Außerdem brannte der Mattenbelag des Autos. Ich trat das Feuer aus und stieg hinein, stellte mich dem fahrenden Chauffeur als Schwester vor und sagte ihm, daß ich ihm behilflich sein wollte. "17

Während sie sich dem sterbenden und schon bewußtlosen Rathenau zuwandte, gelang es Prozeller, den an Motor und Getriebe unbeschädigt gebliebenen Wagen anzukurbeln ${ }^{18}$. Er wollte zu einer nahen Polizeiwache fahren, wurde aber durch die Krankenschwester umgestimmt: „Der Chauffeur wendete den Wagen, und ich sagte, als ich die schwere Verwundung sah, ,Schnell, schnell zum Arzt'. Hierauf erwiderte der Chauffeur, daß er in 5 Minuten zu Hause sei. Ich stützte den Herrn, und auf der Fahrt zur Hundekehle merkte ich, daß er in meinen Armen verschied. " ${ }^{19}$ Nur als Toter kehrte der Außenminister kaum zehn Minuten, nachdem er es verlassen hatte, wieder zu seinem Haus zurück und wurde mit Hilfe von Passanten erst in seinem Arbeitszimmer auf den Fußboden gebettet, etwas später aber in das Schlafzimmer im ersten Stock getragen und auf das Bett gelegt ${ }^{20}$. Prozeller benachrichtigte das nächste Polizeirevier und einen Arzt, der kurz darauf den Tod Rathenaus feststellte. Dem Obduktionsprotokoll zufolge war der Minister von fünf aus nächster Nähe abgegebenen Schüssen getroffen worden, die seinen Körper sämtlich von links hinten nach rechts vorne durchschlagen hatten und folglich in der ersten Phase des Überholvorgangs abgegeben worden waren. Tödlich war bereits der erste Rückenschuß gewesen, der am linken Schulterblatt eingedrungen und dann Wirbelsäule, Brusthöhle und rechten Lungenflügel durchbohrt hatte. Drei weitere Einschußkanäle verliefen etwas seitlicher parallel zueinander und hatten oberflächliche Rückenverletzungen verursacht; der letzte Schuß war durch den Hals gegangen, hatte die Unterlippe gespalten und den Unterkiefer zersplittert ${ }^{21}$.

${ }^{16}$ Bericht Polizeiamt Wilmersdorf, 24. 6. 1922, und Aussage Prozeller, 25. 6. 1922, in: SAM, 567-1-2590.

${ }_{17}$ Ebenda, Aussage Helene Kaiser, 26. 6. 1922.

${ }^{18}$ Die spätere Untersuchung ergab, daß der Wagen Rathenaus am Rücksitz durch einen Schuß beschädigt war; Handgranatsplitter hatten zudem den Boden und Teile der Lederpolsterung zerstört. Berliner Tageblatt vom 25. 6. 1922, Morgen-Ausgabe.

${ }^{19}$ SAM, 567-1-2590, Aussage Kaiser, 26. 6. 1922.

${ }^{20}$ Ebenda; DLitM, NL Sudermann, Tagebuch, Eintrag vom 24. 6. 1922.

${ }^{21}$ SAM, 567-1-2590, Bericht Polizeiamt Wilmersdorf, 24. 6. 1922; ebenda, 567-1-2646, Obduktionsbericht Dr. Strassmann und Dr. Fraenkel, 25. 6. 1922. Weitere Verletzungen erlitt der tödlich Verwundete durch die Wirkung der Handgranate, die die Finger der linken Hand - mit der Rathenau im Moment des Attentats seinen Handstock umfaßt hatte - zerfleischte und Knochenzertrümmerungen am rechten Fuß verursachte; ebenda. Vgl. Berliner Lokalanzeiger vom 25. und Vossische Zeitung vom 26.6. 1922, Abend-Ausgabe. 
Die Nachricht von dem Verbrechen verbreitete sich wie ein Lauffeuer. Kurz nach elf Uhr stürzte Staatssekretär Haniel mit der Schreckensmeldung in das Zimmer seines Mitarbeiters Ahrens und bat ihn, die in Erwartung des Ministers zu der üblichen Morgenbesprechung versammelten leitenden Beamten des Auswärtigen Amtes zu informieren ${ }^{22}$. Um 11 Uhr 25 übermittelte der Reichskanzler die Nachricht dem Reichstag. Zur selben Zeit erfuhr Sudermann in einer Straßenbahn auf dem Kurfürstendamm von dem Verbrechen, und um zwei Uhr Rathenaus Schwester Edith Andreae im Kölner Dom ${ }^{23}$. Kurz danach erschienen in Berlin die ersten Extrablätter mit der amtlichen Mitteilung von dem Tode des Ministers, und am Abend machten sämtliche Abendausgaben der zweimal täglich erscheinenden Berliner Zeitungen mit dem Rathenaumord auf, während die Presse im Reich erst tags darauf über das Attentat berichtete. In Gegenden, in denen keine Lokalzeitungen mit Sonntagsausgaben erschienen, erfuhr die Bevölkerung in einer Zeit noch ohne Radio von dem Verbrechen frühestens am Montag, dem 26. Juni, und mancherorts blieb es auch noch Wochen später weithin unbekannt, wie sich während der Fahndung nach den Mördern Rathenaus in der Altmark zeigen sollte ${ }^{24}$.

Unmittelbar nach Bekanntwerden des Attentats hatte die Polizeiwache Grunewald Anstrengungen zur Verfolgung der Täter unternommen, die freilich von vornherein aussichtslos waren, da die eingesetzten Fahrradpatrouillen dem Wagen der Mörder auch dann nicht hätten folgen können, wenn sie während des Überfalls zur Stelle gewesen wären ${ }^{25}$. Immerhin konnte schnell festgestellt werden, daß der Wagen der Täter auf der Flucht die einen Halbkreis beschreibende Wallotstraße durchfahren, dann die Koenigsallee obcrhalb der Mordstelle passiert hatte und durch die Warmbrunner Straße in Richtung Schmargendorf entkommen war. Ferner wurden am Tatort einige Patronenhülsen, Kaliber 9, sowic Teile des Zünders und die Abreißschlaufe der verwendeten Handgranate geborgen. Gegen $12 \mathrm{Uhr}$ trafen der Berliner Polizeipräsident Richter, der Chef der Berliner Kriminalpolizei, Hoppe, und der Leiter ihrer politischen Abteilung, Weiß, mit etlichen Kommissaren an der Stelle des Verbrechens ein, eine dreivicrtel Stunde später auch zwei Vertreter der Staatsanwaltschaft ${ }^{26}$. Von Anfang an schien alles darauf hinzudeuten, daß der Anschlag von langer Hand vorbereitet war, denn die für den Überfall gewählte Straßenkreuzung, die jedes Fahrzeug zu vorsichtigem Fahren zwang und ein Entkommen in verschiedene Richtungen erlaubte, war so günstig gewählt, daß die Täter die Fahrgewohnheiten ihres Opfers genau ausgekundschaftet haben mußten. In der Tagespresse wurde noch am selben Tag der Verdacht laut, daß hinter ihnen eine „Mörderzentrale“, nämlich die O.C., gestanden habe ${ }^{27}$.

22 Vgl. Ahrens, Erinnerungen, S. 3; Zechlin, Pressechef, S. 27 f.; Stockhausen, Reichskanzlei, S. 40.

${ }^{23}$ DLitM, NL Sudermann, Tagebuch, Eintrag vom 24. 6. 1922; NL Andreae, Tagebuch, Eintrag vom 24. 6. 1922.

24 Vgl. Weiß, Polizei und Politik, S. $141 \mathrm{ff.}$

25 Berliner-Tageblatt vom 25. 6. 1922, Morgen-Ausgabe. Immerhin wurden alsbald sämtliche Polizeistationen an den aus Berlin herausführenden Autostraßen angewiesen, auf den Kraftwagen der Mörder zu achten; Berliner Lokalanzeiger vom 25. 6. 1922. Darstellungen, denen zufolge der „Wagen nach der Tat in eine Seitenstraße gesteuert [worden war], wo man, nur wenige hundert Meter vom Tatort entfernt, [...] die alarmierten Polizeiwagen kaltblütig hatte vorbeirasen lassen " (Hannover/HannoverDrück, Politische Justiz, S. 117) schmücken eine erfundene Darstellung Salomons (Die Geächteten, S. 368) weiter aus.

${ }^{26}$ SAM, 567-1-2590, Bericht Völkel, 24. 6. 1922; ebenda, 567-1-2646, Vermerk des Oberstaatsanwalts beim Landgericht III, 26. 6. 1922.

27 Berliner Tageblatt vom 24. 6. 1922, Abend-Ausgabe. 
$\mathrm{Zu}$ einer Festigung dieses unbestimmten Verdachts konnten die Erhebungen der Polizei zunächst allerdings nichts beitragen. Immerhin ergab die Untersuchung, daß die Munition der zum Anschlag verwendeten Maschinenpistole aus Heeresbeständen stammte und die auf Rathenau geschleuderte Handgranate eine Kriegsanfertigung war $^{28}$. Die polizeiamtliche Bekanntmachung vom 24. Juni 1922, die auf Hinweise zur Ergreifung der Täter die Summe von einer Million Mark auslobte, ließ aufgrund der sich hier widersprechenden Zeugenaussagen sogar offen, ob in dem Wagen der Angreifer außer dem Chauffeur noch zwei oder drei Insassen gesessen hatten, und gab ihr Alter vage mit "etwa zwanzig bis dreißig Jahre" an ${ }^{29}$. Die Ermittlungen wurden daher vorerst in drei Richtungen geführt: "Zunächst wird versucht, den Zusammenhang mit früheren ähnlichen Attentaten (Erzberger, Scheidemann pp.) aufzuklären; es wird den zahlreichen Drohbriefen nachgegangen, die Rathenau bis in die letzten Tage erhalten hat." Zum anderen sollte den zahlreichen Hinweisen aus der Bevölkerung sorgsam nachgegangen, und drittens sollten Ermittlungen gegen Organisationen und Personen angestellt werden, denen cin solches Verbrechen zuzutrauen $\operatorname{se}^{30}$. Durchsuchungen bei der Organisation Roßbach, dem Verband nationalgesinnter Soldaten, dem Stahlhelm, dem Deutschvölkischen Schutz- und Trutzbund und anderen Vereinigungen der militanten Rechten blieben aber ebenso ergebnislos wie eine Reihe von Verhaftungen in Rechtskreisen ${ }^{31}$, so daß der vorerst einzige verwertbare Fingerzeig die nun schon ältere Beschuldigung des untergetauchten Brüdigam gegen die ihm bekannten Funktionäre der O.C. blieb. Noch am Tag der Ermordung ordnete der Kasseler Oberstaatsanwalt die Festnahme von Brüdigam selbst und der von ihm angeschuldigten Hoffmann, Tillessen, Plaas und Heinz an ${ }^{32}$. Die beiden letzteren konnten schon am selben Tag in Frankfurt ergriffen werden ${ }^{33}$, tags darauf Karl Tillessen in Flensburg und Hoffmann in München ${ }^{34}$. Doch die forsche Gangart diente mehr zur Beruhigung der Öffentlichkeit, denn außer Brüdigams vagen Hinweisen hatte man wenig in der Hand, was ihre Festnahme im Zusammenhang mit dem Rathenaumord hätte begründen können. So konnten Ehrhardts Funktionäre nur unter dem Verdacht der Beihilfe zum Mordversuch an Scheidemann in Haft genommen werden. Zudem bestritten sie katego-

${ }^{28}$ SAM, 567-1-2590, Gutachten der Deutschen Versuchs-Anstalt für Handfeuerwaffen, 27. 6. 1922. Die Maschinenpistole selbst, die die Täter während eines Haltes auf ihrer Flucht in ein Gartengrundstück in Berlin-Schmargendorf geworfen hatten, wurde erst am 3.7. 1922 gefunden. Sic enthielt noch 24 Schuß Munition; Kieler Neueste Nachrichten vom 4. 7. 1922.

${ }^{29}$ Die Summe wurde von privater Seite im Zuge einer vom Berliner Tageblatt initiierten Sammlung erheblich erhöht; vgl. Berliner Tageblatt vom 27. 6. 1922, Morgen-Ausgabe; 29. 6. 1922, MorgenAusgabe.

${ }^{30}$ SAM, 567-1-2646, Vermerk ORA Ebermayer, 26. 6. 1922.

${ }^{31}$ So wurde z. B. der Student Werner Flesch, der am Mordtage Helfferich ein Blumenbukett mit schwarzweißroter Schleife und der Inschrift „Dem Retter der deutschen Ehre“ überreicht hatte, erst verhaftet, dann mangels Tatverdacht freigelassen und am 26.6. wieder verhaftet, nachdem eine vermeintliche Verbindung Fleschs zu Ehrhardt bekannt wurde; Berliner Tageblatt vom 27. 6. 1922, Morgen-Ausgabe; vgl. Weiß, Polizei und Politik, S. $94 \mathrm{f}$. Das Blumengebinde hatte übrigens keinen Bezug zur Ermordung Rathenaus, sondern war am 23. 6. 1922 vom Deutschen Kriegerbund in Rio de Janeiro als Anerkennung der Reichstagsrede Helfferichs vom selben Tage in Auftrag gegeben worden; vgl. Schleswig-Holsteinische Volkszeitung vom 30. 6. 1922.

${ }^{32}$ SAM 567-1-2647, Bericht Oberstaatsanwalt Dr. Noetzel an den RMJ, 26. 6. 1922.

${ }^{33}$ Ebenda, Bericht Oberstaatsanwalt Dr. Noetzel an den RMJ, 27. 6. 1922.

${ }^{34}$ Vossische Zeitung vom 25. 6. 1922, Abend-Ausgabe. 
risch, mit dem Anschlag auf Rathenau in irgendeiner Verbindung zu stehen ${ }^{35}$, so daß die bereits im Reichstag geäußerte Überzeugung, die O.C. stehe hinter dem Anschlag, zumindest vorläufig keine Bestätigung fand ${ }^{36}$.

Dennoch hatte die Polizei schon am 25. Juni kurz vor einem entscheidenden Erfolg gestanden, als der Corpsdiener der Studentenverbindung Teutonia in Berlin der Polizei meldete, daß dort am Tag vor dem Attentat um zehn Uhr vormittags der Verbindungsstudent Ernst Werner Techow mit einem dunkelbraunen Auto in Begleitung dreier Herren vorgefahren sei und für einige Stunden zwei Lederkoffer deponiert habe; die Beschreibung des Autos und seiner Insassen stimmte mit den ersten veröffentlichten Zeugenaussagen überein ${ }^{37}$. Wäre die Kriminalpolizei dieser Spur nachgegangen, hätte sie möglicherweise schon am Tag nach dem Verbrechen neben dem Fahrer des Mordwagens auch die Mordschützen fassen können, die sich zu dieser Zeit noch in Berlin aufhielten. Daß sie es nicht tat, hing möglicherweise damit zusammen, daß die Auto- und Täterbeschreibung der polizeilichen Bekanntmachung vom 24. Juni 1922 durch die Angaben eines neu erschienenen Augenzeugen so stark abgeändert worden war, daß sie nicht mehr der Beobachtung des Corpsdieners entsprach und dessen Aussage entwertete. Dieser Zeuge, ein angeblicher Oberförster, meldete sich am 25. Juni und wollte gesehen haben, daß der fragliche Wagen Minuten vor dem Anschlag mit laufendem Motor in der Bismarckallee Ecke Koenigsallee gewartet habe. Ein Insasse habe hinter dem Chauffeur gesessen, während ein anderer zwischen dem Auto und der Straßenecke mehrfach hin- und hergegangen $\operatorname{se}^{38}$. Die Angaben des Zeugen hätten nicht exakter sein können und beeindruckten durch die außerordentlich präzise Beschreibung des Tatfahrzeuges und seiner Besatzung - aber sie waren pure Erfindung. Der vermeintliche Zeuge, ein gewerbsmäßiger Schwindler, hatte sich als Förster ausgegeben, um seinen Phantasieangaben Seriosität zu verleihen und sich so einen Teil der im Fahndungsaufruf vom 24. Juni ausgelobten Belohnung zu sichern ${ }^{39}$. So wurde die Untersuchung der Polizei gerade dort behindert, wo sie erste Erfolge aufzuweisen meinte ${ }^{40}$. Achtundvierzig Stunden nach der Tat waren die Ermittlungen noch keinen entscheidenden Schritt vorangekommen, obwohl die unternommenen Anstrengungen in der Geschichte der Berliner Kriminalpolizei ohne Beispiel waren.

Die Wende brachte am 26. Juni eine Anzeige, wonach ein Student Willi Günther sich in einer Versammlung des deutschnationalen Jugendbundes Hansa der Mittäterschaft gebrüstet und behauptet habe, während des Anschlags auf einem Notsitz des Täterwagens gesessen zu haben ${ }^{41}$. Günther wurde noch am selben Tag gefaßt und gestand nach anfänglichem Leugnen,

${ }^{35}$ BA, NL 150, 10, Beiakten, H. 18, Aussage K. Tillessen, 27. 6. 1922; ebenda, H. 21, Aussagen Hoffmann, 7. 7. und 4. 8. 1922. Hoffmann blieb bei seiner Darstellung und wurde später außer Verfolgung gesetzt. Auch die meisten übrigen auf bloße Zugehörigkeit zu militanten Rechtsverbänden gegründeten Verhaftungen mußten wieder aufgehoben werden; Vossische Zeitung vom 29.6. 1922, MorgenAusgabe.

36 Am 25. 6. hatte der sozialdemokratische Abgeordnete Wels dem Reichstag von den wesentlichen Aussagen Brüdigams Mitteilung gemacht und behauptet, daß Tillessen und Hoffmann im Auftrag der O.C. die Anschläge auf Scheidemann und Rathenau organisiert hätten; Schleswig-Holsteinische Volkszeitung vom 25.6. 1922.

37 SAM, 567-1-2590, Aussage Guderjahn, 25. 6. 1922.

38 Vgl. Kieler Neueste Nachrichten vom 2. 7. 1922; Weiß, Polizei und Politik, S. 143.

39 Kieler Neueste Nachrichten vom 2. 7. 1922; Weiß, ebenda.

${ }^{40}$ So berichtete das Berliner Tageblatt in seiner Morgen-Ausgabe vom 27. 6. 1922, daß nach den Angaben des Oberförsters der Täterwagen als ein Fabrikat der Marke Opel identifiziert sei; tatsächlich aber handelte es sich um einen Mercedes.

41 BA, NL 150, 10, Beiakten, H. 3. 
mit dem Schüler Heinz Stubenrauch in Kontakt zu stehen, der ihm etwa sechs Wochen vorher seinen Plan eröffnet hatte, Rathenau im Reichstag oder vor dem Hause des Kommerzienrats Mamroth zu erschießen. Günther hatte diesen Plan seinem früheren Schulkameraden Ernst Werner Techow mitgeteilt, der ihn am 19. Juni mit zwei Männern zusammenbrachte, die sich für Günthers Vorhaben interessierten. Ihnen, die sich als „Knauer“ und „Fischer“ vorstellten, gelang es, Günther den Plan mit dem Versprechen auszureden, daß sie ihn statt dessen an eigenen Vorbereitungen zur Ermordung Rathenaus beteiligen wollten. Günther half den beiden beim Versuch, eine Maschinenpistole zu beschaffen, und er besorgte bei einem Garagenbesitzer Schütt in Berlin-Schmargendorf eine Unterstellmöglichkeit für das zur Tat vorgesehene Auto. Bereitwillig gestand cr nun auch, daß er am Tage des Mordes die Täter auf ihrem Weg Richtung Grunewald begleitet hatte, bis sie in den von Techow gelenkten Wagen stiegen, und er bezeugte schließlich, um elf Uhr auf Schütts Garagenhof von dem eben allein im Auto zurückgekchrten Techow mit den Worten empfangen worden zu sein: „Die Sache hat geklappt, Rathenau liegt. “42

Durch das rückhaltlose Geständnis Günthers hatte die Polizei mit einem Schlage einen Großteil der Umstände aufklären können, unter denen das Verbrechen an Rathenau begangen worden war. Um der Haupttäter habhaft zu werden, wurde die Presse dennoch zunächst gar nicht oder nur in vagen Andeutungen informiert; sie sollte vor allem durch die Bekanntgabe kleinerer Fahndungsfortschritte den auf der kriminalpolizeilichen Ermittlung lastenden Druck vermindern ${ }^{43}$. Die wirklichen Erfolge hingegen wurden der Öffentlichkeit vorerst nicht bekanntgegeben: Noch am 27. Juni 1922 vermochten die Ermittler die Gymnasiasten Hans-Gerd Techow (einen Bruder des als Fahrer des Mordwagens gesuchten Ernst Werner Techow) und Heinz Stubenrauch festzunehmen ${ }^{44}$. Am selben Tag stellte die Polizei in der von Günther angegebenen Garage in Schmargendorf den Tatwagen sicher und verhaftete Schütt sowie seinen Kompagnon Diestel. Doch erst am Abend des 28. Juni, als die Polizei davon ausgehen mußte, daß die Mordschützen und ihr Fahrer sich nicht mehr in Berlin aufhiclten, wandten die Ermittlungsbehörden sich mit einem Fahndungsaufruf an die Öffentlichkeit. Er enthielt eine genaue Personenbeschreibung von Ernst Werner Techow, Fischer alias Vogel und Knauer alias Körner alias Kern und gab bekannt, daß Knauer/Kern und Vogel/Fischer sich möglicherweise nach Norden gewandt hätten, Techow hingegen Berlin am Abend des 25. Juni mit dem Zug nach Halle verlassen habe ${ }^{45}$. Weiß hoffte nun, daß die Empörung über die Ermordung sich in „der regsten Beteiligung des Publikums an der Aufklärung des Verbrechens" niederschlage ${ }^{46}$, und er kalkulierte zumindest in einem Fall richtig: Bereits am folgenden Tag konnte Techow auf Gut Biegen bei Jacobsdorf nahe Frankfurt/Oder festgenommen werden. Er hatte sich am Tag nach dem Attentat erst nach Halle, dann nach Jena und

${ }^{42}$ Aussagc Günther, 27. 6. 1922, in: Ebenda; Aussage Günther, 29./30. 6. 1922, in: SAM, 567-1-2570.

${ }^{43}$ Vgl. Berliner Tageblatt vom 27.6. 1922, Abendausgabe. Die Diskretion der Ermittlungsbehörden fand besonders auf der äußersten Linken herbe Kritik, so in der Roten Fahne vom 27. 6. 1922. Zu Wciß' Vorgehen in der Ermittlungsarbeit vgl. Bering, Kampf um Namen, S. $49 \mathrm{f}$.

${ }^{44}$ BA, NL 150, 10, Beiakten, H. 3, Aktenvermerk des Polizeipräsidiums, o.D.

${ }^{45}$ Berliner Tageblatt, Morgen-Ausgabe, und Schleswig-Holsteinische Volkszeitung vom 29. 6.1922. Der Name Techow hatte ein Dreivierteljahrhundert zuvor bereits einmal die Öffentlichkeit beschäftigt, als im Juni 1848 der Leutnant Gustav Techow - der Großvater des Gesuchten - für die kampflose Übergabe des Berliner Zeughauses an die Revolutionäre gesorgt hatte und dafür später zu 15 Jahren Festungshaft verurteilt worden war, der er nach einem Jahr zu entfliehen vermochte; vgl. Streckfuß, März 1848, S. 168 f.; Hammer, Gustav Techow, S. 52 ff.; Harden, Schutz der Republik, S. 27 ff.

${ }^{46}$ Schleswig-Holsteinische Volkszeitung vom 29. 6. 1922. 
Erfurt begeben, um Corpsbrüder zu besuchen, und war schließlich auf das Gut seines Onkels Erwin Behrens ${ }^{47}$ gefahren, wo er am Morgen des 28. Juni ankam. Als Behrens am 29. Juni den Namen seines Neffen in der Zeitung las, hielt er ihn bis zum Eintreffen der Polizei fest. Techow gestand schon tags darauf in seiner zweiten Vernehmung, das Auto geführt zu haben, aus dem heraus Knauer/Kern bzw. Fischer geschossen hatten. Sie hätten bei ihm einige Tage vor dem Attentat vorgesprochen und sich als frühere Mitglieder der Brigade Ehrhardt zu erkennen gegeben, um eine Verbindung zu Stubenrauch aufzunehmen, von dessen Mordplan sie bereits wußten. Schritt für Schritt seien er und sein Bruder Hans-Gerd dann in die Ausführung des Vorhabens einbezogen worden. So habe er das zur Tat benutzte Auto, das von dem Fabrikanten Johannes Küchenmeister in Freiberg/Sachsen stamme, im Auftrag Knauer/Kerns zusammen mit einem Dresdener Verbindungsmann namens Günther Brandt abholen und nach Berlin fahren müssen ${ }^{48}$. Auch die Herkunft der Maschinenpistole, mit der Rathenau erschossen worden war, konnte nun bald ermittelt werden: Sie stammte von dem deutschvölkischen Funktionär Christian Ilsemann, den Kern und Fischer in Schwerin zwei Tage vor dem Anschlag mit dem von Techow gesteuerten Wagen aufgesucht hatten ${ }^{49}$.

Ungeklärt aber blieb vorerst, ob auch O.C.-Funktionäre aus München oder Frankfurt/ Main in das Attentat verwickclt waren. Karl Tillessen führte zu seiner Entlastung an, er habe sich in der fraglichen Zeit überhaupt nicht in Berlin aufgehalten. Vielmehr sei er am 21. Juni von Jena, wo sein Adjutant Hartmut Plaas und er vergeblich den Landesleiter des Neudeutschen Bundes, Günther Brandt, zu treffen versucht hätten, nach Flensburg zu seinem Bruder Werner gereist und dort bis zu seiner Festnahme geblieben ${ }^{50}$. Die Ermittler gaben sich mit dieser Erklärung nicht zufrieden, denn Brandt war bereits von Techow als Mittelsmann der Attentäter bezeichnet worden und hatte sich seiner Verhaftung ebenso wie Johannes Küchenmeister durch die Flucht ins Ausland entzogen ${ }^{51}$. Auch hatte der ältere Techow zwei „Unbekannte“ erwähnt, die am Mittwoch und Donnerstag vor dem Anschlag mit Kern und Fischer zusammengewesen seien ${ }^{52}$. Daß es sich bei den Unbekannten in Wirklichkeit um Tillessen und Plaas handelte, wurde offenbar, als Günther gestand, daß Tillessen am 21. und

${ }^{47}$ Dicser Onkel war nicht mit dem AEG-Architekten Peter Bchrens verwandt (Mitteilung von Till Behrens an den Verfasser, 9. 9. 1989), unterhielt aber geschäftliche Beziehungen zu Walther Rathenau; BA, NL 150, 10, Beiakten, H. 2, Aussage Erwin Behrens, o. D.

${ }^{48}$ SAM, 567-1-2593, Bericht Kriminalkommissar Fluth, 29.6.1922, und Aussage E. W. Techow, 2. 7. und 30. 6. 1922. Der politisch rechtsstehende Küchenmeister betrieb mit seinem Bruder Fritz in Freiberg/ Sachsen eine Flachsverarbeitungsanstalt und besaß z.wei Personenkraftwagen, von denen einer nach den Feststellungen der nach Freiberg entsandten Polizisten in der Garage stand, während Küchenmeister sich mit dem anderen in der Woche vor dem Mord von seinem Chauffeur nach Dresden hatte fahren lassen. Anschließend hatte Küchenmeister seinen Chauffeur mit der Begründung nach Hause geschickt, er haben den Wagen einem Schulfreund für eine Probefahrt überlassen, und war selbst tags darauf olnne Wagen nach Freiberg zurückgekehrt; BA, NL 150, 10, H. 7; BA/P, 30.01-5053/1, Anklageschrift gegen Techow u. Gen., S. 24 f.

49 SAM, 567-1-2593, Bericht Fluth, 29. 6. 1922. Ilsemann und sein Mitarbeiter Bade wurden alsbald in Schwerin verhaftet; Frankfurter Zeitung vom 2. 7. 1922, Erstes Morgenblatt.

${ }^{50}$ SAM, 567-1-2621, Aussage K. Tillessen, 3. 7. 1922.

${ }^{51}$ Brandt konnte erst am 30. 4. 1924 bei München verhaftet werden, während Küchenmeister, dessen Auslieferung die österreichischen Behörden abgelehnt hatten, im Dezember 1924 freiwillig nach Deutschland zurückkehrte, nachdem ihm der Staatsgerichtshof sicheres Geleit gewährt hatte; BA/P, 30.03-12J482/24, Anklageschrift gegen Brandt und Küchenmeister, S. 3.

52 SAM, 567-1-2593, Aussage E. W. Techow, 30. 6. 1922. 
22. Juni 1922 in Berlin und in den Mordplan zumindest eingeweiht gewesen war. In die Enge gedrängt, gab Tillessen zu, daß seine bisherigen Erklärungen falsch gewesen seien und er von dem Attentatsplan nicht nur gewußt habe, sondern mit Plaas am 21. Juni zu der Verschwörergruppe gestoßen sei. Allerdings wollte er deren Vorbereitungen durchaus nicht unterstützt, sondern vielmehr Kern nachdrücklich von der Ausführung abgeraten haben; er sei am Donnerstag vor dem Anschlag in dem Glauben abgereist, Kern das Verbrechen ausgeredet zu haben ${ }^{53}$.

Damit war es der Kriminalpolizei gelungen, innerhalb von zwei Wochen die Identität fast aller an der Tat beteiligten Komplicen zu klären. Auch die ganz auf die radikale Rechte und besonders auf die O.C. konzentrierten Ermittlungen schienen glänzende Ergebnisse erbracht zu haben: Mochte nach der Verhaftung Günthers die Annahme, daß für das Verbrechen fanatisierte Einzelgänger verantwortlich sein könnten, immerhin noch im Bereich des Möglichen gelegen haben ${ }^{54}$, so verlor diese Vermutung nun, da die wegen des ScheidemannAttentats verhafteten O.C.-Funktionäre Tillessen und Plaas ihre Verwicklung auch in den Mordanschlag auf Rathenau gestanden hatten, jede Wahrscheinlichkeit. Offen blieb nur mehr die Identität eines einzigen Mitglieds der Verschwörergruppe, von dem Tillessen als „unbekanntem jungen Mann“, Plaas als „Schreiber“ sprach; dieser Mann hatte angeblich die beiden in Berlin nicht nur zu Kern und Fischer gewiesen, sondern augenscheinlich auch bei der Tatvorbereitung eine wichtige Rolle gespielt ${ }^{55}$. Ihm kam die Polizei über Ermittlungen auf die Spur, die zunächst einem ganz anderen Verbrechen galten: Am 22. Juni 1922, also schon vor der durch die Ermordung Rathenaus ausgelösten Verhaftungswelle, hatte die Hamburger Polizei einige Männer verhaftet, die einer Serie von Sprengstoffanschlägen unter anderem gegen den kommunistischen Bürgerschaftsabgeordneten Ernst Thälmann und das Revolutionsdenkmal in Hamburg-Ohlsdorf verdächtig waren und sämtlich der O.C. angehörten. Bei dem Leiter dieser Gruppe, Friedrich Warnecke, fand die Polizei zwei Telegramme, deren eines am 17. Juni aufgegeben worden war und lautete: „Besuch 10 Uhr Sonnabend abends Wohnung erwarten = Erwin“", während das andere vom 19. Juni stammte und die Worte enthielt: "11 Uhr 30 Hauptbahnhof Waldemar."56 Warnecke schwieg sich über die Bedeutung der Telegramme aus, aber sein Vertreter Waldemar Niedrig offenbarte, daß die O.C. ein "Spreng- und Mordkommando“ besitze, das aus zwei Männern namens Kern, Fischer und einem Kurier namens Schneider alias Pfeiffer bestehe und mit anderen O.C.-Mitgliedern über telegraphische Besuchsankündigung in Verbindung zu treten pflege ${ }^{57}$. Schneider alias Pfeiffer habe Warnecke und ihn am 17. Juni in Hamburg besucht, um einen Fahrer für ein geplantes Attentat auf Rathenau zu finden. Niedrig habe sich bereit gefunden und sei tags darauf mit Pfeiffer nach Berlin gefahren, um Kern und Fischer in deren Pension am

${ }^{53}$ Aussagen Günther, E. W. Techow und K. Tillessen, alle 5. 7. 1922, in: Ebenda, 567-1-2621.

${ }^{54}$ Besonders linksstehende Zeitungen versuchten aus Günthers DNVP-Mitgliedschaft und aus der Korrespondenz, die er mit prominenten Repräsentanten der äußersten Rechten wie Ludendorff geführt hatte, die zumindest moralische Mitschuld der Deutschnationalen an dem Anschlag herzuleiten; vgl. etwa Schleswig-Holsteinische Volkszeitung und Rote Fahne vom 30. 6. 1922. Diese Vcrmutung ließ sich aber in keiner Weise erhärten, auch wenn sie sich in der Sekundärliteratur wiederfindet; vgl. Orth, Rapallo, S. 147 f. Statt dessen stellte sich heraus, daß Günther, ein pathologischer Aufschneider, mit Funktionären der Rechten vornehmlich korrespondiert hatte, um sich wichtig zu machen, und aus der DNVP wegen Unterschlagung ausgeschlossen worden war; SAM, 567-1-2570, Aussage Günther, 29./30.6. 1922.

${ }^{55}$ Ebenda, 567-1-2621, Aussagen K. Tillessen, 2. und 5. 8. 1922; ebenda, 567-1-2588, Aussage Plaas, 3. 8. 1922.

${ }^{56}$ Ebenda, 567-1-2585, Bericht Zentralpolizeistelle Hamburg, 24. 6. 1922.

${ }^{57}$ Ebenda, Aussage Niedrig, 26. 6. 1922. 
Schiffbauerdamm zu treffen. Dort sei ihm aber zunächst bedeutet worden, daß das in Aussicht genommene Auto erst noch in Dresden beschafft werden müsse, und kurz darauf habe Kern ganz auf Niedrigs Dienste verzichtet, da schon ein anderer Fahrer zur Verfügung stehe ${ }^{58}$.

Schon am Tag des Attentats zeigte sich die Hamburger Polizeibehörde daher überzeugt, daß die „Rathenau- und Scheidemann-Mörder in der O.C. zu suchen“ seien ${ }^{59}$. In der Tat führte die Aussage Niedrigs auf dieselbe richtige Spur wie das Geständnis des unterdes gefaßten Günther. Am 26. Juni ermittelte die Berliner Polizei die Pension Scheer in BerlinMitte, Am Zirkus 10, in der Kern, Fischer sowie Erich Schneider alias Pfeiffer vom 16. bis zum 23. Juni gewohnt hatten ${ }^{60}$, und gewann aus den Fremdenbucheintragungen die in den späteren Fahndungsplakaten abgebildeten Schriftproben Fischers. Doch während in den folgenden Wochen die Fahndung nach Kern und Fischer auf Hochtouren lief, ließ sich über den angeblichen Schneider/Pfeiffer zunächst nichts weiter feststellen. Die Ermittlungen stagnierten, bis sich Niedrig am 14. Juli darauf besann, daß bei seinem Treffen am 17. Juni mit Warnecke und Schneider/Pfeiffer weitere Zeugen anwesend gewesen waren, von denen einer Schneider/Pfeiffer offenbar von der Kadettenschule her kannte ${ }^{61}$. Dieservermutlich ebenfalls zu den militanten Rechtskreisen zählende Zeuge verweigerte anfangs die Aussage, gab den Namen aber preis, als man ihm auf den Kopf zusagte, daß der Gesuchte und er auf derselben Kadettenschule gewesen seien: Hinter Schneider/Pfeiffer verberge sich Ernst von Salomon ${ }^{62}$. Daraufhin gab nun auch Plaas immerhin zu, in Berlin mit einem ihm bis dahin unbekannten "Schreiber" zusammengetroffen zu sein. Daß auch dies noch nicht die ganze Wahrheit war und er sehr wohl wußte, daß es sich um Salomon handelte, ließ er sich auch jetzt noch nicht entlocken $^{63}$. Doch Plaas' und Tillessens Versuch, den flüchtigen Komplizen zu schützen, mißlang: Am 10. August konnte Salomon in seiner Wohnung in Frankfurt verhaftet werden ${ }^{64}$.

Die Spur der cigentlichen Mörder aber hatte die Polizei verloren. Vermutungen, daß sie mit einem Flugzeug von Berlin-Staaken aus entkommen sein könnten ${ }^{65}$, erwiesen sich als haltlos. Den Aussagen Günthers zufolge hatten die Attentäter sich vorgenommen, nur im Falle ciner unmittelbaren Verfolgung mit dem Auto aus Berlin zu flüchten ${ }^{66}$. Nachdem sich dies als nicht erforderlich herausgestellt hatte, waren Kern und Fischer offenbar die nächsten Tage ohne die Bcobachtung irgendwelcher Vorsichtsmaßnahmen in Berlin geblicben. Am Nachmittag des 24. Juni bummelten sie mit den beiden Techow durch den Berliner Zoo; am 26. Juni trafen sie sich mit dem jüngeren Techow am Bahnhof Wannsee zum Rudern.

${ }^{58}$ Ebenda, Aussage Niedrig, 26. und 28. 6. und 8. 8. 1922.

59 Ebenda, Bericht Zentralpolizeistelle Hamburg, 24. 6. 1922.

${ }^{60}$ BA, NL 150, 10, Beiakten, H. 24.

61 Ebenda, Aussage Niedrig, 14. 7. 1922.

62 Ebenda, Vernehmungsprotokoll Winzer vom 16. 7. 1922. Salomon nahm eine erzählcrisch pointierte, aber mit den Tatsachen nicht in Übereinstimmung stehende Schilderung seiner Enttarnung in den "Fragebogen“ auf (S. 125 f.), dic von anderen Autoren übernommen wurde; vgl. Venner, Söldner, S. $12 \mathrm{f}$.

${ }^{63}$ SAM, 567-1-2588, Aussage Plaas, 3. 8. 1922. Erst eine Woche später gestand Plaas: „Nachdem mir soeben mitgeteilt worden ist, daß Warnecke als Namen des,Schneider' oder, Schreiber' angegeben hat Salomon, sehe ich ein, daß es kcinen Zweck mehr hat, den Namen meinerseits zu verschweigen. Der junge Mann [...] war der Bankbeamte Ernst von Salomon aus Frankfurt a. Main, den ich von dorther kannte." Ebenda, Aussage Plaas, 9. 8. 1922.

64 BA, NL 150, 10, Beiakten, H. 24.

65 Berliner Börsencourier, 27. 6. 1922.

${ }^{66}$ SAM, 567-1-2570, Aussage vom 29./30. 6. 1921. 
Unbekannt blieb jedoch vorerst, wo und bei wem sie in dieser Zeit gewohnt hatten. HansGerd Techow vermochte nur anzugeben, daß sie im Anschluß an die Ruderpartie gemeinsam um sieben Uhr abends mit der Wannseebahn in die Stadt zurückgefahren seien. In Steglitz seien Kern und Fischer ausgestiegen, ohne zu sagen, wohin sie sich wenden wollten. Während des Ruderausflugs auf dem Wannsee hatten sie allerdings davon gesprochen, „daß sie Dienstag den 27. Juni mit dem Mittagszug über Hamburg sich nach der Nordseeküste begeben wollten " ${ }^{\circ 7}$. Das waren nur vage Hinweise, zumal sich über Erwin Kern auch in den folgenden Wochen nicht viel mehr ermitteln ließ, als daß er der 1898 in Gumbinnen geborene Sohn eines Verwaltungsdirektors aus Breslau war, der früher mit dem älteren Techow, Ilsemann und Fischer in der Brigade Ehrhardt und später als Seeoffizier in der Reichsmarine gedient haben sollte ${ }^{68}$. Der zwei Jahre ältere, in Florenz geborene Hermann Fischer war in Dresden aufgewachsen, wo sein Vater als Professor und Kunstmaler wirkte, hatte sich im Weltkrieg als Offizier und Kompanieführer ausgezeichnet und anschließend bis März 1922 in Chemnitz Maschinenbau studiert. Wie Kern war er Mitglied verschiedener rechtsgerichteter Organisationen, so der Technischen Nothilfe, des Deutschvölkischen Schutz- und Trutzbundes, des Deutschvölkischen Turnverein Jahn in Chemnitz und eben der Brigade Ehrhardt ${ }^{69}$.

Die polizeilichen Nachforschungen an diesen Orten blieben ohne Ergebnis, obwohl neben Hans-Gerd Techows Auskunft mindestens zwei sachliche Anhaltspunkte für die Möglichkeit sprachen, daß die durch die ersten Pressemeldungen über ihre Personalien in Sicherheit gewiegten Mörder Rathenaus ${ }^{70}$ nicht ins Ausland geflohen waren, sondern tatsächlich im Norden Deutschlands vermutet werden mußten: Zum einen war Kern Student in Kiel und hatte sich im ersten Halbjahr 1922 häufig dort und in Rostock aufgehalten, zum anderen hatten Kern und Fischer einen der beiden Lederkoffer, mit denen sie angereist waren, am 23. Juni in Schwerin bei Ilsemann mit der Bitte deponicrt, ihn nach Rostock zu schicken ${ }^{71}$. Den anderen Koffer, der offenbar ihre Reiseutensilien enthielt, hatte Günther am Mordtag im Auftrag von Kern und Fischer in seine Wohnung geschafft. Von dort hatte ihn noch am selben Tag ein Unbekannter abgeholt ${ }^{72}$. Auf eine hastige Flucht hätte der sperrige Coupékoffer nicht mitgenommen werden können, woraus sich die Mutmaßung ableiten ließ, daß die Mörder Rathenaus zwar noch nicht wagten, in ihre Wohnungen nach Kiel und Chemnitz zurückzukehren, sich aber ungeachtet der fieberhaften Fahndung im norddeutschen Raum aufhielten.

Den Mördern half eine Fahndungspanne. Denn am 5. Juli, als die Polizei über den Aufenthaltsort der beiden noch im dunkeln tappte, hatte ein Vetter Kerns angezeigt, daß die Gesuchten sich zeitweilig bei Verwandten in Berlin-Steglitz aufgehalten hätten. Der Vorgang blieb jedoch im Berliner Polizcipräsidium fast zwei Wochen unbearbeitet liegen - und damit der Polizei verborgen, daß Kern und Fischer kurz nach der Tat bei einer Tante Kerns in Bcrlin

${ }^{67}$ Ebenda, 567-1-2592, Aussagen H.-G. Techow, 27. und 30. 6. 1922.

${ }^{68}$ Ebenda, 567-1-2579, Vermerk Pol.Präs. Berlin, Abt. IA, 8. 7. 1922.

${ }^{69} \mathrm{BA}, \mathrm{NL}$ 150, 10, Akte Fischer; vgl. zu den Beziehungén der Rathenaumörder zur völkischen Turnerbewegung Bernett, Völkische Turner, S. 426.

${ }^{70}$ Die Täterbeschreibung des falschen Obcrförsters entsprach so wenig dem tatsächlichen Aussehen Kerns und Fischers, daß sie Mitwissern später als Ausrede diente, warum sie nicht zur Polizeigegangen seien. Weiß versuchte den Schaden im nachhinein mit der Behauptung zu begrenzen, den Behörden sei die Wertlosigkeit der Aussagen des vermeintlichen Augenzeugen von Beginn an klar gewesen, sie hätten dies aber in der Öffentlichkeit nicht deutlich gemacht, um die Täter irrezuführen; Polizei und Politik, S. 143.

71 SAM, 567-1-2577, Aussage Ilsemann, 3. 7. 1922. Der Inhalt des Koffers bestand aus Wäsche und Büchern; ebenda, Aussage Bade, 1.7. 1922.

72 Ebenda, 567-1-2570, Aussage Günther, 29./30. 6. 1922. 
crschienen waren ${ }^{73}$. Vorgeblich gekommen, um für Fischer in der Stadt eine Stellung zu suchen, wohnten beide bis zum 27. Juni in ihrem Steglitzer Haus und wirkten so vergnügt, daß Kerns Tante die Möglichkeit, ihr Neffe könnte der Mörder Rathenaus sein, auch dann noch ausgeschlossen schien, als sein und Fischers Name auf den Fahndungsplakaten zu lesen war. Beide erweckten durchaus nicht den Eindruck gehetzter Flüchtlinge. Sie seien aus Rostock gekommen, teilte Kern seinem Vetter Walter am 24. Juni mit, und nach Rostock wollten sie auch wieder zurückfahren, als sie sich am Morgen des 27. Juni von ihrer Tante verabschiedeten. Offenbar entsprach diese Reise einem längst vorher gefaßten Plan. Denn Kern hatte die Abreise schon vorher angckündigt, und er führte den am 24. Juni aus Günthers Wohnung abgeholten Coupékoffer mit sich, dessen Gegenstück er vor dem Anschlag in Schwerin mit dem Auftrag deponiert hatte, ihn nach Rostock zu schicken.

Ohne dieses Wissen konnte die Berliner Politische Polizei zu diesem Zcitpunkt nur hoffen, über öffentliche Fahndung und psychologischen Druck die Gesuchten zu einem Fehler zu verleiten und sie womöglich aus ihrem Versteck herauszutreiben. Weiß nutzte am 28. Juni ein längeres Interview mit dem Berliner Tageblatt, um hypothetisch die Fluchtmöglichkeiten Kerns und Fischers zu erörtern, die sich seiner Auffassung zufolge nach Sperrung der Grenzen angeblich auf die Alternative zuspitzten, auf dem platten Land unterzuschlüpfen oder nach Berlin zurückzukehren. Beide Varianten beurteilte Weiß jedoch gleichermaßen pessimistisch, sofern es gelinge, die Öffentlichkeit zur Mithilfe zu bewegen und die Täter von jeder Unterstützung abzuschneiden ${ }^{74}$. Mit der deutlichen Absicht, die mutmaßlichen Täter zu verunsichern, legte Weiß dar, daß Kern und Fischer auf die Hilfe ihrer Leute nicht mehr rechnen könnten, da die Polizei entsprechende Maßnahmen bereits getroffen habe.

Ein neues Fahndungsplakat, das am 30. Juni 1922 erschien und besonders in Mittel- und Norddeutschland verteilt wurde, war geeignet, den Ring um die Gesuchten noch enger zu schließen. Es wies in Fettdruck auf Fischers „sächsische Mundart“ hin und zeigte neben ciner Handschriftenprobe auch fünf Lichtbilder des Gesuchten ${ }^{75}$. Zumindest für ihn war nun die Möglichkeit nahezu ausgeschlossen, ohne Risiko etwa per Bahn dem Zugriff der Polizei zu entrinnen. Im Grunde konnten er und Kern nur noch über See nach Skandinavien zu entkommen oder in einem Versteck so lange zu überstehen trachten, bis das öffentliche Interesse an ihrer Ergreifung abflauen würde. Dieser Zeitpunkt schien in den letzten Junitagen freilich noch sehr fern zu sein. Die ungeheuere Erregung schlug sich vielmehr in gebietsweise fieberhaften Nachforschungen nach dem Verbleib der Rathenaumörder nieder. Aus verschiedenen Landesteilen wurden Gerüchte über den Aufenthalt der Mörder laut und Verhaftungen mitgeteilt ${ }^{76}$. Schon am 30 . Juni meldeten viele Zeitungen, „daß die Fahndungsbeamten den Tätern dicht auf der Spur sind “77, doch erwies sich dies als Falschmeldung. Trotz allen Aufwandes hatten die Ermittler auch zwei Wochen nach dem Attentat die Spur der steckbrieflich gesuchten Mörder noch nicht gefunden und den Anhaltspunkt, den ihnen Ilsemann mit dem Zielort des bei ihm deponierten Koffers gegeben hatte, nicht zu interpretieren gewußt.

${ }^{73}$ Aussagen W. Kern, 19.7. 1922, und K. Kern, 24.7.1922; Vermerk vom 19.7. 1922; alle in: Ebenda, 567$1-2579$.

${ }^{74}$ Berliner Tagcblatt vom 29. 6. 1922, Morgen-Ausgabe.

75 SAM, 567-1-2629.

${ }^{76}$ Vgl. z. B. Berliner Tageblatt vom 30. 6. 1922, Abend-Ausgabe.

77 Schleswig-Holsteinische Volkszeitung vom 30. 6. 1922. In derselben Ausgabe wurde der Vermutung Ausdruck gegeben, die Rathenaumörder könnten mit einem Minensuchboot der von EhrhardtLeuten beherrschten Marine ins Ausland zu entkommen versuchen. 
Am 8. Juli aber ging im Berliner Polizeipräsidium ein Anruf aus Lenzen ein: Der Bürgermeister des Ortes an der Elbe teilte mit, daß zwei junge Männer, auf die die steckbriefliche Beschreibung der Attentäter passe, im dortigen Gasthaus abgesticgen seien und sich verdächtig gemacht, aber einer Festnahme durch den Polizeiposten mittels schleuniger Flucht in Richtung Elbe entzogen hätten. „Verfolgung wurde mit Krafträdern aufgenommen. Als Verfolger an den Elbstrom gelangten, befand sich das Fährschiff mit Verfolgten bereits in Strommitte. Zurufe wurden von dem Fährmann nicht verstanden. Die Verfolgten entwichen linkselbwärts. "78 Es konnte schnell festgestellt werden, daß es sich bei den Flüchtigen tatsächlich um die gesuchten Rathenaumörder handelte. Sie hatten am 7. Juli abends in Lenzen bei einem Kaufmann Paul Büsch vorgesprochen und sich als Rostocker Studenten vorgestellt. Kern und Fischer, die Fahrräder mit sich führten und angaben, über die Elbe zur Lüneburger Heide radeln zu wollen, wurden von Büsch in das Gasthaus "Zur Sonne" in Lenzen gewiesen, wo sie sich als „Richard Leonhardt" und "Gerhardt Zimmermann" eintrugen ${ }^{79}$. Als am folgenden Tage bei der Polizeiverwaltung Lenzen eine Anzeige einlief, daß Büsch die flüchtigen Rathenaumörder aufgenommen habe ${ }^{80}$, wurde der Kaufmann festgenommen und ins Polizeigefängnis gebracht. Der Weg dorthin führte am Gasthaus ,Zur Sonne" vorbei, in dem Kern und Fischer, die sich am Morgen in einem örtlichen Konfektionshaus neu eingekleidet hatten, gerade zu Mittag aßen ${ }^{81}$. Der beglcitende Polizeiassistent meldete anschließend, „daß, als er mit Büsch soeben an dem Hotel vorbeigegangen sci, er in der Tür des Hotels einen jungen Mann habe stehen sehen, auf den die Beschreibung des einen der'Täter ziemlich genau gepaßt und der sich mit Büsch zusammen ganz merkwürdig auffällig angesehen hätte“. Der Bürgermeister ließ sogleich nachforschen; die Gesuchten aber waren, von Büschs warnendem Mienenspiel alarmiert, schon aus dem Gasthaus verschwunden ${ }^{82}$.

Auf die Nachricht, daß die Rathenaumörder gesehen worden seien, setzte die Berliner Politische Polizei einen großen Apparat in Bewegung. Ein Fahndungskommando von 150 Mann ${ }^{83}$ wurde in die Altmark geschickt und in Gardelegen eine Einsatzzentrale errichtet, von der aus Bernhard Weiß selbst die Verfolgung Kerns und Fischers mit Autos, Motorrädern, Fahrrädern und Polizeihunden leitete. Um möglichst rasch zur Stelle zu sein, sobald ihm irgend wo eine aussichtsreiche Spur gemeldet wurde, stand ihm mit dem-nunmehr beschlagnahmten - Mercedes-Kabriolett Johannes Küchenmeisters eben der Kraftwagen zur Verfügung, aus dem die nun Gejagten zwei Wochen zuvor ihr Verbrechen begangen hatten ${ }^{84}$. Es konnte festgestellt werden, daß die Flüchtigen nach Überquerung der Elbe ihre Flucht per Fahrrad in südlicher Richtung fortgesetzt hatten. Den wichtigsten Anhaltspunkt für die weitere Fahndung stellte eine Generalstabskarte von Arendsee und Umgebung dar, die ein Landjäger am 9. Juli 1922 um drei Uhr morgens in Ziemendorf am Wegrand gefunden hatte. Kern und Fischer mußten sie kurz zuvor unterwegs verloren haben, denn am Nachmittag des

${ }^{78}$ BA/P, 30.03-12J383/22, Bd. 1, Vermerk Pol.-Präs., Abt. I A, 8. 7. 1922. Einer der Fluchthelfer Kerns und Fischers gab später an, daß der Fährmann den Rufen der Polizisten nicht Folge geleistet habe, weil er von Kern und Fischer bedroht worden sei; Staatsarchiv München, Pol. Dir. 8103, Bericht Puttkamer, 18. 1.1923.

${ }^{79} \mathrm{BA} / \mathrm{P}, 30.03-12 \mathrm{~J} 383 / 22, \mathrm{Bd}$. 1, Aussage Büsch, 9. 7. 1922, und Mitteilung des Berliner Polizeipräsidiums, 25. 7. 1922.

${ }^{80}$ Ebenda, 30.01-5053/1, Mitteilung des ORA, 23. 9. 1922.

81 Vorwärts vom 27. 10. 1922.

${ }^{82}$ BA/P, 30.03 12J383/22, Bd. 1, Vermerk des Lenzener Bürgermeisters Scheel, o. D.

${ }^{83}$ Berliner Tageblatt vom 12. 7. 1922, Abend-Ausgabe.

${ }^{84}$ Vgl. die farbige Reportage des Vorwärts-Korrespondenten Victor Schiff, den Weiß auf die Fahrt nach Gardelegen mitgenommen hatte; Vorwärts vom 16. 7. 1922, 1. Beilage. 
9. Juli erschienen im gut fünfzig Kilometer südlich gelegenen Ort Jerchel bei Gardelegen zwei junge Leute mit Fahrrädern, die auf dem Weg ins Braunschwcigische waren und erzählten, sie seien „fremd in dieser Gegend und hätten in den Morgenstunden ihre Wegkarte verloren "85. Da Weiß annahm, daß Kern und Fischer entweder weiter nach Süden oder aber nach Berlin zu entkommen versuchen würden, wurde das Gebiet südlich und östlich von Gardclegen durch ein Massenaufgebot an örtlichen und Berliner Polizeikräften eingekreist und systematisch durchkämmt ${ }^{86}$. Die aus der Altmark nach Berlin führenden Chausseen wurden mit Polizeiposten besetzt, die alle Fuß- und Radwanderer bis zur genauen Feststellung ihrer Personalien festhiclten; die Zugstationen der Staats- und Kleinbahnen unterlagen lückenloser Überwachung. In jeder Ortschaft wurdc ein Fahndungsplakat mit den auf den neuesten Stand gebrachten Steckbriefen der Flüchtigen angeschlagen ${ }^{87}$. Gleichzcitig erging ein besonders an die Landbevölkerung gerichteter Aufruf, der die Erhöhung der bisher ausgelobten Belohnung auf nun zwei Millionen Mark bekanntgab: „Achtet besonders auf Radfahrer! Achtet besonders auf Personen, die Euch um Lebensmittel angehen! Achtet besonders auf abgelegene Gegenden! “88 Bei der Verteilung der Bekanntmachungen half die Reichszentrale für Hcimatdienst, deren sächsische Landesabteilung beispielsweise zwischen dem 13. und 15. Juli 10000 Steckbriefe und 15000 Aufrufe als Flugblätter in 670 sächsische Ortschaften zur weiteren Verteilung versandte. Die Bevölkerung wurde in den Bckanntmachungen nachdrücklich darauf hingewiesen, daß jegliche Begünstigung der Flüchtigen unnachsichtig geahndet würde ${ }^{89}$.

Es ist kaum nachvollziehbar, wie es den so eingekreisten, von ihren Verbindungsleuten abgeschnittenen, vermutlich ohne Geld und jedenfalls ohne genaue Orientierung das Land durchquerenden Attentätern gelingen konnte, durch das engmaschige Fahndungsnetz hindurchzuschlüpfen. Allerdings hatten auch die Fahnder mit erheblichen Schwierigkeiten und Widerständen zu kämpfen. Der Versuch etwa, 20000 Flugblätter per Bahn mit einem Kommando radfahrender Schupobeamter nach Gardelegen zu bringen und dort in den Ortschaften der Umgebung verteilen zu lassen, scheiterte am Widerstand der Reichsbahn, die

${ }^{85}$ BA/P 30.03-12J383/22, Mitteilung des Bcrliner Polizeipräsidiums, 25. 7. 1922. Der Wirt der Gastwirtschaft „Zu den drei Linden“ in Jerchel sagte aus, daß die beiden Radfahrer von ihm eine Karte von Gardelegen verlangt hätten. „Als der Wirt erklärte, daß er eine solche Karte nicht habe und sie auf eine an der Wand hängende Landkarte aufmerksam machte, fertigte der eine der Gäste eine Skizze an und zwar von der Gegend in Richtung Kalvörde-Braunschweig." Berliner Tageblatt vom 14. 7. 1922, Morgen-Ausgabe.

${ }^{86}$ Ebenda vom 13. 7. 1922, Morgen-Ausgabe: „Anhand von Generalstabskarten werden sämtliche Bauernhäuser, Gelände und Feldwege, durch die eine mutmaßliche Spur der Mörder führt, mit Spürhunden abgesucht. Die großen Straßen werden von Automobilen abgefahren, dabei werden die Güter und dic an den Hauptstraßen liegenden Ortschaften und Bauerngehöfte genau durchsucht." Über die Sorgfalt, mit der die ausgesandten Patrouillen Straßen, Dörfer und selbst einzelne Waldstücke absuchten, geben etwa die Protokolle des Kommandos Schwerin der Mecklenburgischen Ordnungspolizei beredte Auskunft; Staatsarchiv Schwerin, Ministerium des Inncrn, Schwerin, Nr. 21437.

${ }^{87}$ StAL, Min. d. Inn. 11106 a, Teil 2. Der alktualisierte Aufruf hob hervor, daß jeder der Flüchtigen ein „Fahrrad bci sich [hat] mit aufgeschnalltem Rucksack und Mantel“; vgl. Berliner Lokalanzeiger vom 13. 7. 1922, Morgen-Ausgabe.

${ }^{88}$ StAL, Min. d. Inn. 11106a, Teil 2; vgl. Münchener Post vom 12. 7. 1922.

${ }^{89}$ Ebenda, Mitteilung der Reichszentrale für Heimatdienst, Landes-Abteilung Sachsen, 15. 7. 1922, amtliche Mitteilung des Berliner Polizcipräsidiums, abgedruckt im Bcrliner Tageblatt vom 13.7. 1922; Morgen-Ausgabe. 
keinen Sonderzug zu stellen bereit oder in der Lage war ${ }^{90}$. Das zu durchsuchende Gebiet war groß und außerordentlich dünn besiedelt; selbst wachsamste Patrouillen konnten nicht jeden Fleck durchkämmen. Wichtige Spuren konnten nicht sogleich verfolgt werden, weil der Telefondienst auf dem Lande um sieben Uhr, in kleineren Städten um neun Uhr abends aufhörte; ein Antrag, in Gardelegen für die Zeit der Fahndung nach Kern und Fischer Nachtdienst einzuführen, wurde von der Oberpostdirektion Magdcburg abgelehnt. Die Landbevölkerung Mitteldeutschlands erwies sich vielerorts als gleichgültig und oft auch ahnungslos; die Trauerreden des Reichskanzlers und des Reichstagspräsidenten vom Juni waren entgegen einem Reichstagsbeschluß in kaum einer Ortschaft angeschlagen worden ${ }^{91}$.

Als es dann durch die Flugblattaktion gelang, die Suche in jedes Dorf zu tragen, erwies sich die sprunghaft steigende Mithilfe der Bevölkerung eher als Bumerang. Es lief eine solche Vielzahl von Meldungen ein, daß die Fahndungstätigkeit der Polizei bis zur Ineffektivität zersplittert wurde. Alsbald wiesen Spuren von der Altmark nach Hannover, in die Lüneburger Heide, nach Genthin, Apolda, Torgau, Wittenberge, Luckenwalde und nach Sachsen, die sich später sämtlich als nichtig erwicsen ${ }^{92}$. Als besonders aussichtsreich wurde eine Meldung bewertet, die die Einsatzkräfte auf Thale im Harz lenkte, wo zwei Männer auf Fahrrädern in eiliger Fahrt in Richtung Süden beobachtet worden waren, auf die die Beschreibung genau paßte. Die Verdächtigen konnten schnell festgenommen werden; sie stellten sich als harmlose Touristen heraus. Die Polizei mußte feststellen, daß sie durch Bekundungen angeblicher Augenzeugen absichtlich in falsche Richtungen geführt wurde, und sie verzeichnete eine auffällige Häufung von Radwanderern, die plötzlich so zahlreich in der fraglichen Gegend auftauchten und in ihrer Kleidung den steckbrieflichen Angaben über die Gesuchten so irritierend ähnelten, daß der Schluß unabweisbar war, es handle sich um Helfershelfer, die auf ihre Weise die Fahndung zu behindern suchten ${ }^{93}$.

Das Entkommen der Flüchtigen wurde durch den Umstand begünstigt, daß sie mehrfach ihre Kleidung wechselten und die Steckbriefe dadurch nur noch bedingt zutrafen. Zudem änderten sie bald ihre Taktik, nachdem sie zuerst in pausenloser Tag- und Nachtfahrt über Packebusch und Gardelegen mit dem richtigen Kalkül in Richtung Süden geeilt waren, sich nur so vor einer Einkreisung retten zu können. Tags darauf aber, am 9. Juli, schlugen sie spätnachmittags hinter Jerchel einen Weg ein, der südwestlich in Richtung Braunschweig führte, um so ihren Fluchtweg weniger leicht berechenbar zu machen; sie unterliefen von nun an die polizeilichen Suchaktionen, indem sie sich tagsüber verborgen hielten und erst im Schutz der Dunkelheit weiterradelten ${ }^{94}$. Weitere fünf Tage später, am 14. Juli, blieb der

90 Vgl. Vorwärts vom 16. 7. 1922, 1. Beilage. Die Eisenbahndirektion Berlin stellte später zwar ein Fehlvcrhalten in Abrede; auf einer Pressekonferenz am 18.7.1922 räumte der Berliner Polizeipräsident Richter jedoch ein, daß es zwischen Eisenbahndirektion und Polizeipräsidium zu „Unstimmigkeiten“ gekommen sei; BA/P, 30.01-5053/1.

91 Vorwärts vom 16. 7. 1922, 1. Beilage; Berliner Tageblatt vom 12. 7. 1922, Abend-Ausgabe. Der Vorwärts schrieb: „Ein Ortsvorsteher (!) bei Salzwedel wußte überhaupt nicht, daß es einen Minister Rathenau gab, der ermordet worden war! ,Ich lese keine Zeitungen', antwortete er gelassen dem Kommissar." (16. 7. 1922, 1. Beilage). Die im Vorwärts erwähnten Mißstände wurden Gegenstand einer vom Preußischen Ministerpräsidenten Braun angeregten Besprechung des Reichskabinetts; BA, R 43/904, Der Preußische Ministerpräsident an den Reichskanzler, 20. 7. 1922; vgl. Vossische Zeitung vom 19. 7. 1922.

92 Ebenda; vgl. Berliner Lokalanzeiger vom 13. 7. 1922, Morgen-Ausgabe, und 14. 7. 1922, MorgenAusgabe; Berliner Tageblatt vom 14. 7. 1922, Morgen-Ausgabe.

${ }^{93}$ Schleswig-Holsteinische Volkszeitung vom 13. 7. 1922; Berliner Tageblatt vom 13. 7. 1922, MorgenAusgabe und Abend-Ausgabe; Vorwärts vom 14. 7. 1922.

${ }^{94}$ Berliner Tageblatt vom 13. 7. 1922, Morgen-Ausgabe und Abend-Ausgabe. 
Polizei nichts anderes übrig als einzugestehen, daß sie die Spur der Gesuchten verloren hatte. Alle Hinweise aus der Bevölkerung hatten sich als irrig herausgestellt ${ }^{95}$, man mußte davon ausgehen, daß Kern und Fischer sich wohl längst in einer ganz anderen Gegend aufhielten ${ }^{96}$.

Schon am Tag zuvor aber, am 13. Juli, waren erste vage Hinweise aufgetaucht, daß die Rathenaumörder nach Thüringen geflüchtet sein könnten, um von dort Bayern zu erreichen $^{97}$. Der Vorwärts warnte am 14. Juli, die Flüchtigen könnten über Thüringen die baycrische Grenze überschreiten, und wies auf die massiven Widerstände gegen eine denkbare Verletzung bayerischer Hoheitsrechte durch die preußische Polizei hin ${ }^{98}$; die bayerische Landesabteilung der Reichszentrale für Heimatdienst ließ tags darauf 6000 Flugblätter mit dem Steckbrief der Gesuchten an ihre Vertrauensleute in Nordbayern hinausgehen ${ }^{99}$. Dennoch war es am Ende nur der Unvorsichtigkeit Kerns und Fischers selbst zu verdanken, daß sie doch noch entdeckt wurden. Am 16. Juli wurde der Polizei in Halle durch zwei auf der thüringischen Rudelsburg an der Saale zu Besuch weilende Gäste mitgeteilt, daß sie auf einem bewohnten Turm der gegenüberliegenden Burg Saaleck Licht bemerkt hätten, obwohl deren Besitzer Hans Wilhelm Stein sich vor einigen Tagen beim Wirt der Rudelsburg zu einer Reise abgemeldet habe. Dadurch aufmerksam geworden, hätten sie auf einem Spaziergang die Burg beobachtet und dort zwei Gestalten gesehen, deren Aussehen mit den mittlerweile auch in Naumburg und Bad Kösen angeschlagenen Steckbriefen der Rathenaumörder übcrcinstimmten ${ }^{100}$. Am nächsten Morgen ergaben Nachforschungen der Halleschen Kriminalpolizei, daß tatsächlich zwei junge Männer, auf die die Beschreibung der Gesuchten paßte, in Bad Kösen nach dem Burgbesitzer Stein gefragt hatten. Als daraufhin am Vormittag zwei Kriminalbeamte auf Saaleck erschienen, fanden sie die Eingangstür zur Burg nur eingeklinkt, das eiserne Gitter, das im Burginnern den bewohnbaren der beiden Türme sicherte, hingegen verschlossen. Ein hinzugezogener Schlossermeister war außerstande, die Gittertür zu öffnen, so daß das Schloß aufgemeißelt werden mußte ${ }^{101}$. Beim Absuchen des Burghofes im unbewohnten zweiten Turm fand sich ein in Packpapier verschnürtes Paket, das zwei Jackettan-

95 Schleswig-Holsteinische Volkszeitung vom 14. 7. 1922.

96 Berliner Tageblatt vom 14. 7. 1922, Abend-Ausgabe.

${ }^{97}$ Dies meldete zuerst das Berliner Tageblatt am 15. 7. 1922, Morgen-Ausgabe, in einer auf den 13. 7. datierten Meldung. Am selben Abend betitelte die Zeitung ihren Bericht bereits „Mördersuche in Thüringen", konnte aber noch keine genaueren Spuren angeben.

98 Tatsächlich war einigen zur Untersuchung nach München entsandten Beamten der Berliner Polizei vom Münchener Vertreter des ORA jede Tätigkeit in Bayern untersagt worden, was zu einer Kontroverse des bayerischen Innenministers Schweyer mit preußischen und Reichsbehörden führte; vgl. Berliner Zeitung am Mittag und Münchener Post vom 12. 7. 1922; Münchner Neueste Nachrichten vom 13. 7. 1922, Morgen-Ausgabe; BayHStA, MInn 66304, Vermerk des bayerischen Innenministeriums, 13. 7. 1922; Innenminister Schweyer an Staatsministerium des Äußern, 13. 7. 1922; BA/ P, 30.01-5053/1, Stellungnahme des Berliner Polizeipräsidenten, 18. 7. 1922.

99 BayHStA, MInn 66304, Die Reichszentrale für Heimatdienst, Landesabteilung Bayern, an den bayerischen Innenminister, 15. 7. 1922.

100 Berliner Tageblatt vom 18. 7. 1922, Abend-Ausgabe. Kerns Schwester Gisela behauptete später, daß die Gäste, ein Hamburger Brüderpaar Kuhne, die Flüchtigen im Walde entdeckt und ihnen,nachspioniert' hätten; BA, NS 26/1236, Gisela Kern, Lebenslauf Erwin Kern. Vgl. dagegen die eigene Darstellung der Gebrüder Kuhne, die übrigens lange auf die Auszahlung der ausgelobten Belohnung drängen mußten und schließlich nur eine durch die Inflation fast völlig entwertete Summe erhielten; BA/P, 30.01-5053/1, Paul und Walter Kuhne an den Reichspräsidenten, 14. 3. 1923.

101 Die folgende Darstellung beruht auf dem Bericht der Hallenser Kriminalwachtmeister Kagemann und Zabel, 17. 7. 1922, in: SAM, 567-1-2632. 
züge enthielt und so den Verdacht erweckte, für die weitere Flucht der Attentäter bestimmt gewesen zu sein ${ }^{102}$. Die Vermutung erhärtete sich, nachdem das Türschloß zum Wohnturm aufgebrochen worden war: Frische Essensreste auf einem Tisch im ersten Stock zeigten, daß sich hier Personen aufhielten; die Tür zum Schlafzimmer im dritten Stock war von innen verriegelt. Bei dieser Sachlage erbaten die Hallenser Kriminalpolizisten telefonisch Verstärkung beim Kommandeur der Schutzpolizei in Naumburg und schritten zu einer förmlichen Belagerung der Burg.

Bis die angeforderte Hilfe eintraf ${ }^{103}$, postierten sich der unbewaffnete Schlosser und einer der aus Halle entsandten Polizisten auf den Treppenstufen. Zwanzig Minuten später waren von innen vorsichtige Schritte die Treppe hinab zu hören, woraufhin die Beamten sich an den Turmeingang zurückzogen. Kurz darauf zeigte sich dort ein Gesicht, das sofort wieder verschwand. Offenbar hatten Kern und Fischer versucht, etwaige Fluchtmöglichkeiten zu erkunden. Als der Beamte ihnen nun herunterzukommen befahl, antwortete eine Stimme: „Fällt mir gar nicht ein, wer sind Sie denn überhaupt und was wollen Sie denn von uns?" Dann entfernten sich die Schritte wieder nach oben. Einer der Beamten ging nun zu dem 40 Meter entfernten gegenüberliegenden, unbewohnten Turm, um zu verhindern, daß die Gesuchten am Blitzableiter oder an einem Strick herabklettern und entkommen könnten. Kurze Zeit darauf erschienen Kern und Fischer auf der Dachplattform der Burg und riefen zwei Leipziger Studenten an, die sich gerade als Spaziergänger im Burghof aufhielten: „Wir sind Kieler Studenten, grüßen Sie bitte Kapitän Ehrhardt von uns. Kapitän Ehrhardt, er lebe hoch, hoch, hoch." Anscheinend wollten sie den Studenten noch eine Botschaft übermitteln und warfen drei oder vier Zettel herab, die der starke Wind aber in Richtung Saale davontrieb ${ }^{104}$. Im Bericht der Hallenser Polizei heißt es weiter: „Nun verabschiedeten sich die beiden Studenten mit ihren Damen durch Grüßen mit der Mütze und Händewinken. Dabei riefen sie noch hinauf: ,Sie müssen ja wissen, was Sie in Ihrer Lage zu tun haben'. Als Antwort von oben kam: ,Wir wissen, wie wir zu sterben haben, wir sterben für unsere Ideale, unsere Nachfolger werden sich einstellen." “

Fischer, der schon zuvor mit dem Gewehr in der Hand die Studenten mit ihren Begleiterinnen aufgefordert hatte, den Burghof zu verlassen, weil jetzt scharf geschossen werde, legte nun auf den im Burghof stehenden Polizisten an, der sofort in Deckung ging. Einer der beiden Polizisten gab kurz darauf fünf Schüsse auf das zum Innenhof hin gelegene Turmfenster des obersten Stocks ab, von denen drei durch das Fenster gingen und einer, von den Beamten unbemerkt, Kern am Kopf traf und tödlich verwundete ${ }^{105}$. Auch der andere Attentäter

102 Das Packpapier trug die Anschrift Wolfgang Dietrichs, eines früheren Marinekameraden Kerns, der anschließend wegen Verdachts auf Begünstigung der Rathenaumörder verhaftet wurde; BA/P, 30.03.-5053/9, Anklageschrift gegen Wolfgang Dietrich.

103 Das Schutzpolizeikommando in Naumburg wurde laut Bericht um sechs Uhr abends alarmiert und entsandte sofort einen Personenwagen mit fünf Beamten, der binnen vierzig Minuten an der Burg eintraf, und anschließend einen Lastkraftwagen mit weiteren 19 Polizisten und zusätzlichem Gerät; SAM, 567-1-2632, Bericht Schutzpolizeikommando Naumburg, 18. 7. 1922.

${ }^{104}$ Vgl. Berliner Tageblatt vom 19.7. 1922, Morgen-Ausgabe; BA, NS 26/1236, Gisela Kern, Lebenslauf Erwin Kern.

105 SAM, 567-1-2632, Bericht Heller, 28. 7. 1922. In ihrem ersten Bericht ging die Kriminalpolizei Halle davon aus, daß Kern Selbstmord verübt habe; vgl. BA/P, 30.01-5053/1, Pressekonferenz vom 18. 7. 1922; Berliner Tageblatt vom 18. 7. 1922, Abend-Ausgabe. Die genauere Untersuchung ergab aber: „Auf das Fenster sind von unten von dem gegenüberliegenden Turm her [...] vier Schuß aus einem Karabiner abgegeben worden [...]. Das Fenster zeigt unten rechts drei Durchschüsse, während der vierte außerhalb desselben am Gesims zu bemerken ist. Einer dieser Schüsse muß nun Kern, der am 
konnte nicht lebend gefaßt werden. Als die Beamten nach Eintreffen der polizeilichen Verstärkung gegen neun Uhr abends die Tür zum obersten Stock gewaltsam öffneten, fanden sie die bekleideten Leichen Kerns und Fischers in den Betten des Schlafzimmers. Fischer hatte seinen Kameraden noch auf ein Bett geschleppt und zugedeckt, bevor er sich auf das Nebenbett legte und selbst einen tödlichen Kopfschuß beibrachte ${ }^{106}$. Beide Toten trugen Kleidung, dic zum Teil aus der Garderobe des Burgbesitzers Stein stammte ${ }^{107}$; Kerns Leiche wies an beiden Oberschenkeln erst halb verheilte Schrotschüsse auf, die mindestens acht Tage alt ${ }^{108}$ und darauf zurückzuführen waren, daß die beiden „auf ihrer Flucht wahrscheinlich Nahrungsmittel gestohlen hatten und dabei überrascht und angeschossen wurden " ${ }^{109}$. Bei den Toten fanden sich zwei Bierflaschen, die aus Lüchow bei Gardelegen stammten, mehrere Landkarten aus Mecklenburg und Nordsachsen, ein Harzwanderbuch und gut 3000 Mark Bargeld; ihre Fahrräder hingegen waren nicht mehr auffindbar ${ }^{110}$. In der Presse wurde zusätzlich mitgeteilt, daß die Mörder Rathenaus in letzter Stunde aufgespürt worden waren, bevor sie durch Helfer, die schon von München aus unterwegs gewesen sein sollten, abgeholt und ins Ausland gebracht worden wären ${ }^{111}$. Diese Meldung fand keine behördliche Bestätigung ${ }^{112}$; wohl aber wurde der Burgbesitzer Stein, der am Abend des 17. Juli 1922 von seiner Reise zurückgekehrt war, am darauffolgenden Tag wegen mutmaßlicher Begünstigung der Rathenaumörder verhaftet ${ }^{113}$.

\section{Der Rathenaumord vor dem Staatsgerichtshof}

Nachdem mit Erwin Kern und Hermann Fischer die Haupttäter auf Burg Saaleck umgekommen waren, konnte nur noch ihren Komplicen der Prozeß gemacht werden, soweit sie nicht wie Günther Brandt und Johannes Küchenmeister flüchtig waren. Das Verfahren fand zwischen dem 3. und dem 14. Oktober 1922 vor dem neugebildeten Staatsgerichtshof in

Fenster [...] stand, getroffen haben. Nach Erhalt des Schusses ist er anscheinend nach rückwärts zusammengesunken, wobei er mit der blutenden Kopfwunde die Wand unten rechts gestreift hat." SAM, 567-1-2632, Bericht Heller, 18. 7. 1922.

106 Wie die polizeilichen Feststellungen unmittelbar nach Auffindung der Toten ergaben, war der Tod cines der beiden - offenbar Fischers - erst kurz vor dem Eindringen der Polizei eingetreten; ebenda, Bericht Heller, 22. 7. 1922. Vgl. dic Darstellung Gisela Kerns: „Fischer hat wohl noch versucht das Blut zu stillen, wie die mit blutigen Wattebauschen gefüllte Waschschüssel bewies u. ihm einen Kopfverband gemacht, als er die Aussichtslosigkeit einsah, ihn auf's Bett gelegt, die Hände übereinander, u. unter die Schuhe Packpapier. [...] Dann gab Fischer aus seinem Revolver 2 Probeschüsse gegen die Wand ab, legte sich in's 2. Bett, lehnte sich etwas hinaus, um die Matratze zu schonen, und erschoß sich." BA, NS 26/1236, Lebenslauf Erwin Kern.

107 BA/P, 30.03-5053/9, Anklageschrift gegen Dr. Stein.

${ }^{108}$ SAM, 567-1-2632, Obduktionsbericht Dr. Malade, 18. 7. 1922.

${ }^{109}$ Berliner Tageblatt vom 19. 7. 1922, Morgen-Ausgabe. Gisela Kern zufolge hatten sie Rüben vom Feld zu stehlen versucht; BA, NS 26/1236, Lebenslauf Erwin Kern.

${ }^{110}$ SAM, 567-1-2632, Berichte Heller, 18. und 21.7. 1922.

111 Bcrliner Tageblatt vom 18. 7. 1922, Abend-Ausgabe; Münchener Post vom 19. 7. 1922.

112 BaHStA, MInn 66034, Die Polizeidirektion München an das bayerische Innenministerium, 21. 7. 1922, und Vermerk des bayerischen Innenministeriums, November 1922.

113 BA/P, 30.03-5053/9, Anklageschrift gegen Dr. Stein. 
Leipzig gegen dreizehn Personen statt, die von Oberreichsanwalt Ludwig Ebermayer des Mordes (Ernst Werner Techow), der Beihilfe zum Mord (Hans-Gerd Techow, Günther, Ilsemann, Steinbeck, Niedrig, Warnecke und Salomon), der Begünstigung (Schütt und Diestel) sowie der Nichtanzeige eines geplanten Verbrechens (Karl Tillessen, Plaas und Voß) angeklagt waren ${ }^{1}$. Neben dem Senatspräsidenten Hagens als Vorsitzendem und zwei weiteren Berufsrichtern, den Reichsgerichtsräten Doehn und Zeiler, wurden gemäß den Bestimmungen des Republikschutzgesetzes sechs Laienrichter bestellt, von denen drei durch die süddeutschen Staaten nominiert worden waren, nämlich der Gesandte Karl Hildenbrand durch Württemberg, der Universitätsjurist Wilhelm van Calker durch Bayern und der frühere Reichskanzler Konstantin Fehrenbach durch Baden. Durch die übrigen vom Reichspräsidenten berufenen Laienrichter, die der SPD (Hermann Müller) ${ }^{2}$, der USPD (Hermann Jäckel) $)^{3}$ und der DDP (Gustav Hartmann) ${ }^{4}$ zuzurechnen waren ${ }^{5}$, schien gewährleistet, daß der Staatsgerichtshof mit der Tradition einer rechtslastigen Rechtspflege brechen und die Täter im Geiste der republikanischen Verfassung aburteilen würde ${ }^{6}$. In diesem Sinne hatte Hagens vor Prozeßbeginn dem Reichsjustizminister geschrieben: „Sämtliche von mir vorgeschlagenen Mitglieder stehen ebenso, wie ich selbst, fest und mit voller Überzeugung auf dem Boden der Republik und sind sich ihrer Aufgaben bewußt. " 7 Diesen Versuch, das Mißtrauen der demokratischen Politiker in die Repräsentanten deutscher Justiz zu verringern, beantworteten die der Rechten zuzuordnenden Verteidiger ${ }^{8}$ am ersten Verhandlungstag prompt mit einem Befangenheitsantrag. Er stützte sich auf eben diesen Ausweis republikanischer Gesinnung und lehnte neben Hagens und den anderen Berufsrichtern auch die der Linken zuzurechnenden Laienrichter ab, weil sie als Exponenten politischer Richtungen den Anforderungen des Richteramtes angeblich nicht genügten?

Die Teilnahme der Öffentlichkeit an diesem Prozeß war enorm, der 700 Personen fassende

1 Ebenfalls im Oktober 1922 verhandelte der Staatsgerichtshof in mehreren Verfahren gegen mutmaßliche Helfershelfer, denen vorgeworfen wurde, Kern und Fischer auf ihrer Flucht von Rostock bis Lenzen unterstützt zu haben, sowie gegen Hans-Wilhelm Stein und Wolfgang Dietrich wegen Begünstigung der Rathenaumörder in Saaleck.

2 Der Potsdamer SPD-Funktionär und Reichstagsabgeordnete Hermann Müller war nicht personengleich mit dem späteren Reichskanzler Hermann Müller.

3 Jäckel war Vorsitzender des deutschen Textilarbeiterverbandes.

4 Hartmann leitete die Hirsch-Dunckerschen Gewerkschaften.

5 Heydeloff, Political-Judicial Career, S. 153.

6 Allerdings äußerten auch republikfreundliche Juristen Vorbehalte über die Bildung eines Sondergerichts für politische Straftaten; vgl. Hachenberg, Juristische Rundschau, Sp. 494.

7 Zit. nach Berliner Tageblatt vom 3. 10. 1922, Abend-Ausgabe.

8 Es waren dies Justizrat Hahn und Rechtsanwalt Sack als Verteidiger der Gebrüder Techow sowie Rechtsanwalt Bloch, der Steinbeck, Niedrig, Warnecke, Tillessen und Plaas vertrat, und Luetgebrune als Anwalt Salomons. Alle vier Verteidiger stimmten ihr Vorgehen in mehreren Besprechungen vor Prozeßbeginn ab, um sich gegen die weniger "nationalgesinnte" Strategie der anderen Verteidiger Alsberg und Gollnick zu wappnen, und sorgten dafür, daß Luetgebrune die Mitverteidigung von E. W. Techow übertragen wurde, „damit Alsberg soweit wie möglich ausgeschaltet wird“. BA, NL 150, 11, Justizrat Dr. Hahn an RA Luetgebrune, 28. 9. 1922.

9 Berliner Tageblatt vom 3. 10. 1922, Abend-Ausgabe. Vorher hatte Hahn bereits beantragt, der Staatsgerichtshof wolle sich für verfassungswidrig erklären, da das ihm zugrundeliegende Gesetz zum Schutz der Republik unter dem Druck der Straße und der Gewerkschaften zustande gekommen und somit ebenfalls verfassungswidrig sei. Nach einer Erwiderung Ebermayers, der den Status des 
Zuhörerraum im großen Sitzungssaal des Leipziger Reichsgerichts am ersten Verhandlungstag schon eine halbe Stunde vor Sitzungsbeginn bis auf den letzten Platz gefüllt ${ }^{10}$. Das Interesse der Öffentlichkeit richtete sich, sofern es nicht nur aus Sensationslust geboren war, vor allem auf die Frage, „ob Rathenaus Ermordung nur die Tat einiger unreifer Burschen [war] oder eine Tat einer Mörderorganisation, auf der der Verdacht der Mordanschläge auf Erzberger, Gareis, Scheidemann, Harden und anderer Gewalttaten ruht “11. Doch klammerte die Anklageschrift den O.C.-Komplex überraschenderweise gänzlich aus und beschränkte sich auf die Rekonstruktion der Tatvorbereitungen durch die Angeklagten ${ }^{12}$. Ursprünglich hatte Oberreichsanwalt Ebermayer sogar noch erheblich weitergehen und seine Ausführungen mit der entlastenden Feststellung einleiten wollen, daß die O.C. „als solche" nicht an dem Mord beteiligt gewesen sei. Reichsjustizminister Radbruch versuchtc zu verhindern, daß auf diese Weisc Ehrhardts Geheimbund schon vor der Hauptverhandlung aus der Verantwortung entlassen würde, und verlangte die Streichung dieser Ausführungen als „sachlich nicht überzeugend. Sie werden durch die folgende Darstellung der Tat sogar widerlegt." ${ }^{\text {"13 }}$

Die endgültige und weisungsgemäß um die ursprünglich vorgesehene Stellungnahme zur O.C. gekürzte Fassung der Anklageschrift ging in der Rekonstruktion derTatvorbereitungen bis Mitte Juni 1922 zurück. Bis zu dieser Zeit läßt sich der Aufenthalt Fischers, der sich am 12. Juni aus Chemnitz verabschiedet hatte ${ }^{14}$, und Kerns in Berlin zurückverfolgen. Am 16. Juni zogen beide mit Ernst von Salomon von einer Pension in der Bernburger Straße in die Pension Scheer in Berlin-Mitte ${ }^{15}$. Am 17. Juni reiste Salomon im Auftrag Kerns erst nach Kiel und dann nach Hamburg, um einen Kraftwagen für das geplante Unternehmen zu besorgen ${ }^{16}$, und kehrte tags darauf mit Waldemar Niedrig aus Hamburg nach Berlin zurück. Kern empfing die beiden am Lehrter Bahnhof und brachte sie in die Pension am Schiffbaucrdamm, wo zusammen mit Fischer das Vorhaben detailliert erörtert wurde: Der Täterwagen sollte in der Nähe der Wohnung Rathenaus warten, bis dessen kleiner Wagen mit der Nummer A 5151 auftauche. Dann wollten die Attentäter ihr Opfer verfolgen und in der Nähe einer die Koenigsallee kreuzenden Straße überholen, so daß Rathenau mit Pistolen erschossen werden könnte. Auch von Maschinenpistolen wardie Rede, die gegen etwaige Verfolger Verwendung

Staatsgerichtshofs als Sonder-, nicht aber als Ausnahmegericht erläuterte und in der Tradition der geltenden positivistischen Rechtslehre darauf verwies, daß die Verfassungsmäßigkcit eines Gesetzes nicht von den Motiven seiner Urheber, sondern von seinem ordnungsgemäßen Zustandekommen abhänge, lehnte der Staatsgerichtshof den Antrag Hahns ab. Vgl. Schleswig-Holsteinische Volkszeitung vom 4. 10. 1922.

10 Vgl.das Stimmungsbild der Verhandlungsatmosphäre in Joseph Roths Gerichtsreportage für die Neue Berliner Zeitung - 12 Uhr Blatt vom 4. 10. 1922; Roth, Berliner Saisonbericht, S. 51. Unter dem Publikum fanden sich auch Anhänger der Angeklagten, so etwa als Münchener Vertreter Alfred Hoffmann; ebenda, S. 60.

11 Berliner Tageblatt vom 3. 10. 1922, Morgen-Ausgabe.

12 BA/P, 30.01-5053/1, Anklageschrift gegen E. W. Techow u. Gen.

${ }_{13}$ Der ursprüngliche Entwurf der Anklageschrift ist nicht erhalten. Der Inhalt der Passage über die O.C. geht aber aus der Weisung hervor, die Radbruch dem ORA am 26. 8. 1922 erteilte; BA/P, 30.01$5053 / 1$.

14 Bereits am 5. 6. hatte Fischer einem Arbeitskollegen angekündigt, „daß er voraussichtlich von unserer Firma auf cinige Wochen nach Ungarn als Montageleiter geschickt wcrde, einen Ort nannte cr nicht". BA, NL 150, 10, Beiakten, H. B, Aussage Holzweißig, 1. 7. 1922.

15 BA/P, 30.01-5053/1, Anklageschrift gegen E. W. Techow u. Gen.

${ }^{16} \mathrm{Daß}$ Salomon entgegen seiner Behauptung in den "Geächteten“ (S. 355) den wahren Zweck seines Auftragcs schr wohl kanntc, räumte er in der Hauptverhandlung selbst ein; SAM, 567-1-2585, Aussage Salomon, 16. 8. 1922, und Aussage Niedrig, 19. 7. 1922. 
finden sollten. Bei dieser Gelegenheit erfuhr Niedrig dann glcichzeitig, daß er als Fahrer nicht in Frage komme, da schon andere Autoführer in Aussicht genommen seien ${ }^{17}$.

Am selben Tag hatten Kern und Fischer aber auch Bezichungen zu Ernst Werner Techow geknüpft, der um die Mittagszeit des 18. Juni telefonisch von ihm unbekannten Männern, die sich als Mitglieder der Brigade Ehrhardt vorstellten, in die Pension am Schiffbauerdamm bestellt sein wollte. Dort wurde Techow gebeten, Näheres über den Mordplan des Gymnasiasten Stubenrauch mitzuteilen, von dessen Vorhaben Kern und Fischer gehört hatten. Techow erfuhr auch, daß in den nächsten Stunden ein Chauffeur aus Hamburg kommen werde, der ein Auto aus Sachsen - angeblich für eine Gefangenenbefreiung - holen solle, und erklärte sich, da auch er einen Führerschein besaß, „aus reiner Lust am Autofahren“ bereit, selbst den Wagen zu holen, falls der andere Fahrer ausbleibe ${ }^{18}$. Über Einzelheiten des Stubenrauchschen Mordvorhabens hingegen war Ernst Werner Techow nicht unterrichtet und verwies Kern und Fischer an seinen jüngeren Bruder Hans-Gerd, der über seinen Bekannten Willi Günther zuerst von diesem Plan erfahren habe. Als der ältere Techow spätabends nach Hause kam, fand er eine Nachricht seines Bruders Hans-Gerd vor, mit dem sich Kern unterdes für den kommenden Abend verabredet hatte: Er habe am nächsten Morgen, dem 19. Juni 1922, per Zug nach Dresden zu reisen, wo er am Bahnhof erwartet würde. Techow befolgte die Anweisung und traf in Dresden auf Günther Brandt, mit dem zusammen er tags darauf bei Johannes Küchenmeister in Freiberg den für die Tat bestimmten Mercedes abholte.

Unterdessen trafen sich am Montagabend Kern, Fischer und Günther beim jüngeren Techow in dessen elterlicher Wohnung zu einer eingehenden Beratung des Stubenrauchschen Vorhabens, Rathenau vor dem Hause Mamroths zu crschießen. Der Plan wurde schließlich verworfen, weil Stubenrauch noch zu jung sei und eine anschließende Besichtigung des Mamrothschen Hauses in der Sigismundstraße die Schwierigkeiten der Ausführung klarwerden ließ ${ }^{19}$. Am folgenden Tag, dem 20. Juni, trafen sie sich alle mittags mit Stubenrauch im Steglitzer Ratskeller, um ihm sein Vorhaben auszureden. Gleichzeitig erteilte Kern Günther den Auftrag, sich nach einer möglichst billigen Garage für den aus Sachsen erwarteten Wagen umzusehen. Offenbar besaßen Fischer und er nur noch höchstens 5000 Mark; Fischer hatte sich schon zwei Tage zuvor besorgt bei Niedrig erkundigt, ob Salomon ,in Hamburg große Gelder ausgegeben hätte, denn er hätte in fünf Tagen sechstausend Mark verbraucht" ${ }^{\text {"20 }}$. Um Mitternacht trafen Techow und Brandt mit dem Wagen aus Dresden ein und benachrichtigten Kern und Fischer. Am nächsten Tag traf Salomon auf Kerns Anweisung in der - laut

17 „Nach derTat sollten die Maschinenpistolen dann nach Hamburg unserer Gruppe überwiesen werden ,zur Ausbildung، “ Ebenda, 567-1-2585, Aussage Niedrig, 19. 7. 1922. Nach Salomon schien Kern der Chauffeur „durchaus unzulänglich. Er sandte ihn zurück.“ (Die Geächteten, S. 355) Niedrig selbst hatte gegen seine Benennung eingewandt, daß er keinen Führerschein besitze - ein zusätzliches Risiko im Falle von Verkehrskontrollen - und zudem eine kranke Hand habe; SAM, 567-1-2585, Aussage Niedrig, 26. 6. 1922, und Aussage Warnecke, 1. 7. 1922. Nicdrig fuhr am folgenden Tag, dem 19. 6., nach Hamburg zurück und war an den weiteren Attentatsvorbereitungen nicht mehr beteiligt.

${ }^{18}$ Die Darstellung der Attentatsvorbereitungen folgt im weiteren, wo nicht anders angegeben, den Aussagen E. W. Techows (ebenda, 567-1-2593, Aussagen vom 30. 6.-2.7. und 22.-25. 7. 1922) und der Anklageschrift des ORA gegen Techow und Gen. (BA/P, 30.01-5053/1, S. 20 ff.).

${ }^{19}$ SAM, 567-1-2592, Aussage H.-G. Techow, 30. 6. 1922.

${ }^{20}$ Ebenda, 567-1-2585, Aussage Niedrig, 26. und 28./29. 6. 1922. Auch Salomon erinnerte sich rückblikkend: „Wir waren gezwungen, mit einer unwahrscheinlich geringen Geldsumme hauszuhalten." Die Geächteten, S. 354. 
Anklageschrift - „Berliner Wohnung des Brandt“ zwei Neuankömmlinge im Verschwörerkreis: Plaas und Karl Tillessen, die kurz zuvor mit dem Zug eingetroffen waren. Um dieselbe Zeit fuhren Kern und Fischer mit Günther in dem von Techow gelenkten Wagen nach Wannsee und Nikolskoc. Auf dem Rückweg unternahmen sie im Grunewald mit ihren Mauserpistolen Schießversuche, deren Ergebnisse ihnen aber unbefriedigend erschienen, weil die Waffen zu stark streuten. Daher erhielt Günther den Auftrag, Maschinenpistolen zu besorgen, was ihm allerdings nicht gelang. Die Nacht zum Donnerstag, dem 22. Juni, verbrachten Techow in der elterlichen Wohnung, Fischer, Kern, Salomon, Tillessen und Plaas hingegen in der Pension am Schiffbauerdamm.

Donnerstag früh verließen Tillessen und Plaas Berlin, während sich Kern und Fischer mittags oder abends entschlossen, mit dem wiederum von Techow gesteuerten Wagen nach Schwerin zu fahren, um eine Maschinenpistole zu beschaffen. Dort suchten sie am nächsten Morgen Erich Bade, den Mecklenburger Gauleiter des Deutschvölkischen Schutz- und Trutzbundes, und dessen Sekretär Christian Ilsemann auf, der ihnen eine angeblich im Mai von Kern zur Aufbewahrung erhaltene Maschinenpistole übergab. Abends um halb acht trafen die Verschwörer wieder in Berlin ein, wo Günther sie verabredungsgemäß am Reichskanzlerplatz erwartete und zu einer unterdes besorgten Garage in Schmargendorf dirigierte. Deren Besitzer Richard Schütt hatte sich mit seinem Teilhaber Franz Diestel bereits tags zuvor auf Bitten Günthers bereit erklärt, seine Garage „Ehrhardt-Leuten“ kostenlos zu überlassen, und war auf das Eintreffen des dringend reparaturbedürftigen Wagens vorbereitet. Techow trug Maschinenpistole und Gepäck in Schütts angrenzende Wohnung, wo für Fischer, Kern und Techow Schlafgelegenheiten hergerichtet wurden und die drei mit Schütt, Günther und dem jüngeren Techow den Abend über zechten ${ }^{21}$. Bei dieser Gelegenheit wurde unter Zurateziehung Techows die genaue Stelle des Überfalls festgelegt. Techow gab an, Kern und Fischer hätten ihn erst jetzt zu ihrem Chauffeur bestimmt, denn ,ich sei jetzt in einem solchen Maße in ihr Vorhaben eingeweiht, und ich wisse über die in Frage kommenden fahrtechnischen Seiten der Angelegenheiten so gründlich Bescheid, daß ich mich schon entschließen müsse, das Auto bei der Tat zu führen“22. Offenkundig versuchte Techow, sich mit dieser Darstellung vor dem Todesurteil zu retten, denn es wirkte mehr als unglaubwürdig, daß die Frage nach dem Fahrer erst in letzter Stunde angeschnitten worden sein sollte, nachdem alle anderen Mitverschwörer sich bereits zur Erledigung weiterer Vorbereitungen entfernt hatten. Weit näher liegt die Annahme, daß an diesem Abend, als der längst ausgearbeitete Plan bekräftigt und die verabredetc Rollenverteilung noch einmal durchgesprochen wurde, Techow unter dem Einfluß des reichlich genossenen Alkohols die ihm zudiktierte Aufgabc in letzter Stunde loszuwerden versuchte und so Kern und Fischer veranlaßte, ihn daran zu erinnern, daß es zum Aussteigen nun zu spät sei.

Am 24. Juni jedenfalls stand Techow früh um sieben Uhr auf, um nach dem bereits in Reparatur befindlichen Wagen zu sehen. Um neun Uhr erklärte er dem mittlerweile erschienenen Günther, daß der Wagen in einer Stunde fahrbereit sei. Er „befürchte aber, daß es dann schon zu spät sei“. Kern, Fischer, Techow und Günther besprachen daraufhin noch einmal das Vorgehen, und Techow erklärte auf die Frage, ob er seine Geistesgegenwart nicht verliere, daß er für sich garantieren könne. Daraufhin entschieden Kern und Fischer, „sie wollten sehen, ob sie Rathenau nicht doch noch heute [...] vor die Pistole bringen könnten “23.

21 SAM, 567-1-2570, Aussage Günther, 29./30. 6. 1922.

22 Ebenda, 567-1-2593, Aussage E. W. Techow , 2. 7. 1922.

${ }^{23}$ Ebenda, 567-1-2570, Aussage Günther, 27. 7. 1922. 
Günther verstaute die Maschinenpistole im Wagen hinter dem Notsitz, während Fischer mit der Fertigstellung falscher Autonummern beschäftigt war und Kern nervös auf Beeilung drängte, da sie sonst Rathenau auf keinen Fall mehr erreichen würden. Kurz vor halb elf Uhr lenkte Techow den Wagen auf die Straße. Vor der Kreuzung Roseneck stiegen Kern und Fischer zu, während Günther sich entfernte. Techow fuhr bis in die Nähe der Villa Rathenaus und gab Kern Bescheid, daß der Wagen wieder in Ordnung sei. Daraufhin stieg Kern aus und „erklärte, wir sollten ihn am Hasensprung [...] erwarten und uns gleichzeitig für eine größere Tour bereitmachen" ${ }^{24}$. Fischer und Techow fuhren ein Stück weiter in den Grunewald hinein und zogen sich dort um; beide setzten eine Fahrkappe auf, Techow zusätzlich eine Chauffeursbrille. Am Hasensprung nahmen sie Kern auf, der Techow mit kleinen Umwegen in die bei Rathenaus Haus von der Koenigsallee abzweigende Josef-Joachim-Straße ${ }^{25}$ dirigierte und dort den Motor abstellen ließ.

Ihr Wagen hatte kaum eine Minute gehalten, als ein kleinerer Kraftwagen die Koenigsallee aus Richtung Hundekehle entlangkam und die Josef-Joachim-Straße passierte. Im selben Augenblick rief Kern Techow zu: „Fahren Sie los, und machen Sie das besprochene Manöver! " ${ }^{26}$ Techow startete seinen Wagen und verfolgte Rathenaus Auto mit einer Geschwindigkeit von etwa 30 Stundenkilometern in 200 Metern Abstand. Kern „rief mir zu, ich solle schneller fahren, ich tat das aber nicht, weil ich die Straße überschen konnte und in der Ferne ein Fuhrwerk bemerkte, das den verfolgten Wagen veranlassen mußte abzustoppen. Das geschah denn auch, und ich holte den Wagen in der Nähe der besprochenen Stelle ein. Der Wagen, den ich verfolgte, fuhr nicht vorschriftsmäßig rechts, sondern auf den Gleisen der Straßenbahn, d.h. etwa in der Mitte des Fahrdamms. Als ich ihn überholte, befand ich mich von ihm nach meiner Schätzung höchstens einen halben Meter entfernt. In diesem Augenblick hörte ich hinter mir Schüsse. Ich habe mich jedoch nicht umgesehen, sondern fuhr in die Wallotstraße hinein, wo ich wegen Bauausführungen die Geschwindigkeit auf etwa $25 \mathrm{~km}$ abstoppen mußte. Hier rief mir einer der beiden Insassen zu: ,Wir haben Rathenau erschossen, fahren Sie so schnell wic möglich'. Kurz nach diesen Worten hörte ich einen dumpfen Knall." ${ }^{27}$ Techow lenkte den Wagen in scharfem Tempo durch die Wallot- und Herbertstraße in die Hubertusbader und Karlsbader Straße, wo er kurz anhielt und sich am Motor zu schaffen machte, während die Insassen ihre Fahrkappen mit Hüten vertauschten und die Maschinenpistole aus dem Auto warfen. Gleich darauf stiegen Kern und Fischer am Hohenzollerndamm aus; Techow hingegen brachte den Wagen zur Schüttschen Garage zurück und teilte dem kurze Zeit später eintreffenden Günther mit: „Die Sache hat geklappt, Rathenau liegt." ${ }^{28}$ Anschließend hielt Techow sich daheim zum Mittagessen und dann auf einem Tennisplatz auf, bevor er verabredungsgemäß um 17 Uhr Kern und Fischer im Zoologischen Garten traf und von ihnen 1000 Mark zur Erstattung seiner Auslagen erhielt. Abends besuchte er mit seinem Bruder das Corpshaus Teutonia und verbrachte dort auch die Nacht. Tags darauf verließ er Berlin, und am 27. Juni reisten schließlich auch Kern und Fischer ab.

Dic Anklageschrift hatte die Kette der zu Rathenaus Ermordung führenden Handlungen zwischen dem 16. und dem 24. Juni 1922 fast lückenlos rekonstruiert, aber die innere Logik

${ }^{24}$ Ebenda, 567-1-2593, Aussage E. W. Techow, 2. 7. 1922. Der Hasensprung geht wenige Fußminuten stadteinwärts von der Koenigsallee ab. Um dorthin zu gelangen, mußte Kern an Rathenaus Haus vorbeikommen.

${ }^{25}$ Heute Gottfried-von-Cramm-Weg.

${ }^{26}$ BA/P, 30.01-5053/1, Anklageschrift des ORA gegen Techow u. Gen.

27 SAM, 567-1-2593, Aussage E. W. Techow vom 2. 7. 1922.

${ }^{28}$ Ebenda, 567-1-2570, Aussage Günther, 29./30. 6. 1922. 
des Geschehens nur so weit aufgedeckt, wie es erforderlich schien, um die Tatbeteiligung der nach dem Tod von Kern und Fischer noch verbliebenen Komplicen strafrechtlich zu würdigen. So wurde nicht geklärt, auf welche Weise der in Kicl lebende Kern und der aus Chemnitz kommende Fischer Verbindung zueinander aufgenommen und sich über ihre gemeinsame Mordabsicht verständigt hatten. Offen blieb, wie sie überhaupt den Kontakt zu ihren Helfershelfern hergestellt hatten: Salomons Bekundung, daß cr Kern „zufällig“ in Potsdam getroffen habe, trug nur allzudeutlich den Stempel der Unwahrhaftigkeit, und der ältcre Techow wußte überhaupt kcine Antwort auf die Frage, wie Kern und Fischer auf ihn gekommen waren und woher sic von Stubenrauchs Mordplan gewußt hatten. Auch Karl Tillessen und Plaas konnten nicht verständlich machen, aus welchem Grund und mit welcher Absicht sic am Mittwoch vor der Tat ihre zuerst sogar geleugnete Reise nach Berlin unternommen hatten und weshalb sie plötzlich mit Kern und Fischer zusammentrafen, ja sich sogar in deren Pensionszimmer cinquartierten, obwohl sic von beider Anwesenheit und Vorhaben in Berlin nichts gewußt haben wollten. Verblüffend mutete auch an, mit welcher Leichtigkeit die Verschwörer über das ganze Reich gespannte Verbindungen zur Durchführung ihrer Absicht nutzen konnten, in Hamburg ebenso prompt einen Chauffeur für den geplanten Mord fanden wie in Schwerin einc Maschinenpistole, im sächsischen Freiberg einen Kraftwagen und in Dresden den Vcrmittler zu ihm. Daß eine immer spürbare „Geheimbundatmosphäre" die Verschwörung gegen Rathenau beherrschte und ihre Aufdeckung behinderte, zeigte sich schließlich mit aller Deutlichkeit an der einen und von keinem der Angeklagten plausibel beantworteten Frage, woher die im ganzen doch beträchtlichen Mittel stammten, mit denen Kern und Fischer ihre Unternchmung finanziert hatten und ihre Komplicen quer durch Deutschland gereist waren ${ }^{29}$.

In der Voruntersuchung waren diese Aspekte ungeklärt geblieben, so daß nur die Hauptverhandlung selbst noch eine Aufklärung bringen und vor allem die Frage beantworten konnte, ob die Organisation Consul hinter dem Anschlag auf Walther Rathenau gestanden hatte oder nicht. Doch in ihren Auslassungen bemühten sich die Angeklagten in sorgfältig abgestimmten Erklärungen und oft unter Widerrufung früherer Aussagen, jeden möglichen Bezug zur O.C. zu vermeiden und glaubhaft zu machen, sie hätten unter Kerns Plan eine Gefangenenbefreiung oder cine Waffenschiebung im besetzten Gebiet, aber keinesfalls einen Ministermord verstanden ${ }^{30}$. Techow erklärte zusätzlich, die ihm als Ehrhardt-Männer vorgestellten Kern und Fischer als seine Vorgesetzten betrachtet zu haben, weshalb er auch die Aufforderung, die Steuerung des zur Tat verwendeten Kraftwagens zu übernehmen, nicht ablehnen konnte, da er sein Ehrenwort gegeben habe ${ }^{31}$. Woraus Kern seine besondere Macht schöpfte, um seine Helfer auch dann noch zum Mitmachen zu zwingen, wenn sie innerlich

29 Nicht zuletzt auf diese Auffälligkeit stützte auch Radbruch seinc Kritik an Ebermayers Anklageentwurf: „Es bleibt die schnelle Anknüpfung von Beziehungen zwischen bisher miteinander unbekannten Beteiligten der 'Tat, die sofort bis zur Vertrautheit über geheimste Vorhaben geht und so ohne eine zugrundeliegende Organisation und Treue- und Verschwiegenheitspflicht gar nicht verständlich ist." $\mathrm{BA} / \mathrm{P}, 30.01-5053 / 1$, Weisung vom 26. 8. 1922.

$30 \mathrm{Vgl}$. etwa Günthers Aussage in der Hauptverhandlung (SAM, 772-2-194, Rathenau-Prozeß, 3. Verhandlungstag, S. 27 ff.). Niedrig wollte gar weismachen, er habe nach der Festnahme scine Beihilfe zum Mord nur erfunden, um das Auffliegen einer Waffenschiebung zu verhindern. Außerdem sei der Untersuchungsrichter ihm „zwcimal bestimmt, cvt. dreimal mit dem Worte Quatsch über den Mund [gefahren]. Ich hatte nach dieser Behandlung die Energie und den Mut verloren, meine polizeiliche Aussage richtig zu stellen." (Ebenda, S. 149) Das Verhandlungsprotokoll des Berliner Tageblatts vom 6. 10. 1922, Morgen-Ausgabe, vermerkte hier mehrfach „Großc Hcitcrkcit“.

3I SAM, 772-2-19, Rathenau-Prozeß, 2. Verhandlungstag, S. 12 und 63 f. 
widerstrebten, war dem Angeklagten nicht zu entlocken. Erst nachdem der Oberreichsanwalt am letzten Verhandlungstag auf Mittäterschaft plädiert hatte, brach Techow angesichts des ihm drohenden Todesurteils zusammen und gestand nun immerhin, von Kern zur Tat gezwungen worden zu sein: „Er hat gesagt, nachdem ich mein Wort gegeben hatte, wenn ich mich jetzt weigern würde, würde er mich niederschießen. "32 Von einer erheblichen Gewaltbereitschaft Kerns gegenüber seinen eigenen Komplicen berichtete auch der Garagenbesitzer Schütt, dem Kern am Morgen des Anschlags sagte: „Schütt, Verräter gehen bei uns um die Ecke." Schütt war sich nach dicser Bemerkung sicher, daß hinter Kern und Techow eine Organisation stand ${ }^{33}$.

$\mathrm{Da}$ die Angeklagten hierüber schwiegen, war eine Klärung während des Leipziger Prozesses allenfalls von der Aussage Theodor Brüdigams zu erwarten. Doch der Mann, der mehrere Vorstrafen wegen Betruges und schweren Diebstahls auf dem Konto, jahrelang in der Landesirrenanstalt Marburg und während des Krieges als Soldat im Nervenlazarett gelegen hatte, machte selbst auf wohlmeinende Beobachter einen ungünstigen Eindruck ${ }^{34}$. Dem Oberreichsanwalt schien er „ein zu wenig klassischer Zeuge“, und den Verteidigern fiel es nicht schwcr, seine Glaubwürdigkeit zu erschüttern: Brüdigam mußte eingestehen, daß er sich bei Tillessen mit falschen Angaben eingeschlichen und ihn möglicherweise zu unbedachten Äußerungen provoziert hatte ${ }^{35}$. Andererseits mußte Tillessen einräumen, Brüdigam am 13. oder 14. Juni gefragt $\mathrm{zu}$ haben, was seiner Ansicht nach geschehe, wenn Rathenau ermordet werde. Und er stritt auch die schon von Plaas erwähnte Äußerung nicht ab, notfalls „Rathenau eine Kugel in den Kopf und mir eine ins eigene Herz zu schießen“. Diesen Satz wollte Tillessen nun aber nur gesagt haben, um Brüdigam loszuwerden ${ }^{36}$.

Das Gericht folgte ihm und nicht Brüdigam. Es ließ - auch auf Bitten des Oberreichsanwalts - den Zeugen unvereidigt und klammerte, von den Verteidigern gedrängt ${ }^{37}$, den O.C.Komplex aus der weiteren Beweisaufnahme aus. Daran vermochte auch ein Giftmordversuch nichts zu ändern, mit dem Unbekannte versuchten, Günther an weitcren Aussagen zu hindern. Der Angeklagte hatte während des vierten Verhandlungstages Pralinenkonfekt gegessen, das angeblich die Firma Sarotti geschickt hatte, und in der Mittagspause auch vier Mitangeklagten davon angeboten; er selbst fühlte sich bereits am Nachmittag so unwohl, daß die Verhandlung um 15 Uhr abgebrochen wurde. In der folgenden Nacht erkrankten auch die übrigen Angeklagten, die von dem Konfekt gegessen hatten, so daß die Verhandlung auf den 9. Oktober vertagt werden mußte. Die Untersuchung ergab, daß die Pralinen geöffnet und mittels einer Spritze mit Arsen gefüllt worden waren ${ }^{38}$. Die Sendung war schon am 30. Sep-

${ }^{32}$ PA/AA, Rathenau-Prozeß, 9. Verhandlungstag, S. 5.

${ }^{33}$ SAM, 772-2-194, Rathenau-Prozeß, 4. Verhandlungstag, S. 48 bzw. 56.

${ }^{34}$ PA/AA, Rathenau-Prozeß, 8. Verhandlungstag, S. 15 f.; SAM, 567-1-2621, Aussage Brüdigam, 4. 8. 1922; vgl. Berliner Tageblatt vom 11. 10. 1922, Morgen-Ausgabe.

${ }^{35}$ PA/AA, Rathenau-Prozeß, 8. Verhandlungstag, S. 168 bzw. $24 \mathrm{f}$.

${ }^{36}$ Ebenda, S. 15, und 38. Vgl. weiter oben, S. 67, Anm. 80.

37 „Es ist merkwürdig. Sobald in dieser Prozeßverhandlung die Organisation C oder ein anderer Geheimbund genannt wird, schnellt aus der rechten Gruppe der Verteidiger der eine oder andere empor und sucht festzustellen, daß von einer Beteiligung dieser Organisation gar keine Rede sein kann." Berliner Tageblatt vom 7. 10. 1922, Abend-Ausgabe. Vgl. Alsbergs spätere Kritik an scinen Anwaltskollegen (Rathenau-Prozeß, Sp. 663 ff.) und Heydeloff, Staranwalt, S. $384 \mathrm{ff}$.

38 Vgl. Leipziger Neueste Nachrichten vom 8. 10. 1922; Heydeloff, ebenda, S. 386. „Die Menge arseniger Säure in den einzelnen Pralinen beträgt 0,336 bis $0,496 \mathrm{~g} ; 0,1$ bis $0,2 \mathrm{~g}$ arseniger Säure genügen aber, den Tod eines Menschen herbeizuführen. Nur dem Umstande, daß diejenigen, die davon gegessen hatten, sich erbrechen mußten, ist es zuzuschreiben, daß die Pralinen dic beabsichtigte tödliche Wirkung nicht 
tember 1922 in Berlin aufgegeben worden und hatte dic Adressaten noch vor der Hauptverhandlung erreichen sollen, traf aber verspätet ein. Trotz einer ausgelobten hohen Belohnung blieben die Täter unentdeckt; der vom Leipziger Oberstaatsanwalt geäußerte Verdacht, „daß die Täter der Geheimorganisation Consul (O.C.) angehören oder ihr doch nahestehen "39, konnte daher nicht bestätigt werden. Spätere Hinweise deuteten darauf, daß der Anschlag von Friedrich Wilhelm Heinz inszeniert worden war, dem auch in die Attentate auf Scheidemann und Rathenau verwickelten Mitarbeiter Tillessens in der Frankfurter O.C. ${ }^{40}$.

Trotz der unklaren Beweislage hielt der Oberreichsanwalt immerhin an der vagen Erkenntnis fest, „daß die Täter mit gewissen Organisationen in Verbindung gebracht werden können, und daß diese Organisationen den Tätern den Gedanken zur Tat eingegeben haben. Ich gehe sogar noch einen Schritt weiter. Ich sage, daß diese Organisationen ihnen bei der Tat behilflich gewesen sind. Bei allen Attentaten auf Erzberger, auf Rathenau, auf Scheidemann, sind es immer dieselben Kreise, sie haben alle gemeinsame Beziehungen, dic sich lange zurückverfolgen lassen. Es ist ein Unsinn zu glauben, daß alle dicse Angeklagten hier nach Berlin gekommen seien, jeder zu einem anderen Zweck. Ich bin der festen Überzeugung, daß sie alle vorher wußten, was geschchen sollte, daß sie sich planmäßig verabredeten und in Berlin sich getroffen haben. Deshalb liegt auch die Vermutung nahe, daß der Mord von den Angeklagten planmäßig organisiert war, daß er nicht ein dem Zufall entsprungenes Verbrechen gewesen ist, daß nicht Kern und Fischer allein die Urheber des Mordes waren." 41 Genauer mochte sich auch das Gericht nicht festlegen. Es folgte dem Strafantrag des Oberreichsanwaltes in drei Fällen und urteilte in cinem härter, in den übrigen milder; vor allem aber wertete es den Mord als gemeine und ehrlose Tat, der nicht das Prädikat eines politischen Verbrechens zugebilligt werden dürfe ${ }^{42}$, und erkannte den zu Zuchthausstrafen Verurteilten die bürgerlichen Ehrenrechte auf unterschiedlich lange Dauer ab. Aufsehen erregte, daß das Gericht bei dem älteren Techow statt auf Mittäterschaft nur auf Beihilfe entschied und ihm somit die sonst sichere Todesstrafe ersparte; es war sich nach der Beweisaufnahme nicht mehr hinreichend sicher gewesen, daß Techow die Tat als eigene gewollt hatte ${ }^{43}$. Um diese wichtigste Entscheidung war im Richterkollegium lange gerungen worden ${ }^{44}$. Seine Bereitschaft zur Milde wurde durch einen verzeihenden Brief der Mutter Rathenaus an die Mutter Techows gestärkt, den Techows Verteidiger heranzog ${ }^{45}$. Im

gehabt haben." Aufruf des Oberstaatsanwalts beim Landgericht Leipzig, 19.10. 1922, zit. nach Brammer, Ergebnis des Rathenau-Prozesses, S. 42.

${ }^{39}$ Ebenda.

40 Dies bezeugte Schmidt-Halbschuh (Oberhessische Volkszeitung vom 25. 3. 1927). Auch Heinz selbst schilderte in "Sprengstoff“ den Anschlag als sein Werk, behauptete aber, nur ein Abführmittel in die Pralinen injiziert zu haben, S. 154 ff.; vgl. Meinl, Revolutionär, S. 98.

${ }^{41} \mathrm{Zit}$. nach Berliner Tageblatt vom 12. 10. 1922, Morgen-Ausgabe.

42 BA/P, 30.01-5053/1, Urteil gegen E. W. Techow u. Gen., S. 28.

43 Ebenda, S. 14 f.

${ }^{44}$ Vgl. Zeiler, Mitarbeit, S. 53. Für den Fall, daß Techow wegen Mittäterschaft zun Tode verurteilt worden wäre, hatte Reichsjustizminister Radbruch allerdings bereits Übcrlegungen zur Begnadigung Techows angestellt; vgl. Radbruch, Der innere Weg, S. 120.

45 PA/AA, Rathenau-Prozeß, 10. Verhandlungstag, S. 94 f.; vgl. Norlind, Gespräche und Briefe, S. 98 ff. Der von RA Hahn so effektvoll genutzte Brief war seinerzeit von Frau Techow gar nicht und von ihrem Anwalt mit einer bloßen Empfangsbestätigung beantwortet worden; NL Edith Andreae, Tagebuch, Eintrag vom 25. 7. 1922. Salomons Behauptung, der Brief sei von der Polizei abgefangen und in der Presse veröffentlicht worden, bevor ihn Techows Mutter bekommen habe (Fragebogen, S. 138 f.), ist falsch. Daß Mathilde Rathenaus Brief einen der Mörder ihres Sohnes vor dem Todesurteil schützen 
einzelnen wurden verurteilt: Ernst Werner Techow wegen Beihilfe zum Mord zu 15 Jahren Zuchthaus, Hans-Gerd Techow und Günther wegen Beihilfe in Tateinheit mit Begünstigung zu vier Jahren und einem Monat Gefängnis bzw. zu acht Jahren Zuchthaus, Niedrig und Salomon wegen Beihilfe zu je fünf Jahren Zuchthaus, Schütt und Diestel wegen Begünstigung zu je zwei Monaten Gefängnis, Tillessen und Plaas wegen Nichtanzeige eines drohenden Verbrechens zu drei bzw. zwei Jahren Gefängnis, Ilsemann wegen Vergehens gegen die Waffenverordnung zu zwei Monaten Gefängnis. Freigesprochen wurden die Angeklagten Steinbeck, Warnecke und Voß ${ }^{46}$.

Das Urteil wurde in der deutschnationalen Presse mit Erleichterung begrüßt und als "Zusammenbruch der ruchlosen Hetze ,gegen rechts “" gewertet ${ }^{47}$. Nach Auffassung vieler konservativer Blätter hatte das Urteil den Verdacht, eine Mörderorganisation könnte hinter dem Anschlag gestanden haben, als haltlos erwiesen, während liberale Blätter genau umgekehrt argumentierten. Tatsächlich hatte der Staatsgerichtshof beide Interpretationsmöglichkeiten zugelassen und einerseits unterstrichen, daß die Hauptverhandlung keine sichere Stütze für die Annahme eines organisierten Komplotts ergeben habe, andererseits aber dessen Möglichkeit durchaus eingeräumt und die Entscheidung auf den noch schwebenden Prozeß gegen die O.C. vertagt. Das Urteil genügte den Hoffnungen der Konservativen, insofern es die Erörterung der Schuldfrage auf die dreizehn Angeklagten beschränkte, und befriedigte die Ansprüche der demokratisch gesinnten Öffentlichkeit zumindest in der Deutlichkeit der gefällten Urteile ${ }^{48}$ ebenso wie in der Offenhaltung der Frage nach möglichen Drahtziehern ${ }^{49}$.

Eine neue Chance zu ihrer Beantwortung bot im Juni 1925 der zweitc RathenaumordProzeß gegen die seinerzeit entkommenen, aber unterdes gefaßten Tatbeteiligten Günther Brandt und Johannes Küchenmeister; denn der in den Aussagen seiner verurteilten Komplicen immer wieder genannte Brandt hatte in der Mordverschwörung offenbar eine Schlüsselrolle eingenommen, durch die beständig das Wirken einer Hintergrundorganisation durchzuschimmern schien ${ }^{50}$. Als er Ende April 1924 am Ammersee in Bayern festgenommen wurde, trug er zwei gefälschte amtliche Ausweise bei sich. Nach seinen Angaben hatte ihn Kern bei einer Berliner Tagung von Marineoffizieren schon einige Wochen vor dem Rathenaumord gebeten, einen Kraftwagen zu besorgen; daß das Auto für ein politisches Verbrechen verwendet werden sollte, habe er allerdings nicht gewußt. Doch dagegen sprach eine frühere Aussage Karl Tillessens, nach der Brandt einmal erwähnt hatte, daß Kern und Fischer

half, hinderte nationalsozialistische Autoren später nicht, ihn als „Dokument des kaltberechnenden Pharisäismus“ zu verleumden (Frank, „Höre Israel!“, S. 297). Vgl. auch Lamm, Denker und Staatsmann, S. $67 \mathrm{f}$.

${ }^{46} \mathrm{BA} / \mathrm{P}, 30.01-5053 / 1$, Urteil gegen E. W. Techow u. Gen.

${ }^{47}$ Deutsche Zeitung vom 17. 10. 1922. Tags darauf hieß es gar: „Jetzt sollen Reichskanzler und Reichstagspräsident für ihre Reden vom 24. Juni Rechenschaft ablegen. Jetzt sollen die nationalen Kreise vor Gericht Sühne fordern für den Schimpf, den man ihnen damals angetan hat. "Vgl. Brammer, Ergebnis des Rathenau-Prozesses, S. 6.

48 Teile der sozialdemokratischen und liberalen Presse kritisierten das Gericht allerdings wegen seiner angeblich zu milden Überparteilichkeit; vgl. Schleswig-Holsteinische Volkszeitung vom 16. und Frankfurter Zeitung vom 13. 10. 1922.

49 Erst der unbefriedigende Ausgang des O.C-Prozesses 1924 führte dazu, daß die Prozeßführung des Vorsitzenden weniger behutsamer Kritik unterzogen wurde (vgl. Hannover/Hannover-Drück, Politische Justiz, S. 124). Dennoch bestand auch nach 1945 in Ost und West Einigkeit darüber, daß, anders als in vielen anderen politischen Verfahren der Weimarer Republik, die Urteile selbst angemessen waren; vgl. Streit, Klassenjustiz, S. 206; Gumbel, Fememord, S. 44.

50 Die Prozeßdarstellung stützt sich, sofern nicht anders angegeben, auf die Anklageschrift (BA/P, 30.015053/1) und das Urteil gegen Brandt und Küchenmeister (ebenda 30.03-12J482/24, Bd. 1). 
bei jener Offizierstagung durchaus schon über ihre Mordabsichten gesprochen hätten. In der Hauptverhandlung präzisierte Brandt, daß diese Tagung zu Pfingsten-also am 4./5. Juni 1922 - als „kameradschaftliche Besprechung ehemaliger Marineoffiziere“ abgehalten worden sei, über deren Inhalt er unter Rücksicht auf die Staatssicherheit nur unter Ausschluß der Öffentlichkeit auszusagen bereit sei. Die Vermutung, daß es sich um eine durchaus nicht nur der Traditionspflege dienende Zusammenkunft gehandelt habe, konnte von der Presse nicht substantiiert werden, da das Gericht Brandts Verlangen nachkam und die Öffentlichkeit ausschloß ${ }^{51}$.

Das weitere Geschehen stellte sich nach der Voruntersuchung so dar: In der Woche vor dem Anschlag hatte Kern seine Bitte nach einem Kraftwagen brieflich erneuert und Brandt sich daraufhin an die Brüder Fritz und Johannes Küchenmeister gewandt. Fritz Küchenmeister bekundete, daßer Brandt am 17. Juni an seinen Bruder Johannes verwiesen und dieser sich am 19. Juni einverstanden erklärt habe, den Wagen für einen „nationalen Zweck“ zur Verfügung zu stellen. Offen blieb, wieso Brandt dann schon am 18. Juni an Kern telegrafieren konnte, dieser möge einen Autoführer nach Dresden schicken. Weiter behauptete der anschließend mit Techow in Küchenmeisters Wagen nach Berlin gefahrene Brandt, erst nach seiner Ankunft von Kerns und Fischers Mordabsicht erfahren zu haben. Er habe gegen die nicht abgesprochene Verwendung des Wagens protestiert und die Mordtat zu verhindern gesucht. Daß dies nicht die ganze Wahrheit sein konnte, zeigte schon ein Notizzettel, den Brandt bei seiner Verhaftung bei sich trug und der sich vermutlich auf ein Gespräch mit seinem Anwalt bezog: „Angelegenheit von G.B. Was haben Kaptl. Tillessen, Plaas und Techow über G.B. ausgesagt? (Aktenabschrift). Was muß G. B. aussagen?" 52

Nicht ganz zu erhellen war auch die Rolle Johannes Küchenmeisters, der von mehreren Zeugen als ein sehr religiöser und allem Fanatismus abholder Mensch geschildert und einer Beteiligung an politischen Verbrechen nicht für fähig erachtet wurde. Unverständlich blieb, wie er dem ihm bis dahin unbekannten Brandt seinen teueren, sonst nur zu Repräsentationszwecken verwendeten Kraftwagen überlassen konnte, ohne über den genauen Verwendungszweck orientiert zu sein. Allerdings hatte er sich aus der Untersuchungshaft in Österreich, wo er am 30. Juni 1922 festgenommen worden war, seinem Vater gegenüber brieflich mit Überlegungen zu rechtfertigen gesucht, dic Zweifel an Brandts Darstellung wecken mußten: „Ich wußte nicht, wer gerichtet werden sollte, es war nicht einmal die Rede davon, daß jemand gerichtet werden sollte, aber ich habe es mir gedacht. Es sollte sich um eine Flucht handeln. Die Tat geht vor sich, so oder so. "53 Das Gericht hielt diese Äußerung nicht für erheblich, da Küchenmeister nach einem Sachverständigengutachten eine psychopathische Persönlichkeit sei, die bei Erregungszuständen zu grundlosen Selbstvorwürfen neige, und schenkte statt dessen Brandts Versicherung Glauben, von Kern über den Verwendungszweck des Kraftwagens getäuscht worden zu sein. Tillessens entgegenstehendes Zeugnis, daß Kern seine Mordabsicht bereits auf dem Pfingsttreffen der Marineoffiziere „in ziemlich versoffener Stimmung" bekundet habe, hiclt das Gericht durch die Einlassung Brandts für widerlegt, „daß von einer versoffenen Stimmung bei der nur kurzen Zusammenkunft, bei der es nur dünnes Bier gab, gar nicht die Rede gewesen sein könne “54. Auch seine Flucht nach der Ermordung Rathenaus konnte Brandt nach Auffassung des Gerichts plausibel mit seiner Befürchtung erklären, „als Ehrhardt-Offizier, wie viele andere, bei der großen Erregung verhaftet zu werden“. Es konnte danach kaum überraschen, daß beide Angeklagten vom

51 Vossische Zeitung vom 25. 6. 1925, Abend-Ausgabe.

52 BA/P, 30.01-5053/1, Anklageschrift gegen Brandt und Küchenmeister, S. 24.

53 Küchenmeister, Brief vom 30.6. 1922, zit. nach ebenda, S. 27.

${ }^{54}$ Ebenda, 30.03-12J482/24, Bd. 1, Urteil gegen Brandt und Küchenmeister, S. 13f. Auch Tillessen selbst wollte sich in der Verhandlung seiner früheren Behauptung nicht mehr ganz sicher sein. 
Vorwurf der Beihilfe zum Mord freigesprochen wurden und nur Brandt wegen Nichtanzeige eines geplanten Verbrechens vier Jahre Gefängnis erhielt.

Je nach politischer Ausrichtung würdigte die deutsche Tagespresse das Verfahren unterschiedlich. Während etwa die Deutsche Zeitung das Urteil gegen Brandt, dessen Höhe sich an der 1922 gegen Tillessen verhängten Strafe bemaß, als „ungewöhnlich hart" bezeichnete ${ }^{55}$, bemängelte die Vossische Zeitung dic Zurückhaltung der Reichsanwaltschaft und notierte als Ausdruck der Verhandlungsatmosphäre, daß das Gericht sich ausdrücklich geweigert hatte, über das Wirken Rathenaus ein Urteil abzugeben ${ }^{56}$. Die liberalen Blätter verglichen darüber hinaus die in der Praxis des Staatsgerichtshofs mittlerweile überdeutlich gewordene Diskrepanz zwischen der Ahndung politischer Verbrechen von rechts und links und kritisierten das „unverständliche Urteil“ als Verletzung des allgemeinen Rechtsempfindens ${ }^{57}$. Die Frankfurter Zeitung fand, „daß der Gerichtshof allen Angaben der Angeklagten unbedingten Glauben geschenkt hat und daß auch der Anklagevertreter darauf verzichtete, das von den Angeklagten und ihren Verteidigern vorgebrachte Entlastungsmaterial kritisch zu prüfen“. Dadurch war ungeklärt geblieben, weshalb Brandt den angeblich für eine Gefangenenbefreiung benötigten Wagen nicht wieder mitgenommen habe, nachdem er erfahren hatte, daß Kern und Fischer ihn für einen von ihm nicht gebilligten Mord einsetzen wollten ${ }^{58}$. Unbefriedigend blieb der Ausgang dieses Prozesses daher nicht nur für die konservative, sondern auch für die demokratische Publizistik - wenn auch aus entgegengesetzten Gründen.

\section{Die Motive der Attentäter}

Um der Frage näherzukommen, ob Walther Rathenau rechtsradikalen Einzeltätern oder dem Komplott einer Hintergrundorganisation zum Opfer gefallen war, hätte es eines genaueren Blicks auf die Beweggründe der Tatbeteiligten bedurft. Doch während der Verhandlung des Leipziger Staatsgerichtshofs 1922 gegen die dreizehn zumeist jugendlichen Angeklagten war von dem Motiv, das sie zu ihrer Bluttat gebracht hatte, nur wenig die Rede gewesen. Das Urteil hatte statt dessen allgemein auf den ,blindwütigen Judenhaß“ hingewiesen, der weite Volkskreise beherrsche und „in unklaren und unreifen Köpfen einen wilden Mordtrieb“ geweckt habc. Als Beweis für diesen fanatischen Haß der Täter, der in dem Juden Rathenau „das eigentliche Haupt der Regierung der Erfüllungspolitik" gesehen und ihm die Schuld an der niedergedrückten Lage des Landes gegeben habe, zitierte das Urteil die Gründe, mit denen Kern Techow am Abend vor dem Attentat von dessen Notwendigkeit hatte überzeugen wollen: Durch Rathenaus Beseitigung solle die Linke zum Losschlagen gereizt werden, damit dic nationalen Parteien ans Ruder kämen; außerdem sei der Minister ein Anhänger des schleichenden Bolschewismus, der als einer der dreihundert Weisen von Zion die Ziele des internationalen Judentums verfolge, seine Schwester mit dem russischen Kommunisten Karl Radek verheiratet und scine Berufung an die Spitze des Auswärtigen Amts durch ultimative Drohungen crpreßt habe ${ }^{1}$.

Nun vereinte diese Auflistung ganz unterschiedliche Beweggründe, dic zum einen auf Rathenau selbst und die von ihm angeblich ausgehende Gefahr gerichtet waren, zum anderen aber Rathenaus Beseitigung als bloßes Mittel zum Zweck einer politischen Umwälzung

${ }^{55}$ Deutsche Zeitung vom 27. 6. 1925.

56 Vossische Zeitung vom 26. bzw. 27. 6. 1925.

57 Berliner Tageblatt vom 27. 6. 1925, Abend-Ausgabe.

${ }^{58}$ Frankfurter Zeitung vom 28. 6. 1925.

${ }^{1}$ BA/P, 30.01-5053/1, Urteil gegen E. W. Techow u. Gen. 
ansahen. Nur der erste Motivstrang ließ sich in die vom Gericht beschworene Gedankenwelt der antisemitischen Verhetzung einbetten, während der zweite auf eben das politische und militärische Hintergrundmilieu verwies, das der Staatsgerichtshof in seiner Beweisaufnahme weitgehend ausgespart hatte. Konsequent vernachlässigte die weitere Urteilsbegründung diese zweite Motivkategorie und führte das Verbrechen ausschließlich auf die Wirkung antisemitischer Hetzparolen zurück, die es erlaubten, den Mord als isolierte Tat unreifer Fanatiker zu deuten: „Alles in Allem hat die Hauptverhandlung keinen Zweifel darüber gelassen, daß nicht nur die Tat Kerns in jenem Haß gegen den Juden und den Staatsmann Rathenau wurzelte, sondern daß auch dic anderen Angeklagten, soweit sie verurteilt worden sind, - mit Ausnahme von Schütt und Diestel - mehr oder weniger dieses Geistes gewesen sind." 2

Das Gericht, das sich folgerichtig weigerte, den Angeklagten politische Motive zuzubilligen, sah sich allerdings mit dem irritierenden Umstand konfrontiert, daß Techow in der Verhandlung eine angeblich von dem Ermordeten ausgegangene Gefahr überhaupt nicht darzulegen vermochte. Nicht nur Techow attestierte dem Rapallo-Vertrag einen im Grunde außerordentlich günstigen Charakter und Rathenau "ganz entschieden “ ideale Gesinnung ${ }^{3}$, auch Tillessen wollte nie daran gezweifelt haben, daß Rathenau, der „ein eminent kluger Mann war und zweifellos auch tatsächlich in deutschem Sinne tätig gewesen ist“, seine politische Arbeit „im Interesse Deutschlands tut, aus der Idee, daß es augenblicklich das einzige ist, was hilft" ${ }^{\text {. }}$. Das Urteil verwarf die Auslassungen Tillessens als unglaubwürdige Schutzbehauptungen und wertete die Unfähigkeit Techows, einen nachvollziehbaren Beweggrund für die Tötung Rathenaus zu formulieren, als Ausweis intellektueller Unreife. Mit dieser Aufassung stand der Staatsgerichtshof keineswegs allein; den Glauben, daß Rathenau primär aus antisemitischen Gründen ermordet worden war, teilten Repräsentanten so unterschiedlicher Richtungen wie der Zionist Kurt Blumenfeld und der Nationalrevolutionär Ernst Jünger ${ }^{5}$. Schießlich konnte nicht geleugnet werden, daß es Rechtsradikale gewesen waren, bei denen das zuerst im August 1921 von oberschlesischen Freikorps gesungene Hetzlied immer weitere Verbreitung gefunden hatte, dessen letzte Strophe zum Mord am Juden Rathenau aufrief ${ }^{6}$ und das Rathenau selbst als Ausdruck der über ihn schwebenden Bedrohung zitiert hatte. Die Geschichtsschreibung ist mit nur wenigen Ausnahmen dieser Sicht gefolgt und hat die Bluttat vom 24. Juni 1922 als Anschlag völkisch verhetzter, unreifer Jugendlicher ${ }^{7}$ auf den Juden und Erfüllungspolitiker Rathenau bewertet ${ }^{8}$. Unter diesem Blickwinkel scheint cs alles andere als ein Zufall zu sein, daß der Ermordung scharfe Angriffe des Deutschnationalen Karl Helfferich gegen die Erfüllungspolitik als Ursache des deutschen Elends unmittelbar vorausgegangen waren. Daß Helfferich „der Mörder, der wirkliche,

2 Ebenda, S. 12.

3 SAM, 772-2-194, Rathenau-Prozeß, 2. Verhandlungstag, S. 59 f. und 63 f.

4 PA/AA; Rathenauprozeß, 6. Verhandlungstag, S. 65.

5 Vgl. Blumenfeld, Judenfrage, S. 140; Salomon, Fragebogen, S. 131.

6 Vgl. Lohalm, Völkischer Radikalismus, S. 220.

7 Vgl. Brccht, Schweigen, S. 43.

8 Vgl. neben Kessler (Rathenau, S. 320) in jüngerer Zeit besonders Zechlin, Juden im Ersten Weltkrieg, S. 59; Erdmann, Weimarer Republik, S. 162; Schulin, Integrationsversuch, S. 35 f.; Létourneau, Rêve prométhéen, S. 291; Berding, Moderner Antisemitismus, S. 187; Huber, Deutsche Verfassungsgeschichte, Bd. 7, S. 253 f.; Battenberg, Zcitalter der Juden, S. 237; Winkler, Antisemitismus, S. 271 ff. Noch dezidierter interpretiert Hamilton den Rathenaumord als Auftakt zur Judenvernichtung (L' illusion fasciste, S. 148 f.), während Volkov zufolge Rathenau als Symbol der Republik getötet wurde (Ermordung Rathenaus, S. 99 ff.). 
verantwortliche“ sei, hielt Harry Graf Kessler schon in einer Tagebuchnotiz vom Tag des Attentats für ausgemacht ${ }^{9}$. Er blieb dabei auch in seiner späteren Rathenau-Biographie und gab damit eine bis heute weithin akzeptierte Meinung vor ${ }^{10}$.

In der Tat steht außer Zweifel, daß Ehrhardt-Offiziere wie Kern und Tillessen von tiefem $\mathrm{Haß}$ auf Rathenau erfüllt waren. Dies zeigt etwa ein Artikel, den Karl Tillessen im Mai 1922 in der Frankfurter Völkischen Rundschau über ,jüdische Leiterfamilien " verfaßt hatte ${ }^{11}$, und auch Plaas ließ in seinen Tagebucheintragungen erkennen, daß seine während des Rathenaumord-Prozesses zur Schau getragene Konzilianz nur vorgetäuscht war ${ }^{12}$. Gleichklingende Anschauungen verbreitete das publizistische Organ der Ehrhardt-Leute, Der Wiking, der im Februar 1922 Rathenaus Ernennung zum Außenminister als Gipfel einer politischen Groteske und dankenswerte Offenbarung der Republik als "Synagogengemeinde“ bewertete: Rathenau betreibe cine an den Interessen des internationalen Finanzgeistes statt des deutschen Volkes orientierte Politik; seine ultimativ erzwungene Ernennung zeige, wie „fest das Judentum sich heute bereits im Sattel sitzend wähnt"13. Der Artikel formulierte als Konsequenz, „daß wir die jüdische Frage als die Kardinalfrage und den Angelpunkt unserer gesamten inneren, wie äußeren Politik betrachten“, und schloß mit einem Appell, der sich wie ein Tataufruf an die eigene Anhängerschaft liest: „So gewiß ein deutscher Gott im Himmel lebt, so sicher werden wir das Netz zerreißen, in das uns das Judentum eingesponnen hat, und so sicher werden wir mit einem Schlage das jüdische Joch zertrümmern, unter das sich zurZeit ein Volk von 60 Millionen beugt. Der Weg zu diesem Ziele der Befreiung wird sich finden lassen, wenn es an der Zeit ist, und ebenso wird es auch wenig ausmachen, ob und wie viel Späne dann beim Hobeln fliegen werden."

Um so mehr muß überraschen, daß der Wiking Rathenau später nicht mehr zur Zielscheibe seiner Angriffe machte ${ }^{14}$. Die Ergebnisse der Konferenz von Genua wertete das Blatt - anders als die meisten rechtsstehenden Zeitungen - sogar fast uncingeschränkt positiv ${ }^{15}$; offenbar war auch in der Ehrhardt-Bewegung das Urteil über Rathenau durchaus nicht einheitlich. Ebenso räumte Ernst von Salomon dreißig Jahre später zwar ein, daß die „nationale Bewegung“, der die Rathenaumörder sich zurechneten, ausnahmslos antisemitisch eingestellt gewesen sei und ihr einziger gemeinsamer Nenner geheißen habe: „Schluß mit der Erfüllungspolitik!"16 Dennoch habe Rathenau keinesfalls sterben müssen, weil er Jude war.

${ }^{9}$ Pfeiffer-Belli, Kessler. Tagebücher, S. 322.

${ }^{10}$ Kessler, Rathenau, S. 320 ff.; Hannover/Hannover-Drück, Politische Justiz, S. 114. Schulin hat allerdings zu Recht darauf hingewiesen, daß Helfferichs Rede vom 23. 6. 1922 „bei aller Härte maßvoll im Vergleich zu sonstigen Angriffen" gewesen sei (Walther Rathenau, S. 134 f.). Auch der Bruder des deutschnationalen Politikers bemühte sich später, den Vorwurf der Mittäterschaft zu entkräften; Helfferich, Rathenau und Helfferich, S. 24.

${ }^{11}$ Der mit „T. Essen“ gezeichnete Artikel suchte den Deutschen die Augen über das „verbrecherische Treiben des Judentums" zu öffnen und verlangte die Ausbürgerung aller deutschen Juden; Völkische Rundschau vom 15. 4. 1922.

12 Vgl. die Notiz vom 20. 4. 1922, in der Plaas den eben geschlossenen Rapallo-Vertrag als Schritt zum Weltbolschewismus deutet, dessen Drahtzieher Rathenau und Parvus-Helphand seien; NL Plaas, Tagebuch.

${ }^{13}$ Anonymus, Minister Rathenau, 15. 2. 1922.

${ }^{14}$ So verurteilte das Blatt zwar in fast jeder Nummer die Erfüllungspolitik als Verrat am deutschen Volk, zielte aber kaum mehr auf einzelne Personen und wenn, dann weniger auf Rathenau als auf den Kanzler: „Wir werden uns nach Genua wieder sprechen, Herr Wirth!“ Anonymus, Genua, 15. 3. 1922.

${ }^{15}$ Anonymus, Genua. III., 1. 6. 1922.

${ }^{16}$ Fragcbogen, S. 129. 
Salomon erwähnt im „Fragebogen“ eine Unterhaltung mit Ernst Jünger, in der er sich gegen dessen Behauptung wehrt, Rathenau sei aus antisemitischen Motiven getötet worden, und führt in diesem Zusammenhang eine Äußerung seines Mitverschworenen Plaas an: „Ich möchte beinahe sagen, er wurde getötet, obgleich er Jude war." ${ }^{17}$ In einem eigenartigen Zwiespalt bewegen sich schon zeitnähere Gedanken Salomons zur selben Frage. Im Zuchthaus von Striegau reflektierte der verurteilte Attentäter 1923/24 über das mit der Ermordung Rathenaus angesteuerte Ziel so: „Rathenau fiel auf dem Felde der Ehre. Auf dem Wege zum Amt. Ein großes Herz stand still. Es ist eine erschütternde Tragödie. - Der edle Jude Rathenau - der edelste Jude Deutschlands - hatte gehandelt im glühendsten, reinsten Idealismus für sein Volk! Ihm kann nicht ein einziger schmutziger Beweggrund nachgesagt werden! Er ist der Märtyrer seiner Ideen geworden; [...] daß er alle Mittel benützte, die ihm zu Gebote standen, daß das Glück seines Volkes nicht das Glück des deutschen Volkes sein konnte, sondern notwendig dessen Unglück - das kann nichts hinweg nehmen von seiner Größe."18

Mußte Rathenau nach dieser Betrachtungsweise sterben, weil er angeblich gerade wegen seiner menschlichen Lauterkeit als Jude Deutschland gefährlich wurde, so betonte Heinz in seiner Beschreibung des Attentats, daß die „äußeren Gründe, welche [...] Kern und Fischer bewegten, Rathenau zu töten, [...] unwesentlich [sind]. Sie haßten ihr Opfer nicht "19. So wenig wie Salomon nutzte Heinz die gängigen Vorwürfe der Radikalantisemiten gegen Rathenau, und auch er konnte den Sinn des Attentats nicht mit der Person des Opfers legitimieren, sondern nur mit „einem seelischen Zwang“, unter dem Kern und Fischer angeblich gehandelt hätten. Nicht weniger wehrten sich die Gebrüder Techow gegen die Zuschreibung antisemitischer Tatmotive. Hans-Gerd versicherte 1928, das Attentat sei weder allein aus „fanatischem Antisemitismus" geboren, noch habe es lediglich der Person des Außenministers selbst gegolten. „Der Stoß wurde gegen das System geführt, das in ihm seine Verkörperung fand. Rathenau war also durchaus eine sekundäre Erscheinung. " 20 Was sich hinter dieser vagen Andeutung verbarg, mochte er allerdings ebensowenig aufdecken wie sechs Jahre darauf sein Bruder Ernst Werner in seiner Rechtfertigungsschrift „Gemeiner Mörder?!“, die der Persönlichkeit Rathenaus ein ganzes Kapitel widmet. Was der Mörder seinem Feind vorzuwerfen hat, ist wenig genug: Rathenau habe „sich den Stuhl Bismarcks angemaßt“, heißt es schon im Vorwort, und er gilt Techow als der Mann, „der die Drähte des Marionettenspiels in der Hand hielt". Die weiteren Ausführungen lesen sich wie ein Nachruf, der das Wesen des Toten zu ergründen versucht, nicht aber seine Vernichtung zu legitimieren unternimmt. „Zwiespältig in seinem Wesen“ war Rathenau für'Techow, hin- und hergerissen zwischen „Blut und Staatsangehörigkeit“, daneben ein wandlungsfähiger Geldmensch, der den "plutokratischen Sozialismus" schaffen wollte und zu dessen Triebfedern besonders die Eitelkeit zählte. Ein mögliches Mordmotiv ist in diesen Einlassungen, die auf die Erfüllungspolitik gar nicht und auf die jüdische Herkunft Rathenaus nur beiläufig Bezug nehmen, auch nicht in Umrissen zu erkennen. Konsequent orientiert Techow seine Leser über Rathenaus Ende aus der Sicht eines Unbeteiligten: „Eitelkeit und Machtstreben sind Rathenau zum Verderben geworden. “21

17 Ebenda, S. 131.

${ }^{18}$ NL von Salomon, Ernst von Salomon, Wikinger. Gestalten und Wege zum völkischen Aufstieg, MS 1923/24 (Hervorhebungen im Orig.).

19 Nation, S. 138.

20 Minister Rathenaus Ende, 22. 10. 1928.

21 E. W. Techow, „Gemeiner Mörder?!“, S. 3 f., 20 ff. 
Nimmt man die Tatsache dazu, daß weder Erzberger noch Scheidemann Juden waren und dennoch unter Mitwirkung derselben Täterkreise überfallen wurden, verdient die Annahme, Judenhaß sei der treibende Beweggrund des Anschlags auf Rathenau gewesen, erhebliche Zweifel. Zumindest einige der Attentäter teilten den fanatischen $\mathrm{Haß}$ auf den Juden und Erfüllungspolitiker Rathenau nur eingeschränkt oder wollten ihn jedenfalls nicht als Triebfeder ihrer Tat gelten lassen. Offenbar hatte ihre Beteiligung an dem Verbrechen Gründe, die mit den individuellen Motiven der einzelnen Teilnehmer keineswegs identisch waren und die Salomon im „Fragebogen“ seinen früheren Komplizen Plaas so andeuten läßt: „Ich glaube, man muß da zwei Dinge auseinanderhalten. Einmal den Plan, das Konzept, in dem die Sache beschlossen war - und dann die persönlichen Motive, welche die Einzelnen bewogen, an der Tat teilzunehmen. " ${ }^{22}$ Um diese persönlichen Beweggründe zu entschlüsseln, ist ein Blick auf den überraschend einheitlichen sozialen Hintergrund hilfreich, der die Tatbeteiligten überhaupt erst zu der paramilitärischen Schattenwelt der O.C. mit ihrem Ehrenkodex und ihrer absoluten Gehorsamsverpflichtung finden ließ. Daß „Söhne fundierten Bürgertumes“, „aus guter Familie", ganze Mordserien besprachen, wie sich Salomon rückblickend selbst wunder$\mathrm{te}^{23}$, ist nicht zu denken ohne den gesellschaftlichen Statusverlust dieser Bürgersöhne nach dem verlorenen Krieg, aus dem sie entwurzelt und ohne greifbare Zukunftsaussicht zurückkehrten. Rathenau selbst hatte nach der Ermordung Erzbergers den Nährboden des politischen Terrorismus so hellsichtig beschrieben, daß Oberreichsanwalt Ebermayer ihn in seinem Plädoyer vor dem Staatsgerichtshof 1922 nur zu zitieren brauchte: „Rathenau hat sich unter anderem dahin geäußert, daß der sterbende Mittelstand das gefährlichste Gift im Organismus unseres Staates sei. Die Beamten, Offiziere und Kleinrentner könnten mit ihrem Einkommen nicht mehr leben und fielen dem Elend anheim. Ihre Söhne aber, die konservativ erzogen worden seien, würden dann rechtsradikale Reaktionäre der Tat. “24 Die Biographien der Täter lesen sich wie Schulbeispiele dieser prophetischen Diagnose: Kern und Fischer hatten wie viele andere aus dem Verschwörerkreis den Weltkrieg als Offiziere mitgemacht und sich danach im Zivilleben nicht mehr einzurichten gewußt. Kern wurde 1921 aus der Marine entlassen; sein Komplice Fischer ließ sich zur Verschwörung gegen Rathenau mit der Begründung anwerben, ihm liege nichts mehr am Leben ${ }^{25}$. Willi Günther stellte sich vor dem Staatsgerichtshof selbst als verbummelten Studenten hin, der im Krieg wegen Fahnenflucht und nach seinem Ende wegen Unterschlagung straffällig geworden war; der 22jährige Waldemar Niedrig war erst Melker, dann Privatdetektiv und hatte beide Berufe aufgegeben, um 1921 zum Oberschlesischen Selbstschutz zu gehen. Christian Ilsemann war erst im Frühjahr 1922 nach Deutschland zurückgekommen, nachdem sein Versuch gescheitert war, in Mexiko eine Existenz aufzubauen; Ernst von Salomon hatte nach seiner Entlassung aus der Kadettenanstalt Berlin-Lichterfelde und wechselnden militärischen Engagements im Baltikum und beim Oberschlesischen Selbstschutz überhaupt keinen bürgerlichen Beruf erlernt. Karl Tillessen erklärte auf Befragen, daß er sich nach seiner Entlassung aus der Marine als Kapitänleutnant mit privaten Sprachstudien auf einen kaufmännischen Beruf im Ausland vorbereitet, aber trotz langen Wartens nichts Geeignetes gefunden habe ${ }^{26}$. Der ältere Techow schließlich war nach dem Zeugnis einer Bekannten seit seiner Entlassung aus der Marine im November 1919 und einigen Freikorpseinsätzen völlig verbittert, da er als Fähnrich seine Existenz schwinden sah und das Schicksal seines ältesten Bruders vor Augen hatte, der sein

\author{
22 Fragebogen, S. 129. \\ ${ }^{23}$ Ebenda, S. 133. \\ ${ }^{24}$ Zit. nach Berliner Tageblatt vom 12. 10. 1922, Morgen-Ausgabe. \\ 25 BA, NS 26/1236, Gisela Kern, Lebenslauf Erwin Kern. \\ ${ }^{26}$ Alle Angaben nach nach: SAM, 772-2-194, Rathenau-Prozeß, 2. Verhandlungstag, S. 93 ff.
}


Vermögen in einem Zeitungsunternehmen verloren habe ${ }^{27}$. Keiner der jugendlichen Täter war älter als 25 Jahre, sämtlich stammten sie aus gutbürgerlichen Familien. Unter ihren Vätern waren Universitätsprofessoren, höhere Beamte und ein General, und sie alle einte das Bewußtsein, in Rathenau einen Mann zu töten, der als Jude wie als Politiker für ihre wirtschaftliche Not und soziale Deklassierung persönlich haftbar gemacht werden konnte.

Unabhängig aber von der persönlichen Verbitterung jedes einzelnen war nach den Worten von Plaas in Salomons „Fragebogen“ das größere „Konzept“, die gemeinsame Strategie, in die der Mordanschlag eingebettet war. Eine Andeutung über das Motiv der Gesamtplanung findet sich schon in den „Geächteten “. Dort läßt Salomon Kern sagen, daß er es nicht ertragen könne, „wenn aus dem zerbröckelnden, aus dem verruchten Bestande dieser Zeit noch einmal Größe wüchse“. Die Beseitigung des Außenministers wird in dieser Sicht zu einer Auseinandersetzung zwischen zwei möglichen Lebensformen der Nation. Rathenau repräsentiert dic überkommene Zeit, die in den Augen der Nationalisten mit den Begriffen Westen, Kompromiß, Materialismus gekennzeichnetc Existenzweise. Sie muß zerstört werden, um dic neue Nation zu schaffen, die Salomon „Sieg der Deutschheit über die Erde“ und „Erfüllung unsres deutschen Schicksals" nennt, und ihre Vorkämpfer sind dic Nationalrevolutionäre der O.C.: „Wir fechten nicht, damit das Volk glücklich werde. Wir fechten, um es in seine Schicksalslinie zu zwingen." In diesem Kampf wollten Salomon zufolge Kern und seine Gefolgsleute die erste Bresche schlagen, den Anstoß geben und so eine unaufhaltsamc Revolution auslösen. Vor Rathenau seien Politiker ausgeschaltet worden, die das alte System nur verkörperten: „Schlag auf Schlag fielen die Exponenten der Haltung, dic es um jeden Preis zu vernichten gilt." Jetzt gehe cs darum, mit Rathenau auch jede Hoffnung zu zerstören, daß dieses überlebte System zu neuer Kraft erwachsen könne: „Das Blut dieses Mannes soll unversöhnlich trennen, was auf ewig getrennt werden muß." 28 In der geschichtswissenschaftlichen Literatur ist dies als Versuch gewertet worden, „die völlige Sinnlosigkeit der Tat in einen höheren Sinn um[zudeuten] “29. Diese Kritik wcist mit Grund das Bemühen der Attentäter zurück, ihr Verbrechen als legitime Auseinandersetzung zwischen zwei gleichwertigen Positionen moralisch zu rechtfertigen. Sie ist gleichzeitig fragwürdig, sofern sie die subjektive Einschätzung der Attentäter negiert, durch ihre Tat einen politischen Erdrutsch auszulösen. Denn in dieser - individuell variierten - Auffassung begegnen sich die veröffentlichten Schilderungen aller Mittäter, die nach 1922 zur Feder griffen. Aus dem Abstand von dreißig Jahren fand Salomon deutlichere Worte, um das doppelte Motiv der Mörder zu umreißen: Einmal erhofften die O.C.-Aktivisten, „daß jedes einzelne Attentat zumindest, die Entwicklung weiter tricb“, daß cs, Fanale‘ seicn, Anzeichen einer wirklichen, bedrohlichen Verzweiflung, die den Erfüllungspolitikern die ungeheure Verantwortlichkeit ihres Weges und dessen Folgen zcigen sollten“, zum andcren stellten die geplanten und die ausgeführten Morde nur Mittel dar, um eine viel grundsätzlichere Wendung auszulösen: die „nationale Revolution “ 30 .

${ }^{27}$ BA, NL 150, 10, Beiakten, H. 2, Aussage Christina Erkens; vgl. E. W. Techow, „Gemeiner Mörder?!“, S. $14 \mathrm{ff}$.

${ }^{28}$ Salomon, Die Geächteten, S. 344 f., 351 und 357.

${ }^{29}$ Krüger, Brigade Ehrhardt, S. 93. Auch andere Autoren charakterisieren die Beweggründe der Mörder Rathenaus als Ausfluß „dürrer, halbgarer, verblasener ,Grundsätze“" (Berglar, Walther Rathenau, S. 20) und als "verworrenes Geschwätz" (Plat, Attentate, S. 205), das in Lichte der Memoiren Salomons den "Eindruck der gcistigen Verworrenheit“ (Hannover/Hannover-Drück, Politische Justiz, S. 121) nur verstärkt. Eine psychoanalytische Deutung versucht Theweleit; sie ist allerdings schon im sorglosen Umgang mit den Tatsachen problematisch (Männerphantasien, Bd. 1, S. 29).

${ }^{30}$ Fragebogen, S. 130. 
Daß das übergeordnete gemeinsame Motiv in der Hoffnung lag, mit dem Terroranschlag die politische Ordnung von Weimar zu sprengen, spricht auch Techow an: „Der Stoß gegen Rathenau mußte das System ins Herz treffen." 31 Offener noch gibt Heinz Einblick in die Strategie der O.C., wenn er Salomon im Zusammenhang mit den Anschlägen auf Scheidemann und Rathenau folgende Äußerung zuschreibt: „Wir dürfen nicht zuerst losschlagen. Die Kommunisten müssen es tun! [...] Man muß sie dazu zwingen! [...] Man muß Scheidemann, Rathenau, Zeigner, Lipinski, Cohn, Ebert und die ganzen Novembermänner hintereinander killen. Dann wollen wir doch mal sehen, ob sie nicht hochgehen in Korona, die rote Armee, die U.S.P., die K.P.D. “32 In einer späteren Darstellung verdeutlicht Heinz die taktische Funktion, der auch der Rathenaumord dienen sollte: Es handle sich um „die macchiavellistische Utopie [...], durch Rathenaus Tod die Kommunisten zum Losschlagen bewegen zu wollen, damit im Gegenschlag der schnell aufgestellten Freikorps Ehrhardt die Macht an sich reißen und die Diktatur verhängen könne “33. Kein anderer O.C.-Mann hat je öffentlich so ungeschminkt das politische Kalkül benannt, mit dem Ehrhardt das Attentat auf Rathenau für seine politischen Absichten auszunutzen hoffte. Daß dieses ungeschminkte Eingeständnis auch zehn Jahre nach den Ereignissen noch an ein sorgfältig gehütetes Arcanum rührte, gibt Heinz selbst zu erkennen, wenn er im weiteren die aus seiner Darlegung abzuleitende Verantwortung Ehrhardts als Drahtzieher der Mordanschläge zur bloßen Utopie seines Gefolgsmannes Kern abzuschwächen versucht.

Unzweifelhaft war es die auf den Umsturz der Verfassung zielende Provokationsstrategie des Ehrhardt-Bundes, die Salomon im „Fragebogen“ als das „größere Konzept“ andeutete, und mit der heimlichen Berufung auf den höheren politischen Zweck, dessen Erreichung den Mord geadelt hätte, versuchte er seiner Selbstverurteilung als gemeiner Mörder zu entgehen: "Als ich verhaftet wurde, ging ich in das Gerichtsverfahren mit der Gewißheit, daß alles, was wir uns mit den Attentaten vorgenommen hatten, völlig gescheitert sei. Das war vielleicht das Bitterste. Im Verfahren konnte ich natürlich darüber nichts aussagen. " ${ }^{34}$ Auch Techow hatte aus der Untersuchungshaft seiner Mutter in einem von der Polizei abgefangenen Brief versichert, „daß ich niemals meine Hand zu einer derartigen Tat gereicht und mich dazu zur Verfügung gestellt hätte, wenn ich nicht des unerschütterlichen Glaubens gewesen wäre, daß durch diese Tat oder vielmebr durch ibre politischen Folgen eine Besserung der Zustände unseres Vaterlandes herbeigeführt werden könnte. Daß die Wirklichkeit der Voraussetzung nicht entspricht, dauert mich. Mein Opfer ist dadurch illusorisch geworden. "35 Was er damit meinte, verriet Techow in diesem Brief nicht. Aber es wurde deutlich aus einem Satz, mit dem ihn der über den Anschlag entsetzte Garagenbesitzer Richard Schütt zitierte: „Sie hätten das nicht zum Vergnügen getan; sie hätten es aber tun müssen, um die rote Armee zum Angriff zu reizen. “36

In seiner Vernehmung vor dem Leipziger Staatsgerichtshof erläuterte Techow das hinter dieser Formulierung stehende politische Programm: „Beim Essen in der Technischen Hochschule hatte mir Kern seine Pläne entwickelt und mir erzählt, wie er politisch denke. [...] Er war vollkommen national gesinnt und überzeugt, daß Deutschland nur [...] durch eine nationaldenkende Regierung wieder in die Höhe kommen könnte. [...] Er sagte dabei, daß seiner Meinung nach [...] nur möglich wäre, diesen Zustand zu erreichen, indem man in

${ }^{31}$ Techow, „Gemeiner Mörder?!“, S. 24.

${ }^{32}$ Heinz, Sprengstoff, S. 76.

${ }^{33}$ Heinz, Nation, S. 139.

${ }^{34}$ Fragebogen, S. 132.

${ }^{35}$ SAM, 567-1-2593, E. W. Techow an G. Techow, 5. 7. 1922 (Hervorhebung d. Verf.)

${ }^{36}$ Ebenda, 567-1-2642, Aussage Schütt, 3. 7. 1922; vgl. Gumbel, Verschwörer, S. 78. 
irgendeiner Form einen inneren Krieg und durch diesen eine Klärung zwischen den Linksparteien und rechts auf gewaltsamem Wege herbeiführt, und zwar sollte dies gewissermaßen eine Machtprobe gegen die rote Armee sein. Er sagte, daß das natürlich seiner Meinung nach nicht auf gesetzlichem Wege erreicht werden könnte, sondern es bedürfe dazu eines gewaltsamen Anstoßes, und zwar müßte das die Beseitigung eines politisch linksstehenden Führers sein. “37 Daß Techow die Ideen Kerns richtig wiedergab, bestätigte Günther: „Die [...] Mörder Rathenaus haben mir [...] in den Tagen vor dem 24. 6. mehrfach auseinandergesetzt, daß die Linksparteien provoziert werden müßten, so daß die Rechtsstehenden Grund zum Losschlagen hätten. Eine solche Provokation werde wohl die Ermordung Rathenaus bieten. Die beiden Täter nahmen an, daß mit dem Fortfall der Hauptstütze des Kabinetts Wirth zunächst radikal linksgerichtete Elemente die Regierung an sich reißen würden und daß dieser Zustand, der voraussichtlich nur von kurzer Dauer hätte scin können, die Schaffung einer rechtsgerichteten Regierung ausgelöst hätte. ${ }^{" 38}$ Ebenso behauptete Karl Tillessen, daß Kern „mir nunmehr seine Idee dahin [enthüllte], es müsse eine Rechtsregierung kommen. Zu dem Zwecke müsse Rathenau beseitigt werden, der sämtliche Fäden in der Hand habe und dessen Sturz daher den Sturz der gesamten Regierung nach sich ziehen würde. [...] Der Anschlag müsse zur Folge haben, dic Linksradikalen zu einer Aktion zu veranlassen, die sie viclleicht [...] vorübergehend noch zur Regierung brächte. Dann würde als Reaktion dagegen eine Rechtsregierung folgen. " 39

Freilich fühlten sich dieser Strategie nicht allein Kern und Fischer verpflichtet, wie Tillessen glauben machen wollte. Er selbst hatte Ende April 1922 den neu angeworbenen Theodor Brüdigam gleich beim ersten Treffen mit dem Grundgedanken seiner politischen Überzeugung vertraut gemacht, „eine Änderung der Verhältnisse sci nur zu erreichen, wenn man die Arbeiterschaft provoziere "40. Eine präzisere Auskunft wollte Brüdigam dann in der Münchener O.C.-Zentrale von Hoffmann erhalten haben, der Brüdigam aufgrund der Empfehlung Tillessens volles Vertrauen schenkte. Ehrhardts Stellvertreter offenbarte unverblümt, daß Rathenau, Scheidemann, Hellmut von Gerlach und andere ermordet werden müßten, „um möglicherweise cinen Umsturz von links hervorzurufen, damit es Hoffmann - sagen wir besser - der Organisation C möglich wäre, ihrerseits dann die Militärdiktatur zu errichten " ${ }^{41}$. Die Tragweite dieses terroristischen Konzepts hat Brüdigam selbst gar nicht voll erfaßt. Sonst hätte ihm klarwerden müssen, daß sein späterer Versuch, Tillessen die Sinnlosigkeit eines Attentats auf Rathenau klarzumachen, den Frankfurter O.C.-Funktionär gerade umgekehrt in diesem Vorhaben bestärken mußte. „Ich warnte Tillessen [...], indem ich [...] sagte, daß bei einer evtl. Ermordung Rathenaus genau das Gegenteil von dem erreicht werden würde, was er und scine Leute erstrebten. Die gesamten Linksparteien einschließlich der Demokraten würden sich zusammenschließen, der Generalstreik würde einsetzen, und man würde zu den schärfsten Abwehrmaßnahmen greifen." Natürlich war Brüdigam auch als vermeintlich intimer Kenner der Arbeiterparteien eine viel zu unbedeutende Figur, um die putschistische Strategie der O.C. zu beeinflussen. Dennoch wurde seine Skcpsis von den Frankfurter Erhardt-Leuten als willkommene Bestätigung ihrer Auffassungen verstanden, wie Brüdigam unwissentlich selbst überlieferte: „Tillessen entgegnete, daß der Generalstreik diesmal klappen wird, davon bin ich selber überzeugt. “42

37 SAM, 772-2-194, Rathenau-Prozeß, 2. Verhandlungstag, S. 49 f.

${ }^{38}$ Ebenda, 567-1-2570, Aussage Günther, 3. 7. 1922.

39 BA, NL 150, 10, Beiakten, H. 18, Aussage K. Tillessen, 2. 8. 1922.

${ }^{40}$ PA/AA, Rathenau-Prozeß, 7. Verhandlungstag, Aussage Brüdigam, S. 112.

41 Ebenda, Aussage Brüdigam, S. 115 f.

42 SAM, 567-1-2621, Aussage Brüdigam, 5. 7. 1922. 
Nach all diesen Zeugnissen ging das Urteil gegen die Mörder des Reichsaußenministers fehl, als es die Beweggründe der Täter auf ihren Haß gegen die Person Rathenaus einengte. So virulent die Ablehnung Rathenaus bei den einzelnen Mitgliedern der Verschwörergruppe sein mochte, war sie doch nur sekundär gegenüber dem sehr viel weitergreifenden Ziel der Zerschlagung der Weimarer Staatsordnung. Anders als das Gericht hatte der Oberreichsanwalt die Unterschiedlichkeit der hinter dem Attentat stehenden Motivstränge durchaus erkannt. Er hiclt es für erwiesen, daß die Mörder Rathenaus „das Verbrechen aus fanatischem Antisemitismus und in dem Wahne begangen haben, sie könnten durch gewaltsame Beseitigung eines hervorragenden Mitglieds der Regierung, deren Politik ihnen verhängnisvoll erschien, eine Erhebung der Arbeiterschaft und nach deren [...] Niederwerfung die Einsetzung einer rechtsradikalen Regicrung herbeiführen "43. Seiner Argumentation konnten die Richter aber schon deshalb nicht folgen, weil dann die ganze Prozeßstrategie obsolet geworden wäre. Denn ein Tatmotiv zu akzeptieren, das das zur Verhandlung stehende Verbrechen als Anstoß zu einem grundlegenden politischen Machtwechsel begriff, hätte bedeutet, nach der politischen oder militärischen Gruppierung zu fragen, in deren Interesse - und womöglich Auftrag - die Mörder Rathenaus ihre Terroranschläge verübt hatten.

\section{Die neuformierte Organisation „Consul“}

Sosehr sich dic Vermutung aufdrängt, daß sowohl das Scheidemann- wie das RathenauAttentat von der Organisation "Consul" ausgegangen war, so unvereinbar ist sie mit der in der Forschungsliteratur vielfach übernommenen Auskunft aller verantwortlichen EhrhardtLeute, daß die O.C. zum Zeitpunkt beider Anschläge schon ein Dreivierteljahr lang gar nicht mehr bestanden habe ${ }^{1}$. Unbeirrt beharrten die O.C.-Funktionäre, an ihrer Spitze Ehrhardts damaliger Stellvertreter Hoffmann, auf der Auffassung, daß ihr Verband infolge der Verhaftungswelle nach dem Erzbergermord bereits im September 1921 zerschlagen gewesen sci, folglich als Organisation für Putschpläne und Verbrechen gar nicht verantwortlich sein könne ${ }^{2}$. Auch Ehrhardt selbst stellte nach dem Erzbergermord in ciner Presseerklärung nachdrücklich in Abrede, noch irgendwelche putschistische Gedanken zu hegen. Allerdings ist schon der Wortlaut dieser Erklärung bei näherem Zusehen durchaus nicht eindeutig, denn Ehrhardt wollte aus dem kläglich gescheiterten Märzputsch 1920 nur die Lehre gezogen haben, sich nicht "nochmals an einem solchen unvorbereiteten, planlosen Unternehmen “ $z u$ bcteiligen. Definitiv versicherte Ehrhardt nur, nichts zu unternehmen, was dem Land und seinem Volk schaden könnte, und beurteilte die Frage im übrigen taktisch: „Ich sehe ganz klar, daß cin neuer Putsch zum Scheitern verurteilt ist. Das Bürgertum ist zerrissener und uneinheitlicher denn je. Die Machtmittel des Staates sind im Vergleich zum März 1920 erheblich gefestigter. Die Führer denken nicht daran, ihr sicheres Brot zu riskieren. " ${ }^{3}$ Welche Haltung er allerdings einnehmen wollte, wenn das innenpolitische Klima günstiger wäre, teilte cr nicht mit.

Wie wenig auf diese Absage Ehrhardts an alle Putschgedanken zu bauen war, erhellen dic zeitgleichen Tagebucheintragungen seines Gefolgsmannes Hartmut Plaas: „Im Deutschen Tageblatt lesen wir eine Erklärung Ehrhardts, die uns nicht gefallen will. Wie ist sie

${ }^{43}$ BA/P, 30.03-5053/1, Anklageschrift E. W. Techow u. Gen.

${ }^{1}$ So z. B. Winkler, Weimar 1918-1933, S. 174.

${ }^{2}$ Vgl. z. B. BA, NL 150, 113, Der „Norddeutsche Bund“ (Richtlinien); NA T 253/14/3, Aussage Hoffmann, 5. 8. 1922.

${ }^{3}$ Deutsche Allgemeine Zeitung vom 4. 10. 1921, Abend-Ausgabe. 
zustandegekommen, und was soll damit bewirkt werden? Müssen nicht alle knarschen Kerle einen Schrecken davon bekommen? Wohl ein Schachzug, den wir hier draußen nicht beurteilen können. [...] War es nicht besser, einfach zu schweigen?" Interessanterweise erwähnte Plaas mit keinem Wort die Möglichkeit, daß die Erklärung Ehrhardts ernst gemeint sein könnte, und er fand sich einige Tage später durch eine interne Information bestätigt, nach der „Ehrhardt [...] wirklich der Verfasser der Erklärung sein [soll], zu der er anscheinend von anderer polit. Seite gedrängt ist“" . Nachdem kurz darauf gegen ihn ein weiterer Haftbefehl wegen Verdachts der Beteiligung an der Ermordung Erzbergers erlassen war, trug Ehrhardt schließlich der Irritation in seinen Reihen mit einer neuerlichen Presseerklärung Rechnung, in der er in scharfen Worten die Forderung, sich zu stellen, zurückwies und ankündigte, sich „jedem Versuch, meiner auf andere Weise habhaft zu werden, mit den mir zu Gebote stehenden Mitteln [zu] widersetzen "5. Daß die neue Sprache des Kapitäns jedenfalls die in der O.C. aufgetretene Unsicherheit beseitigte, erhellt wiederum aus Plaas' Tagebucheintragungen: „Es steht eine knarsche Erklärung Ehrhardts in den Blättern [...]. Das ist er selber, uns ist ein Alp von der Seele." 6

Doch nicht nur ihr Leiter, auch die vermeintlich zerschlagene O.C. hatte neuen Tritt gefaßt. Gleich nach ihrer Aufdeckung im Herbst 1921 waren Schritte zur Reorganisation des Ehrhardt-Bundes eingeleitet worden, die sich über mehrere Monate hinzogen, aber auch weitreichende Vorkehrungen einschlossen, um einem neucn Schlag durch die staatlichen Behörden vorzubeugen. Die wohl wichtigste Maßnahme bestand in der oganisatorischen Verselbständigung zweier weitgehend getrennt voneinander cxistierender Gliederungen innerhalb der O.C., von denen eine als legaler Verein mit ordentlichem Statut bestand, während die andere Abteilung um so diskreter im geheimen operierte. In Verfolgung der erstgenannten Absicht wurde am 24. April 1922 in München von Alfred Hoffmann, gegen den immer noch bei der Offenburger Staatsanwaltschaft das Geheimbündelei-Verfahren schwebte, ein Ncudeutscher Bund ins Leben gerufen ${ }^{7}$, den Karl Tillessen und Hartmut Plaas in ihren späteren Aussagen als den eigentlichen Nachfolger der angeblich zerschlagenen O.C. hinstellten ${ }^{8}$. Im Rathenaumord-Prozeß nutzte Tillessen den Neudeutschen Bund als Eckpfeiler seiner Entlastungsstratcgie, indem er jede Verbindung zur O.C. in Abrede stellte, statt dessen aber einen Landesverband des Neudeutschen Bundes in Frankfurt mit eigener Geschäftsstelle geleitet haben wollte, der unter anderem Nachrichten aus linksradikalen Kreisen gesammelt und zur weiteren Auswertung an die Bundeszentrale gesandt habe. Der Neudeutsche Bund in München werde - so Tillessen - von seinem Gründer Alfred Hoffmann geleitet, und sein politisches Ziel sei die Zusammenfassung anderer Verbände ${ }^{9}$. Die Bundesstatuten deckten diese Behauptung, denn "Zweck des Vercins ist: Zusammenschluß aller Nationalgesinnten aller Volksschichten mit dem Ziel: ,Einigkeit und Recht und Freiheit für das deutsche Vaterland" und Werbetätigkeit dafür in Wort und Schrift “10. „Jeder anständige

${ }^{4}$ NL Plaas, Tagebuch, Einträge vom 5. und 10. 10. 1921.

${ }^{5}$ Münchner Neueste Nachrichten vom 31. 10. 1921.

6 NL Plaas, Tagebuch, Eintrag vom 31. 10. 1921.

${ }^{7}$ Das Gründungsdatum geht aus cinem Werbeaufruf des Bundes hervor (BA, NL 150, 113). Der entsprechende Beschluß soll von Ehrhardt und Hoffmann allerdings bereits im Januar/Februar 1922 gefaßt worden sein; NA, T 253/14/3, Aussage Hoffmann, 5. 8. 1923.

${ }^{8}$ SAM, 567-1-2588, Aussage Plaas, 8. 7. 1922, und Aussage K. Tillessen, 3. 7. 1922. Zum Neudeutschen Bund finden sich in der Literatur nur verstreute und vorwiegend unrichtige Angaben; vgl. Gumbel,

Verschwörer, S. 116; Krüger, Brigade Ehrhardt, S. 98.

9 SAM, 567-1-2588, Aussage K. Tillessen, 3. und 5. 7. 1922.

10 BA, NL 150, 113, Satzungen des Neudeutschen Bundes. 
Deutsche" konnte gegen einen Mitgliedsbeitrag von 2 Mark monatlich dem Bund beitreten, der den gesetzlichen Bestimmungen entsprechend über Vorsitzenden, Kassenwart und Schriftführer verfügte, reichsweit in Gaue gegliedert und durch ehrenamtliche Gauleiter geführt werden sollte, denen eine Aufwandsentschädigung zustand.

Doch beschränkte der Bund seine satzungsgerechte Tätigkeit auf die bloße Absichtserklärung, „den Zusammenschluß aller nationalen Verbände, die bis dahin selbständig gewirkt oder sich sogar gegenseitig bekämpft hatten", zu erstreben ${ }^{11}$. Mit Ausnahme eines vom Vorstand des Neudeutschen Bundes unterzeichneten Aufrufs zur Werbung von Gau- und Ortsgruppenleitern entfaltete er nicht die geringsten Aktivitäten, die auf die Verfolgung der Vereinsziele schließen ließen ${ }^{12}$. Nach seiner Gründung trat er praktisch nicht mehr in Erscheinung und wurde im darauffolgenden Jahr auch äußerlich durch die Gründung einer weiteren Nachfolgeorganisation, den Wikingbund, abgelöst. Welchen Zweck der mysteriöse Bund in Wirklichkeit verfolgte, läßt sich aus dem Aussageverhalten der Ehrhardt-Offiziere herauslesen, die nach den Attentaten auf Scheidemann und Rathenau abermals in den Verdacht hochverräterischer Geheimbündelei gerieten. Wie die nachgelassenen Papiere des für die O.C. als eine Art Hausjurist tätigen Strafverteidigers Walter Luetgebrune belegen, hatten Ehrhardt und Hoffmann eine detaillierte Gründungslegende des Bundes fingiert, um die Verfassungstreue ihrer Mitglieder unter Beweis zu stellen. Hiernach hätten Ehrhardt und Hoffmann sich Ende Januar 1922 darüber verständigt, daß ,jeglicher Versuch, in ähnlicher Weise wie in der O.C. im Interesse des Vaterlandes zu arbeiten, unzweckmäßig, wenn nicht überhaupt unmöglich wäre, denn es würde wiederum [...] jegliche solche Arbeit als [...] Fortsetzung der O.C. angesprochen“. Daher sollte ein Bund gegründet werden, „der äußerlich und innerlich so grundverschieden von der früheren O.C. wäre, daß man außer Personenzusammenhänge mit der früheren O.C. keine weiteren konstruieren könnte“. So sei die Neugründung auch nicht als Schöpfung Ehrhardts anzusehen, sondern werde durch ihren alleinigen Gründer Hoffmann geleitet. Der Bund, der sich allerdings an alle früheren O.C.Mitglieder wende und auch „im übrigen die Beziehungen der O.C. ausgenutzt“ habe, hebe sich von der O.C. in einem weiteren, entscheidenden Aspekt ab: Er wolle kein militärischer Verband sein, sondern habe sich statt dessen einen geheimen Nachrichtendienst geschaffen ${ }^{13}$.

Die so umrissene Marschrichtung, die Ehrhardt ganz aus dem Schußfeld nahm und den Vorwurf der Geheimbündelei von vornherein gegenstandslos machen sollte, konnte nur zum Ziel führen, wenn ihr alle Betroffenen folgten. Doch während sich Hoffmann in seinen richterlichen Vernehmungen strikt an die „Richtlinien“ hielt ${ }^{14}$, war es ausgerechnet der flüchtige Ehrhardt selbst, der im Juli 1922 in einer Presseerklärung aus Wien verlauten ließ, daß der Neudeutsche Bund Rechtsnachfolger der O.C. und er selbst sein Leiter sei ${ }^{15}$. Den dadurch angerichteten Schaden suchte er dann durch ein eiliges Dementi zu begrenzen, das er - diesmal aus Salzburg - an die Presse wie an den Leipziger Untersuchungsrichter sandte, um die „Mißverständnisse zu zerstreuen, weil sie vielleicht Ankläger um jeden Preis zu Versuchen führen könnten, daraus den Opfern der gewissenlosen Hetze gegen die ehemalige Organisation C einen Strick zu drehen "16. In ihrer gewundenen Argumentation illustriert diese Erklärung eindrucksvoll Ehrhardts Mühe, die mit Hoffmann vereinbarte Sprachrege-

11 SAM, 567-1-2588, Aussage Plaas, 8. 7. 1922.

12 BA, NL 150, 113. Die Münchener Post bezweifelte daraufhin schon im Juli 1923, daß der Neudeutsche Bund mehr sei als eine Scheingründung (4. 7. 1923).

13 BA, NL 150, 113, Der „Neudeutsche Bund“ (Richtlinien).

${ }^{14}$ NA, T 253/14/3, Aussage Hoffmann, 5. 8. 1922.

15 Kieler Neueste Nachrichten vom 20. 7. 1922.

16 SAM, 567-2-17788, Erhardt an Untersuchungsrichter Alken, 12. 8. 1922. 
lung einzuhalten, ohne seine eigenen Äußerungen Lügen zu strafen: „Es ist selbstverständlich, daß die Wendung, ich hätte die Leitung des Neudeutschen Bundes, nur eine kurze bildliche Wendung darstellt, dic in knapper Form zum Ausdruck bringen sollte, daß die Führer des Neudeutschen Bundes [...] diesen Bund so führen, wie es nach ihrer Überzeugung meinem Denken, Wollen und Empfinden entspricht. [...] Daß der [...] Ausdruck ,Rechtsnachfolger' nur einen lapsus linguae darstellt, müßte für jeden denkenden Leser von vornherein klar sein. Ich glaube nicht, daß irgendein zu objektivem Urteil Entschlossener daraus ungünstige Schlüsse über den Neudeutschen Bund oder seine Mitglieder ziehen wird. Die Organisation C brach im September vorigen Jahres auseinander und konnte so, wie sie gewesen war, nicht wieder entstehen, wenn man sie nicht leichtsinnig gefährden wollte. "17 Mit diesem letzten Satz seines Dementis enthüllte Ehrhardt die Funktion des neugegründeten Vereins unfreiwillig doch.

Der Neudeutsche Bund hatte allerdings nicht nur die Aufgabe, den Angehörigen der bisherigen O.C. ein legales Alibi zu verschaffen; er tarnte daneben in seinem betont harmlosen und offenen Äußeren eine politische Arbeit, die das Licht der Öffentlichkeit weitaus weniger suchte. Denn die neuformierte O.C. verstand sich in der Tat auch als Sammelstelle für Nachrichten aus dem Lager linksstehender Gegner und entwickelte auf diesem Gebiet erhebliche Anstrengungen, die ihr nicht nur wertvolle Informationen über die politische Lage, sondern vor allem den erwünschten engeren Kontakt zur Reichswehr einbrachten, der sich Ehrhardts Bund als Partner andienen wollte. Von der Öffentlichkeit kaum bemerkt, fiel während des Rathenaumord-Prozesses ein klcines Licht auf diese Spionagearbeit, als Karl Tillessen zugab, daß er Theodor Brüdigam als Spitzel geworben habe, um dic von ihm erhofften Erkenntnisse über Linksparteien an eine Nachrichtenstelle des Leutnants Friedrich Wilhelm Heinz in Kassel weiterzuleiten ${ }^{18}$. Daß Heinz nicht etwa auf eigene Rechnung, sondern im Auftrag der O.C. tätig war, ließ sich wiederum aus der Instruktion entnehmen, mit der Alfred Hoffmann den ihm von Tillessen geschickten Brüdigam in München in seine neue Arbeit einführte: „Meinen Einwurf, daß dies wohl die Organisation C (d. h. Konsul) sei, bejahte er mit dem Hinzufügen, daß sich diese Organisation in verschiedene Unterabteilungen gliedere. Meine Aufgabe umriß er [...] dahingehend, daß ich in scinem Bezirke, d. h. in Bayern, die politischen Strömungen innerhalb der Linksparteien beobachten und das Ergebnis einem Vertrauten von ihm, einem ehemaligen Offizier [...], überbringen sollte, der in München unter der Maske eines Detektivinstituts die Nachrichtenabteilung der Organisation darstellt. “19

Was Hoffmann und seine Mitarbeiter nach der vermeintlichen Zerschlagung der O.C. im September 1921 in aller Stille aufgebaut hatten, war nicht weniger als ein nationaler Nachrichtendienst, der mit Hilfe regionaler Agenturen wie der von Friedrich Wilhelm Heinz in Hessen einen solchen Umfang annahm, daß Salomon nach dem Zweiten Weltkrieg die O.C. kurzerhand mit der getarnten deutschen „Abwehr“ identifiziert wissen wollte ${ }^{20}$. In einem allerdings hatte Salomon recht: Mit ihrem Nachrichtendienst hatte die O.C. erreicht, was Ehrhardt seit

17 Ebenda; vgl. Berliner Tageblatt vom 20. 8. 1922.

${ }^{18}$ SAM, 772-2-194, Rathenau-Prozeß, 4. Verhandlungstag, Aussage K. Tillessen, S. 179 ff.; vgl. Berliner Tageblatt vom 7. 10. 1922, Morgen-Ausgabe.

19 SAM, 567-1-2647, Aussage Brüdigam, 12. 6. 1922.

${ }^{20}$ Salomon, Fragebogen, S. 399. Heinz blicb dieser Profession auch später treu und avancierte nach 1945 zu einer der schillerndsten Figurcn der im Aufbau begriffenen Gehcimdienste der Bundesrepublik; vgl. Der Spiegel, Nr. 47/1953, S. 9 ff.; Boveri, Verrat, S. 111 f.; Mcinl/Krüger, Friedrich Wilhelm Heinz, S. $54 \mathrm{ff}$. 
dem gescheiterten Kapp-Lüttwitz-Putsch angestrebt hatte und was nach dem Erzbergermord angesichts des schwebenden Geheimbündelei-Verfahrens gänzlich illusorisch geworden zu sein schien - die schützende Verbindung zu staatlichen Stellen. Eben dies versuchte Karl Tillessen in der Verhandlung des Staatsgerichtshofs zu verbergen, als der hellhörig gewordene Vorsitzende auf der Frage nach dem Charakter des Kasseler Spionagedienstes insistierte ${ }^{21}$. Immerhin ließ er sich entlocken, daß die Stelle von zwei Hauptleuten geleitet wurde, also offenbar Teil der Reichswehr war. Etwas genauer hatte in der Voruntersuchung sein Adjutant Plaas zu erkennen gegeben, daß die von ihm als „Deutscher Überseedienst“ bezeichnete Dicnststelle in Kassel cine Nachrichtensammelstelle über Spionageumtriebe der Franzosen unterhaltc und daneben auch Nachrichten über linksradikale Geheimorganisationen zusammentrage ${ }^{22}$. Die Angeklagten wußten, warum sie zumindest im Gerichtssaal ihre Zusammenarbeit mit der Kasseler Dienststelle der Reichswehr zu verschleiern suchten: Die Enthüllung der Wahrheit hätte einen Skandal provoziert. Und sie wäre nie aktenkundig geworden, hätten Heinz und Plaas nicht unmittelbar nach ihrer Verhaftung ihre staatlichen Verbindungen offengelegt, im Glauben, sich so einen Schutz vor der drohenden juristischen Verfolgung schaffen zu können. Eingangs seiner ersten Vernehmung gab Heinz am 26. Juni 1922 zu verstehen: „In vaterländischem Interesse arbeite ich [...] mit Herrn von Bose bzw. Herrn Reinert in dessen Nachrichtenabteilung für den Überseedienst. Das Büro befindet sich in Kassel." Reinert habe ihn um die Beschaffung von Nachrichten gebeten, „welche das vaterländische Interesse berührten, und hob besonders französische Handelsspionage und Nachrichten über Umsturzbewegungen von links hervor"23. Über einen in diesem Zusammenhang besonders interessanten Umstand ging Heinz allerdings hinweg: daß nämlich durchaus nicht nur die Ehrhardt-Leute als Lieferanten auftraten, sondern daß die Reichswehrstelle in Kassel in gleicher Währung entlohnte. Dies gab nach seiner Festnahme wiederum Plaas zu Protokoll: „Tillessen erhielt von Hauptmann von Bose die laufenden Berichte über das feindliche Nachrichtenwesen und solche wirtschaftlicher Natur regelmäßig übersandt. “24

Schon diese Zusammenarbeit zwischen einer staatlichen Behörde und einem Geheimbund, der im Verdacht hochverräterischer Umtriebe und politischer Kapitalverbrechen stand, rechtfertigtc die besonders in der linksstchenden Presse artikulierte Besorgnis, daß gegen die O.C. aus politischen Rücksichten nicht energisch genug vorgegangen werde. Doch auch die mißtrauischsten Kritiker hätten nicht ahnen können, daß die im RathenaumordProzeß beiläufig angesprochene Reichswehrstelle in Kassel im Juni 1922 die durch die Anzeige Brüdigams in Gang gesetzte Ermittlungsarbeit der Strafverfolgungsbehörden regelrecht behindert, ja geradezu hintertrieben hattc. Seinen Verbindungsoffizieren in Kassel nämlich hatte der von Brüdigam belastete und unmittelbar nach dem Rathenaumord festgenommene Friedrich Wilhelm Heinz es zu verdanken, daß cr bei seiner ersten Vernehmung über die gegen ihn erhobenen Vorwürfe durchaus im Bilde war: „Mit der Frühpost des 18. d. Mts. [Juni] crhiclt ich von Herrn Reinert einen Privatbrief von ctwa eineinhalb Seiten, in

21 „Präsident: Was ist das für eine Nachrichtenstelle? - Angckl. Tillessen: Eine private Nachrichtenstelle. - Präsident: Hat mit der Regierung nichts zu tun? - Angekl. Tillessen: Nein! - Präsident: Ist es eine Parteisache? - Angekl. Tillessen: Nein, um Gottes willen! [...] - Präsident: Hängt sie mit dem Kriegsministerium zusammen? - Angekl. Tillessen: Nein! - Präsident: Aber indirekt? - Angekl. Tillessen: Ja - aber ich bitte darüber nichts sagen zu dürfen." SAM 772-2-194, Rathenau-Prozeß, 4. Tag, Aussage K. Tillessen, S. $180 \mathrm{f}$.

22 Ebenda, 567-1-2588, Aussage Plaas, 8. 7. 1922.

23 Ebenda, 567-1-2647.

${ }^{24}$ Ebenda, Aussage Plaas, 26. 6. 1922. 
welchem mir Hauptmann Reinert mitteilte, daß ein gewisser Brüdigam aus Frankfurt a. M. [...] bei Gericht folgende Angaben gemacht hatte: Brüdigam stände im Dienste Tillessens und [von] mir, um Nachrichten über Linksverbände zu besorgen. "25 Am 12. Juni 1922 hatte Brüdigam seine umfangreiche Anzeige zu Protokoll gegeben; sechs Tage darauf war ihr präzise zusammengefaßter Inhalt nicht nur zur Kenntnis eincr sachlich überhaupt nicht befaßten Reichswehrstelle gelangt, sondern von ihr auch bereits an zwei der Hauptbeschuldigten weitergegeben worden! Bis Plaas und Heinz wcitere acht Tage später verhaftet wurden, hatten sie anschließend genügend Zeit gehabt, um ihre Angelegenheiten zu ordnen und insbesondere alle Schriftstücke beiseite zu schaffen, die über ihre politische Arbeit hätten Auskunft geben können.

Offen ließen sie in der Vernehmung nur, ob sie Brüdigam für seinen Verrat zur Rechenschaft zu ziehen versucht hatten. Doch auf diese Frage gibt Brüdigams Verhalten, das dem Kasseler Oberstaatsanwalt Noetzel so unverständlich erschienen war, selbst beredte Auskunft: Am 10. Juni hatte Brüdigam Scheidemann gegenüber scine Aussagebereitschaft erklärt, aber gebeten, von einer amtlichen Vernehmung verschont zu werden. Am 12. Juni durchkreuzte Brüdigam seine vorgesehene Vorführung, indem er sich an diesem Tag auf dem Kasseler Rathaus in Gegenwart Scheidemanns durch einen eigens aus Berlin gerufenen Kriminalkommissar vernehmen ließ. Offenbar hatte er zu den Kasseler Behörden kein volles Vertrauen. Noetzel fügte sich widerstrebend, wollte aber Brüdigam wenigstens nach der Vernehmung zugeführt wissen. Dies verhinderte allerdings nun Scheidemann mit Rücksicht auf Brüdigams uncrklärliche Angst, der Kasseler Anklagebehörde Auskunft zu geben ${ }^{26}$. Am selben Tag fuhr Brüdigam in seine Wohnung nach Frankfurt zurück. Am 14. Juni traf er sich noch einmal mit Plaas und Tillessen, dic zu diesem Zeitpunkt vom Verrat ihres Spitzels noch nichts wußten. Am selben Abend schickte Noetzel einen Kriminalkommissar mit der Weisung nach Frankfurt, Brüdigam zur Vernehmung und Beeidigung dem dortigen Amtsgericht zuzuführen. Dies geschah am 16. Juni, und in der kurzen Vernehmung belastete Brüdigam Tillessen abermals schwer, bevor er aufgrund der Arbeitsüberlastung des Amtsrichters hcimgeschickt und auf den 19. Juni wieder einbestellt wurde. Daß er an diesem Montag nicht mehr auf dem Gericht erschien, hatte einen plausiblen Grund: Am selben Morgen waren Heinz und Plaas von ihrer Verbindungsstelle bei der Reichswehr über die Doppelrolle ihres Spitzels orientiert worden. Brüdigam, den nun die Angst vor der Rache seiner O.C.-Genossen schleunigst untertauchen ließ, hatte sich in seinem Mißtrauen gegenüber dem Gerichtswesen in Kassel nicht getäuscht; nur von dort konnten die genauen Informationen über seine Aussagen gekommen sein, in deren Besitz die örtliche Reichswehrstelle schon kurzc Zeit später war.

Während die wahre Bestimmung des Neudeutschen Bundes auf diese Weise wenigstens in Umrissen deutlich wurde, blieb die Existenz einer anderen Abteilung des neuformierten Ehrhardt-Bundes der Öffentlichkeit gänzlich verborgen. Ende Oktober 1921 notierte Plaas crfreut: „Ich soll mich klarmachen, zu Tilly [Karl Tillessen] nach Frankfurt zu fahren, auf direkten Befehl des Consuls. Welch glänzender Wechsel von Schmidt zu Tilly! “27 Auf Anordnung der Zentrale wartete Plaas unter konspirativen Umständen, bis in Frankfurt eine

25 Ebenda, Aussage Heinz, 26.6. 1922. Auch Plaas gab nach seiner Verhaftung an: „Mit dem Gegenstande meiner Vernehmung bin durch das Schreiben des Hauptmann Reinert aus Kassel vertraut. "Ebenda, Aussage Plaas, 26. 6. 1922.

${ }^{26}$ Ebenda, Bericht Oberstaatsanwalt Dr. Noetzel an den RMJ, 22. 6. 1922.

27 NL Plaas, Tagebuch, Eintrag vom 31.10.1921. In seinem 1936 für das SS-Personalhauptamt verfaßten Lebenslauf läßt Plaas „die Arbeit für die O.C. “ auch erst mit der „Bcrufung“ nach Frankfurt beginnen; BDC, Personalaktc Plaas, Lebenslauf, 24. 6. 1936. 
Wohnung gefunden war. Am 3. Dezember 1921 war er in München, offenbar, um sich bei Ehrhardt vorzustellen. Seit dieser Zeit veränderte das Tagebuch - offenbar als Folge entsprechender Empfehlungen - seinen Charakter; am Neujahrstag des Jahres 1922 notierte Plaas vielsagend: „Ich schließe das alte Tagebuch ab. In Zukunft muß ich mich sehr vorsichtig und unverfänglich ausdrücken, und wenn dadurch manches unerwähnt bleibt. Es ist bei meiner augenblicklichen Tätigkeit zu gefährlich, weil wir täglich ,Besuch“ bekommen können. Kein Zettel darf gefunden werden, folglich darf keiner da sein. Wir haben genug Schaden gehabt. " 28 In der Tat erforderte das neue Einsatzfeld von Plaas und Tillessen auch konspirative Fähigkeiten. In Frankfurt hatte sich bereits 1920/21 um Friedrich Wilhelm Heinz eine später an die O.C. angegliederte "National-Armee" gebildet, die Waffenlager anlegte, geheime Manöver abhielt und Aktionen gegen die französische Besatzungsmacht durchführte ${ }^{29}$. Die Stadt war zu einem Sammelort rechtsextremer Umtriebe geworden, an dem der Deutschvölkische Schutz- und Trutzbund seit Sommer 1921 allwöchentliche Werbeveranstaltungen abhielt und seit Juli 1921 eine radikalantisemitische Völkische Rundschau in einer Auflage von 10000 Exemplaren erschien. Nachdem Heinz im Oktober 1921, aus der Untersuchungshaft in der Mordsache Erzberger entlassen, nach Frankfurt zurückgekehrt war, erwuchs ihm in Tillessen und Plaas wirksame Unterstützung: Plaas übernahm die Schriftleitung der Völkischen Rundschau ${ }^{30}$, Tillessen wandelte den deutschvölkischen Turnverein Jahn in eine schlagkräftige Saalschutztruppe ${ }^{31}$ um und gründete mit Plaas reihenweise Ortsgruppen des Verbandes nationalgesinnter Soldaten, der, in der O.C. als Mitgliederreservoir eingestuft, mancherorts anscheinend sogar als Tarnmantel benutzt wurde ${ }^{32}$.

Doch erschöpfte sich das Tun der Frankfurter Aktivisten nicht in Mitgliederwerbung und völkischem Vereinsleben. Die dokumentarische Literatur aus der Feder Heinz' und Salomons beschreibt, wie das so gewonnene aggressive Potential, das im Sturz des Weimarer Staates sein gemeinsames Ziel sah ${ }^{33}$, seine Kraft in Gefangenenbefreiungen, Femeanschlägen und Angriffen auf französische Besatzungseinrichtungen erprobtc. Der Stamm dieser Gruppe wurde gebildet aus Tillessen, Plaas, Heinz, Salomon und Kern ${ }^{34}$ - denselben O.C.Männern, die dann (mit Ausnahme von Heinz) der Beteiligung an der Ermordung Rathenaus überführt wurden ${ }^{35}$. Unter ihren Aktionen ragen zwei heraus, die in gleicher Weise den

${ }^{28}$ NL Plaas, Tagebuch, Eintrag vom 3. 12. 1921 bzw. 1. 1. 1922.

${ }^{29}$ Dazu und zum folgenden Schön, Nationalsozialismus in Hessen, S. $21 \mathrm{ff}$.

${ }^{30}$ NL Plaas, Tagebuch, Eintrag vom 20. 4. 1922; vgl. Meinl, Revolutionär, S. 93.

31 BA, NS 26/531, Otto Schroeder, Meine Kampferlebnisse, 15. 2. 1937.

32 Vgl. Heinz, Sprengstoff, S. 75.

33 "Jede neue Ortsgruppe, die Tillessen oder Georg [= Friędrich Wilhelm Hcinz] gründeten, bildete einen Knoten, der das Netz enger knüpfte. [...] Alle ihre örtlichen Gruppen, Verkleidungen, Masken waren in ihrer Gesamtheit dennoch das, was die O.C. werden sollte: Eine weitreichende soldatische Verschwörung gegen den Staat von Weimar!" Ebenda, S. $87 \mathrm{ff}$.

${ }^{34}$ Vgl. Salomons Darstellung: „Kern hatte Heinz und mich aufgefordert, aus all den vaterländischen Bünden die besten und aktivsten Burschen herauszulesen [...] und somit eine kleine, aber gehärtete Schar zu sammeln, mit der man [...] gewisse Dinge unternehmen könne, die allerdings mit der bestgemeinten patriotischen Begeisterung allein nicht geschafft werden konnten. “Die Geächteten, S. 246.

${ }^{35} \mathrm{Daß}$ er nicht weniger beteiligt war als scine verurteilten Kameraden, gab Heinz nach 1933 selbst öffentlich zu: „Um das Maß der Groteske voll zu machen, stellte schließlich cin Reichsgerichtsurteil fest, daß es eine O.C. niemals gegeben habe. Und da das Reichsgericht [...] bekanntlich nicht zu irren vermag, muß auch der Verfasser notgedrungen sich zur Auffassung bekennen, daß seine Tätigkeit in den Jahren 1920 und 1923 nur ein Traumerlebnis darstellt. [...] Er kommt jedoch im gleichen Augenblick mit seiner Pflicht als Historiker dieser Zeit in Konflikt, wenn er etwas über die Beseitigung 
Zusammenhalt und die Arbeitswcise der von Tillessen geleiteten O.C.-Gruppe verdeutlichen: dic Befreiung des Seeoffiziers Dithmar aus dem Naumburger Gefängnis am 28. Januar 1922 und der Mordversuch an dem abtrünnigen O.C.-Mann Wagner im März 1922 in Bad Nauheim. Die vom Reichsgericht Lcipzig 1921 als Kriegsverbrecher zu je vier Jahren Gefängnis verurteilten Oberleutnants Boldt und Dithmar galten in nationalistischen Kreisen als Opfer der Willkür, mit der dic Alliierten eigene Verstöße gegen das Völkerrecht ignorierten, aber vermeintliche Verfehlungen deutscher Offiziere um so unnachsichtiger verfolgten. Von einer Befreiung dieser nach ihrer Verurteilung in Leipzig einsitzenden Sceoffiziere konnte sich die O.C. Zustimmung im ganzen Reich versprechen; nach Salomons Darstellung wetteiferten rechtsradikale Gruppen förmlich um das Vorrecht, die beiden zu befreien ${ }^{36}$. Am 17. Juli 1921 schrieb Karl Tillessen seinem Bruder Heinrich, er halte es für erforderlich, „daß wir die beiden Leipziger heraushauen. Ich bin gerne erbötig, dieses Unternehmen zu leiten bzw. mich daran zu beteiligen. [...] Würde gern Kern dazu mitnehmen. Sprich' noch einmal mit Lammatsch. “ ${ }^{37}$ Hoffmann schien die erbetene Zustimmung erteilt zu haben, denn ein Leipziger O.C.-Aktivist namens Wegelin bekam, wie cr gestand, „Mitte Juli von Tillessen aus Chemnitz einen Brief, ich sollte mich einmal erkundigen, was die Kriegsverbrecher Boldt und Dithmar machen " 38 . Wegelin stellte daraufhin Nachforschungen über Fluchtmöglichkeiten an und besorgte auf Verlangen Tillessens einige Ausrüstungsgegenstände, um dessen Brigadeuniform in cine solche der Sicherheitspolizei zu verwandeln.

Nachdem außerdem ein Auto und cin Chauffeur von auswärts besorgt waren ${ }^{39}$, fuhren Karl Tillessen und Kern zusammen mit einem weiteren O.C.-Angehörigen in dem mit gefälschtem Berliner Kennzeichen verschenen Auto am 10. August 1921 vor dem Leipziger Gefängnis vor, um als angebliche Sipo-Beamte eine Verlegung der beiden verurteilten Seeoffiziere nach Berlin vorzunehmen. Die Befreiung scheiterte, weil das - möglicherweise vorher gewarnte - Wachpersonal sich nicht bluffen ließ, sondern seinerseits Sipo-Leute aufbot. Die verhinderten Befreier allerdings entkamen; erst nach über einem Jahr wurde der kurz zuvor im Zusammenhang mit dem Rathenaumord verurteilte Tillessen auch wegen versuchter Gefangenenbefreiung mit einer zusätzlichen Gefängnisstrafe von einem Monat belegt ${ }^{40}$. Dithmar mußte dennoch nicht mehr lange im Gefängnis ausharren. Mittlerweile in die Strafanstalt Naumburg/Saale verlegt, wurde er im Januar 1922 aus der Haft befreit und entkam wie der in Hamburg einsitzende und gleichfalls geflohene Boldt nach Spanien. Daß diese Aktion wiederum vom selben Frankfurter Aktivistenkreis der O.C. durchgeführt wurde wie der gescheiterte Befreiungsversuch vom Sommer 1921, erfuhren die Justizbehör-

Rathenaus berichten soll. Denn diese Tat wurde zweifellos wiederum von Angehörigen jenes Frankfurter Arbeitskreises ausgeführt, der sich um Karl Tillessen, Hartmut Plaas, Ernst von Salomon und W. F. Heinz schartc." Politische Attentate in Deutschland, S. 207.

${ }^{36} \mathrm{Vgl}$. Salomon, Die Geächteten, S. 316.

${ }^{37}$ StAF, Nr. 83, K. Tillessen an H. Tillessen, 17. 7. 1921. Mit „Lammatsch“ ist Hoffmann gemeint (ebenda, Nr. 112, Aussage Siebel, 14. 9. 1921). Offenkundig bedurfte selbst eine vergleichsweise kleine Unternchmung wie diese Gefangenenbefreiung der vorherigen Erlaubnis der Münchener O.C.-Zentrale.

38 StAL, MdI, 11106a, Aussage Wegelin, 5. 10. 1921.

${ }^{39}$ Vgl. zu den Schwierigkeiten, einen geeigneten Fluchtwagen und einen zuverlässigen Fahrer zu beschaffen: Aussage Seffner, 19. 10. 1921; Verhandlungsprotokoll in der Strafsache gegen K. Tillessen u. a., 10. 7. 1923; Aussagen Sundermeyer, 24. 7. und 1. 10. 1923, in: Ebenda.

${ }^{40}$ Hcinz berichtet, ein frühcrer Marinevorgesetzter Kerns und Tillessens habe trotz aller Sympathie für die Tat seine Kenntnis von dem Befreiungsplan an die Bchörden weitergegeben, da das Vorhaben die Statsautorität gefährde (Heinz, Sprengstoff, S. 79 f.); StAL, ebenda, Verhandlungsprotokoll in der Strafsache gegen K. Tillessen u. a. und Urteil vom 10. 7. 1923. 
den nicht, und die Straftat wäre ohne die erst nach der Amnestie von 1925 veröffentlichten Erinnerungen der Beteiligten vielleicht nie bekanntgeworden. Das Unternehmen wurde wiederum von Karl Tillessen und vielleicht auch von Kern geleitet ${ }^{41}$, die sich diesmal der Hilfe Fischers und des Erfurter O.C.-Mannes Wolfgang Dietrich bedienten; zusätzlich waren mit Heinz, Plaas, Brandt und dem kurz zuvor zu der Gruppe gestoßenen Ernst von Salomon ${ }^{42}$ sämtliche Frankfurter O.C.-Männer beteiligt, die später auch bei der Ermordung Rathenaus in Erscheinung treten sollten. Dithmars Frau schmuggelte Sägeblätter in die Zelle ihres Mannes ${ }^{43}$, und zum vereinbarten Datum drangen die Befreier auf den Gefängnishof, während Dithmar, der Wochen gebraucht hatte, um ohne Geräuschaufwand die Stahlstäbe vor seinem Zellenfenster zu durchtrennen, sich an einem Strick vom dritten Stockwerk abzuseilen versuchte. In einigen Metern Höhe riß das Seil jedoch, der Ausbrecher stürzte ab und blieb mit einer Rückgratverstauchung im Gefängnishof liegen. Kern gelang es, den Verletzten auf eine herabgelassene Strickleiter zu zerren und über die Gefängnismauer zu hieven, während das unterdes alarmierte Gefängnispersonal herzueilte, aber von Dietrich abgelenkt wurde. In letzter Sekunde entkamen die Befreier, die sich wie beim ersten Befreiungsversuch eines von auswärts beschafften Autos samt Chauffeur bedienten ${ }^{44}$. Sie schüttelten ihre Verfolger ab und fuhren nach Freiroda, einem Örtchen zwischen Naumburg und Saaleck. Von dort schleppten Kern und Fischer den verletzten Dithmar zur Burg, deren Bewohner Hans Wilhelm Stein sie bereits erwartete. Auf Burg Saaleck blieb Dithmar 17 Tage unter ärztlicher Obhut und floh dann über die Schweiz nach Spanien; Ehrhardt verlieh darauf Heinz und vermutlich auch den anderen Befreiern des Marineoffiziers in Anerkennung ihrer Leistung eine „Auszeichnung der Brigade mit der Aufschrift: 'Verdienst ums Vaterland! “ “45

Erst 1927 wurde eine weitere Straftat bekannt, die die Frankfurter O.C.-Männer kurz darauf begangen hatten: der versuchte Fememord an eben dem Mann, der den Fluchtwagen bei Dithmars Befreiung gesteuert hatte ${ }^{46}$. In der Nacht vom 4. auf den 5. März 1922 hatten zunächst Unbekannte einen Mordanschlag auf Erwin Wagner alias Weigelt im Kurpark von Bad Nauheim verübt. Das durch einen Totschläger am Kopf getroffene Opfer erlitt einen Schädelbruch und wurde, mit einem Stein beschwert, in den Teich des Kurparks geworfen. Als Wagner dennoch wieder in die Höhe kam - der Stein war offenbar aus dem zugeknöpften Mantel gerutscht - und sich an Land retten konnte, wurden auf ihn drei Schüsse abgegeben, die ihr Ziel aber verfehlten, so daß es dem Opfer gelang, schwimmend das andere Ufer zu erreichen und seinen Angreifern zu entkommen. Aus Angst vor weiterer Verfolgung tauchte Wagner anschließend jedoch unter und zeigte das gegen ihn verübte Verbrechen nicht an. Erst

${ }^{41}$ Heinz nennt Tillessen (Sprengstoff, S. 83). Nach G. Kern hingegen war die Vorbereitung zur Befreiung Dithmars - und damit die Verantwortung gegenüber der O.C.-Führung - Kern übertragen worden; BA, NS 26/1236, Gisela Kern, Lebenslauf Erwin Kern.

${ }^{42}$ Vgl. Salomon, Die Geächteten, S. 319; BDC, Personalakten Plaas und Brandt.

${ }^{43}$ Vgl. Heinz, Sprengstoff, S. 82.

${ }^{44}$ Abermals hatte sich die Organisierung eines unverfänglichen Wagens, der nicht sofort auf die Spuren der Frankfurter O.C.-Aktivisten führen konnte, als schwierig erwiesen (Heinz, ebenda), bis ein Fabrikant aus Halle sich überreden ließ, seinen Wagen auszuleihen (Salomon, Die Geächteten, S. 327). Auch der Fahrer kam wieder nicht aus der O.C., sondern war ein thüringischer Orgesch-Mann; ebenda, S. 320.

${ }^{45}$ Heinz, Sprengstoff, S. 86; vgl. Stein, Burg Saaleck, S. 8 f.; Salomon, Die Geächteten, S. 322 ff.; ders., Fragebogen, S. 434.

${ }^{46}$ Den Anschlag griff in der Literatur zuerst Gumbel auf (Verräter, S. 56 ff.); vgl. Hannover/HannoverDrück, Politische Justiz, S. 132 ff. Die Angaben zum Tathergang nach: Stadtarchiv Gießen, Abt. 83/ 92, Anklageschrift gegen Schwing, Salomon und Heinz, 30. 12. 1926. 
durch die Tätigkeit des Femeausschusses des Reichstages kam Licht in das Dunkel; in einem Brief vom 6. August 1926 an das Frankfurter Polizeipräsidium behauptete der spätere Hauptbclastungszeuge Karl Schmidt-Halbschuh, daß Heinz, Tillessen, Kern und Salomon die Tat verübt hätten ${ }^{47}$. Ein halbes Jahr später wurde Anklage gegen Heinz, Salomon und einen weiteren O.C.-Mann namens Ernst Schwing - Gründer und Vorsitzender des Verbandes nationalgesinnter Soldaten in Bad Nauheim - wegen versuchten Mordes bzw. Anstiftung zum Mord erhoben ${ }^{48}$. Der Verhandlungsverlauf war der Wahrheitsfindung nicht eben günstig. Salomon und Heinz leugneten ihre Mitgliedschaft in der O.C. ${ }^{49}$, über die die Ehrhardt-Offiziere Karl Tillessen und Eberhard Kautter obendrein behaupteten, daß ihr sogenannter Femeparagraph nicht ernst gemeint gewesen sei oder höchstens in gesellschaftlicher Ächtung bestanden habe. Dic Zeugen nahmen, offensichtlich von früheren Gesinnungsgenossen bearbeitet, ihre belastenden Aussagen aus der Voruntersuchung in Bausch und Bogen zurück. Der Staatsanwalt wurde am vierten Prozeßtag so rüde angegriffen, ohne Schutz durch den Gerichtsvorsitzenden zu finden, daß er nur mit Mühe davon abgehalten werden konnte, die Anklagevertretung niederzulegen; die Verhandlungsführung war sichtlich von der Stimmung des Publikums im Gerichtssaal beeindruckt, das ganz auf seiten der Angeklagten stand. Am 31. März 1927 verurteilte das Gericht, das die eigentliche treibende Kraft in dem irdischer Vcrantwortung entzogenen Kern erblickte und eine Mordabsicht bei allen Angeklagten verneinte, Salomon wegen Körperverletzung zu drei Jahren und Schwing wegen Beihilfe zum versuchten Totschlag zu einem Jahr und sechs Monaten Gefängnis; Heinz wurde „wegen nicht ausreichender Beweise“ freigesprochen. Der Staatsanwalt legte Revision ein, die das Reichsgericht verwarf ${ }^{50}$.

Das Urteil war ein glatter Fehlspruch, wie Salomon später offen eingestand: „Ursprünglich hatten Kern und ich die Absicht, Wagner zu töten. [...] Daß die Tötung nicht geschah, war, wie Kern ausdrückte, einfach ein Versager. "51 Außerdem beruhte der Freispruch von Heinz maßgeblich auf der falschen Annahme, daß der Angeklagte an der Befreiung Dithmars nicht beteiligt gewesen und somit kein Motiv für die Anstiftung zur Tötung Wagners gehabt haben könnte ${ }^{52}$. Selbst nachdem Heinz sich auf einer Magdeburger „Stahlhelm“-Versammlung mit dem Geständnis gebrüstet hatte, beim Entkommen Dithmars aktiv mitgeholfen zu haben ${ }^{53}$, wurde der Revisionsantrag des Staatsanwalts vom Reichsgericht verworfen, da das freisprechende Urteil zu Recht diese „Äußerung des Heinz für den Fall, daß sie gemacht worden sein sollte, als leere Renommisterei bezeichnet" habe ${ }^{54}$. Immerhin konnte in der Verhandlung aber der Grund herausgeschält werden, aus dem heraus der frühere Chauffeur in O.C.-Diensten im Nauheimer Kurpark überfallen worden war. Wagner schien der O.C.

47 Oberhessische Volkszeitung vom 25. 3. 1927.

$48 \mathrm{Vgl}$. zum folgenden Knauß, Gießener Fememordprozeß, S. 118 ff.

49 Gießener Anzeiger vom 22. 3. 1927.

50 Stadtarchiv Gießen, Abt. 83/92, Revisionsantrag in der Strafsache gegen Schwing u. Gen., 25. 4. 1927, und Entscheidung des Reichsgerichts vom 30. 9. 1927.

51 Fragebogen, S. 144.

52 Der Staatsanwalt schrieb später: „Wäre die wenn auch nur entfernte Teilnahme von Heinz an der Dithmar-Befreiung klargestellt worden [...], so wäre auch das Motiv bei Heinz für die Anstiftung Schwings zu Wagners Ermordung offenbar gewesen, und ich hätte mit allem Nachdruck auf Verurteilung des Heinz mindestens wegen Beihilfe plädieren können. So aber war es nach der Beweislage unmöglich." Hessisches Staatsarchiv Darmstadt, Abt. G 21a, Konvolut 1745, Bericht Justizrat Weidemann an den Gießener Oberstaatsanwalt, 29. 4. 1931.

$53 \mathrm{Vgl}$. Knauß, Gießener Fememordprozeß, S. 145.

54 Stadtarchiv Gießcn, Abt. 83/92, Entscheidung des Reichsgerichts vom 30. 9. 1927. 
nach der Befreiung Dithmars gefährlich geworden zu sein: Er habe „Erpresserbriefe mit der Drohung [geschrieben], die Dithmarsache der Polizei zu verraten “55; er sei ein unwahrhaftes Subjekt und dringend verdächtig, als Spion in französischem Sold zu stehen ${ }^{56}$.

Wagner, dessen Kenntnisse über die O.C. sich weitgehend auf das Umfeld der DithmarBefreiung beschränkt haben dürften, wußte vermutlich nicht, daß er sich mit seinem Erpressungsversuch einen Gegner geschaffen hatte, der seinen Femeparagraphen durchaus nicht nur als die harmlose gesellschaftliche Ächtung verstand, zu der Kautter und Tillessen ihn später herunterzuspielen trachteten. Salomon ließ zehn Jahre später seine Leser an dem Gespräch in der Frankfurter O.C. über den Abfall Wagners teilhaben, das sich „mit beispielloser Roheit den verschiedenen Todesarten zu[wandte], die den einzelnen Abarten des Verrates zu folgen hatten“, und er deutete auch an, wer außerdem noch an der Angelegenheit interessiert sei: „Die Reichswehr fahnde nach ihm, denn ein ihm anvertrauter Wagenpark sei verschoben worden. Die nun aufgelöste Orgesch habe ihn wegen Unregelmäßigkeiten entlassen müssen. "Wagner hatte in den Augen der O.C. den Tod verdient, weil er nach dieser Auskunft schon mehrfach als Verräter an der nationalen Sache hervorgetreten war. Folgerichtig fiel die Entscheidung, ihn umzubringen, nach den Worten Salomons endgültig erst, als einer der Frankfurter O.C.-Männer ,eine Liste der Spitzelabwehr, die in Kassel ergänzt und an die Gruppen verteilt worden war, auf den Tisch [legte] “57.

Bearbeiter dieser Liste war offenkundig dieselbe Nachrichtenstelle der Reichswehr in Kassel, die im Rathenaumord-Prozeß zur Sprache gekommen war. Was dort als bloßer Austausch von gegenseitig interessierenden Nachrichten hingestellt worden war, entpuppte sich in der Rückschau Salomons als eine Arbeit, für die Jasper den Begriff der „lizensierten Illegalität" geprägt hat. Die O.C. war offenbar ein weit über die Beschaffung von Informationen hinausgehendes Kooperationsverhältnis mit der örtlichen Reichswehrbehörde eingegangen, das vor allem die Erledigung illegaler Aufträge beinhaltete und sie zu cinem Teil der Schwarzen Reichswehr machte. Was darunter zu verstehen war, ließ Salomon nicht im dunklen: Kampf gegen die Separatistenbewegung in der Pfalz, Sabotageaktionen und Gefangenenbefreiungen in den französisch besetzten Gebieten, Waffenschiebungen im ganzen Reich ${ }^{58}$. Seine Darstellung mochte romanhaft ausgeschmückt sein; erfunden war sie nicht. Denn schon während des Gießener Fememordprozesses 1927 war durchgesickert, daß es eine von der Reichswehr geführte Liste mit den Namen für Frankreich tätiger Spione gewesen sei, die Tillessen zugespielt worden war und zum Mordversuch an Wagner geführt habe. Der Staatsanwalt unterstellte in seinem Plädoyer gar als bewiesene Tatsache, es sei das Wehrkreisgruppenkommando in Kassel gewesen, „das die Beseitigung Wagners wegen

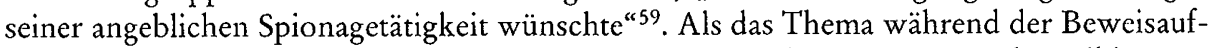
nahme im Zusammenhang mit einer Instruktion Heinz' an die Ortsgruppen des Wiking von

${ }^{55}$ So gab Salomon in der Verhandlung die Argumentation Kerns wieder; Gießener Anzeiger vom 22. 3. 1927.

56 Diese falsche Behauptung Salomons (Stadtarchiv Gießen, Abt. 83/92, Anklageschrift gegen Schwing, Salomon und Heinz, S. 6), fand später auch in die "Geächteten" Eingang (S. 327 ff.). Heinz belastete Wagners Schuldkonto noch um den ebenfalls unrichtigen Vorwurf, der Chauffeur habe das Fluchtauto zur Dithmar-Befreiung nicht zurückgegeben, sondern verschoben (Frankfurter Nachrichten vom 23. 3. 1927). Der Eigentümer des Wagens stellte jedoch in der Verhandlung klar, daß er den Wagen ordnungsgemäß zurückerhalten habe; Oberhessische Volkszeitung vom 24. 3. 1927.

57 Die Geächteten, S. 327 ff..

${ }^{58}$ Ebenda, S. 258 und $307 \mathrm{f}$.

${ }^{59}$ Knauß, Gießener Fememordprozeß, S. 139; vgl. Frankfurter Zeitung vom 29. 3. 1927. 
1923 zur Sprache kam, wurde die Öffentlichkeit ausgeschlossen ${ }^{60}$. Offen zutage trat aber immerhin, daß die enge Zusammenarbeit zwischen O.C. und Reichswehr von höchsten Dienststellen gedeckt worden war und beispielsweise Friedrich Wilhelm Heinz schon bei einer Verhaftung 1924 auf die Hilfe der Reichswehr hatte zählen können: Nach einem späteren Polizeibericht wurde er alsbald auf „telegrafische und persönliche Intervention des Generals Reinhardt in Stuttgart auf freien Fuß gesetzt [...], da er im Interesse der Landesverteidigung tätig war'“61.

Doch entschloß sich die O.C. zur Ermordung ihres früheren Chauffeurs anscheinend nicht nur, weil sein Name auf einer Spitzclliste des Kasseler Reichswehrkommandos verzeichnet war. Ein späteres Zeugnis von Heinz deutet an, daß der Überfall auf Wagner mehr als eine isolierte Strafaktion gegen einen Denunzianten war und unmittelbar mit der Vorbereitung eines größeren politischen Schlages zusammenhing: „Der Orgeschmann [Wagner] ist ein Feind, und man selbst befindet sich im Krieg. Fallen Tillessen, Kern und alle die andern aus, die Ditmar befreit haben, so ist mehr verloren als dessen Freiheit. ,Dieses Jahr hat es zu knallen! “62 Wagner gefährdete nicht so schr das Ergebnis der Januaraktion - Dithmar war Anfang März 1922 längst im sicheren Exil ${ }^{63}$-, sondern eine terroristische Gesamtstrategie, in deren Mittelpunkt nach den Worten Salomons die Ermordung Rathenaus stand: „Wagner [...] versuchte, uns zu erpressen, und da er damit die ganzen Attentatsvorbereitungen zu lähmen drohte, wurde sein Tod beschlossen." ${ }^{64}$ Daß Wagner dennoch mit dem Leben davonkam, lag an Salomon selbst, der im entscheidenden Moment, als Kern schon auf den hilflos im Wasser rudernden Wagner angelegt hatte, den Arm seines Komplicen hochschlug, so daß dessen Schüsse ihr Ziel verfehlten ${ }^{65}$. Eigentlich hätte Salomon, wie er schreibt, selbst schießen sollen. Doch er vermochte es nicht, weil sich seine Skrupel noch als zu groß erwiesen. In den Augen seiner Gesinnungsgenossen hatte er sich damit als unfähig erwiesen und wäre von den geplanten weiteren Aktionen beinahe ausgeschlossen worden: „Kern hatte mich dann später nur mit Widerstreben doch noch in die Rathenau-Sache eingeteilt." "66 Auch hier zeigt sich, daß offenbar eine innere Verbindung zwischen dem Parküberfall auf Wagner und den politischen Anschlägen des Frühsommers 1922 bestanden haben muß. Drei Monate später mochte in einer ganz ähnlichen Lage nicht zuletzt das Wissen um Wagners Schicksal Theodor Brüdigam zum plötzlichen Untertauchen bewogen haben. Auf jeden Fall war unzweifelhaft auch sein Leben auf das äußerste gefährdet gewesen, nachdem der Name des Verräters wiederum vom Kasseler Reichswehrkommando übermittelt worden war-denn zu diesem Zeitpunkt war Brüdigams Aussage noch gar nicht protokolliert und damit auch nicht beweiskräftig. Tatsächlich genügte dann schon sein bloßes Verschwinden, um die polizeiliche

60 Vorher hatte Heinz erklärt, „es handle sich dabei um ein Rundschreiben, das im Interesse der Landesverteidigung vom Reichswehrgruppenkommando 6 in Stuttgart gebilligt worden sei“. Frankfurter Zeitung vom 29. 3. 1927. Das Blatt kommentierte in derselben Ausgabe: „Noch ein anderes ist aus den Prozeßergebnissen hervorzuheben, was zu schweren Bedenken Anlaß gibt: die enge Verbindung, die in jener kritischen Zeit zwischen Reichswehrgruppen und dem Bund Wiking, diesem Nachfolger der Organisation C, bestanden hat." Vgl. Vorwärts vom 20. 3. 1927.

${ }^{61}$ BA, NS 26/1349, Bericht des Polizeipräsidenten Hannover, 14. 9. 1929; vgl. Meinl, Revolutionär, S. 114.

${ }^{62}$ Sprengstoff, S. 92.

${ }^{63}$ Mainzer Anzeiger vom 29. 3. 1927.

${ }^{64}$ Salomon, Fragebogen, S. 141.

${ }^{65} \mathrm{Vgl}$. Heinz, Sprengstoff, S. 95.

${ }^{66}$ Seine Tcilnahme am Rathenaumord verstand Salomon daher nicht zuletzt als Bewährungssituation, in der er, "gerade durch das würgende Gefühl des ,Versagens' angetrieben, den inneren Graben übersprungen hatte"; Salomon, Fragebogen, S. 144. 
Ermittlungsarbeit zu einem vorläufigen Stillstand zu bringen und die Vorbereitungen zum Mord an Rathenau planmäßig weiterlaufen zu lassen.

Als militärischer Leiter und, neben Kern, treibende Kraft all dieser O.C.-Aktionen erscheint Karl Tillessen, in dessen Frankfurter Wohnung die Fäden sowohl der agitatorischen wie der terroristischen Arbeit zusammenliefen. Er vor allem entschied, wer als Helfer jeweils auszuwählen war, und an ihn gingen die laufenden Reichswehrberichte aus Kassel. Die Vermutung, daß er den Kopf einer eigenen, von Ehrhardt mit terroristischen Sonderaufgaben betrauten Abteilung der O.C. bildete, bestätigte Tillessen 15 Jahre später selbst: In cinem 1937 für seine SS-Personalakte verfaßten Lebenslauf hielt er die Etappen seines weiteren Aufstiegs in der O.C. fest, der ihn 1921 bereits zur Leitung der O.C. in Sachsen geführt hatte: „Januar 1922 Leiter der Organisation Konsul für Westdeutschland. Später zugleich Führer der Aktivistengruppen im ganzen Vaterland. " ${ }^{7}$ In dem im September 1921 beschlagnahmten Organisationsentwurf tauchte Karl Tillessen noch als Obcrbezirksleiter des neu zu bildenden Oberbezirks I (Hamburg) auf ${ }^{68}$; die Änderung sollte am 1. Oktober 1921 in Kraft treten. Zu diesem Zeitpunkt waren jedoch mit Ausnahme Tillessens sämtliche der im Entwurf vorgesehenen Leiter wegen Verdachts auf Beteiligung am Erzbergermord inhaftiert. Es lag deshalb nahe, auf weniger exponierte Funktionäre zurückzugreifen, so daß Tillessen zu Beginn des neuen Jahres zusammen mit seinem Adjutanten Plaas die O.C.-Leitung in einem ungleich größeren Gebiet erhielt, nämlich in den zusammengelegten Oberbezirken II (Hannover) und IV (Frankfurt).

Laut Aufgabenbeschreibung hatten die Oberbezirksleiter als Mittler zwischen Zentrale und Bezirken zu fungieren, eine straffe Organisation durchzusetzen, brauchbare Leute zu erfassen, den Zusammenschluß mit dem Verband nationalgesinnter Soldaten zu fördern und für eine paramilitärische Ausbildung der O.C.-Männer zu sorgen. Wie das Tagebuch von Plaas zeigt, hat Tillessen all diesen Aufgaben gerecht zu werden versucht; nicht weniger Raum nahmen jedoch weitgespannte Reisen und Kontaktc ein, die offensichtlich der Führung von Aktivistengruppen in ganz Deutschland und der Aufrechterhaltung des engen Kontaktes zur Münchener O.C.-Zentrale dienten. Dem korrespondiert eine Vielzahl von der O.C. verbundenen Besuchern, die Tillessen und Plaas in Frankfurt empfingen; das Tagebuch enthält für die ersten sechs Monate des Jahres 1922 über vierzig verschlüsselte Namen. Wo eine Identifikation möglich ist, handelt es sich um O.C.-Aktivisten aus genau dem Kreis, der zuerst bei der Befreiung Ditmars und dem Fememordversuch an Wagner in Erscheinung trat - und dann bei den Attentaten auf Scheidemann und Rathenau ${ }^{69}$.

Wenn sie auch auf schriftliche Notizen soweit wie möglich verzichteten und Mitteilungen durch Kuriere statt auf dem Postwege bestellen ließen, glaubten Tillessen und Plaas in ihren Besuchskontakten auf die Einhaltung konspirativer Regeln nicht angewiesen zu sein. Statt dessen nutzten sie ihre Tätigkeit als Bezirksleiter des Neudeutschen Bundes, um unter dem Mantel harmloser politischer Vereinstätigkeit einzelne terroristische Aktionen zu organisieren, mit deren Ausführung sie kleine Kader um Kern, Heinz und Salomon betrauten, die fallweise um weitere, von außen kommende „Aktivisten“ vermehrt wurden, wenn es etwa

${ }^{67}$ BDC, Personalakte K. Tillessen. Auch H.-G. Techow führte in seinem Bericht 1933 über die Neugestaltung des Grabes für Kern und Fischer in Saaleck an, daß Tillessen die Weiherede am Grab als „Führer der ehemaligen Aktivistengruppen“ hielt; BA, R43I/904, Bericht H.-G. Techow, 4. 1. 1934.

${ }^{68}$ StAF, Nr. 89, Organisationsentwurf der O.C.

${ }^{69}$ Interessant ist, daß der von Plaas erwähnte Personenkreis 1921 unverschlüsselt erscheint, ebenso wie in den ex post nachgeholten Eintragungen für die Zeit ab Juni 1922 - cin weiteres Indiz dafür, daß Plaas sich in der Zwischenzeit nach einer langfristig konspirativen Strategie richtete. 
galt, ein benötigtes Auto zu beschaffen oder zu steuern. Die erforderlichen Kräfte wurden aus der O.C. selbst ausgesucht; ihre Verpflichtung geschah nach den förmlichen Regeln des Femeparagraphen der O.C.-Satzung. Wer abzufallen drohte, lief wie Wagner Gefahr, umgebracht zu werden. Insgesamt läßt sich festhalten, daß die O.C. den verheerenden Schlag im Herbst 1921 überwand, indem sie unter Fortsetzung ihrer militärischen Sammlungstätigkeit weitgehend zwischen legalen und illegalen Aktivitäten trennte. Durch den ordnungsgemäß im Vereinsregister eingetragenen Neudeutschen Bund in ihrem organisatorischen Aufbau weniger angreifbar geworden, hatte sie im Schatten dieses Vereins einen Nachrichtendienst aufgebaut, der sie zu einem gefragten Kooperationspartner der Reichswehr machte. Zunehmend war aus der Nachrichtenbeschaffung die Übernahme illegaler Operationen im Auftrag der Reichswehr geworden, für die die O.C. als Gegenleistung Unterstützung gegen die Verfolgung durch staatliche Behörden crwarten konnte und auch erhielt. Zur Durchführung dieser Aufträge wurde unter Karl Tillessen eine eigene Abteilung in der O.C. geschaffen, die die verdeckten Operationen spezieller Kommandos koordinierte und die dezentral von Frankfurt aus geführt wurde, so daß auch bei etwaiger Verhaftung - anders als im Falle der Erzbergermörder - keine direkte Spur zur O.C.-Leitung führen würde. Im Ergebnis, so läßt sich sagen, war die O.C. nach ihrer Enttarnung im September 1921 durchaus nicht schwächer, sondern eher noch stärker geworden.

\section{Die Verschwörung gegen die Republik}

Im Leipziger Prozeß gegen die Rathenaumörder waren Reichsanwaltschaft und Verteidigung stillschweigend übereingekommen, die zahlreichen über die dreizehn Angeklagten hinausweisenden Spuren nicht zu verfolgen. Dennoch war sich auch Oberreichsanwalt Ebermayer durchaus darüber im klaren gewesen, daß die Vermutung eines O.C.-Hintergrundes den Prozeß in erheblichem Maße bestimmt hatte. In seinen Erinnerungen suchte er jedoch den Vorwurf zu entkräften, nicht mit der nötigen Energie vorgegangen zu sein, um diese Verbindung aufzudecken. Die Untersuchung habe ergebnislos bleiben müssen, weil „eben überhaupt keine strafbaren Handlungen vorlagen oder [...] die Beteiligten es verstanden, ihr strafbares Verhalten so zu verbergen, daß ihnen nichts nachzuweisen war" "1. Der Oberreichsanwalt stützte seine Argumentation nicht zuletzt darauf, daß weder Kern und Fischer noch irgendein anderer Tatbeteiligter außer Techow nachweislich Mitglieder der O.C. gewesen seien. Schon angesichts des Prozeßverlaufs war dies eine einigermaßen gewagte Feststellung, denn bereits am ersten Verhandlungstag hatten sich die Angcklagten, die durch ihre Sitzordnung links und rechts vom Richtertisch ihre Zusammengehörigkeit bzw. Distanz deutlich dokumentierten ${ }^{2}$, durchaus unterschiedlich auf die Frage geäußert, ob sie Angehörige der O.C. seien: Der ältere Techow bejahte die Mitgliedschaft; über seine Reisen für die O.C. verweigerte er jedoch nach kurzem Zögern die Aussage und stellte Ehrhardts Bund in Abweichung von seinen früheren Aussagen als „eine kameradschaftliche Vereinigung“ hin, deren Mitglieder „sich gegenseitig Treue und Hilfe zugelobten für den Fall, daß irgendein

1 Ebermayer, Dienst am Recht, S. 185.

2 Sämtliche der Zugehörigkeit zur O.C. Verdächtigen, nämlich die beiden Techow, Tillessen, Salomon, Plaas, Warnecke, Niedrig, Ilsemann und Steinbeck saßen rechts, die politisch ungebundenen Schütt und Diestel sowie der als Psychopath von allen abgelehnte Günther (vgl. Salomon, Die Geächteten, S. 358) hingegen links vom Präsidententisch (Berliner Tageblatt vom 4. 10. 1922, Morgen-Ausgabe). 
Aufstand kam, [...] um die Regierung bzw. das Deutsche Reich zu retten“3. Sein jüngerer Bruder bestätigte, daß er früher der O.C. angehört habe, wollte aber wegen Organisationsschädigung aus ihr ausgeschlossen worden sein. Warnecke gestand, über Killinger zur O.C. gekommen zu sein, während der seiner Hamburger Gruppe zugeteilte Niedrig sein frühercs Geständnis, der O.C. angehört zu haben, mitsamt allen von ihm seinerzeit preisgegebenen Namen und Interna zurückzog. Auch Ilsemann bestritt die Mitgliedschaft in der O.C., war aber nach eigener Aussage zu Ehrhardts Stellvertreter Alfred Hoffmann nach München gereist, um bei ihm eine Anstellung zu finden. Steinbeck verneinte seine Zugehörigkeit zur O.C. ebenso kategorisch wie Salomon, der aber immerhin nicht mehr auf seiner früheren Behauptung beharrte, vor dem Rathenaumord bloß „vergnügungshalber“ nach Berlin gefahren zu sein, sondern jetzt zur Vorbereitung einer Gefangenenbefreiung in die Stadt gekommen sein wollte 4 . Tillessen wiederum, der ebenso wie alle anderen Angeklagten der „rechten Bank" mit Ausnahme Niedrigs und Salomons früher zur Brigade Ehrhardt ${ }^{5}$ gehört hatte, wollte zwar nicht Mitglied der O.C. gewesen sein, aber ihr immerhin nahegestanden haben. Plaas schließlich hatte zwar angeblich noch nic etwas Näheres über dic O.C. gehört, gab aber $\mathrm{zu}$, während seiner Tätigkeit in einer landwirtschaftlichen Arbeitsgemeinschaft ehemaliger Ehrhardt-Männer persönliche Beziehungen zu Alfred Hoffmann in München angeknüpft zu haben ${ }^{6}$.

Mit Ausnahme Salomons und Steinbecks stritt also kein Angeklagter der „rechten Bank“ Beziehungen zu Ehrhardts Organisation oder ihren Leitern ab; Tillessen gestand sogar, von der O.C.-Nachfolgeorganisation Neudeutscher Bund ein monatliches Gehalt bezogen zu haben ${ }^{7}$. Angelpunkt ihrer Verteidigung gegen den Vorwurf, gemeinschaftlich den Mord im Auftrag der O.C. vorbereitet zu haben, war die Behauptung, daß auch Kern und Fischer

3 SAM, 772-2-194, Rathenau-Prozeß, 1. Verhandlungstag, S. 85 f. In dieser Formulierung klang deutlich die von Hoffmann in München für den O.C.-Prozeß festgelegte Sprachregelung an. Vor dem Untersuchungsrichter hatte Tcchow noch offener ausgesagt, daß ,ich der Organisation $\mathrm{C}$ seit Entstehen im Frühjahr 1920 an [gehöre]. Als Mitglied der Organisation C war ich zur Treue gegen die Mitglieder und zum Gehorsam gegen die Vorgesetzten verpflichtet, auch zur Verschwiegenheit hinsichtlich der Themen bei Besprechungen und Vorträgen. Zu solchen Besprechungen bin ich wiederholt für die Organisation C auf Reisen nach auswärts gewesen. "Ebenda, 567-1-2593, Aussage E. W. Techow, 22. 7. 1922.

4 Ebenda, 772-2-194, Rathenau-Prozeß, 1. Verhandlungstag, Aussagen H.-G. Techow (S. 91), Friedrich Warnecke (S. 127 f.), Waldemar Niedrig (S. 122 ff.), Christian Ilsemann (S. 111 f.), Gustav Steinbeck (S. 117), Ernst von Salomon (S. 150).

5 Der ältere Techow war Ende 1919 in die Brigade Ehrhardt aufgenommen worden und hatte am KappPutsch teilgenommen (ebenda, Aussage E. W. Techow, S. 84), sein jüngerer Bruder war während des Kapp-Putsches als Ordonnanz in der Reichskanzlei eingesetzt (ebenda, 567-1-2592, Aussage H.-G. Techow, 27. 6. 1922); Warnecke kannte Ilsemann und die Brüder Tillessen von der gemeinsamen Dienstzeit bei der Brigade Ehrhardt (ebenda, 567-1-2564, Aussage Warnecke, 5. und 19.7. 1922); und ebenso war Steinbeck bei der Ehrhardt-Truppe mit Kern, Techow, Plaas und anderen Komplicen des Rathenau-Attentats bekannt geworden (ebenda, 567-1-2638, Aussage Steinbeck, 2. 8. 1922). K. Tillessen gab an, alle Kämpfe der Brigade Ehrhardt mitgemacht zu haben (ebenda, 567-1-2621, Aussage K. Tillessen , 2. 8. 1922), und in der Brigade war wiederum Plaas auf Tillessen und Brandt getroffen (ebenda, 567-1-2588, Aussage Plaas, 8. 7. 1922). Daß schließlich auch Fischer mit Kern, Techow, Ilsemann in der Brigade Ehrhardt gedient hatte, hielt ein auf den Aussagen von Beschuldigten beruhender Bericht der Politischen Polizei Berlin fest (ebenda, 567-1-2579, Vermerk Pol. Präs. Bcrlin, 8. 7. 1922).

6 Ebenda, 772-2-194, Rathenau-Prozeß, 1. Verhandlungstag, Aussage Plaas, S. 185.

7 Ebenda, 567-1-2621, Aussage K. Tillessen, 3. 7. 1922. 
Ehrhardts Geheimbund gar nicht angchört hätten. In eine besonders schwierige Lage hatte sich Techow mit seinem Zugeständnis manövriert, daß er Kern und Fischer als Vorgesetzte angesehen habe, denen er unbedingt Folge leisten mußte. Nur mit der Behauptung, daß die beiden keine Verbindung zur O.C. gehabt hätten, konntc er nun noch die auf der Hand liegende Vermutung abwehren, im Auftrag einer Geheimorganisation zur Mitwirkung an dem geplanten Verbrechen verpflichtet worden zu sein ${ }^{8}$. Das Gericht begnügtc sich mit dieser Erklärung und stellte im Urteil lapidar fest: „Auch für eine Zugehörigkeit von Kern und

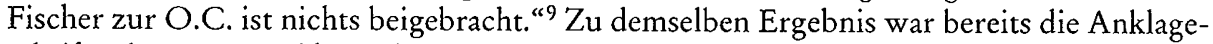
schrift gekommen und hatte dabei auf ein Zeugnis zurückgegriffen, das ausgerechnet Alfred Hoffmann Kern ausgestellt hatte. Der MünchnerO.C.-Funktionär bejahte die Bekanntschaft mit Kern, der nach seinem Ausscheiden aus der Marine gefragt habe, ob er nicht in die O.C. aufgenommen werden könnte. Angeblich aber, so erklärte Hoffmann, habe man ihm einen ablehnenden Bescheid geben müssen, da es der Organisation an Geld gefehlt habe, um auch ihm noch ein Gehalt zu zahlen ${ }^{10}$.

Hoffmanns Auskunft war falsch. Die Reichsanwaltschaft hätte nur auf die Untersuchungsakten zum Erzbergermord zurückgreifen müssen, um den tatsächlichen Sachverhalt festzustellen: Kern zählte mit Brandt zu der Gruppe republikfeindlicher Seeoffiziere, die im Mai 1921 geschlossen aus der Marine ausgeschieden waren, um zu Ehrhardt zu gehen ${ }^{11}$. Daß Kern sich anschließend bei der O.C. nicht in Untätigkeit ergangen hatte, war der Justiz nicht verborgen geblieben: Schon im Juli desselben Jahres wurde er zusammen mit Karl Tillessen als Organisator der ersten, mißglückten Befreiung der Seeoffiziere Boldt und Dithmar aus dem Leipziger Untersuchungsgefängnis gleich bei zwei Staatsanwaltschaften aktenkundig; aus einem beschlagnahmten Brief ging zudem - wie oben erwähnt - hervor, daß sein Einsatz sogar ausdrücklich mit der Münchener O.C.-Führung abgestimmt war ${ }^{12}$. Auch den im September 1921 beschlagnahmten Bezirkseinteilungen der O.C. hätte die Reichsanwaltschaft unschwer entnehmen können, daß Kern in der O.C. keine Randfigur war, sondern zum Kreis ihrer leitenden Funktionäre gehörtc: In ihnen wird Kern als Adjutant des Bezirksleiters Wende im Bezirk A genannt, dessen Zuständigkeit sich auf Kiel, Hamburg und Rostock erstreckte $^{13}$. Diese Angabe deckt sich mit der späteren Aufstellung Gisela Kerns, nach der Kern vor seiner Berufung zum Adjutanten Wendes für die O.C. in Chemnitz und Zwickau tätig gewesen war ${ }^{14}$. Vermutlich von Chemnitz aus ging Kern Anfang September 1921 kurzzeitig nach München, um die Flucht der Erzbergermörder Schulz und Heinrich Tillessen zu unterstützen ${ }^{15}$. Seit dem 26. Oktober 1921 war er in Kiel als aus Zwickau kommend gemeldet ${ }^{16}$. Mit der Neustrukturierung des Münchener Geheimbundes um die Jahreswende

${ }^{8}$ Ebenda, 772-2-194, Rathenau-Prozeß, 2. Verhandlungstag, S. 12 f.

${ }^{9}$ BA/P, 30.01.-5053/1, Urteil gegen E. W. Techow u. Gen.

${ }^{10}$ SAM, 567-1-2580, Aussage Hoffmann, 7. 7. 1922.

11 BA/P, 15.07-341, „Ludwig“ [Paul Werber] an Hoffmann, 25. 5. 1921; vgl. zur Biographie Kerns auch Exiner, Erwin Kern.

${ }^{12}$ StAF, Nr. 83, K. Tillessen an H. Tillessen, 17. 7. 1921; ebenda, Nr. 180, Aussage Lauch, 1.9. 1921; StAL, Ministerium des Innern, 11106a, Aussagen Wegelin, 5. 10. 1921, und Krebs, 18. und 22. 10. 1921.

${ }^{13} \mathrm{Daß}$ der in Kicl ansässige Leiter der O.C. für Hamburg, Schleswig-Holstein und Mecklenburg ein „Kapitänleutnant Wende“ sei, behauptete nach seiner Festnahme auch Niedrig und stellte damit zusätzlich die Richtigkeit seines später zurückgezogenen Geständnisses unter Beweis; SAM, 567-12585, Aussage Niedrig, 26. 6. 1922.

${ }^{14}$ BA, NS 26/1236, Gisela Kern, Lebenslauf Erwin Kern.

${ }^{15}$ StAF, Nr. 6, Urteil gegen H. Tillessen, 28. 2. 1947.

${ }^{16}$ Einwohnermeldeamt Kiel, Archiv, Melderegisterkarte E. Kern. 
1921/22 verstärkten sich die Kontakte Kerns zu anderen O.C.-Männern, mit denen er später bei der Vorbereitung des Mordanschlags auf Rathenau zusammenarbeiten sollte, insbesondere zu Karl Tillessen. Aufgrund seiner Rücksichtslosigkeit und Unerschrockenheit entwikkelte sich Kern alsbald zu einer Leitfigur des politischen Terrorismus in der O.C., ohne seine Arbeit als Verbandsfunktionär aufzugeben. Parallel zu einer ausgedehnten Reise- und Vortragstätigkeit als Adjutant des norddeutschen O.C.-Bezirksleiters beteiligte Kern sich an nahezu allen bekanntgewordenen Unternehmungen, die die Frankfurter Gruppe initiierte. Eines davon, nämlich die diesmal erfolgreiche Befreiung Dithmars im Januar 1922, setzte Kern bereits gemeinsam mit seinem späteren Mordkomplicen Fischer in Szene. Aber nicht nur deshalb mutet dieser Coup wie ein Vorgriff auf das Rathenau-Attentat an: Um Dithmar auf Burg Saaleck verborgen zu halten, nutzte Kern die Hilfe derselben beiden Männer, die ihm und Fischer ein halbes Jahr später am gleichen Ort vergeblich das Entkommen zu ermöglichen versuchten: des Erfurter O.C.-Mannes Dietrich und des Saalecker Burgbesitzers Stein.

Kerns Aktionsradius war weitgespannt, und die Liste der von ihm ausgeführten Aufgaben im Dienst der O.C. umfaßte allem Anschein nach weit mehr als dic behördlich aufgedeckten Delikte. Seit seiner Abkommandierung nach Kiel war er offensichtlich an Anschlägen in den französisch besetzten Gebieten, an Waffenschiebungen und anderen O.C.-Unternehmen beteiligt ${ }^{17}$, die ihn immer wieder in engen Kontakt mit Aktivisten wie Tillessen, Plaas, Heinz und Salomon brachten, so daß es nicht verfehlt scheint, diesen Kreis als ein in wechselnder Zusammensetzung erprobtes und über ganz Deutschland operierendes Terrorkommando der O.C. zu apostrophieren ${ }^{18}$. Auch Günther Brandt gehörte zu dieser Gruppe. Wie Kern 1920 aus der Marine geschiedener Seeoffizier, war er gleich ihm der O.C. beigetreten und widmete sich organisatorischen Aufgaben, die ihn beständig durch das Land reisen und Wohnungen in Jena, Leipzig und Kiel unterhalten ließen ${ }^{19}$. Seine Kieler Adresse teilte er seit dem 1. Mai 1922 mit Wende und Kern im Hause seines Vaters, des Zoologieprofessors Karl Brandt. Wie Brandt war auch Kern zumeist auf Reisen und hielt sich nur so selten in Kiel auf, daß er sich zwar pro forma an der Kieler Universität immatrikuliert hatte, aber bis zum 1. Mai 1922 ohne Anschrift gemeldet war und in der Stadt offenbar keinen eigenen Hausstand begründet hatte ${ }^{20}$.

Einzig Fischer schien in dieser Gruppe Außenseiter zu sein. Ihn hatte Kern erst im Januar 1922 anläßlich der Befreiung Dithmars kennengelernt, und er zählte auch nicht zu dem Frankfurtcr Kreis um Tillessen und Plaas; Mitglied der O.C. war aber auch $\mathrm{er}^{21}$. Nach Salomon, der ihn als, Leiter der sächsischen Aktionen' bezeichnet, hatte er unter anderem eine dann verratene Waffenschiebung von Freiberg/Sachsen zu den Sudetendeutschen in der Tschechoslowakei vorbereitct ${ }^{22}$. Ein von der Polizei am 1. Juli 1922 in Freiberg entdecktes Waffenlager läßt vermuten, daß diese Behauptung der Wahrheit entsprach; es befand sich just auf dem Gelände der Spinnanstalt des Fabrikanten Küchenmeister, der für den Rathenaumord das Auto zur Verfügung stellte ${ }^{23}$. All dies läßt darauf schließen, daß Kern mit Fischer

${ }^{17}$ Vgl. Salomon, Die Geächteten, S. $353 \mathrm{ff}$.

${ }^{18} \mathrm{Vgl}$. Heinz, Politische Attentate in Deutschland, S. $206 \mathrm{f}$.

${ }^{19}$ Vgl. NL Plaas, Tagebuch, Eintrag vom 27. 3. 1922. In Kiel war Brandt allerdings nur bis zum 31. 12. 1918 gemeldet; Einwohnermeldeant Kiel, Archiv, Hausbuch Düppelstraße 3.

${ }^{20}$ BA/P, 30.03-12J917/22, Bd. 2, Schreiben des Polizeipräsidiums Kiel, 12. 2. 1923; Einwohnermeldeamt Kiel, Archiv, Melderegister E. Kern.

${ }^{21}$ BA, NS 26/1236, Gisela Kern, Lebenslauf Erwin Kern.

22 Salomon, Die Geächteten, S. 325 und 353.

${ }^{23}$ Berliner Tageblatt vom 10.10. 1922, Morgen-Ausgabe. Ein daraufhin unter anderem gegen Johannes Küchenmeister angestrengtes Strafverfahren wurde im Februar 1923 eingestellt, obwohl das Waffen- 
und Salomon eine von mehreren Zellen des politischen Terrorismus in der O.C. bildete, dessen Gesamtleitung Tillessen übertragen war. In dieselbe Richtung weist Salomons Behauptung, daß Kern und Fischer neben dem Rathenaumord eine ganze Reihe weiterer terroristischer Vorhaben planten und Salomon baten, sie durch die Übernahme eine dieser Aktionen zu entlasten ${ }^{24}$. Genauso hatte, wie oben behandelt, der wegen seiner Verwicklung in die Hamburger Sprengstoffattentate festgenommene Waldemar Niedrig schon kurz nach seiner Festnahme ausgesagt, daß in der O.C. ein Spreng- und Mordkommando existiere, dem die zu diesem Zeitpunkt noch unbekannten Kern, Fischer und ein dritter Mann angehören sollten, der später als Salomon identifiziert wurde ${ }^{25}$. Den Angaben des Hamburger O.C.Mannes zufolge hatte sich das dreiköpfige Kommando bereits vor dem Rathenau-Attentat zu Terroranschlägen zusammengefunden und im Mai 1922 einen antisemitisch motivierten Mord begangen ${ }^{26}$. Salomon ,hat mir selbst erzählt, daß sie alle drei zu dem Sinai [sic!] Aronsfrau in Mannheim ins Büro gckommen scien und ihn gefragt hätten, ob er der Sinai Aronsfrau sei. Auf seine Bejahung hätten sie gesagt: ,Sie haben wir gerade gesucht' und sofort

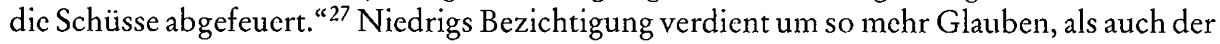
mit ihm nicht bekannte Theodor Brüdigam behauptete, für den Mord an Aronsfrau zeichne die O.C. verantwortlich ${ }^{28}$.

Die eigentliche Leitfigur der O.C.-Aktivisten war nicht der draufgängerische Anführer dieses Mordkommandos, Kern, sondern sein Vorgesetzter Karl Tillessen. Auch über ihn hatte die Anklagebehörde im Rathenaumord-Prozeß nicht mehr zu ermitteln versucht, als er und die übrigen Angcklagten selbst zuzugeben bereit waren. So blicb dem Oberreichsanwalt in seinem Plädoyer nur eine rhetorische Geste des Bedauerns, daß Tillessen und sein Adjutant Plaas nicht über die Nichtanzeige eines drohenden Verbrechens hinaus strafrechtlich belangt werden könnten, „obwohl es mir in hohem Maße wahrscheinlich erscheint, daß insbesondere Tillessen [...] einer der Hauptorganisatoren gewesen ist “29. Der konnte statt dessen sogar unwiderlegt behaupten, daß er vor dem Attentat in Berlin Kern eher zufällig getroffen, ihm dann aber energisch den Mordplan ausgeredet habe ${ }^{30}$. Daß auf sein Vorbringen freilich nicht viel zu geben war, hatte Tillessen durch seine eigene Aussagetaktik bestätigt, die von der ersten Vernehmung an darauf abzielte, bclastende Tatsachen von seiner Reise nach Berlin bis hin zu sciner Kenntnis des Mordplans so lange abzustreiten, bis sie ihm schlüssig nachgewiesen werden konnten. Immerhin stand gegen seine Darstellung die Behauptung Brüdigams, daß vor dem Attentat in Frankfurt ein Treffen mit Tillessen, Plaas und Heinz stattgefunden habe, auf dem die Ermordung Rathenaus erörtert worden sei. In der Tat verzeichnet das Tagebuch von Hartmut Plaas für den Mai 1922 eine auffällige Häufung von Reisen und auswärtigen Besprechungen Tillessens, die in ihrer Verschlüsselung auf ein größeres Vorha-

lager den Reichswehrbehörden nicht bekannt war, da sich die Beschuldigten im guten - wiewohl irrtümlichen - Glauben an eine Kenntnis der Behörden befunden hätten; BA/P, 30.03, 12 J 1249/22.

${ }^{24}$ Salomon, Die Geächteten, S. 353 f.

${ }^{25}$ SAM, 567-1-2585, Aussage Niedrig, 26. 6. 1922; vgl. weiter oben, S. 94.

${ }^{26}$ Der nie aufgeklärte Mord wurde in der Frankfurter Zeitung vom 25. 5. 1922 (Erstes Morgenblatt) in einer kurzen Notiz angezeigt: „Dcr Händler Sina Aronsfrau wurde gestern abend in seinem Hause am Markt, worin er seit Jahren ein Kurzwaren-Engrosgeschäft betreibt, durch einen Schuß in den Rücken ermordet aufgefunden. Es ist nichts geraubt worden."

27 SAM, 567-1-2585, Aussage Niedrig, 26. 6. 1922.

${ }^{28}$ Ebenda, 567-1-2621, Mitteilung RKO, 29. 6. 1922. Daß er noch an weiteren politischen Verbrechen beteiligt war, räumte auch Salomon im „Fragebogen“ (S. 141) indirekt ein.

${ }^{29}$ PA/AA, Rathenau-Prozeß, 8. Verhandlungstag, S. 167.

${ }^{30}$ Ebenda, 6. Verhandlungstag, Aussage K. Tillessen, S. 74 ff.; SAM, 567-1-2621, Aussage K. Tillessen, 2. 8. 1922. 
ben deuten. Genau eine Woche vor dem Anschlag auf Rathenau fuhr'Tillessen eigener Angabe zufolge und angeblich aus privaten Gründen nach München zu Ehrhardts Stellvertreter Hoffmann. Am 18. Juni hielt er sich in Nürnberg auf, am 19. Juni abermals bei Hoffmann in München, tags darauf hingegen in Jena, um Brandt zu treffen, und immer logierte er unter falschem Namen ${ }^{31}$. Zur selben Zeit wurde er bereits dringend in Berlin von Kern und Fischer crwartet, die bei ihren Vorbereitungen des Anschlags in finanziclle Nöte geraten waren. Günther und Salomon äußerten übereinstimmend, zwischen Kern und Fischer sei immer wieder davon die Rede gewesen, daß Tillessen und Plaas demnächst kommen müßten, und Günther schloß aus dem Verhalten seiner Komplicen, daß Tillessen ihnen Geld mitbringen sollte und dies dann auch wirklich getan habe, als er, aus Jena kommend, in Berlin eintraf ${ }^{32}$.

Ganz offensichtlich spielte Tillessen in der Verschwörung gegen Rathenau eine wcit entscheidendere Rolle, als im Prozeß erwiesen werden konnte. Es war Tillessen, der als Leiter aller Aktivistengruppen der O.C. die Anschlagsvorbereitungen von Frankfurt aus begleitete und vor allem den Kontakt des Attentatskommandos zur Münchener O.C.-Führung um Hoffmann wahrte. Doch daß die Zentrale mit der Mordsache Rathenau befaßt sein könnte, stellten die Geheimbündler natürlich vehement und unter Hinweis auf ihre Alibis in Abrede. So konnte der durch Brüdigams Aussagen belastete Hoffmann jeder konkreten Beschuldigung mit dem Nachweis den Boden entziehen, daß er sich vor dem Anschlag vom 24. Juni 1922 weder in München noch in Berlin aufgehalten habe ${ }^{33}$. Wie Hoffmann mit Hilfe gleich einer ganzen Reihe von Zeugen belegte, hatte er sich vielmehr in der Zeit vor dem Mord auf einer Reise im rheinisch-westfälischen Industriegebiet mit der harmlosen Aufgabe befaßt, Ehrhardt-Offizieren Anstellungen in der Industrie zu verschaffen. „Die Nachricht von der Ermordung Rathenaus habe ich in Köln bei dem Syndikus der Rheinisch-Westfälischen Sprengstoffaktiengesellschaft Herrn Breucker, Köln, Zeppelinstraße 1-3, auf dem Büro von Herrn Breucker erfahren, dem diese Nachricht in meinem Beisein telephonisch übermittelt wurde. [...] Herr Breucker wird gern bereit sein, Zeugschaft für mich abzuleggen, daß ich zur Zeit der Tat auf seinem Büro saß." ${ }^{34}$ Doch hatte Hoffmann mit dieser Berufung auf den früheren Ludendorff-Adjutanten Breucker offenbar nur einen Teil der Wahrheit enthüllt: Unter den Reaktionen, die Ernst von Salomon auf die Veröffentlichung seines „Fragebogen“ empfing, findet sich auch ein Schreiben Wilhelm Breuckers, den die Behauptung des Autors irritierte, Ehrhardt sei über den Rathenaumord nicht informiert gewesen - weil sie nämlich nicht mit seiner eigenen Erinnerung zusammenstimmte: „Wenige Tage vor der Ermordung Rathenaus erhielt ich von dem Adjutanten Ehrhardts [...] eine offene Postkarte folgenden Inhalts: ,Im Auftrage des Herren, den Sie neulich in Neuhaus-Schliersee trafen, wird Sic am 24.6. morgens Herr Hoffmann aufsuchen. 'Der Herr, den ich [...] in Neuhaus getroffen hatte, war Ehrhardt. Am 24. 6. 1922 erschien [...] ziemlich früh ein Herr in meinem Büro in Köln, Zeppelinstraße 1, der sich als Kapitänleutnant Hoffmann auswies und mir Grüße von Ehrhardt überbrachte. " ${ }^{35}$ Breucker zufolge erzählte Hoffmann dann ohne Umschweife, daß in Kürze Rathenau durch die dem Ludendorff-Adjutanten bekannten Offizierc Kern und Fischer getötet werden würde, er selbst aber die Tat organisiert habe. „Ich bin gestern abend von Berlin abgefahren, in Elberfeld ausgestiegen und mit einer neuen Fahrkarte Elberfeld Köln weitergefahren. Heute nachmittag will ich nach München weiterreisen, wo ich vermut-

31 Ebenda, Aussage K. Tillessen, 3. 7. 1922.

32 Ebenda, 567-1-2570, Aussage Günther, 3. 7. 1922; ebenda, 567-1-2594, Aussage Salomon, 16. 8. 1922; ebenda, 772-2-194, Rathenau-Prozeß, 3. Verhandlungstag, Aussage Günther, S. 21 ff.

33 Ebenda, 567-1-2588, Aussage Hoffmann, 4. 8. 1922.

${ }^{34}$ Ebenda, 567-1-2580, Aussage Hoffmann, 26. 6. 1922.

${ }^{35}$ NL von Salomon, Breucker an Salomon, 28. 6. 1951. 
lich sofort festgenommen werde. Für die Nacht in Elberfeld habe ich ein Alibi, ich brauche nur noch eins für den heutigen Vormittag, und der Kapitän riet mir, mich an Sie zu wenden. " 36 Die Glaubwürdigkeit von Breuckers Zeugnis wird dadurch noch erhöht, daß auf genau dieselbe Weise sich auch Brandt, Tillessen und Plaas ein Alibi für die Tatzeit zu beschaffen gesucht hatten: Brandt war am 21. Juni 1922 von Berlin aus an seinen Wohnort Jena gefahren und konnte belegen, sich am 24. Juni in seiner Wohnung aufgehalten zu haben ${ }^{37}$; Tillessen hatte sich am 22. Juni zu seinem Bruder, dem Kommandanten der Marineschule in FlensburgMürwik, begeben und dort die Zeit bis zum 25. Juni 1922 verbracht; Plaas war am 22. Juni nach Ludwigslust zu einem Bekannten und am Abend des nächsten Tages zurück nach Frankfurt gereist, wo er an Vormittag des 24. Juni 1922 anlangte ${ }^{38}$.

Auch während der Hauptverhandlung im Oktober 1922 blitzte immer wieder auf, daß das Komplott gegen den Minister eine nicht enthüllte zentrale Steuerung besessen haben mußte ${ }^{39}$. Besonders prägnant zeigte sich dies an der mysteriösen Berliner Wohnung Brandts, die als Treffpunkt für die Verschwörer gedient hatte und deren Adresse keiner von ihnen preisgeben wolltc. Auch wenn die Aussagen der Angeklagten sie immer nur ganz beiläufig streiften, hatte diese Wohnung bci der Attentatsplanung offensichtlich cine herausragende Rolle gespielt: In sie hatte sich Salomon am Mittwoch vor dem Anschlag auf Weisung Kerns begeben, um Post abzuholen, in ihr hatte er - angeblich überraschend - die frisch in Berlin angelangten Mitverschwörer Plaas und Tillessen getroffen. Auf entsprechende Nachfrage reagierte Salomon allerdings ausweichend: „Wo dic Wohnung war, möchte ich nicht sagen. “40 Plaas bestätigte, daß er gleich nach seiner Ankunft in Berlin zusammen mit Tillessen zu Brandts Wohnung gegangen sei. Brandt sei zwar nicht anwesend gewesen, habe aber hinterlassen, daß er anrufen werde, und statt seiner habe sich "Schreiber" alias Salomon in der Wohnung befunden; „Straße und Hausnummer weiß ich nicht mehr. “41 Tillessen schließlich wollte erst in der Wohnung Brandts von Kerns Anwesenheit in Berlin erfahren haben und war in sie zurückgekehrt, nachdem er vergeblich Kern zu treffen versucht hatte. Auf die Adresse wußte er sich so wenig wie sein Adjutant zu bcsinnen ${ }^{42}$. Der einzige, der sich nicht auf seine Vergeßlichkeit hätte berufen können, war der flüchtig gegangene Wohnungsgeber. Fest stand allerdings, daß ausgerechnet er sich in dieser Wohnung während seiner Anwesenheit in Berlin gar nicht aufgehalten hatte ${ }^{43}$. Die Gelegenheit, den Sachverhalt aufzuklären, kam erst im zweiten Rathenaumord-Prozeß 1925. Doch wie seine Komplicen verweigerte Brandt jede nähcre Auskunft über diese von ihm zwar häufig genutzte, aber anscheinend nicht selbst

${ }^{36}$ Ebenda. Der vermutlich nicht weniger interessante Antwortbrief Salomons ließ sich nicht auffinden; Breuckers schriftlicher Nachlaß wurde nach seinem Tod 1958 vernichtct (Mitteilung Günther Breucker, Frankfurt a. M., an den Verf., 6. 8. 1991).

${ }^{37}$ BA/P, 30.01-5053/1, Anklageschrift gegen Brandt und Küchenmeister, S. 22.

38 SAM, 567-1-2621, Aussage K. Tillessen, 3. 7. 1922; ebenda, 567-1-2588, Aussage Plaas, 3. 8. 1922.

${ }^{39}$ Auch Salomon gab nach seiner Haftentlassung „einem der fachjuristischen Beisitzer aus dem Rathenau-Prozeß [...] zu, was er vermutet hatte, daß nämlich vicl mehr vorgelegen hatte, als das Beweismaterial ergab"; Fragebogen, S. 140.

40 SAM, 567-1-2594, Aussage Salomon, 16. 8. 1922.

${ }^{41}$ Ebenda, 567-1-2588, Aussage Plaas, 3. 8. 1922.

42 Ebenda, 567-1-2621, Aussage K. Tillessen, 2. 8. 1922.

${ }^{43}$ Nach seiner Ankunft in Berlin am Abend des 20. 6. übernachtete Brandt mit Techow in cinem Hotel in Berlin-Wilmersdorf. Am nächsten Tag traf er mit Kern, Fischer und Salomon im Tiergarten zusammen und reiste noch am selben Abend nach Jena zurück. Ebenda, 567-1-2593, Aussage E. W. Techow, 30. 6. 1922; BA/P, 30.01-5053/1, Anklageschrift gegen Brandt und Küchenmeister, S. 15 ff. und S. 22. 
gemietete Wohnung, so daß die Anklageschrift nur feststellen konnte: „Über dieser ,Berliner Wohnung Brandts' schwebt ein gewisses Dunkel. Weder Brandt selbst noch die Zeugen Salomon, Tillessen und Plaas wollen darüber nähere Angaben machen können. Da Brandt damals in einem fremden Gasthause übernachtet hatte, muß es sich um ein Quartier handeln, in dem er sonst abzusteigen pflegte, und das er und die Zeugen aus irgendeinem Grunde nicht bezeichnen wollen." ${ }^{44}$

Ganz offenkundig handelte es sich bei der vorgeblichen „Berliner Wohnung Brandts“ um einen konspirativen Treffpunkt der den Rathenaumord vorbereitenden O.C.-Gruppe, dessen Offenlegung das ganze Anklagegebäude auf eine neue Grundlage gestellt hätte. Hier war das logistische Zentrum der Verschwörung, hierhin wurde Tatbeteiligten dic Post gesandt, hier crfuhren sie von dem Aufenthalt ihrer Mitverschwörer. Da kein Anhaltspunkt dafür spricht, daß Kern und Fischer eigens für das Attentat eine Wohnung in Berlin gemietet hatten - was im übrigen auch nicht sonderlich verschweigenswürdig gewesen wäre -, kann es sich nur um die Wohnung eines Berliner O.C.-Funktionärs gehandelt haben, deren Aufdeckung dic O.C. selbst in die Anschlagsvorbereitung verwickelt hätte. Leiter der Berliner O.C. war zu dieser Zeit der später wegen Geheimbündelei verurteilte Wilhelm Ehrentraut. Er war nach dem Anschlag auf Rathenau kurzzeitig verhaftet worden, weil Mitbewohner des Mietshauses zwischen dem 24. und dem 26. Juni 1922 einen überaus auffälligen Besucherverkehr in seiner Wohnung festgestellt hatten. So seien am 24. Juni 1922 früh zwei Herren erschienen, die jeweils in einem bestimmten Rhythmus gegen die Tür geklopft und ein Stichwort gerufen hätten, sobald innen jemand erschienen sei. Darauf sei die Tür geöffnet, aber beide Male der Einlaßbegehrende erst nach Präsentation einer Visitenkarte endgültig eingelassen worden ${ }^{45}$. Zwar wies Ehrentraut den Verdacht von sich, daß seine Wohnung als konspirativer Treff in der Mordsache Rathenaus gedient haben könnte. Aber er mußte zugeben, Ernst Werner Techow von Zusammenkünften der Mitglieder der ehemaligen Ehrhardt-Brigade näher, seinen Bruder Hans-Gerd immerhin „flüchtig“ zu kennen und die beiden sogar in ihrer Wohnung besucht zu haben. Auch Kern, Fischer, Tillessen, Plaas und weitere Mitglieder der Verschwörergruppe waren ihm ebenso bekannt wie die Funktionäre der Münchener O.C.Lcitung; Kern hatte ihn, wie Ehrentraut eingestand, sogar ein oder zwei Wochen vor dem Attentat noch aufgesucht ${ }^{46}$. Wie schon die Tatbeteiligung der Brüder Techow andeutete, operierte das von Kern geleitete Mordkommando also durchaus nicht ohne Verbindung zu der Berliner Ortsgruppe der O.C. Wenn auch ein voller Beweis nicht erbracht werden kann, spricht doch viel dafür, daß die Berliner O.C. mit der Wohnung Ehrentrauts auch den nicht identifizierten konspirativen Treffpunkt der Attentäter und damit die organisatorische Basis der Anschlagsvorbereitung gestellt hatte ${ }^{47}$; zumindest aber war mit ziemlicher Gewißheit Ehrentraut der Mann, der die im Rathenaumord-Prozeß unaufgeklärt gebliebene Verbindung zwischen Kern und den Brüdern Techow hergestellt hatte.

${ }^{44}$ Urteil gegen Brandt und Küchenmeister, S. 10, und Anklageschrift gegen Brandt und Küchenmeister, S. 16; in: Ebenda.

${ }^{45}$ SAM, 567-1-2644, Vermerk des Berliner Polizeipräsidiums, 29. 6. 1922.

${ }^{46}$ Ebenda und Aussage Ehrentraut, 8. 8. 1922.

${ }^{47}$ H.-G. Techow erwähntc in einer Vernehmung einen Spaziergang vom Kurfürstendamm in Richtung Martin-Luther-Straße, auf dem Kern in ein Haus gegangen sei, um einen Brief abzugeben, während er draußen warten mußte (ebenda, 567-1-2592, Aussage H.-G. Techow, 30. 6. 1922). Möglicherweisc verbirgt sich in dieser Bemerkung ein Besuch Kerns in der auf dem Weg liegenden Wohnung Ehrentrauts in der Meierottostraße 4. 
Nicht zuletzt war auch Techow als Mitglied der Berliner O.C. entgegen seiner eigenen Behauptung ebenso zur Mitwirkung bei dem Anschlag „eingeteilt"48 worden wie andere Helfershelfer. In einem Brief, den er kurz nach der Festnahme seiner Mutter aus dem Untersuchungsgefängnis schrieb und in dem er sich infolge der Briefkontrolle mit Andeutungen begnügen mußte, heißt es: „Bei meinem Eintritte in die Organisation habe ich mein Ehrenwort gegeben, über dieselbe zu schweigen und zu gehorchen. Man sagt mir hier, Du fordertest, ich solle aussagen. [...] Ich soll mein Wort brechen, wo ich es die eine Hälfte gchalten habe?"49 Unzweideutig läßt Techow hier erkennen, daß es seine Unterstellung unter die O.C.-Disziplin war, die ihn zuerst zwang, trotz allen Sträubens Kerns Auftrag Folge zu leisten, und dann seine Vorgesetzten unter keinen Umständen zu belasten. Freilich war der so verpflichtete Berliner O.C.-Mann ein Unsicherheitsfaktor geblieben, der noch unmittelbar vor dem Anschlag den Gehorsam vergebens aufzukündigen versucht hatte. Er zeigte hierin dasselbe Verhaltensmuster wie der Unbekannte, der durch sein Bekenntnis vor einem katholischen Pfarrer die Attentatsvorbereitungen schon im Vorfeld hätte zunichte machen können. Kessler zufolge hatte der anonyme Informant dem Priester gestanden, er sei zur Ausführung der Tat „ausgelost“ worden. Gerade dieser Umstand legt es nahe, daß die geheimnisvolle Warnung tatsächlich mit dem Attentatsplan der O.C. in Beziehung stand; denn auch im Zusammenhang des Erzbergermordes waren die zur Tat bestimmten Mitgliedcr des Münchener Geheimbundes über ein vorgespicltes Losverfahren ausgewählt worden. Daß die Auslosung eine für die Ehrhardt-Organisation charakteristische Methode bei der Vollstreckung von Mordbefehlen darstellte, hatte bereits ein von den französischen Besatzungsbehörden durchgeführtes Gerichtsverfahren im Dezember 1921 festgestellt $^{50}$ und zeigte sich gleichermaßen an den vertraulichen Äußerungen Oehlschlägers kurz vor dem Scheidemann-Anschlag.

Welcher der zum Mord an Rathenau Verschworenen aber konnte es gewesen sein, der sich „zitternd“ einem Priester öffnete und selbst zu tief in das Verbrechen verstrickt war, als daß er es bei der Polizei hätte anzeigen können? Auf keinen Beteiligten an dem Mordanschlag trifft diese Beschreibung besser zu als auf Ernst Werner Techow selbst, der der O.C. angehörte und von Kern zu einer Tat gezwungen wurde, die er nicht aus eigenem Antrieb gewollt hatte, aber auch nicht zu verraten fähig war. Der Prozeß hatte gezeigt, daß Techow in der Attentätergruppe kein vollwertiges Mitglied, sondern ein bloßes Werkzeug darstellte, dessen Meinung allenfalls in technischen Fragen etwas galt. Tillessen charakterisierte Techow als „einen Menschen, der vollkommen auf Kern dressiert“ ist; Kcrn stellte ihn mit den Worten vor: „Der macht alles und fragt nach nichts “51; Techow selbst fand es normal, daß er bei den Autoausflügen Kerns und Fischers vor der Tat an einem anderen Tisch Platz nehmen mußte, $\mathrm{da}$ er ja Chauffeurskleidung trug und „ein gewisses Dienstverhältnis zwischen uns“ bestanden habe ${ }^{52}$. Ein weiteres Indiz dafür, daß es möglicherweise tatsächlich Techow war, der sich ratsuchend an einen Geistlichen gewandt hatte, bildet die Identität des katholischen Priesters.

${ }^{48}$ Den Terminus gebraucht Salomon, Fragebogen, S. 144.

49 SAM, 567-1-2593, E. W. Techow an Gertrud 'Techow, 5. 7. 1922.

50 „Spezielle Organismen, die Kommissionen z.b.V. [zur besonderen Verwendung] werden mit der Ausführung der Urteile beauftragt. Ihre Mitglieder, die an cinem vom Vollstreckungsort sehr weit entfernten Platze wohnen müssen, werden unter denen zu allem entschlossenen Angehörigen der Brigade ausgesucht; die Bestimmung erfolgt durch das Los. Die Vollstrecker haben freie Wahl der Waffe, [...] müssen jedoch die Ausführung bis zu einem gesteckten Zeitpunkt melden können, andernfalls sie selbst dem Fchmgericht verfallen. "Welt am Montag vom 27.12.1921; BA/P, 15.07-339, Bericht der Oberstaatsanwaltschaft Offenburg, 10. 3. 1922.

51 PA/AA, Rathenau-Prozeß, 6. Verhandlungstag, Aussage K. Tillessen, S. 126.

52 SAM, 772-2-194, Rathenau-Prozcß, 2. Verhandlungstag, Aussage E. W. Techow, S. 19. 
Wirth konnte und wollte sie natürlich nicht enthüllen; es war der Geistliche selbst, der das Rätsel löste. In den nachgelassenen Papieren des katholischen Pfarrers Dr. Heinrich Lampe in Rheine fanden sich Belege, die zeigen, daß unzweifelhaft er es war, der Rathenau über Wirth warnen lie $\beta^{53}$. Lampe war aktives Mitglied des Zentrums und trat auf vielen Veranstaltungen seiner Partei als Redner auf; mit Wirth war er persönlich bekannt ${ }^{54}$. So erklärt sich auch, daß Lampe mit seiner Botschaft sofort bis zu Wirth vordringen konnte und der Reichskanzler die Angaben für hinreichend vertrauenswürdig hielt, um Rathenau sofort zu einem Gespräch zu bitten. Im Jahre 1922 versah Lampe als Kaplan die Pfarrstelle der katholischen St.-MatthiasKirche in Berlin-Schöneberg, deren damaliger Sprengel den Norden Schönebergs bis zum Rande des Tiergartens umfaßte, darunter auch die von-der-Heydt-Straße, in der zu dieser Zeit Ernst Werner Techow im Haushalt seiner Eltern wohnte. Techow war Protestant. Was er einem katholischen Kaplan anvertraute, war weder Beichtgeheimnis noch auch Verrat an seinen Komplicen; Techow konnte sicher sein, daß der Priester seinen Namen nicht preisgab und die Polizei nicht einschaltete. Auch hier läßt sich ein im letzten stichhaltiger Beweis nicht erbringen ${ }^{55}$. Ebenso muß offenbleiben, ob Techow durch sein Geständnis nur seine Gewissensnot lindern oder aber einen Weg suchen wollte, einen Mord zu verhindern, vor dessen Ausführung er sich anders nicht glaubte retten zu können. Beide Auslegungen erlauben aber gleichermaßen den Schluß, daß Techow zu Recht nicht wegen Mittäterschaft verurteilt wurde, und stärken die Vermutung, daß die Verschwörergruppe um Kern ihre Attentatsvorbereitung nicht auf eigene Faust, sondern im Rahmen der Ehrhardt-Organisation betrieb, die ihr Befehlsgewalt auch über etwa widerstrebende Mitglieder ihrer Berliner Ortsgruppe verlieh.

Zusammengefaßt zeichnet sich die Vorgeschichte des Attentats vom 24. Juni 1922 so ab: Die vielleicht schon seit dem Frühherbst 1921 in der O.C. gehegten Überlegungen, Rathenau zu beseitigen ${ }^{56}$, waren aufgrund der Enttarnung der O.C. und der Verhaftung ihrer führenden Mitglieder im September 1921 vorerst gegenstandslos geworden. Sie wurden aber im Zusammenhang mit der Bildung von Aktivistengruppen unter Tillessens Leitung Ende 1921 wieder aufgenommen und im Frühjahr 1922 soweit verdichtet, daß Tillessen zur Abstimmung einer konkreten Planung unter Hinzuziehung Kerns im Mai nach München fuhr ${ }^{57}$. Um die O.C. als Organisation und besonders die Zentrale in München nicht zu gefährden, wurde Kern beauftragt, den Anschlag mit den von ihm ausgewählten Mittätern in Eigenregie auszuführen und den Kontakt zur Organisation ausschließlich über Kuriere aufrechtzuerhalten. Als seinen Verbindungsmann bestimmte Kern Salomon, der so nach dem mißglückten Mordversuch an Wagner die Gelegenheit bekam, sich „wieder zu qualifizieren“58. Salomon wurde

${ }^{53}$ Vgl. Kleinhans, Bemerkenswerter Fund, S. 41 ff.; Blasberg, Nachwort, in: Kessler, Rathenau (Neuausg.), S. 361.

${ }^{54}$ Mitteilung Ludger Kleinhans an den Verf., 10. 8. 1992.

${ }^{55}$ Nicht uninteressant ist in diesem Zusammenhang, daß Techow in seiner Darstellung des Anschlags anders als Heinz und Salomon auf die Priesterwarnung ausdrücklich einging: „Auch von anderer Seite war Rathenau über unseren Plan unterrichtet. Ein Geistlicher hatte dem Reichskanzler Wirth Mitteilung von dem gemacht, was ihm in der Beichte anvertraut worden war, und Wirth hatte sofort Rathenau davon verständigt.“(„Gemeiner Mörder?!“, S. 27; Hervorhebung durch den Verf.) Techows Wortwahl ist aufschlußreich, denn daß diese Mitteilung sich wirklich auf das von Kern, Fischer und ihm ausgeführte Attentat bezog, konnte Techow nur wissen,wenn er selbst der Beichtende gewesen war.

${ }^{56}$ Der Leipziger O.C.-Mann Lauch nannte bereits im Oktober 1921 Rathenau als potentielles Opfer eines neuen O.C.-Anschlags; StAF, Nr. 180, Aussage Lauch, 1. 10. 1921.

57 Nach Aussage seiner Schwester fand Kern sich im Mai 1922 zum letztenmal - zusammen mit seinem Bezirkleiter Wende - in München ein; BA, NS 26/1236, Gisela Kern, Lebenslauf Erwin Kern.

${ }^{58} \mathrm{NL}$ von Salomon, Jean José Marchand, Interview mit Salomon, 1./2. 7. 1972. 
durch ein Telegramm Kerns nach Berlin beordert ${ }^{59}$. Für die Ausführung des Verbrechens selbst wählte Kern mit Fischer einen bereits bei einem riskanten Unternehmen erprobten Mann der O.C., der nicht zuletzt infolge seiner privaten Lebensumstände bedenkenlos bereit war, sein Leben in die Schanze zu schlagen ${ }^{60}$. Am 2. Juni verließ Kern Kiel, um in Berlin die letzten Vorbereitungen für das Attentat zu treffen, nachdem die Lebensgewohnheiten des vorgesehenen Opfers vermutlich schon ausgekundschaftet worden waren ${ }^{61}$. Zwei Tage später, am 4. Juni 1922, erörterten Fischer und Kern in Berlin mit Brandt und wahrscheinlich weiteren Komplicen ihre Absicht, Rathenau zu töten, und bestimmten Brandt dazu, ein Auto für die Flucht $\mathrm{zu}$ beschaffen ${ }^{62}$. Bis zu diesem Pfingstsonntag plante Kern wohl noch, Rathenau auf dieselbe Weise zu töten wie Hustert und Oehlschläger den Kasseler Oberbürgermeister Scheidemann, also mit Hilfe von Blausäure ${ }^{63}$. Als aber an diesem Tag das Attentat auf Scheidemann ungeachtet der tödlichen Dosis des verwendeten Säuregemischs mißlang, war damit gleichzeitig auch die bisherige Berliner Mordvorbereitung obsolet geworden. Kern sah sich in seiner Skepsis gegenüber der Tatwaffe bestätigt ${ }^{64}$ und drängte offenkundig darauf, trotz der dadurch eintretenden Verzögerung einen völlig neuen Attentatsplan zu entwickeln. Dics beanspruchte vermutlich einen Großteil der zwischen dem Überfall auf Scheidemann und dem Eintreffen Fischers und Salomons in Berlin liegenden Woche. Mit der in der Geschichte des politischen Attentates kaum weniger revolutionären Idee, den in der Regel ungeschützt im offenen Auto fahrenden Minister von einem anderen Wagen aus zu erschießen, glaubte Kern zu einer Zeit, als es motorisierte Polizeieskorten noch nicht gab, eine im Vergleich zur ursprünglichen Planung sicherere Möglichkeit gefunden zu haben, um den Minister zu beseitigen und selbst zu entkommen.

Allerdings war die Ausführung dieses Unternehmens nun von der Hilfe eines weit größeren Personenkreises abhängig. Und es stellten sich erhebliche Schwierigkeiten in den Weg: Neben dem angemessen motorisierten Wagen mußte ein geschickter und nervenstarker Fahrer gefunden werden, dazu eine auch ohne ruhige Ziclmöglichkcit zuverlässig treffende Mordwaffe, schließlich ein ortskundiger Vertrauensmann, der unter Rücksicht auf Verkehrsdichte und Fluchtwege die geeignetsten Straßenabschnitte zu bezeichnen vermochte. Kern und sein Komplice aktivicrten ihre Verbindungen: Fischer kannte aus seiner Chemnitzer Tätigkeit für die O.C. Küchenmeister als einen „nationalen“ Fabrikanten in Sachsen, der ihm sein Gelände bereits für ein geheimes Waffenlager zur Verfügung gestellt hatte, und errcichte mit Brandts Hilfe, daß der Fabrikant sein Auto tatsächlich überließ. Kern wiederum schaltete seinen Vorgesetzten Wende im O.C.-Gau Norddeutschland ein, um einen zuverlässigen

${ }^{59}$ Die Geächteten, S. 353. Mit dieser Angabe stellte Salomon seine Auskunft gegenüber dem Untersuchungsrichter, cr habe Kern rein zufällig in Bcrlin getroffen (SAM, 567-1-2594, Aussage vom 16. 8. 1922), selbst als unrichtig hin.

60 Ebenda, 567-1-2624, Aussage Werber, 3. 7. 1922; BA, NS 26/1236, Gisela Kern, Lebenslauf Erwin Kern.

61 Ebenda; BA/P, 30.01-5053/1, Anklageschrift gegen E. W. Techow u. Gen., S. 17.

62 Auf diese Zeitangabe legte Tillessen sich allerdings erst in der Hauptverhandlung des zweiten Rathenaumord-Prozesses fest; Vossische Zcitung vom 25. 6. 1925, Abend-Ausgabe, und 26. 6. 1925, Morgen-Ausgabe.

63 BA, NS 26/531, Otto Schroeder, Meine Kampferlebnisse, 15. 2. 1937.

64 Vgl. Salomons Darstcllung: „Kern war von jener freien und leichten Heiterkeit, die in den Schwingungen ihrer Kraft tausend Pläne reifen läßt und tausend Möglichkeiten birgt. Der Mißerfolg des Attentates auf Scheidemann befriedigte ihn fast. Er war, wie er crzählte, von Anfang an dafür eingetreten, das Blausäuregemisch in dem zur Tat benutzten Gummibällchen in einem verschlossenen Raum auszuprobieren.“ Die Geächteten, S. 353. 
Fahrer zu besorgen. In Kerns Auftrag reiste Salomon zu Wende nach Kiel ${ }^{65}$, wurde dort aber nicht fündig und daher an die O.C.-Hauptgruppe Hamburg verwiesen, wo mit Niedrig cin passend scheinender Mann bereitstand.

In der Zwischenzeit war aber auch die Berliner O.C.-Gruppe um Unterstützung angegangen worden. Ursprünglich hatte Kern in der Attentatsvorbereitung wohl nur auf ihren Leiter Ehrentraut, dessen Wohnung von Anfang an als Post- und Kontaktadresse gedient haben mochte, und vielleicht den älteren Tcchow zurückgegriffen, um den Kreis der Eingeweihten zu begrenzen und keine unnötigen Spuren zu hinterlassen. Dic neue Attentatsplanung und die Sorge vor weiterem Zeitverlust ließen diese Bedenken in den Hintergrund treten. Spätestens jetzt, während Salomon noch einen auswärtigen Chauffeur aufzutreiben vermochte, zogen Kern und Fischer mit Ernst Werner Techow einen Berliner O.C.-Mann in den engsten Verschwörerkreis hinein. Techow, nach eigener Auskunft Angehöriger der O.C. seit ihrer Gründung, war ein in untergeordneten Funktionen vielfach erprobter Mann, der seit langem als Kurier gedient und für seine Reisen sogar Aufwandsgelder bezogen hatte ${ }^{66}$. Solcherart ausgewiesen, obendrein passionierter und ortskundiger Automobilist, schien er genau über die erforderliche Qualifikation zu verfügen.

Während dieser Sondierungen erfuhren Kern und Fischer über die Berliner Ortsgruppe der O.C. auch von dem eigenen Mordplan des Gymnasiasten Stubenrauch. Über Ernst Werner Techow und seinen gleichfalls ungebrochen in der O.C. aktiven Bruder Hans-Gerd ${ }^{67}$ stellten sie einen Kontakt zu Stubenrauch und seinem Freund Günther her, der ihnen bei der weiteren Vorbereitung des geänderten Attentatsplans sehr zustatten kam. Während Stubenrauch mit Hinweis auf sein jugendliches Alter ausgeschaltet wurde, durfte sein Freund bei der Verschwörergruppe bleiben, denn die scheinbar weitreichenden Verbindungen Günthers im rechtsradikalen Milieu ließen ihn als einen geeigneten Helfershelfer bei den letzten Vorbereitungen erscheinen. Weder Kern noch seine Mitverschwörer ahnten, daß der renommiersüchtige Günther Beziehungen vortäuschte, die er gar nicht besaß, und sein nicht zu unterdrükkender Geltungsdrang nach dem Anschlag schließlich sogar die Polizei auf ihre Spur führen würde. In der Zwischenzeit hatte sich der mit Salomon aus Hamburg eingetroffene Fahrer Niedrig nach Ortskenntnis und fahrerischer Geschicklichkeit besonders im Vergleich mit

${ }^{65}$ SAM, 567-1-2594, Aussage Salomon, 16. 8. 1922.

${ }^{66}$ Ebenda, 567-1-2593, Aussagen E. W. Techow, 6. und 22. 7. 1922; ebenda, 772-2-194, RathenauProzeß, 2. Verhandlungstag, S. 2 f. In München wollte Techow zuletzt als Kurier in der Zeit nach den Festnahmen im Mordfall Erzberger gewesen sein; ebenda, 567-1-2593, Aussage vom 3. 8. 1922. Seine Angabe wurde von anderer Seite bestätigt; Staatsarchiv München, Pol.Dir. 8103, Bericht Puttkamer, 12. 1. 1923.

${ }^{67}$ H. - G. Techows Behauptung, er sei mangels Verschwiegenheit aus der O.C. wieder ausgeschieden, war falsch. Ehrhardt selbst bescheinigte ihm 1933 in einem militärischen Dienstzeugnis: „Nach Auflösung der aktiven Brigade gehörte er ihren Nachfolgeverbänden an, bis er im Juli 1922 in den Verfahren wegen der Erschießung des Ministers Rathenau verhaftet und zu vier Jahren Gefängnis verurteilt wurde." BDC, Personalakte H.-G. Techow, Bescheinigung vom 13. 9. 1933. Nach seiner Haftentlassung ging H.-G. Techow sofort wieder zu Ehrhardts nunmehr "Wiking" genannter Organisation zurück (ebenda). Er selbst schrieb in seinem Lebenslauf: „Als Mitglicd der O.C. habe ich an der [...] Erschießung des jüdischen Reichsministers Dr. Rathenau in Bcrlin mitgewirkt" (ebenda, Lebenslauf H.-G. Techow, 23. 9. 1935). In der O.C. war Techow eigener Angabe zufolge zum Zeitpunkt des Anschlags als "Adjutant des Landesreferenten Preußen für die vormilitärische Jugenderziehung" zuständig. 
Techow als Fehlbesetzung herausgestellt ${ }^{68}$. Techows überzeugende Vorschläge trugen wesentlich zur Entscheidung bei, den Anschlag an einer verkehrsarmen Stelle zu verüben, vor der der Wagen des Ministers stark abbremsen mußte und die seinen Verfolgern ausreichend Möglichkeit zum Entkommen bieten würde. Nachdem Techow auch den unterdes in Freiberg bereitstchenden Wagen nach Berlin gebracht hatte, bestimmte Kern, daß er und nicht Niedrig den Wagen am Tag des Attentates zu steuern habe, und Techow fügte sich gemäß der in der O.C. geltenden militärischen Gehorsamspflicht dem Befehl seines Vorgesetzten. Unterdes hatte weisungsgemäß Salomon, vielleicht zusammen mit anderen Komplicen, Fahrtstrecke und Wohnhaus Rathenaus nochmals genau beobachtet und sich vor allem vergewissert, zu welcher Zeit und unter welchen Vorsichtsmaßnahmen der Minister morgens in das Auswärtige Amt zu fahren pflegte ${ }^{69}$.

Infolge des gescheiterten Anschlags auf Scheidemann hatten sich die Vorbereitungen so weit in die Länge gezogen, daß den Verschwörern das Geld auszugehen drohte ${ }^{70}$. Tillessen, bei dem Kern um Unterstützung nachsuchte, brachte daraufhin in der Nacht vom 20. auf den 21. Juni eine weitere Summe nach Berlin, die er wahrscheinlich selbst erst in München bei der O.C.-Lcitung hatte beschaffen müssen. Auch die Frage der Bewaffnung wurde in diesen Tagen endgültig geklärt. Nachdem Kern und Fischer ihre Neun-Millimeter-Mauserpistolen bei Schießübungen im Grunewald ausprobiert und festgestellt hatten, daß sie stark streuten ${ }^{71}$, beschlossen sie, aus eigenen Kräften eine Maschinenpistole zu beschaffen. Als dies mißlang, erwies es sich abermals als notwendig, eine örtliche, nämlich diesmal die Schweriner, O.C.Gruppe um Unterstützung zu ersuchen. Wie Kiel, Rostock und Hamburg war auch Schwerin dem Bezirk A der Ehrhardt-Organisation zugeordnet, in dem Kern als Adjutant des Bezirksleiters besondere Befehlsgewalt besaß, und wieder hatte Kern sich an die Anweisung zu halten vermocht, zunächst auf die Ressourcen seines eigenen Bezirkes zurückzugreifen, bevor er sich an Tillessen in Frankfurt wandte. Männer der O.C.-Ortsgruppe Schwerin übergaben ihm am 23. Juni eine aus eigenen Beständen oder einem geheimen Waffenlager stammende Maschinenpistole und nahmen im Gegenzug den Koffer mit Kleidungsstücken zur Weiterleitung nach Rostock in Empfang, die Kern und Fischer zwar nicht mehr in Berlin, wohl aber in Rostock bis zu ihrer endgültigen Rückkchr nach Kiel und Chemnitz zu tragen beabsichtigen mochten.

Waren die bis dahin aufgetretenen Schwierigkeiten noch glatt überwunden worden, taten sich nun am Vortag des Anschlags Hindernisse auf, die die ganze Planung in Frage stellten: Zunächst hatte sich der Kraftwagen auf der Fahrt von und nach Berlin als unzuverlässig crwiesen. Besonders ein an der Ölzuführung aufgetretener Defekt verlangte umgehende Reparatur, die erst am Morgen des 24. Juni vorgenommen werden konnte und möglicherweise eine Aufschiebung des Verbrechens erzwingen würde ${ }^{72}$. Unerwartet stand Kerns Atten-

${ }^{68} \mathrm{Vgl}$. Salomon, Fragebogen, S. 137. Kern hatte sich anscheinend fest darauf verlassen, daß Salomon einen ganz bestimmten Fahrer aus Kiel mitbringen würde (SAM, 772-2-194, Rathenau-Prozeß, 2. Verhandlungstag, Aussage E. W. Techow, S. 9), und war außerordentlich ungehalten, als dieser unerwartet mit Niedrig zurückkam; Salomon, Die Geächteten, S. 355.

${ }^{69}$ BA/P, 30.01-5053/1, Anklageschrift gegen E. W. Techow u. Gen., S. 36, und Urteil gegen E. W. Techow u. Gen., S. 13. In cinem nicht veröffentlichten Abschnitt des „Fragebogen“ beschrieb Salomon, wie er "cin paar Tage vor dem Attentat vor jenem Hause [Rathenaus] stand und cs bcobachtete. Ich sah Rathenau ganz kurz, wie er aus seinem Hause trat und den Wagen bestieg, um ins Auswärtige Amt zu fahren." NL von Salomon, Der Fragebogen, Ms, S. 203.

70 SAM, 567-1-2570, Aussage Günther, 3. 7. 1922; ebenda, 567-1-2594, Aussage Salomon, 16. 8. 1922.

${ }^{71}$ Ebenda, 772-2-194, Rathenau-Prozcß, 3. Verhandlungstag, Aussage Günther, S. 23 f.

72 Ebenda, 2. Verhandlungstag, Aussage E. W. Techow, S. 195. 
tatsplan am selben Abend sogar vor dem endgültigen Scheitern, als noch einmal alle Details durchgesprochen wurden und Techow, der erkennen mußte, daß er nun ungeachtet seines Bekenntnisses gegenüber Pfarrer Lampe doch zum Mörder zu werden drohte, sich plötzlich weigerte, die ihm zudiktierte Rolle als Fahrer des Mordwagens auszufüllen. Nachdem er sich erst unter Androhung der Erschießung zu dem verlangten Gehorsam bereit gefunden hatte, mußte Kern und Fischer klargeworden sein, daß sie mit dem Anschlag nicht länger zögern durften, um nicht ein erneutes Abspringen Techows zu riskieren. So beschlossen sie, das Attentat, wenn irgend möglich, doch noch am nächsten Vormittag auszuführen, obwohl sich die Reparatur des Wagens am Morgen des 24. Juni hinauszögerte, bis die gewöhnliche Zeit, zu der Rathenau sein Haus verließ, bereits überschritten war. Um so mehr trieb Kern zur Eile, nahm in Kauf, daß die vorbereiteten falschen Nummernschilder nicht mehr über das gültige Kennzeichen des Freiberger Wagens geklebt wurden ${ }^{73}$, obwohl allein diese Unterlassung hätte hinreichen können, die Polizei auf die Spur der Täter zu führen. Angesichts dieses überhasteten Vorgehens ist nicht einmal unwahrscheinlich, daß auch Techow, wie er immer wieder behauptete, bis zur letzten Minute darüber im unklaren gelassen wurde, daß Kern und Fischer den Außenminister noch an diesem Sonnabend umzubringen gedachten. So mochte der Widerstrebende die befohlene Fahrt durch den Grunewald nahe Rathenaus Villa in bewußtem Kalkül seiner Vorgesetzten immer noch für eine bloße Erprobung des frisch reparierten Wagens halten ${ }^{74}$, als der kurzzeitig ausgestiegene Kern sich bereits davon überzeugt hatte, daß Rathenaus Wagen trotz der vorgerückten Stunde noch vor dem Haus auf seinen Fahrgast wartete. Das anschließende Tatgeschehen vollzog sich in der vom Staatsgerichtshof rekonstruierten Weise; Techow, obwohl „kolossal innerlich erregt“, bewältigte seine fahrerische Aufgabe ohne weiteren Widerstand. Die Maschinenpistole, mit der die Attentäter bei einer etwaigen Verfolgung sich den Weg aus Berlin hatten freischießen wollen, wurde erst in ein Gartengrundstück geschleudert, als sich bei einem Stopp noch in der Nähe des Tatortes zeigte, daß sie unverfolgt entkommen waren. Die Tatsache, daß Techow auch bei diesem Halt wieder zu einer Motorprüfung gezwungen war, weil eine Zündkerze ausgesetzt hatte, läßt es allerdings unsicher erscheinen, ob der Wagen der Beanspruchung einer längeren scharfen Fahrt überhaupt gewachsen gewesen wäre ${ }^{75}$.

Nach dem Attentat wurde Techow von Kern für eine Woche aus Berlin beurlaubt und anscheinend gleichzeitig beauftragt, den in der Schüttschen Garage abgestellten Tatwagen nach Freiberg zurückzufahren, sobald sich die Erregung über den Anschlag und die Intensitität, mit der in der Bevölkerung auf verdächtige Kraftwagen geachtet würde, etwas gelegt hätten ${ }^{76}$. Auch Kern und Fischer trafen keine Fluchtanstalten, sondern blieben unter Abstreifung aller konspirativen Verhaltensmaßnahmen in Berlin, um in den folgenden Tagen die Aufzüge der Volksmassen zu beobachten, „denn sie glaubten sicher, das Attentat würde die Entschcidung auslösen, da die Kommunisten schon lange loszuschlagen drohten "77. Ihr Verhalten fügt sich in die Logik der Mordmotive, nach der weniger die Treffsicherheit der

${ }^{73}$ BA/P, 30.01-5053/1, Anklageschrift gegen E. W. Techow u. Gen., S. 38, und Urteil gegen E. W. Techow u. Gen., S. 13.

${ }^{74}$ An dieser Behauptung hielt Techow ungeachtet aller Zweifel an ihrer Glaubwürdigkeit unbeirrt fest; SAM 772-2-194, Rathenau-Prozeß, 2. Verhandlungstag, Aussage E. W. Techow, S. 75 ff.

75 Ebenda, S. 112 bzw. 101.

76 Techow selbst erklärte, daß er nach der Rückkehr von seiner Reise das Auto seinem Eigentümer habc zurückbringen wollen, ohne darüber aber selbst mit Küchenmeister gesprochen zu haben; ebenda, 567-1-2593, Aussage E. W.Techow, 7. 8. 1922.

77 BA, NS 26/1236, Gisela Kern, Lebenslauf Erwin Kern. 
Täter über den Erfolg des Anschlags entschied als vielmehr die Wucht der durch ihn hervorgerufenen Reaktion in den revolutionär gesonnenen Teilen der Arbeiterschaft. Kern und Fischer mochten darauf hoffen, daß allein der Entrüstungssturm über die Ermordung des bedeutendsten Politikers der deutschen Reichsregierung in den erhofften Bürgerkrieg münden und eine Fortsetzung der geplanten Attentatsserie überflüssig machen könnte. Bis zum Tage der Beisetzung Rathenaus verfolgten sie die politische Entwicklung in Berlin, bevor sie am 27. Juni 1922 nach Rostock abreisten, sei es, um die routinemäßige Bezirksarbeit für die O.C. wieder aufzunehmen, sei es, um sich angesichts des ausbleibenden Bürgerkriegs an der Vorbereitung weiterer Terroranschläge zu beteiligen.

Eine zentrale Frage ist allerdings mit dieser Rekonstruktion des Attentats auf Rathenau noch nicht beantwortet: nämlich ob Ehrhardt selbst als Chef des Geheimbundes von dem geplanten Attentat auf Rathenau Kenntnis gehabt, es gebilligt, vielleicht sogar angeordnet hatte. Gegen diese Vermutung steht vor allem Salomons Schilderung, nach der Ehrhardt über die "Wahnsinnstat" in höchste Wut geriet, weil sie ,seine eigene Politik zu zertöppern" drohe ${ }^{78}$. Doch angesichts der Tatsache, daß zur Ausführung des Anschlags O.C.-Kräfte aus dem ganzen Reich und in Abstimmung mit der Münchener Zentrale operierten, kann es kaum zweifelhaft sein, daß der unbestrittene Leiter dieses Bundes in ein Vorhaben eingewciht gewesen sein mußte, dessen Gelingen ihn in das Zentrum der politischen Macht hätte tragen sollen, dessen Fehlschlag ihn aber trotz aller Vorsichtsmaßnahmen seiner Organisation und Machtbasis hätte berauben können. Allerdings war die mit den Anschlägen auf Scheidemann und Rathenau verfolgte Provokationsstrategie an die unbedingte Voraussetzung geknüpft, daß die Verbindung Ehrhardts zu den Attentätern unter keinen Umständen ruchbar wurde. Der Mann, der im Bürgerkriegschaos darauf setzen wollte, vereint mit der Reichswehr eine sich unter dem Druck der Straße etablierende Linksregierung hinwegzufegen und durch eine von ihm abhängige Rechtsregierung oder gar eine Militärdiktatur zu ersetzen, konnte nicht einmal innerhalb der „vaterländischen Bewegung“ darauf hoffen, zur Löschung der nationalen Feuersbrunst berufen zu werden, wenn er selbst als deren Brandstifter entlarvt würde.

Hier und nicht in dem Anschlag selbst lag der Grund, daß Ehrhardt tatsächlich über Salomons Erscheinen in München „rasend wütend“ gewesen war. Kerns Kurier war nicht, wie er später behauptete, gleich im Anschluß an den Anschlag nach München gefahren ${ }^{79}$, sondern hatte sich erst am 24. Juni nach Frankfurt zu seinen Eltern begeben und zwei Tage später in das Sanatorium Waldhof, den Stützpunkt der Frankfurter O.C.-Aktivisten, wo er zwei Tage blieb. Anschließend fuhr er in der Erwartung nach Berlin zurück, dort auf Kern und Fischer zu treffen. Da diese beiden Berlin aber bereits verlassen hatten, kehrte auch Salomon nach Frankfurt zurück, um später dann nach München zu fahren und unter großen Mühen zu Ehrhardt selbst vorzudringen, „weil ich hoffte, [...] Kern und Fischer behilflich sein zu können"80. Es war die Verletzung der nach dem Erzbergermord aufgestellten Grundregel, daß die Zentrale und ihr Chef selbst unter keinen Umständen in den Anschlag hineingezogen werden dürften, die den Kapitän so erboste. Salomons Vorstoß zu Ehrhardt geschah aus Sorge um das Schicksal Kerns und Fischers, aber er gefährdete gleichzeitig Ehrhardt, der als Kapp-Putschist immer noch steckbrieflich gesucht wurde - und er gefährdete das riskante politische Spiel des Kapitäns.

Genauere Aussagen Beteiligter über Ehrhardts Haltung zu dem von seiner Organisation begangenen Mordanschlag auf Rathenau gibt es nicht. Ehrhardt selbst tat, was cr im Rahmen seiner politischen Strategie tun mußte, und lehnte in einem Leserbrief jede Verantwortung für

${ }^{78}$ Fragebogen, S. 395.

79 Ebenda, S. 394 f.

${ }^{80}$ SAM, 567-1-2594, Aussage Salomon, 16. 8. 1922; ebenda, Aussage Salomon, 12. 8. 1922. 
den Tod Rathenaus ebenso ab, wie er dies wider besseres Wissen nach dem gewaltsamen Tod Erzbergers getan hatte. Die O.C.-Aktivisten wiederum konnten die Wahrheit vor 1933 nicht offenbaren, ohne Ehrhardt politisch zu ruinieren ${ }^{81}$. Nach 1945 lebten einige von ihnen nicht mehr, andere waren wie Heinz an so exponierter Stelle tätig, daß ihnen jeder Hinweis auf ihre terroristische Vergangenheit unlieb sein mußte. Auch Salomon selbst konnte kein Interesse daran haben, 1951 durch literarische Veröffentlichung seinen früheren Chef zu denunzieren, den er 1922 bereits einmal gefährdet hatte. Ebenso schwiegen sich nach 1945 auch die Mörder Erzbergers anfangs nicht ohne Grund über Ehrhardts Rolle aus: Das Offenburger Gericht hatte die Ausdehnung der Voruntersuchung auf Ehrhardt nur abgelehnt, weil dieser angeblich tot war ${ }^{82}$. In Wahrheit hatte er in der Nähe von Furth am Wald in Österreich eine neue Heimat gefunden und lebte dort dank der Solidarität seiner früheren Untergebenen unbehelligt bis zu seinem Tode 1971.

Daß Ehrhardt aber tatsächlich die Ermordung Rathenaus persönlich angeordnet hatte, zeigt nicht nur die durch ihn erfolgte Berufung Tillessens zum Leiter der neugebildeten Aktivistengruppen; er selbst vermerkte in der NS-Zeit auf zumindest einem Schriftstück seine Verantwortung, nämlich auf einer Bescheinigung für Ernst Werner Techow. Das Dokument selbst ist verlorengegangen, aber in der SS-Personalakte des jüngeren Bruders Hans-Gerd wird zum Rathenaumord festgestellt, daß Ernst Werner Techow „als Angehöriger der Brigade Ehrhardt durch Los an dieser Aktion beteiligt [war] und [...] sie nach einer Stellungnahme von Kapitän Ehrhardt mehr aus Angst als aus Vaterlandsliebe durchgeführt“ habe ${ }^{83}$. Dieses Zeugnis war mehr als eine beiläufige Meinungswiedergabe: Die O.C. wurde wie andere Wehrverbände in der NS-Zeit bei der Berechnung von Dienstzeiten genauso wie für die laufbahnmäßige Einstufung in der Wehrmacht als inoffizielle Heeresformation anerkannt. Da es diesen Verbänden naturgemäß an einer geordneten Aktenführung in der Regel gefehlt hatte, wurde in entsprechenden Fällen auf die Aussagen der jeweiligen Kommandanten zurückgegriffen ${ }^{84}$. Eine Bescheinigung, die Ehrhardt in seiner Eigenschaft als militärischer Vorgesetzter Techows ausstellte, bestätigte nicht nur dessen Beteiligung an der Ermordung Rathenaus, sondern auch Ehrhardts Verantwortung für das Verbrechen.

Der den O.C.-Aktivisten erteilte Auftrag Ehrhardts beschränkte sich nicht auf die Ermordung des Außenministers. Daß gerade die vielen Fäden zwischen den Attentaten auf Scheidemann und Rathenau zu einem von langer Hand geknüpften Netz terroristischer Anschläge gehörten, ließ eine Vielzahl von Zeugen- und Beschuldigtenaussagen vor und nach den Attentaten erkennen: Bereits Anfang Oktober 1921 hatte der sächsische O.C.-Funktionär Lauch eine Äußerung seines örtlichen O.C.-Leiters zu Protokoll gegeben, „daß nun noch Rathenau, Scheidemann, Ebert und Lipinski beseitigt werden müßten " 85 . Ähnliches bekundete, allerdings erst Jahre später, Schmidt-Halbschuh, der in einer umfassenden Beschuldigung praktisch der gesamten O.C.-Führung behauptete, sie habe die „Ermordung des Abgeordneten Scheidemann, des Ministers Rathenau, des Bankiers Warburg und des Redakteurs Wolff beschlossen" ${ }^{86}$. Auch Hustert war bekannt, daß der ihm erteilte Auftrag Teil eines

81 Zu Ehrhardts Politik in der späteren Weimarer Republikvgl. Krüger, Brigade Ehrhardt, S. 119 ff., und das beim RKO gesammelte Material; BA/P, 15.07-558.

82 Vgl. Stern, Political crime, S. 258.

${ }^{83}$ BDC, Personalakte H.-G. Techow, Gauleiter Stürtz an die Kanzlei des Führers der NSDAP, 13. 7. 1938.

${ }^{84}$ Eine entsprechende von Ehrhardt unterzeichnete „Bescheinigung“ von der „Brigade Ehrhardt im Verbande der SS“ erhielt am 13. 9. 1933 auch H.-G. Techow; ebenda.

85 StAF, Nr. 180, Aussage Lauch, 1. 10. 1921.

86 Ebenda, Nr. 32, Vermerk des ORA, 19. 11. 1926. 
größeren Planes war, denn er vertraute nach den Attentaten gegen Scheidemann und Rathenau auf der Flucht einem Bekannten an: „Warten Sie nur mal dic Herbstzeit, den November ab, dann sicht es in Deutschland ganz anders aus. Wenn mir auch das Ding daneben gegangen ist, so kommt Nr. 3 doch dran. Auf meine Frage, wer Nr. 3 ist, erklärte er mir, Wirth'“ 87

Offenbar hatten die auf die Provokationsstrategie eingeschworenen O.C.-Aktivisten unter Karl Tillessen im geheimen der gesamten zur Republik stehenden politischen Elite den Krieg erklärt und sich angeschickt, deren führende Köpfe weit über Rathenau und Scheidemann hinaus auszuschalten. Wic ausgereift entsprechende Pläne waren, ist schwer zu beurteilen; die unter den Beteiligten kursierenden Namen der vorgesehenen Opfer sind jedenfalls durchaus nicht dieselben. Während Heinz neben Scheidemann und Rathenau auch Ebert, den sächsischen Ministerpräsidenten Zeigner und seinen Innenminister Lipinski, dazu noch den Unabhängigen Cohn auflistete ${ }^{88}$, sprach Niedrig in seinen ersten Vernehmungen davon, daß Kerns „Spreng- und Mordkommando [...] sich u. a. zur Aufgabe gemacht [habe], ctwa 12 Juden zu beseitigen, die behauptet haben, daß 300 Juden die ganze Welt regieren könnten“. Allerdings fielen ihm nur noch vier der zu ermordenden Repräsentanten einer jüdischen Weltverschwörung ein, nämlich Cohn, Max Warburg, Theodor Wolff und „als Nichtjude Scheidemann"89. Für diesen Widerspruch fand Niedrig selbst keine Erklärung. Scin Wissen hatte er offenbar von Salomon bezogen, von dem auch Nicdrigs Vorgesetzter Warnecke über die in der O.C. vorbereitete Anschlagserie orientiert worden war. Salomon hatte ihm erzählt, „daß horausgekommen sei, daß 12 Leute in Deutschland das Deutsche Reich zerstückcln wollten; sie wollten plötzlich die Kriegsentschädigung an Frankreich als übertrieben bezeichnen und ablehnen; die Russen sollten in Ostpreußen cinrücken. Dic nationale Jugend sollte gegen Frankreich geworfen werden, um sich gegen die technisch besser ausgerüsteten Franzosen aufzureiben, und der Kommunismus in Deutschland hätte dann gewonnenes Spiel. Dieses müßte verhindert werden. "90 Wirrheit und Widersprüchlichkeit bcider Versionen lassen auf ihre vornehmlich taktische Verwendung schließen. Weit entfernt davon, den örtlichen Unterführern dic eigentlichen politischen Zicle der O.C.-Leitung offenzulegen, hielt sich Salomon gegenüber der Hamburger Ortsgruppe an dieselbe Linie wie Kern gegenüber Techow. Glaubhaft ist beide Male nur der sachliche Kern: Die O.C. hatte es nicht bei bloßen Gedankenspielen belassen, sondern tatsächlich eine ganze Liste politischer Gegner aufgestellt, die sie zur Entfesselung eines Bürgerkrieges zu ermorden plante. Es ist nicht verwunderlich, daß Salomon die Bedeutung dieser Listc später zu rclativieren suchte. Sofern seine nicht nachprüfbare Darstellung hier überhaupt authentisch ist, überliefert sic gleichzeitig, mit welcher Willkür in der O.C. über Leben und Tod entschieden wurde: „Die ganze Liste bestand aus einem kleinen, schmutzigen Stïck Papier, auf welchem mit Blcistift kreuz und quer Namen standen, manche durchgestrichen, manche wieder hinzugefügt. "

${ }^{87}$ BA/P, 15.07-340, Aussage Hänel, 7. 11. 1922. Weitere Zeugnisse für eine gemeinsame Planung der Anschläge auf Scheidemann und Rathenau wurden nach 1933 zu den Akten gegeben; BDC, Personalakte Badc, Schreiben Hildebrandt, 20. 9. 1934.

${ }^{88}$ Sprengstoff, S. 76.

${ }^{89}$ SAM, 567-1-2585, Aussage Niedrig, 26. 6. 1922.

${ }^{90}$ Ebenda, 567-1-2564, Aussage Warnecke, 1.7. 1922. Warnecke war nur einer dieser zwölf erinnerlich, die angeblich bloß festgenommen, aber beim geringsten Fluchtversuch erschossen werden sollten: Max Warburg in Hamburg.

${ }^{91}$ Fragebogen, S. 130. Salomon selbst nannte ncben Walther Rathenau die Namen von Theodor Wolff, Alexander Parvus-Helphand, Oskar Wassermann, Joseph Wirth und Walther Schücking; ebenda, S. 130 und 135 . 
Die Vorbereitungen zur Ausführung dieser Mordserie waren allerdings weiter gediehen, als die Öffentlichkeit je erfuhr. Die Hamburger Polizeibehörde nahm das Geständnis Niedrigs, wonach auch Max Warburg umgebracht werden solle und Ilsemann damit beauftragt sei92, so ernst, daß sie Warburg ersuchte, eine für den 27. Juni 1922 angekündigte Rede bei der Gründung des Übersee-Clubs abzusagen ${ }^{93}$. Warburg, der zusätzlich unter ständigen Polizeischutz gestellt wurde ${ }^{94}$, hielt sich auf Anraten des Hamburger Polizeipräsidenten daraufhin eine Zeitlang ganz verborgen und scheute auch später öffentliches Auftreten ${ }^{95}$. Niedrigs Angaben erfuhren fünf Jahre später eine Bestätigung von ganz anderer Seite, als Schmidt-Halbschuh im Gießener Fememord-Prozeß aussagte, daß Friedrich Wilhelm Heinz 1922 Attentate auf Warburg und Theodor Wolff vorbereitet habe ${ }^{96}$. Auch zu dem Anschlag auf Lipinski, dessen Enthüllungen über das Bestehen einer Geheimorganisation in Sachsen das öffentliche Interesse im Herbst 1921 stark beschäftigt hatten, waren dem Anschein nach Vorbereitungen bereits vor dem Mord an Rathenau getroffen worden. Lipinski selbst teilte dem Reichsinnenminister mit, daß ein Unbekannter seit dem 22. Juni versucht habe, sein Grundstück auszuspähen und die Ankunftszeit seines Zuges festzustellen ${ }^{97}$. Nachweislich auf das Konto der O.C. ging außerdem die Serie von Sprengstoffanschlägen, die im Juni 1922 Hamburg erschüttert hatten ${ }^{98}$. Sie wurden von der Hamburger Ortsgruppe unter Friedrich Warnecke verantwortet, waren aber vermutlich von der Frankfurter Aktivistenleitung weder angeordnet noch gebilligt worden. Als Salomon von Kiel nach Hamburg kam, um sich einen Fahrer für das Rathenau-Attentat vermitteln zu lassen, unterband er im Auftrage Kerns die Fortsetzung dieser Anschläge, die Kern „einigermaßen direktionslos“ dünkten" und die Umsetzung des terroristischen Gesamtkonzepts offensichtlich eher störten als unterstützten.

Zur Koordinierung der einzelnen Vorhaben war, wie Schmidt-Halbschuh in Gießen 1927 aussagte, eine unverfängliche Adresse in Elgershausen im vorderen Westerwald ausgewählt worden ${ }^{100}$. Dort bestand 1922 ein Waldsanatorium unter einem Sanitätsrat Dr.

${ }^{22}$ SAM, 567-1-2585, Aussage Niedrig, 26. 6. 1922. Seine Anzeige wirkt um so glaubhafter, als am 26.6. 1922 den Berliner Ermittlungsbehörden der Name Ilsemanns noch völlig unbekannt war und seine Verstrickung in den Rathenaumord sich erst in der Vernehmung Techows herausstellte. Nach dem Tod Kerns und Fischers versuchte Niedrig allerdings Ilsemann zu entlasten, indem er nun behauptete, Fischer habe Kerns Delegierung des Warburg-Attentates widersprochen und gesagt, „das wollten sie, K. [Kern] und F. [Fischer] lieber selbst ausführen"; ebenda, Aussage vom 8. 8. 1922.

${ }^{93} \mathrm{StaH}$, Mitteilung der staatlichen Pressestelle Hamburg, 29.6. 1922; vgl. Germania und Deutsche Allgemeine Zeitung vom 30.6. 1922.

${ }_{94}$ Warburg, Aufzeichnungen, S. 110.

${ }^{95} \mathrm{StaH}$, Pressestelle Warburg an Zinn, 2., 6. und 12. 7. 1922.

${ }^{96}$ BA, NS 26/1349, Bericht des Polizeipräsidiums Hannover, 14. 9. 1929.

${ }^{7}$ BA/P, 15.07-339, Bericht des Württ. Landespolizeiamtes, 3. 11. 1921, und Der sächsische Innenminister an den RMI, 30. 6. 1922.

${ }^{98} \mathrm{Vgl}$. hierzu die detaillierte Berichterstattung in der Hamburger Presse, bes. Hamburger Nachrichten vom 2. und 24. 6. 1922; Hamburger Fremdenblatt vom 2., 3. und 8. 6. 1922; Hamburger Volkszeitung vom 3. und 23. 6. 1922; Hamburger Echo vom 24. 6. 1922.

${ }^{99}$ Salomon, Die Geächteten, S. 355.

${ }^{100}$ Schmidts Enthüllungen besaßen auch 1927 noch erhebliche Brisanz, da sie plötzlich bisher unbekannte Hintergründe der Anschläge auf Scheidemann und Rathenau offenbarten. „Die Schleier reißen“ betitelte die Frankfurter Zeitung ihren Gerichtskommentar vom 30.3.1927 und vermerkte: „Sobald der Zeuge Schmidt-Halbschuh, der Feme-Schmidt, auftrat, wurden auf einmal die sämtlichen Verteidiger zu Anklägern und der Staatsanwalt mußte sich in die Rolle des Verteidigers für diesen Kronzeugen drängen lassen." Frankfurter Zeitung vom 30. 3. 1927. Doch gelang es der Verteidigung 
Liebe ${ }^{101}$, dessen Sohn Herbert am selben Ort einen landwirtschaftlichen Hof betrieb ${ }^{102}$. Liebe junior, der ebenfalls der O.C. angehörte und dann 1923 bei der Befreiung Ehrhardts aus der Leipziger Untersuchungshaft das Fluchtauto steuerte, hatte Kern und Salomon im März 1922 nach ihrem Überfall auf Wagner bei sich aufgenommen ${ }^{103}$. Einige Wochen vor dem Rathenaumord hielt sich auch Schmidt-Halbschuh im Waldsanatorium Elgershausen auf, das sich in dieser Zeit zu einem förmlichen Refugium der O.C.-Aktivisten herausgebildet hatte, und wurde von Heinz über den Anschlag auf Wagner mit dem Bemerken unterrichtet, daß von dem angeblichen Verräter in Zukunft nichts mehr zu befürchten sei ${ }^{104}$. Dort erfuhr Schmidt auch von den geplanten Attentaten gegen Scheidemann und Rathenau, und er war Zeuge, als am 2. Juni abends ein mit „Kerner“ unterzeichnetes Telegramm einlief ${ }^{105}$. Am selben Tag war Kern, der Absender dieses Telegrammes, von Kiel nach Berlin aufgebrochen. Offenkundig hatte die vor dem Angriff auf Scheidemann in Elgershausen versammelte Aktivistenführung um Tillessen und Heinz auf ein verabredetes Signal Kerns über den Stand seiner Vorbereitungen in der Mordsache Rathenau gewartet, denn das "Telegramm veranlaßte Heinz, nach Kassel zu reisen, um, wie er sich ausdrückte, Dampf hinter die Sache zu machen" ${ }^{106}$. Prompt zwei Tage später wurde Scheidemann überfallen. Als aber das für die Anschläge vorgesehene Gift versagte, war auch die Absicht zunichte gemacht, beide Anschläge eng aufeinanderfolgen $\mathrm{zu}$ lassen ${ }^{107}$. In Zeitnot geraten und ohne personelle Verstärkung nicht in der Lage, die neue Idee eines Autoattentats umzusetzen, forderte Kern Unterstützung aus Elgershausen. Erst daraufhin fuhr Salomon, der sich dort seit einigen Tagen aufgehalten hatte ${ }^{108}$, nach Berlin, und einige Tage später folgten Plaas und Tillessen, der sich zuvor in München mit Hoffmann abgestimmt hatte.

In der Zusammenschau hätten die vielen beim Gießener Fememordprozeß aufgetauchten Detailinformationen ein klares Bild der Verbindungen ergeben können, die die einzelnen Anschläge mit der Organisation "Consul“ und ihrer Frankfurter Aktivistenzentrale ver-

nicht, die Glaubwürdigkeit des Zeugen zu erschüttern. Da Schmidt durch seine Aussagen weder materielle noch andere Vorteile hatte und seine Glaubwürdigkeit von einem Vertreter der Berliner Kriminalpolizei sehr günstig beurteilt worden war, wurde er ungeachtet aller Einwände der Verteidigung vereidigt; vgl. Mainzer Anzeiger vom 27., 28. und 29. 3. 1927.

101 Volkswille vom 28. 9. 1929.

102 Vgl. Knauß, Gießener Fememordprozeß, S. 132.

${ }^{103}$ Hessischer Volksfreund vom 25. 3. 1927.

104 Wetzlarer Zeitung vom 25. 3. 1927.

105 Oberhessische Volkszeitung vom 25. 3. 1927, Beilage.

${ }^{106}$ Aussage Schmidt-Halbschuh, 24. 3. 1927, zit. nach ebenda. Daß Heinz der unbekannte Besucher gewesen war, der die Scheidemann-Attentäter kurz vor dem Anschlag aufgesucht hatte, wurde später gleich von zwei verschiedenen Seiten bekräftigt: 1923 sagte in ganz anderem Zusammenhang ein Untersuchungsgefangener namens Otto Schneider aus, „ein gewisser Heinz habe die Spritze geliefert, die bei dem Attentat auf Scheidemann gebraucht worden sei“. BA/P, 15.07-698, Aktenvermerk des RKO. Eine gleichlautende Beschuldigung gab fünf Jahre später der frühere Frankfurter Weggefährte von Heinz, Helmut Klotz, bei einer Vernehmung in Hannover zu Protokoll; BA, NS 26/1349, Aussage Klotz, 5. 10.1928.

107 Diese These bestätigte nach 1933 der damalige Frankfurter VNS-Vorsitzende Schroeder: „Im Frühjahr 1922 wurden große Pläne gefaßt, Scheidemann und Rathenau standen zur Debatte. Ein neues, sicher wirkendes Mittel, Salzsäure ähnlich, sollte diesen Volksverderbern das Handwerk legen. Es ist bekannt, daß sich dieses Mittel bei einer Probe auf Scheidemann Pfingsten 1922 als völlig unzulänglich erwies." Ebenda, NS 26/528, Otto Schroeder, Meine Kampferlebnisse, 15. 2. 1937.

108 SAM, 567-1-2594, Aussage Salomon, 10. 8. 1922. 
knüpften. Doch war keine Prozeßpartei an einer Anknüpfung an die seinerzeit vor dem Staatsgerichtshof verhandelten Verfahren interessiert. So blieb wiederum im dunkeln, inwieweit die Anschlagserie auf einen direkten Befehl Ehrhardts zurückging, obwohl SchmidtHalbschuh mit präzisen Hinweisen aufgewartet hatte, die sich zudem in mancher Hinsicht mit den seinerzeitigen Angaben Brüdigams deckten: Danach hätte aufgrund entsprechender Vorgaben durch Ehrhardt am 5. Mai 1922 in Bad Nauheim oder Frankfurt eine Besprechung zwischen Heinz, Tillessen, Plaas und Salomon über die Ermordung Scheidemanns, Rathenaus und anderer prominenter Persönlichkeiten stattgefunden ${ }^{109}$. Daraufhin habe die „endgültige Festlegung [...] am 13. Mai 1922 in München in einer Verhandlung stattgcfunden, die Ehrhardt geleitct und an der Heinz, Tillessen, Plaas und von Salomon mitgewirkt haben, außerdem noch Hoffmann, Vicbig und Kautter“. Auf ihr sei verabredet worden, „durch weitere Gewalttaten eine noch heftigere Störung der öffentlichen Ordnung herbeizuführen", um den angestrebten Sturz der republikanischen Regierung und Verfassung vorzubereiten. „Zu diesem Zweck sei neben der Begehung von Sprengstoffanschlägen insbesondere die Ermordung des Abgeordneten Scheidemann, des Ministers Rathenau, des Bankiers Warburg und des Redakteurs Wolff beschlossen worden."110

Die von Schmidt-Halbschuh angeführten Namen ließen auf eingchende Kenntnisse der O.C.-Interna schließen; er nannte neben den Frankfurter Aktivisten Ehrhardts Stellvertreter in München, Hoffmann, Ehrhardts Adjutanten Kautter und den in Berlin führend tätigen O.C.-Funktionär Viebig - also ziemlich genau den Personenkreis, der für die Vorbereitung und Durchführung der Anschläge in Berlin und Kassel entscheidungsrelevant sein konnte ${ }^{111}$. In bezug auf nachprüfbare Sachverhalte etwa zu dem vier Jahre zurückliegenden Giftanschlag während des Rathenauprozesses waren Schmidts Auskünfte von so erstaunlicher Exaktheit, daß dies auch der Reichskommissar für Überwachung der öffentlichen Ordnung hervorhob $^{112}$. Schmidts Aussage bildet die konzentrierteste Beschreibung der O.C.-Strategie und ihrer Umsetzung, die vor 1933 aus den Kreisen des Geheimbundes an die Öffentlichkeit drang. Sie deckt sich mit den aus vielen anderen Quellen ableitbaren Befunden, aber sie bleibt dennoch das Zcugnis eines Mannes, der angesichts sciner untergeordneten Position Ehrhardts direktes Eingreifen nicht aus eigenem Erleben berichtete, sondern nur weitergeben konnte, was er von anderen erfahren hatte.

Daß Ehrhardt Mitwisser, viclleicht sogar Anstifter der Attentate auf Rathenau und Scheidemann war, hielt nach Schmidts Aussage immerhin auch der Reichskommissar für vorstellbar. Schwerlich dürfte er allerdings damit gerechnet haben, daß der unter Mordverdacht stehende Geheimbundchef eines Tages unbefangen über seine damalige Rolle reden würde. Doch gleich nach dem Untergang der ersten deutschen Demokratie beeiltc Ehrhardt sich, in der Öffentlichkeit auszusprechen, was er bislang hatte verschweigen müssen. In seiner Rede anläßlich einer Gedenkfeier für die elf Jahre zuvor umgekommenen Rathenau-Atten-

109 StAF, Nr. 31, Vermerk des ORA, 19. 11. 1926; Volksstimme Frankfurt/M. vom 26. 3. 1927. Der im Gießener Prozeß als Zeuge geladene Tillessen bestritt zwar diese Besprechung, gab auf Nachfrage aber zu, „daß cr wohl um dicsc Zeit Gespräche mit den einzelnen Bezirksleitern gehabt haben könnte"; Oberhessische Volkszeitung vom 26. 3. 1927.

110 StAF, Nr. 31, Vermerk des ORA, 19. 11. 1926. Zu den bisherigen Verbrechen der O.C. rechnete Schmidt-Halbschuh auch die Ermordung des sozialdemokratischen Landtagsabgeordneten Gareis in München im Juni 1921, die er Kern und dem späteren Ehrhardt-Adjutanten Liedig anlastete.

111 Plaas erwähnte in seinem Tagebuch keines der von Schmidt-Halbschuh genannten Treffen und beschränkte sich auf vielsagende Andeutungen: „Am 5. 5. bin ich verreist, mit vollem Beutel. [...] Am 9. zurück nach Frankfurt [...] Nachmittags [am 10. 5.] Rollenverteilung und Spaziergang durch die Anlagen." NL Plaas, Tagebuch, Einträge vom 8., 9. und 10. 5. 1922.

112 StAF, Nr. 31, RKO an Untersuchungsrichter Eggler, 23. 12. 1926. 
täter auf Burg Saaleck am 16. Juli 1933 gedachte der O.C.-Leiter zuerst der Männer, die bei der Tat mitgeholfen hatten, dankte dem Besitzer der Burg - und lüftete dann den Schleier, der immer noch über den Attentaten von 1922 lag: „Der Plan war der, daß in der entstandenen Verwirrung Schlag auf Schlag die Köpfe der Regierungsmitglieder fallen sollten, um Deutschland zu befreien. Aber die Männer, die diesen Plan durchführten, kamen schnell hintcr Schloß und Riegel - das System funktionierte noch zu gut. " ${ }^{113}$ Mit diesem Bekenntnis gab Ehrhardt auch preis, daß er und seine Offizicre 1922 die politische Situation und besonders die Handlungsfähigkeit des Staates falsch beurteilt hatten. Offenbar war in der fieberhaften Erwartung einer Gelegenheit zum Losschlagen bloßes Wunschdenken an die Stelle einer realistischen Bewertung der Kräfteverhältnisse getreten ${ }^{114}$. Zeitgleich mit der anrollenden Attentatswelle im Juni 1922 hatte sich in den der O.C. nahestehenden militanten Gruppierungen die Auffassung durchgesctzt, daß in der allernächsten Zeit die endgültige Entscheidung im Kampf mit dem verhaßten Weimarer System fallen müßte. Am 4. Juni 1922, nur Stunden vor dem Attentat auf Scheidemann, meldete sich bei der Zwickaucr Kriminalpolizei ein Mann, der als Gründer und Vorsitzender des Deutschvölkischen Schutz- und Trutzbundes in Zwickau und Mitglicd der mit der O.C. in Verbindung stehenden "Loge Herold“ Kenntnis von Vorgängen erlangt haben wollte, die für sich zu behalten er mit seinem Gewissen nicht mehr vereinbaren könnc. Seinen Angaben zufolge seien die Mitglieder der Loge, des Freikorps Oberland, des Stahlhelm, der NSDAP und anderer Rechtsverbände zu höchster Alarmbereitschaft aufgerufen worden, weil der Sturz der bestchenden Staatsordnung unmittelbar bevorstehe. Die Zahlen, mit denen auf der Rechten jongliert wurde und die der Informant an dic Polizei weitergab, muten abenteuerlich an: Geleitet von Ludendorff, stünden allein in Baycrn 500000 zuverlässige Anhänger der Monarchie aus den Verbänden, der Landespolizei und der Reichswehr zur Verfügung, dazu in Sachsen 200000 Mann, die sich wie weitere Freikorpsanhänger in Schlcsien und den Ostseeprovinzen der bayerischen Leitung unterstellt hätten: „Von Bayern aus sei in der allernächsten Zeit mit cincm Losschlagen der dortigen Königsmacher zu rechnen. Es werde nur noch auf eine günstigc innenpolitische Situation gewartet." 115

Es kam anders. Weit entfernt davon, zum Kampfe um die Macht anzusetzen, konnte die O.C. nach dem Mordanschlag auf Scheidemann und Rathenau nicht einmal ihre eigenen Attentäter dem Zugriff der Polizei entziehen.

113 Zit. nach Der Nationalsozialist vom 17. 7. 1933.

114 Diese plänemachende Realitätsblindheit der extremen Rechten in der Zeit bis 1923 belegt für Bayern cindrucksvoll dic Studic von Thoß, Ludendorff-Kreis, S. $171 \mathrm{ff}$.

115 BA/P, 15.07-339, Bcricht der Zwickauer Kriminalpolizei an den sächsischen Innenminister, 6. 6. 1922. 